\title{
Opportunities and Challenges of Multi-Loop Aquaponic Systems
}

Simon Goddek 


\section{Thesis committee}

\section{Promotor}

Prof. Dr Johan A.J. Verreth

Professor of Aquaculture and Fisheries

Wageningen University \& Research

\section{Co-promotors}

Prof. Dr Karel J. Keesman

Personal chair at Biobased Chemistry \& Technology

Wageningen University \& Research

Dr Sven Würtz

Leader Research Group Ecophysiology and Aquaculture

Leipniz-Institute of Freshwater Ecology and Inland Fisheries, Berlin, Germany

\section{Other members}

Prof. Dr Jaap Molenaar, Wageningen University \& Research

Dr Harry Bruning, Wageningen University \& Research

Dr Chris G. J. van Bussel, Skretting Aquaculture Research, Stavanger, Norway

Dr Paul Rye Kledal, IGFF, Hellerup, Denmark

This research was conducted under the auspices of the Graduate School for Socio-Economic and Natural Sciences of Environment (SENSE) 


\title{
Opportunities and Challenges of Multi-Loop Aquaponic Systems
}

\author{
Simon Goddek
}

Thesis

submitted in fulfilment of the requirements for the degree of doctor at Wageningen University

by the authority of the Rector Magnificus,

Prof. Dr A.P.J. Mol,

in the presence of the

Thesis Committee appointed by the Academic Board

to be defended in public

on Tuesday 24 October 2017

at 4 p.m. in the Aula. 
Simon Goddek

Opportunities and Challenges of Multi-Loop Aquaponic Systems,

170 pages.

PhD thesis, Wageningen University, Wageningen, the Netherlands (2017)

With references, with summaries in English, Dutch, and Portuguese

DOI: $10.18174 / 412236$

ISBN: 978-94-6343-172-9 


\section{Preface}

Which of us is not familiar with this situation during the student time: on a Wednesday night, one wants to go out to grab a beer ("just one Duveltje") with friends. Until the end of the night (and several beers later) one was trapped in several discussions about religion, politics, and one's field of study. I have to admit, that I have been involved in plenty of such discussions, which also stems from the fact that I am a very discussion-friendly and curious person. However, I caught myself often saying the same sentence "well, the idea is great, but it actually does not really work as it should" with respect to two topics: Aquaponics and Communism. This might appear to be a somewhat far-fetched statement, however, for those who have neither read Marx nor followed the development of aquaponics the last 30 years: in a nutshell it can be stated that both of these ideas follow bottom-up (i.e. local and circular) approaches (i.e. for small farmers and individuals).

Additionally to the above, I honestly believe that in times of the financial crisis - in which multinational corporations such as [think of big corporations that produce GMO seeds that are immune to their pesticides] increase their quasi-monopoly positions on the global food market - a paradigm shift back to human-centred and sustainable agricultural development is required to ensure both (1) healthy (i.e. pesticide free) diets and (2) food independence. In contrast, organic, fair trade, and GMO-free food have recently gained rapidly increasing popularity. Consumers want transparent and extensive information about the origin and manufacture of the foodstuffs they buy. The development of agriculture and how to use (finite) resources efficiently will be crucial with respect to the global development and the future of the earth in general. Right now, we are at a crossroads in our history that will determine whether either the people or the corporations will be empowered. I intended to provocatively illustrate this new class conflict on the book cover with the objective to polarize and thus energize the readers themselves to make thoughts and reflections.

So far, I have dedicated over 4 years of my life to study and improve aquaponic systems in the hope that one day their production efficiency will be able to compete with state-of-theart hydroponic food production systems, while improving circularity. In this thesis, I will try to demonstrate why aquaponics does not face the same pitfalls as communism, while sharing the empowering people-minded and bottom-up qualities that are required in the 21st century. 


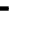




\section{Table of Contents}

Preface

vi

Chapter 1

General Introduction

1

Chapter 2

Challenges of Sustainable and Commercial Aquaponics

13

Chapter 3

Lettuce (Lactuca sativa L. var. Sucrine) Growth Performance in Complemented Aquaponic Solution Outperforms Hydroponics

Chapter 4

Comparison of Lactuca sativa Growth Performance in

Chapter 5

The Effect of Anaerobic and Aerobic Fish Sludge Supernatant on Hydroponic Lettuce.

67

Chapter 6

Navigating towards Decoupled Aquaponic Systems: A System Dynamics Design Approach

Chapter 7

The Necessity of Desalination Technology for Designing and Sizing Multi-Loop Aquaponic Systems

Chapter 8

General Discussion

References

Appendix

Summary 157

Samenvatting 160

Resumo 163

Acknowledgements 166

About the author 167

List of publications 168

Graduate school certificate 



\section{Chapter 1 General Introduction}

\subsection{Global Food Challenges}

A constantly rising world population and a corresponding increase in consumption confront the world with constantly new challenges. In theory, population and food consumption should be a linear relationship: the more people live on the planet, the more food will be consumed. However, there is a discrepancy between the reality and this relationship. The reasons can vary, the consequences are nonetheless worrying.

While more and more food needs to be produced to meet the increasing food demands, usable land for agricultural practices decreases since intensive agriculture tends to land and soil to degrade. Arid and semi-arid regions also experience more droughts and water shortages due to climate change (FAO, 2012a). Agriculture uses 70\% of the fresh water worldwide. According to FAO (2009), the severe water scarcity will increase in the next 25 years due to the expected population growth to more than 9 billion people, as approximately $60 \%$ more food will be needed. Water scarcity is even expected in areas that have relatively sufficient water resources. Major policy changes are required to avoid such trends (Criscuolo and Menon, 2015). These phenomena, in addition to other effects, cause that huge areas of precious rain forests are destroyed, which leads to aggravating soil erosion and therefore to the loss of fertile soils. Also, rainforests help reducing the amount of solar radiation reflected back into the atmosphere, leading to a mitigation of the greenhouse effect. Considering that climate change speeds up by depleting this biodiversity-rich ecosystem shows that we are trapped in a vicious cycle (Brown, 2009).

Another issue that conventional agriculture faces is that generating three centimetres of topsoil takes approximately 1000 years. Regarding the United Nations, the world's top soil could be gone within 60 years if current rates of degradation continue (Arsenault, n.d.). Additionally to that, the FAO of the United Nations reports that the amount of arable land by 2050 will only be a quarter of the level in 1960. This can be attributed to both the growing population and soil degradation. Meanwhile, fertilizer consumption per ha of arable land has risen from $105 \mathrm{~kg}$ in 2002 to $135 \mathrm{~kg}$ in 2013 to counteract soil degradation (FAO, n.d.). 
In addition to nitrogen and potassium, phosphorus is one of the three major nutrients that is required for plant growth and improving soil quality for following crops. Approximately $80 \%$ of all mined rock phosphate is synthesized to agricultural fertilizer (Ekardt et al., 2010). Like oil, phosphorus is a non-renewable resource. There are no substitutes for phosphorus in agriculture to sustain crop yields. A number of scientists have demonstrated that rock phosphate reserves may be depleted within 50-100 years (Cordell et al., 2011; S. Cordell et al., 2009; Ragnarsdottir et al., 2011; Steen, 1998), while phosphorus demand is constantly increasing. The global phosphorus peak is predicted to occur in coming decades (D. Cordell et al., 2009; Walan et al., 2014). According to Sverdrup and Ragnarsdottír (2011), phosphorus will become an expensive material in the future. Recycling policies and innovative agriculture systems are consequently necessary to avoid world hunger and mass mortality (Mórrígan, 2010; Ragnarsdottir et al., 2011) and are still expected to meet the UN Sustainable Development Goal number 1 that addresses eradication of extreme poverty and hunger. A sustainable approach is required in order to prevent tackle the above mentioned issues.

\subsection{Aquaponics}

Traditionally, aquaponics refers to an integrated system in which aquatic animals and soilless-growing plants are cultivated together. In this study, and in line with Nichols and Savidov (2012) as well as Seawright (1998) aquaponics can be defined as a multi-trophic food production system comprising of a recirculating aquaculture system (RAS) and hydroponic (HP) elements (Figure 1.1). In these one-loop aquaponic systems, RAS-derived nutrient-rich water from the HP element is directly constantly directed to the hydroponic unit providing the plants with essential nutrients for plant growth instead of being discharged (Liang and Chien, 2013; Vermeulen and Kamstra, 2013). In one-loop aquaponic systems, the partly demineralized water is led back to the RAS (Graber and Junge, 2009; Licamele, 2009; Rakocy et al., 2006). The advantage of this approach is that both fish and plants can be produced in an environmentally-friendly way. Furthermore, high levels of water reuse (Graber and Junge, 2009a) as well as nutrient recycling (Palm et al., 2015, 2014; Vermeulen and Kamstra, 2013) are ensured. 


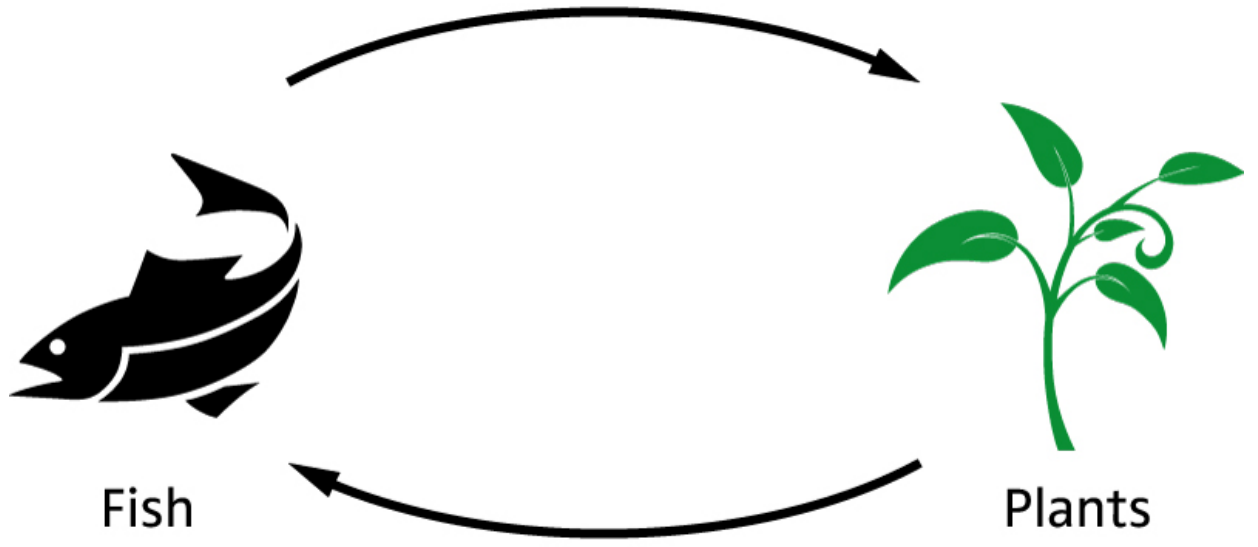

Figure 1.1. Simplified scheme of a one-Loop Aquaponic System. Water recirculates between the aquaculture system and the hydroponic system.

This approach can be considered highly ecological, since it reduces the overall water consumption as well as $\mathrm{CO}_{2}$ emission of both combined systems. Unfortunately, one-loop aquaponic systems fail to achieve industrial fish and vegetable production levels.

\subsubsection{Recirculating Aquaculture Systems (RAS)}

RAS as one part of the aquaponic system are used for land-based fish production, although it is also suitable for other aquatic animals (Lekang, 2007). The systems are usually tankbased in which fish are grown at high density. Biofiltration processes are required to reduce ammonia toxicity. To guarantee optimal growth performances the environmental conditions should be controlled as good as possible. The main advantage of RAS is that only very little water replacement is required. Compared to conventional aquaculture systems, the water exchange is reduced by $90-99 \%$, while requiring less than $1 \%$ of the area (Timmons and Ebeling, 2013). Furthermore, RAS systems convert nutrients from a very toxic to a less toxic form (e.g. ammonia to nitrate). Even though this is a good step towards a more sustainable food production, as it tackles the problems of overfishing and fresh water scarcity, major issues of concern still remain to be raised. 


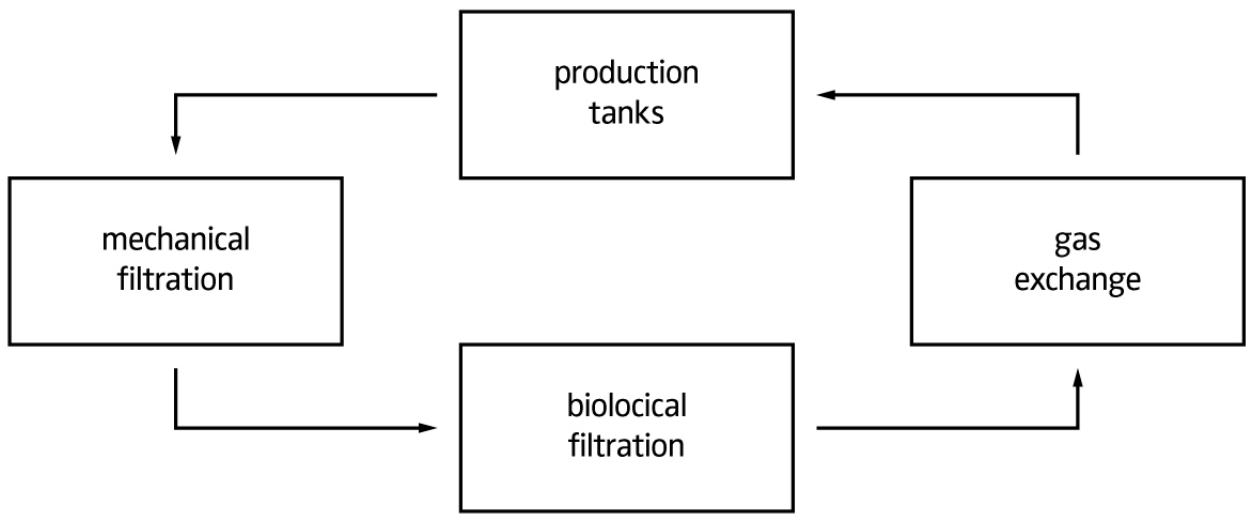

Figure 1.2. Simplified Process Flow Diagram of a Recirculating Aquaculture System (RAS). The fish are cultured in the production tanks. In the mechanical filtration step, solids such as faecal material and uneaten feed are physically removed prior to biological filtration. The latter contains beneficial bacteria that convert toxic ammonia into nitrate, which is relatively harmless to fish. Before the water is recirculated back to the fish, oxygen is injected and carbon dioxide removed.

However, discharged RAS water and fish faeces are still rich in nutrients. In addition to the fact that discharging aquacultural waste might cause eutrophication, valuable nutrients are simply wasted. P is mainly lost through faeces in fish production (Neto and Ostrensky, 2013; Yavuzcan Yildiz et al., 2017). Håkanson et al. (1998) even reported that $70 \%$ of the P fed to fish is lost through faeces. As mentioned in Section 1.1, recycling policies and technologies are required to tackle this valuable loss.

Given fish production data until 2008, Figure 1.3 shows that aquaculture is becoming increasingly important worldwide to meet the future demand of fish. The underlying assumptions in Figure 1.3 are stagnating capture fisheries and the UN population growth forecast. 


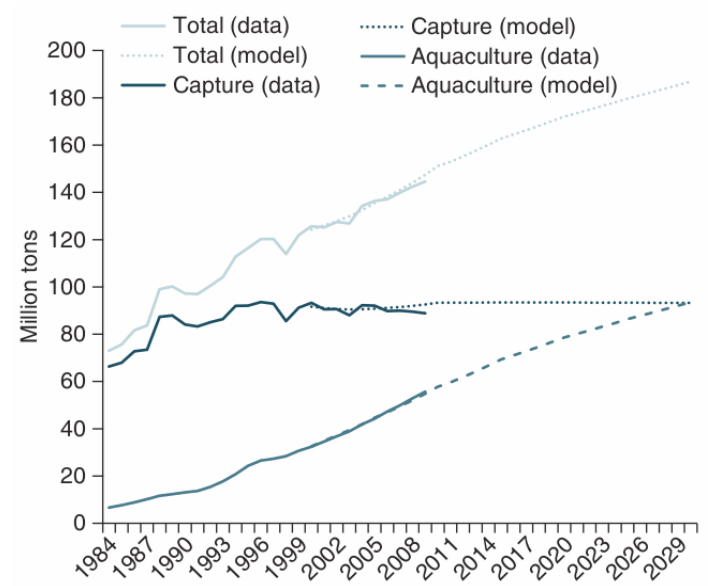

Figure 1.3. Global Fish Production: Data and Projections 1984-2030 (World Bank, 2013). The latest data even expect farmed fish to exceed captured fish in the early 2020s.

\subsubsection{Hydroponics}

The other aquaponic subsystem is hydroponics. Hydroponics is a method to grow plants in a soil-free environment by exposing the roots to a mineral nutrient solution. The plant roots can either be supported by some medium (e.g. rock wool, gravel, volcanic stones, etc.) or simply be exposed to the nutrient solution. The main advantage of applying hydroponic methods is that the roots are constantly exposed to oxygenated and nutrient-rich water. The growth of the plants is dependent on the flow-through velocity (Buzby et al., 2016; Jones, 2005), the nutrient solution formulation (Resh, 2012; Sonneveld and Voogt, 2009a), and general environmental conditions such as light spectra and intensity, air- and water temperature, humidity, etc. (Sonneveld and Straver, 1994),

There are various hydroponic methods. Commercially, the most proven methods are the nutrient flow technique (NFT) and the deep water culture (DWC) technique (Figure 1.4). In NFT systems, plants grow in slightly tilted channels and are supplied with the nutrient solution either by sub- or top-irrigation. NFT top-irrigation (i.e. dripping) systems are often used to grow tomatoes or peppers in rock wool; NFT sub-irrigation systems are rather used for leafy green vegetables whose roots are exposed to a constant shallow stream of nutrient rich water. Compared to NFT systems, the water volume of DWC systems is much higher. In DWC systems, plants are usually floating (in net pots on e.g. polystyrene panels) on approximately $30 \mathrm{~cm}$ deep containers filled with an oxygenated nutrient solution. Just like in NFT systems, the nutrient solution is recirculated and oxygenated. Due to a higher volume, enriching the water with oxygen as well as recirculating the nutrient solution requires more 
energy. The outflow of hydroponic systems still contain unused nutrients and usually flows back to a basin for recirculation purposes.

(a) NFT

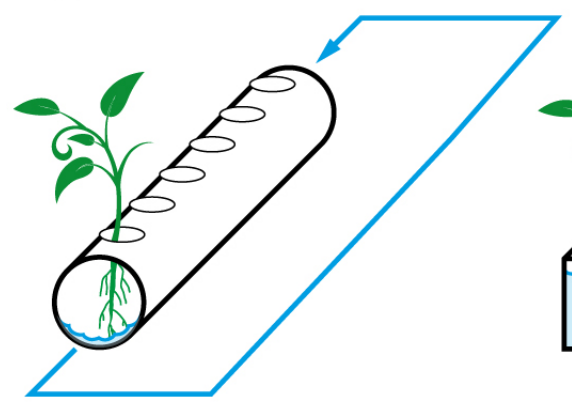

(b) DWC

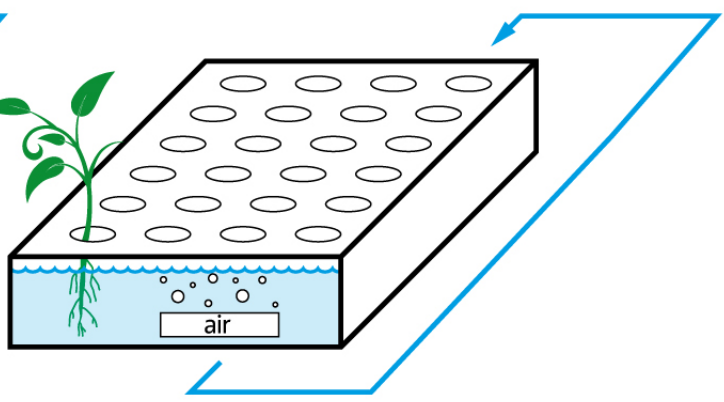

Figure 1.4. Illustration of (a) nutrient flow technique (NFT) and (b) deep water culture (DWC) systems.

Every plant species/variety requires a different nutrient solution formulation. The right composition is subject to ongoing discussions. However, there are many papers that offers empirically grounded data for a high variety of greenhouse crops (Resh, 2013; Sonneveld, 2002; Sonneveld and Voogt, 2009b). There are 6 essential macronutrients and 7 essential micronutrients for plant growth. The 6 essential macronutrients are: Nitrogen $(\mathrm{N})$, Phosphorus (P), Potassium $\left(\mathrm{K}^{+}\right)$, Calcium $\left(\mathrm{Ca}^{2+}\right)$, Magnesium $\left(\mathrm{Mg}^{2+}\right)$, Sulfur $\left(\mathrm{SO}_{4}^{2-}\right)$; and the 6 essential micronutrients are: Iron $\left(\mathrm{Fe}^{2+}\right)$, Zinc $\left(\mathrm{Zn}^{2+}\right)$, Copper $\left(\mathrm{Cu}^{2+}\right)$, Manganese $\left(\mathrm{Mn}^{2+}\right)$, Boron (B), Molybdenum (Mo), and Nickel $\left(\mathrm{Ni}^{2+}\right)$. In practice, special focus lays on both $\mathrm{N}$ and $\mathrm{P}$. Whereas $\mathrm{N}$ is mostly in form of nitrate $\left(\mathrm{NO}_{3}^{-}\right)$or ammonia $\left(\mathrm{NH}_{4}^{+}\right), \mathrm{P}$ is only available for plants in form of ortho-phosphate $\left(\mathrm{PO}_{4}^{3-}\right)$.

\subsection{The Fate of one-loop Aquaponic Systems}

One-loop aquaponic systems, as discussed in the previous section, have been the subject of considerable research over the last 30 years (Adler et al., 1996; McMurtry et al., 1997; Rakocy and Hargreaves, 1993; Rakocy, 1989; Seawright et al., 1998b). From a practical viewpoint, the main advantage of one-loop systems lies in the simplicity of technical measurements and control requirements (i.e. $\mathrm{pH}$, EC, temperature, etc.). More complex system approaches, however, requires improved monitoring and control technologies. Although research has been carried out on this subject for decades, the development of 
aquaponics systems made little progress under the ideological cloak of "cultivating fish and plants in one continuous loop system".

Despite different water quality requirements in the aquaculture and hydroponic systems, traditional aquaponics practice has been based on finding a largely sub-optimal balance between the needs of plants and fish within a single water process loop. Consequently, the efficiency of one-loop aquaponics systems is reduced relative to the sum of productivity in independent single crops and fish systems. Moreover, comparing traditional one-loop aquaponics systems with hydroponic systems, aquaponics systems have a number of limitations. The most prominent limitations is that fish and plants require different environmental conditions such as $\mathrm{pH}$, nutrients and essential minerals. Hence, currently, one-loop aquaponics systems fail to show a growth advantage relative to independent recirculating aquaculture systems (RAS) and hydroponic systems, which both have been optimized and can produce food sustainably without major loss of energy or resources.

Further developments of one-loop systems appeared, when Kloas et al. (2015) began conceptualising the possibility to decouple elements of the system in order to provide optimal conditions to both fish and plants. Their "weakly linked" two-loop INAPRO system that is still under investigation in a running EU project uses less than 100 litres of water to produce $1 \mathrm{~kg}$ of fish (i.e. tilapia) and $1.6 \mathrm{~kg}$ of tomatoes. In comparison to that, RAS and conventional hydroponic systems require approximately 1000 more litres to produce the same amount of fish and tomatoes. In a recent study, both the INAPRO system and a hydroponic control system showed tomato growth performance that was very similar (Suhl et al., 2016).

\subsection{Aim and Approach of this Thesis}

To date, multi-loop aquaponics research is still in an early phase and requires further research, as there is only a modest number of publications available that deal with this topic. The gaps - which can be seen as black boxes - comprise the suboptimal conditions of both plant and fish subsystems, the processing and usage of nutrient-rich aquaculture sludge as well as the identification of the determining factor of the water regime in multi-loop aquaponic systems. Given these gaps and trends, it can be stated that there is scope to optimize aquaponic system technology.

The overall aim of this thesis is to propose and investigate a conceptual framework for multiloop aquaponic systems based on experiments, modelling, and literature reviews. Based on the identified gaps three specific objectives were formulated to meet these overall goals: 
- To determine the status quo of aquaponic systems and identify current bottlenecks that need to be addressed in order to improve commercial feasibility.

- To determine statistically to what degree RAS-derived water as well as effluents from aerobic and anaerobic remineralization reactors have an impact on plant growth rates, and provide hypotheses that could explain these differences.

- To investigate a multi-loop aquaponic system layout by dynamic system modelling considering previous findings and ultimately offer important insights into sizing and designing of such systems.

The presented objectives roughly cover the domains of (1) economy, (2) plant growth performance, (3) remineralization, and (4) system modelling. Each objective is linked to one or more technical chapters.

The domain of aquaponics is multidisciplinary and very little research is available in that field so far. This dissertation rather follows a systems approach. In particular, this dissertation examines two corresponding main research questions that aim to tackle the defined objectives:

1. To what degree does the implementation of technically more complex multi-loop aquaponic systems improve the economic (i.e. production efficiency) and ecological (i.e. nutrient recycling, waste prevention, water consumption, etc.) impact compared with one-loop aquaponic systems?

2. What are the determining parameters for both sizing and designing multi-loop aquaponic systems?

\subsubsection{Experiments}

To investigate the growth performance of plants (i.e. Objective 2), plant growth experiments have been performed. These experiments followed the approach of determination of variables, data collection using sensors as well as lab analyses, (statistical) data analysis, and hypothesis testing. To date, a considerable amount of literature has been published on aquaponics, but no previous study has provided information on plant growth performances in multi-loop aquaponic systems; i.e. comparing the growth of plants grown (in equal nutrient concentrations) in conventional hydroponic systems with those exposed to RAS water. Table 1.1 gives an overview over papers with the subject of their experimental data. 
Table 1.1 Overview of tested aquaponics systems in scientific papers.

\begin{tabular}{|l|l|l|l|}
\hline Kind of System & Plant & Fish & Author(s) \\
\hline One-Loop & Lettuce, Basil & Tilapia & (Rakocy et al., 2006) \\
\hline One-Loop & Water spinach & African Catfish & (Endut et al., 2010) \\
\hline One-Loop & Strawberry & Tilapia & (Villarroel et al., 2011) \\
\hline One-Loop & Lettuce & Tilapia & (Pantanella et al. 2012) \\
\hline Two-Loop & $\begin{array}{l}\text { Lettuce, } \\
\text { Nasturtium }\end{array}$ & Trout & (Buzby and Lin, 2014) \\
\hline Two-Loop & Tomato & Tilapia & (Kloas et al., 2015) \\
\hline Two-Loop & Tomato & Tilapia & (Suhl et al., 2016) \\
\hline One-Loop & Tomato & Tilapia & (Schmautz et al., 2016) \\
\hline One-Loop & Basil & Catfish & (Saha et al., 2016) \\
\hline One-Loop & Basil, Parsley & Tilapia, Catfish & (Knaus and Palm, 2017) \\
\hline
\end{tabular}

\subsubsection{Dynamic System Modelling}

Dynamic systems analysis was used to create a multi-loop aquaponic model to determine water and nutrient flows (Objective 3). Causal loop diagrams as well as flow-charts served as a basis for physically-based dynamic computer modelling conducted with AnyLogic software. The function of the flowcharts was to provide an overview of all procedures considered necessary in the context of a comprehensive diagnostic process, whereas the causal loop diagrams (CLDs) represented a fundamental tool to understand and illustrate the workings of the complex systems. Modelling such a system is important to provide insight into nutrient and water fluxes. Additionally, the model serves as a sizing tool with respect to the determining factors, such as hydroponic phosphorus-availability and RASwater quality. So far, two scholars have developed mathematical computer simulation models for multi-loop aquaponic systems (Karimanzira et al., 2016; Reyes Lastiri et al., 2016), showing that both water and nutrients can be saved when linking the aquaculture waste-water stream with a hydroponics unit. This thesis, however, will look deeper into auxiliary loops in order to increase the system's degree of resource usage.

\subsection{Thesis Outline}

This thesis comprises eight chapters including the general introduction (Chapter 1) and the general discussion (Chapter 8). Figure 1.5 shows that the chapters have been ordered so that they run like a red thread through this thesis. Chapter 2 reviews and analyses the gaps between current research and the potential for development of successful models for commercial medium- and large-scale aquaponics. Chapter 3 provides evidence that multiloop aquaponic systems are more than just a trendy food production system. Chapter 4 
validates the findings from Chapter 3 experimental data on a larger scale. Chapter $\mathbf{5}$ deals with the third loop, the nutrient remineralisation of fish sludge. Before considering the integration of such a third loop in decoupled aquaponic systems, the impact of nutrient-rich supernatants from both aerobic and anaerobic treatments on plant growth needed to be determined. Chapter $\mathbf{6}$ and $\mathbf{7}$ therefore follow a modelling and design approach. Here we combined the knowledge of the conducted experiments with mass balances of the system. Consequently, a model was developed in order to simulate the water flux and nutrient dynamics in decoupled multi-loop aquaponic systems. Finally yet importantly, Chapter 8 discusses our findings with respect to the two main research questions and debates their implications for future developments of multi-loop aquaponic systems. Furthermore, it contains also an outlook of how and to what degree the cycle actually can be closed.

\begin{tabular}{|c|c|c|c|}
\hline \multicolumn{4}{|c|}{$\begin{array}{c}\text { Chapter } 1 \\
\text { General Introduction }\end{array}$} \\
\hline \multicolumn{4}{|c|}{$\begin{array}{c}\text { Chapter } 2 \\
\text { Review Paper ( } \underline{\text { Objective 1) }} \\
\text { ces and challenges of commerc }\end{array}$} \\
\hline $\begin{array}{c}\text { Chapter } 3 \\
\text { Experiment (Objective 2) } \\
\text { Plant growth experiment: } \\
\text { Complemented Aquaponics } \\
\text { vs. Hydroponics vs. } \\
\text { Aquaponics }\end{array}$ & \multicolumn{2}{|c|}{$\begin{array}{c}\text { Chapter } 4 \\
\text { Experiment (Objective 2) } \\
\text { Plant growth experiment: } \\
\text { Complemented Aquaponics } \\
\text { vs. Hydroponics vs. } \\
\text { Aquaponics }\end{array}$} & $\begin{array}{c}\text { Chapter } 5 \\
\text { Experiment (Objective 2) } \\
\text { Plant growth experiment: } \\
\text { Aerobic vs. anaerobic } \\
\text { digestates. }\end{array}$ \\
\hline \multicolumn{2}{|c|}{$\begin{array}{c}\text { Chapter } 6 \\
\text { Modelling ( } \text { Objective } 3 \text { ) } \\
\text { Designing and modelling of a multi-loop } \\
\text { aquaponic system. }\end{array}$} & \multicolumn{2}{|c|}{$\begin{array}{c}\text { Chapter } 7 \\
\text { Modelling (Objective 3) } \\
\text { Identifying and optimizing nutrient fluxes } \\
\text { and concentrations. }\end{array}$} \\
\hline \multicolumn{4}{|c|}{$\begin{array}{c}\text { Chapter } 8 \\
\text { General Discussion }\end{array}$} \\
\hline
\end{tabular}

Figure 1.5. Schematic representation of the chapters of this thesis following the red thread approach. 


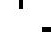

- 


\title{
Chapter 2 Challenges of Sustainable and Commercial Aquaponics
}

This chapter is based on:

Goddek, S., Delaide, B., Mankasingh, U., Ragnarsdottir, K., Jijakli, $H_{\text {., \& }}$ Thorarinsdottir, $R$. (2015). Challenges of Sustainable and Commercial Aquaponics. Sustainability, 7(4), 41994224. http://doi.org/10.3390/su7044199

\begin{abstract}
The world is facing a number of serious problems of which population rise, climate change, soil degradation, water scarcity and food security are among the most important. Aquaponics, as a closed loop system consisting of hydroponics and aquaculture elements, could contribute to addressing these problems. However, there is a lack of quantitative research to support the development of economically feasible aquaponics systems. Although many studies have addressed some scientific aspects, there has been limited focus on commercial implementation. In this review paper, opportunities that have the potential to fill the gap between research and implementation of commercial aquaponic systems have been identified. The analysis shows that aquaponics is capable of being an important driver for the development of integrated food production systems. Arid regions suffering from water stress will particularly benefit from this technology being operated in a commercial environment.
\end{abstract}




\subsection{Introduction}

Aquaponics is an integrated multi-trophic system that combines elements of recirculating aquaculture and hydroponics (Rakocy, 1989), wherein the water from the fish tanks that is enriched in nutrients is used for plant growth. It is a soil-free down-sized natural process that can be found in lakes, ponds and rivers. Using fish waste as fertilizer for crops is an ancient practice. The most well-known examples are the "stationary islands" set up in shallow lakes in central America (e.g., Aztec's Chinampas 1150-1350 BC) (Turcios and Papenbrock, 2014), and the introduction of fish into paddy rice fields in South-East Asia about 1500 years ago (Coche, 1967). In the late 70s and early 80s, researchers at the New Alchemy Institute North Carolina State University (USA) developed the basis of modern aquaponics (Love et al., 2014). The probably most known example was set up at the University of the Virgin Islands (UVI) in 1980 (Rakocy, 1989). A survey, conducted by Love et al. (2014), shows that aquaponics has been receiving growing interest since then (Diver and Rinehart, 2010), which underpins its increasing significance for society as an innovative response for food security.

Its role for food security would be particularly relevant because the global population now exceeds 7.2 billion and is growing rapidly. It is expected to reach 9.6 billion around 2050 with more than $75 \%$ living in urban areas (UN, 2013). Urban population growth will require an increasing demand for animal protein (Alexandratos and Bruinsma, 2012). However, the future of conventional farming, including intensive animal protein production, in meeting this demand is challenged by rising but fluctuating energy and oil costs, climate change and pollution. Resource limitations including the decrease of arable surfaces, constrained freshwater supplies, soil degradation and soil nutrient depletion also add to these challenges (Bindraban et al., 2012; Klinger and Naylor, 2012). This alerts researchers to the necessity to compensate existing sustainability deficits in agricultural food systems.

The interlinking of aquacultural and hydroponic procedures allows some of the shortcomings of the respective systems to be addressed, and this represents a promising sustainable food production method. Aquaponics can be considered a sustainable agricultural production system regarding the definition of Lehman et al. (1993), who define sustainable agriculture as a process that does not deplete any non-renewable resources that are essential to agriculture in order to sustain the agricultural practices. Francis et al. (2003) add that sustainable agricultural production can be achieved by resembling natural ecosystems and "designing systems that close nutrient cycles", which is one of the main characteristics of aquaponics. 
Mineral transfers from aquaculture to hydroponics support efficient nutrient recycling, while water recirculation reduces the water use (Turcios and Papenbrock, 2014). High yield hydroponic systems require a considerable amount of macro- and micronutrients from industrial and mining origin, leading to high energy (i.e., for production and transport) and finite resources use (e.g., phosphorus and oil) (Sverdrup and Ragnarsdottir, 2011). Also, in no-recirculating systems, intermittent disposal of the considerable amounts of nutrient rich water leads to high water consumption as well as surface and groundwater pollution (Gagnon et al., 2010). The regular exchange of water performed in conventional aquacultural systems is not necessary in aquaponics. In this respect, $1 \mathrm{~kg}$ of beef meat requires between 5000 and 20,000 L of water (IME, 2013) and the same amount of fish bred in semi-intensive and extensive conventional aquaculture systems requires a range of 2500-375,000 L (AlHafedh et al., 2003). Recirculating aquaculture systems, on the other hand, have a high degree of water reuse (i.e., 95\%-99\%) (Dalsgaard et al., 2013), with water usage down to below $100 \mathrm{~L} \mathrm{~kg}^{-1}$ of fish produced (Martins et al., 2011). In aquaponics, nitrate in excess is used for valuable plant production instead of being removed in gaseous form in denitrification units (Van Rijn, 2013).

Although preliminary research has shown that developed aquaponic system components are not yet fully realized in view of either cost effectiveness or technical capabilities (Rakocy 2012; Vermeulen \& Kamstra 2013), the aquaponics concept is promising to contribute to both global and urban sustainable food production and should at the same time diminish pollution and need for resources. In order to meet the goal of establishing large-scale ecoefficient and economically viable aquaponic farming projects, this paper reviews the technical and socio-ecological developments that have been undertaken to date and demonstrates which aspects still need to be addressed. The purpose of this paper is to highlight current aquaponics challenges and give directions for further research. For each challenge, various approaches are described.

\subsection{Principles of Aquaponics}

Aquaponics combines hydroponics and recirculating aquaculture elements. Conventional hydroponics requires mineral fertilizers in order to supply the plants with necessary nutrients but the aquaponics systems use the available fish water that is rich in fish waste as nutrients for plant growth. Another advantage of this combination lies in the fact that excess of nutrients does not need to be removed through periodical exchange of enriched fish water with fresh water as practiced in aquaculture systems. The system results in a symbiosis between fish, microorganisms and plants, and encourages sustainable use of water and nutrients, including their recycling (Figure 2.1). Within this synergistic interaction, the 
respective ecological weaknesses of aquaculture and hydroponics are converted into strengths. This combination substantially minimizes the need for input of nutrients and output of waste, unlike when run as separate systems.

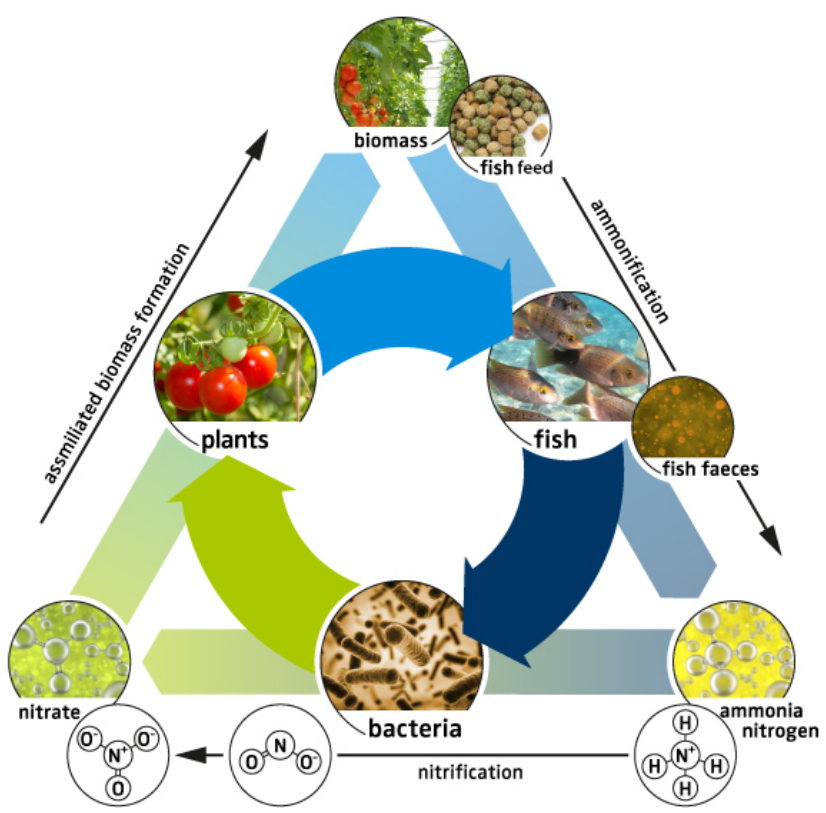

Figure 2.1. Symbiotic aquaponic cycle.

Plants need macronutrients (e.g., C, H, O, N, P, K, Ca, S and Mg) and micronutrients (e.g., Fe, $\mathrm{Cl}, \mathrm{Mn}, \mathrm{B}, \mathrm{Zn}, \mathrm{Cu}$ and $\mathrm{Mo}$ ), which are essential for their growth. Hydroponic solutions contain well-defined proportions of these elements (Resh, 2012) and are added to the hydroponic solution in ionic form with the exception of $\mathrm{C}, \mathrm{H}$, and $\mathrm{O}$, which are available from air and water. In aquaponics systems, plant nutrient input from the fish tanks contains dissolved nutrient rich fish waste (gill excretion, urine and faeces), comprising of both soluble and solid organic compounds that are solubilized to ionic form in the water and assimilated by the plants. To sustain adequate plant growth the concentrations of micro- and macronutrients need to be monitored. Periodically some nutrients may need to be added to adjust their concentration, for example iron is often deficient in fish waste (Rakocy et al., 2004; Seawright et al., 1998). 
Aquaponic systems need to be able to host different microorganism communities that are involved in fish waste processing and solubilization. Ammonia $\left(\mathrm{NH}_{4}^{+}\right)$from fish urine and gill excretion can build up to toxic levels if not removed from the system. This can be done by step-wise microbial conversion to nitrate. One of the most important microbial components is the nitrifying autotrophic bacteria consortium that is established as a biofilm on solid surfaces within the system and is principally composed of nitroso-bacteria (e.g., Nitrosomonas sp.) and nitro-bacteria (e.g., Nitrospira sp., Nitrobacter sp.). The ammonia within the system is converted into nitrite $\left(\mathrm{NO}_{2}{ }^{-}\right)$by nitroso-bacteria, before being transformed into nitrate $\left(\mathrm{NO}_{3}{ }^{-}\right)$by the nitro-bacteria (Tyson et al., 2008). The final product of this bacterial conversion, nitrate, is considerably less toxic for fish and due to its bioconversion, is the main nitrogen source for plant growth in aquaponics systems (Endut et al., 2010; Graber and Junge, 2009a; Rakocy et al., 2006). In most systems, a special biofiltration unit where intensive nitrification occurs is required.

The optimal ratio between fish and plants needs to be identified to get the right balance between fish nutrient production and plant uptake in each system. Rakocy (2007) reports that this could be based on the feeding rate ratio, which is the amount of feed per day per square meter of plant varieties. On this basis, a value between 60 and $100 \mathrm{~g} \mathrm{day}^{-1} \mathrm{~m}^{-2}$ has been recommended for leafy-greens growing on raft hydroponic systems (Rakocy and Bailey, 2012). Endut et al. (2010) found an optimum ratio of 15-42 grams of fish feed day ${ }^{-1}$ $\mathrm{m}^{-2}$ of plant growing with one African catfish (Clarias gariepinus) for eight water spinach plants (Ipomoea aquatica). Hence, finding the right balance necessitates fundamental knowledge and experiences with regard to the following criteria: (1) types of fish and their food use rate; (2) composition of the fish food, for example, the quantity of pure proteins converted to Total Ammonia Nitrogen (TAN); (3) frequency of feeding; (4) hydroponic system type and design; (5) types and physiological stages of cultivated plants (leafy greens vs. fruity vegetables); (6) plant sowing density, and (7) chemical composition of the water influenced by the mineralization rate of fish waste. Additionally, since fish, microorganisms and plants are in the same water loop, environmental parameters such as temperature, $\mathrm{pH}$ and mineral concentrations need to be set at a compromise point as close as possible to their respective optimal growth conditions.

\subsection{System Description}

As outlined above, the aquaponics system can be seen as the connection between a conventional recirculating aquaculture systems (RAS) and hydroponics components. In short, water recirculates in a loop as it flows from the fish tank to filtration units, before it is pumped into the hydroponic beds that are used as water reprocessing units. The filtration 
units are composed of mechanical filtration units for solid particles removal (e.g., drum filter or settling tank), and biofilters for nitrification processes (e.g., trickling or moving bed biofilter). Although system configurations and complexity can vary greatly, Figure 3.2 illustrates a typical layout.

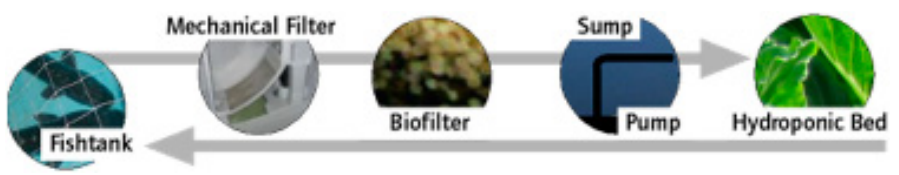

Figure 2.2. Basic aquaponic system layout.

Three types of hydroponic beds are commonly used: media-based grow bed, Deep Water Culture (DWC) bed, and Nutrient Film Technique (NFT) gutter shaped bed. The media-based grow bed is a hydroponic trough filled with inert substrate (e.g., expanded clay, perlite, pumice, gravel), serving as root support and microbial substrate. The water is commonly supplied in an ebb and flow pattern, ensuring sequential nutrition and aeration. The DWC system consists of large troughs with perforated floating rafts, where net plant pots are inserted. In the DWC system, these plant pots are generally filled with media, such as rock wool, coco or pumice that support the roots, which are then continually submerged in the water tank. The Nutrient Film Technique (NFT) consists of narrow channels of perforated squared pipes where the roots are partially immersed in a thin layer of streaming water. A comparison of the advantages and disadvantages of these hydroponic beds versus soil culture is presented in Table 2.1.

Table 2.1. Advantages, disadvantages and nutrient uptake for different grow components in aquaponics with regard to different practical and productivity aspects.

\begin{tabular}{|c|c|c|c|c|}
\hline & Media-based growing bed & $D W C$ & $N F T$ & Soil \\
\hline Advantages & $\begin{array}{l}\text { - Biofiltration: media serves } \\
\text { as substrate for nitrifying } \\
\text { bacteria (Rakocy, 2007) } \\
\text { - Act as a solids filtering } \\
\text { medium } \\
\text { - Mineralization in grow bed } \\
\text { - Colonized by a broad } \\
\text { microflora }\end{array}$ & $\begin{array}{l}\text { - Constant } \\
\text { water flow } \\
\text { - Small sump } \\
\text { tank needed } \\
\text { - Ease of } \\
\text { maintenance } \\
\text { and cleaning } \\
\text { (Endut et al., } \\
\text { 2010) }\end{array}$ & $\begin{array}{l}\text { - Constant } \\
\text { water flow } \\
\text { - Small sump } \\
\text { tank needed } \\
\text { - Ease of } \\
\text { maintenance } \\
\text { and cleaning } \\
\text { - Require } \\
\text { smaller volume } \\
\text { of water }\end{array}$ & $\begin{array}{l}\text { - Less } \\
\text { infrastructure } \\
\text { - Natural roots } \\
\text { environment } \\
\text { - Colonized by } \\
\text { broad } \\
\text { microflora and } \\
\text { fungi (Lennard } \\
\text { and Leonard, } \\
\text { 2006) }\end{array}$ \\
\hline
\end{tabular}




\begin{tabular}{|c|c|c|c|c|}
\hline & & & $\begin{array}{l}\text { - Light } \\
\text { hydroponic } \\
\text { infrastructure, } \\
\text { suits well for } \\
\text { roof farming }\end{array}$ & $\begin{array}{l}\text { - Accepted as } \\
\text { "organic way of } \\
\text { production" }\end{array}$ \\
\hline Disadvantages & $\begin{array}{l}\text { - If flood and drain method: } \\
\text { sizing and reliability plus } \\
\text { large sump tank needed } \\
\text { - Heavy hydroponic } \\
\text { infrastructure } \\
\text { - Maintenance and cleaning } \\
\text { difficult } \\
\text { - Clogging leading to water } \\
\text { channeling, inefficient } \\
\text { biofiltration and inefficient } \\
\text { nutrient delivery to plants } \\
\text { (Endut et al., 2010) }\end{array}$ & $\begin{array}{l}\text { - Separate } \\
\text { biofilter needs } \\
\text { to be added } \\
\text { (Lennard and } \\
\text { Leonard, 2006) } \\
\text { - Require large } \\
\text { volume of } \\
\text { water } \\
\text { - Heavy } \\
\text { hydroponic } \\
\text { infrastructure } \\
\text { - Device for } \\
\text { roots aeration } \\
\text { mandatory } \\
\text { (Bulgarelli et } \\
\text { al., 2013) }\end{array}$ & $\begin{array}{l}\text { - Separate } \\
\text { biofilter needed } \\
\text { - Lower yields } \\
\text { (showed for } \\
\text { lettuce by } \\
\text { (Lennard and } \\
\text { Leonard, 2006)) } \\
\text { - Expensive } \\
\text { material } \\
\text { - the system is } \\
\text { less stable as } \\
\text { there is less } \\
\text { water, }\end{array}$ & $\begin{array}{l}\text { - Small control } \\
\text { on the soil } \\
\text { nutrient } \\
\text { solution } \\
\text { - Good soil not } \\
\text { available } \\
\text { everywhere } \\
\text { - More } \\
\text { vulnerable for } \\
\text { diseases } \\
\text { - Lower basil } \\
\text { and okra yield } \\
\text { than in } \\
\text { aquaponics } \\
\text { (Tyson et al., } \\
\text { 2008) }\end{array}$ \\
\hline Nutrient uptake & - High & - High & $\begin{array}{l}\text { - Lower because } \\
\text { smaller root- } \\
\text { water contact } \\
\text { area }\end{array}$ & - Lower \\
\hline
\end{tabular}

With respect to a holistic system approach, there are many ways to frame an aquaponic system in terms of hydrological and functional design. A few scientific papers provide working knowledge about different design and key parameters. Table 2.2 gives an overview of these.

Table 2.2. Comparison of design and key parameters in well described aquaponic systems found in scientific articles.

\begin{tabular}{|l|l|l|l|l|}
\hline & System $A$ & System $\boldsymbol{B}$ & System $C$ & System $\boldsymbol{D}$ \\
\hline System Type & $\begin{array}{l}\text { Nutrient Film Technique } \\
\text { (NFT) configured in the } \\
\text { conveyor production } \\
\text { system. }\end{array}$ & $\begin{array}{l}\text { Deep Water Culture } \\
\text { (DWC) }\end{array}$ & $\begin{array}{l}\text { Deep Water } \\
\text { Culture (DWC) }\end{array}$ & $\begin{array}{l}\text { Deep Water } \\
\text { Culture } \\
\text { (DWC) }\end{array}$ \\
\hline Source & Adler et al. (2000) & $\begin{array}{l}\text { Roosta and Hamidpour } \\
(2011)\end{array}$ & $\begin{array}{l}\text { Rakocy et al. } \\
\text { (2004) }\end{array}$ & $\begin{array}{l}\text { Endut et al. } \\
(2011)\end{array}$ \\
\hline Location & $\begin{array}{l}\text { The Conservation } \\
\text { Fund's Freshwater } \\
\text { Institute, Shepherdstown, }\end{array}$ & $\begin{array}{l}\text { Iniversity of Rafsanjan, } \\
\text { Iran }\end{array}$ & $\begin{array}{l}\text { University of } \\
\text { Virgin Islands, } \\
\text { USA }\end{array}$ & $\begin{array}{l}\text { University } \\
\text { of Malaysia } \\
\text { Terengganu }\end{array}$ \\
\hline
\end{tabular}




\begin{tabular}{|c|c|c|c|c|}
\hline & W. Va., USA & & & \\
\hline Based on & $\begin{array}{l}\text { The system was } \\
\text { theoretically valuated } \\
\text { using data from studies } \\
\text { conducted at the } \\
\text { Conservation Fund's } \\
\text { Freshwater Institute } \\
\text { during } 1994 \text { and 1995 } \\
\text { (Adler et al., 2000, 1996) }\end{array}$ & UVI-System & $\begin{array}{l}\text { Own setup } \\
\text { (UVI-System) }\end{array}$ & Own Setup \\
\hline $\begin{array}{l}\text { Volume RAS } \\
\left(\mathrm{m}^{3}\right)\end{array}$ & $>38$ & 0.848 & 43 & 3 \\
\hline $\begin{array}{l}\text { Size } \\
\text { Hydroculture } \\
\left(\mathrm{m}^{2}\right)\end{array}$ & 498 & $\begin{array}{l}\text { Unknown (consisting of } \\
8 \text { plants) }\end{array}$ & 220 & 2 \\
\hline $\begin{array}{l}\text { Plant Density } \\
\left(p c s / m^{2}\right)\end{array}$ & 5.7 per meter of NFT trays & - & $\begin{array}{l}8 \text { (basil); } 2-4 \\
\text { (okra) }\end{array}$ & ND \\
\hline $\begin{array}{l}\text { Fish Density } \\
\left(\mathrm{kg} / \mathrm{m}^{3}\right)\end{array}$ & 113.4 & $\begin{array}{l}\text { 17.69 (Common Carp), } \\
\text { 23.58 (Grass Carp), } \\
17.69 \text { (Silver Carp) }\end{array}$ & $61.5-70.7$ & ND \\
\hline $\begin{array}{l}\text { Daily feed input } \\
\text { / plant growing } \\
\text { area }\left(g / \text { day } / \mathrm{m}^{2}\right)\end{array}$ & ND & ND & $81.4-99.6$ & $15-42$ \\
\hline $\begin{array}{l}\text { Fish:Plant Ratio } \\
\text { (kg) }\end{array}$ & ND & ND & ND & $1: 8$ \\
\hline Plants Used & $\begin{array}{l}\text { Basil (Ocimum basilicum); } \\
\text { Lettuce (Lactuca sativa } \\
\text { L.'Ostinata') }\end{array}$ & $\begin{array}{l}\text { Tomato (Iycopersicon } \\
\text { esculentum) }\end{array}$ & $\begin{array}{l}\text { Basil (Ocimum } \\
\text { basilicum); } \\
\text { Okra } \\
\text { (Abelmoschus } \\
\text { esculentus) }\end{array}$ & $\begin{array}{l}\text { Spinach } \\
\text { (Spinacia } \\
\text { oleracea) }\end{array}$ \\
\hline Fish Used & $\begin{array}{l}\text { Rainbow Trout } \\
\text { (Oncorhynchus mykiss) }\end{array}$ & $\begin{array}{l}\text { Common Carp } \\
\text { (Cyprinus carpio), } \\
\text { Grass Carp } \\
\text { (Ctenopharyngodon } \\
\text { idella), Silver Carp } \\
\text { (Hypophthalmichthys } \\
\text { molitrix) }\end{array}$ & $\begin{array}{l}\text { Nile Tilapia } \\
\text { (Oreochromis } \\
\text { niloticus L.) }\end{array}$ & $\begin{array}{l}\text { African } \\
\text { Catfish } \\
\text { (Clarias } \\
\text { gariepinus) }\end{array}$ \\
\hline $\begin{array}{l}\text { Hydroculture } \\
\text { (Wet) Biomass } \\
\left(\mathrm{kg} / \mathrm{m}^{2}\right)\end{array}$ & ND & ND & $\begin{array}{l}2 \text { (basil); } 2.9 \\
\text { (okra) }\end{array}$ & 1.16 \\
\hline Biofiltration & $\begin{array}{l}\text { Fluidized Sand Filter }+ \\
\text { Carbon Dioxide Strippers }\end{array}$ & Net Filter & Net Filter & $\begin{array}{l}\text { Rapid Sand } \\
\text { Filters }\end{array}$ \\
\hline
\end{tabular}




\begin{tabular}{|c|c|c|c|c|}
\hline $\begin{array}{l}\text { Mechanical } \\
\text { Filtration }\end{array}$ & Drum filter & $\begin{array}{l}\text { Clarifier plus Net } \\
\text { Plastic Filter }\end{array}$ & $\begin{array}{l}\text { Clarifier plus } \\
\text { Net Plastic } \\
\text { Filter }\end{array}$ & $\begin{array}{l}\text { Rapid Sand } \\
\text { Filters }\end{array}$ \\
\hline $\begin{array}{l}\text { Water } \\
\text { Parameters ( } \mathrm{pH} ; \\
\left.{ }^{\circ} \mathrm{C}\right)\end{array}$ & pH 7.2; Temp : ND & $\begin{array}{l}\text { pH 7.0-7.7; Temp : } 25.7 \\
{ }^{\circ} \mathrm{C}\end{array}$ & $\begin{array}{l}\text { pH 7.0-7.5; } \\
\text { Temp : } 28^{\circ} \mathrm{C}\end{array}$ & $\begin{array}{l}\text { pH 5.6-7.3; } \\
\text { Temp : } \\
27.5-28.8 \\
{ }^{\circ} \mathrm{C}\end{array}$ \\
\hline $\begin{array}{l}\text { Temporal length } \\
\text { of experiment }\end{array}$ & ND & 108 days & \begin{tabular}{|l}
28 weeks \\
(basil); 11.7 \\
weeks (okra)
\end{tabular} & 35 days \\
\hline $\begin{array}{l}\text { Cost of setup (\$ } \\
\text { U.S.) }\end{array}$ & $\begin{array}{l}\$ 100120 \text { (hydroponic } \\
\text { part)* }\end{array}$ & - & - & - \\
\hline $\begin{array}{l}\text { Cost of annual } \\
\text { running ( } \$ \text { U.S.) }\end{array}$ & $\begin{array}{l}\$ 204040 \text { (lettuce); } \\
\$ 194,950 \text { (basil) }\end{array}$ & - & $\begin{array}{l}\$ 24,440 \\
\text { (tilapia+basil) }\end{array}$ & - \\
\hline $\begin{array}{l}\text { Break-even price } \\
(\$ \text { U.S.) }\end{array}$ & $\begin{array}{l}\$ 13.8 \text { (per box of } 24 \\
\text { lettuces); } \$ 0.53 \text { (per basil } \\
\text { plant) }\end{array}$ & & $\begin{array}{l}\$ 3.23 \text { (per kg } \\
\text { of tilapia); } \\
\$ 1.66 \text { (per kg } \\
\text { of basil) }\end{array}$ & \\
\hline $\begin{array}{l}\text { Potential annual } \\
\text { profit }(\$ \text { U.S.) }\end{array}$ & $\begin{array}{l}\$ 12,350-\$ 44,350 \text { (for box } \\
\text { of } 24 \text { lettuces sold at } 14 \text { - } \\
16 \$ \text { ); } \$ 27750-\$ 66090 \text { (for } \\
\text { basil plant sold at } \$ 0.60- \\
\$ 0.70 \text { ) }\end{array}$ & - & $\begin{array}{l}\$ 116,000 \text { (for } \\
\text { tilapia sold at } \\
\$ 5.5 / \mathrm{kg} \text { and } \\
\text { basil sold at } \\
\$ 22.5 / \mathrm{kg} \text { ) }\end{array}$ & - \\
\hline
\end{tabular}

${ }^{*}$ Economic analysis is only about the hydroponic part / ND: Not described in the source

With respect to Table 2.2, it is particularly noticeable that DWC systems are mainly used, and important design parameters such as fish to plant ratio or daily feed input are sometimes missing from the literature. It must be mentioned that some costs (i.e., labour costs) are not taken into account, so the financial viability can only be partially estimated.

Apart from the UVI system, there is a lack of scientific literature when it comes to aquaponic experiments on large scale and during long time sequences. Moreover, many experimental setups published are small-scale replicates of the UVI design. Limited data on cost and potential profit of such systems are available (Adler et al., 2000; Endut et al., 2011; Love et al., 2015; Rakocy et al., 2004). As aquaponics is still in a maturing experimental phase, scientific research has focused more on technical aspects than economic viability. However, economic challenges need to be addressed. Experiments covering bigger production systems exist, but they are performed by private research centres or companies, whereby confidential findings are not always made accessible to third parties. 


\subsection{Technical Challenges}

Aquaponics system design and application can be considered a highly multidisciplinary approach drawing from environmental, mechanical and civil engineering design concepts as well as aquatic and plant related biology, biochemistry, and biotechnology. System specific measurements and control technologies also require knowledge of subjects related to the field of computer science for automatic control systems. This high level of complexity necessarily demands in-depth knowledge and expertise of all involved fields. The biggest challenge in commercial aquaponics is its multi-disciplinarity, needing further expertise in economics, finance and marketing. Thus, a high degree of field-specific insight in terms of both practical and in-depth theoretical knowledge is required. This leads to an increasing level of complexity, which directly affects the efficiency factors of the running system. In the interest of highest efficiency and productivity, some numerical trade-offs are recommended and are outlined below. They include $\mathrm{pH}$ stabilization, nutrient balance, phosphorus, and pest management.

\subsection{1 pH Stabilization}

A crucial point in aquaponic systems is the $\mathrm{pH}$ stabilization, as it is critical to all living organisms within a cycling system that includes fish, plants and bacteria. The optimal $\mathrm{pH}$ for each living component is different. Most plants need a $\mathrm{pH}$ value between 6 and 6.5 in order to enhance the uptake of nutrients. The fish species Tilapia (Oreochromis) is known to be disease-resistant and tolerant to large fluctuations in $\mathrm{pH}$ value with a tolerance between $\mathrm{pH}$ 3.7 and 11, but achieves best growth performance between $\mathrm{pH} 7.0$ and 9.0. The nitrifying bacteria have a higher optimum $\mathrm{pH}$, which is above 7. Villaverde (1997) observed that nitrification efficiency increased linearly by $13 \%$ per $\mathrm{pH}$ unit within a $\mathrm{pH}$ range between 5.0 and 9.0 with the highest activity of ammonium oxidizers at 8.2. Similar observations were made by Antoniou et al. (1990), who report the overall nitrification $\mathrm{pH}$ of approximately 7.8. There are three major bacteria, for which optimal pH conditions are as follows: (1) Nitrobacter: 7.5 (Keen and Prosser, 1987); (2) Nitrosomonas: 7.0-7.5 (Hatayama et al., 2000), and (3) Nitrospira: 8.0-8.3 (Blackburne et al., 2007).

Based on these data, the highest possible $\mathrm{pH}$ value should be consistent with the prevention of ammonia accumulation in the system. Then, the ideal $\mathrm{pH}$ value for the system is between 6.8 and 7.0. Although root uptake of nitrate raises $\mathrm{pH}$ as bicarbonate ions are released in exchange (Kaiser et al., 2011), the acidity producing nitrification process has a higher impact on the overall system $\mathrm{pH}$, leading to a constant and slight decrease in the $\mathrm{pH}$-value. There are two approaches to counteract that trend: 
(1) Nutritional supplementation is the most applied method in use. By adding carbonate, bicarbonate or hydroxide to the system, the $\mathrm{pH}$ value can temporarily be adjusted in line with the requirements. Also, they increase the alkalinity parameter that prevents large fluctuations in $\mathrm{pH}$ and thus keeps the system stable. The buffers should preferably be based on calcium, potassium, and magnesium compounds, since they compensate for a possible nutritional deficiency of those essential nutrients for plants (Rakocy, 2007). Regarding the composition of the supplementation, it is important to seek a balance between those three elements.

(2) A proposed alternative approach is the implementation of the fluidized lime-bed reactor concept (Sverdrup et al., 1981) into the field of aquaponics. This water neutralization concept consists of the controlled addition of dissolved limestone $\left(\mathrm{CaCO}_{3}\right)$ to the acid water that leads to a continuous $\mathrm{pH}$-elevating effect due to carbonate solubilization that releases hydroxide anions

$\left(\mathrm{OH}^{-}\right)$.

$$
\mathrm{CaCO}_{3}(\mathrm{~s}) \rightleftharpoons \mathrm{Ca}^{2+}+\mathrm{CO}_{3}^{2-}
$$

Depending on $\mathrm{pH}$, when $\mathrm{CaCO}_{3}$ dissolves, some carbonate hydrolyses produce $\mathrm{HCO}_{3}{ }^{-}$

$$
\mathrm{CO}_{3}{ }^{2-}+\mathrm{H}_{2} \mathrm{O} \rightleftharpoons \mathrm{HCO}_{3}^{-}+\mathrm{OH}^{-}
$$

The degree to which the $\mathrm{pH}$ is raised is dependent on the adjustable flow rate. However, this concept requires preliminary empirical measurements with respect to the system's steady $\mathrm{pH}$-drop in order to determine the size of the lime-bed reactor taking the specific flow-rate into consideration.

\subsubsection{Nutrient Balance}

As an innovative sustainable food production system, the challenge in aquaponics is to use the nutrient input efficiently, minimizing its discard and tending to a zero-discharge recirculating system (Gelfand et al., 2003; Neori et al., 2007). Fish feed, the main nutrient input, can be divided into assimilated feed, uneaten feed, and soluble and solid fish excreta (Neto and Ostrensky, 2013). Soluble excreta are mainly ammonia and is the most available mineral until it is successively transformed into nitrite and nitrate by nitrifying bacteria (Chen et al., 2006; Lekang and Kleppe, 2000). Both uneaten feed and solid faeces need to be solubilized from organic material to ionic mineral forms that are easily assimilated by plants. Minerals have different solubilization rates and do not accumulate equally (Seawright et al., 1998b), which influences their concentrations in the water. All involved microorganisms and 
chemical and physical mechanisms of solubilization are not well understood (Krom et al., 2014; Van Rijn, 2013). Under current practices in RAS, the solid wastes are only partially solubilized as they are mechanically filtered out on a daily basis (Cripps and Bergheim, 2000). These filtered wastes can be externally fully mineralized and reinserted into the hydroponic beds.

Given the objective of obtaining a low environmental footprint, a zero-discharge recirculating system concept should be achievable according to Neori et al. (2007), but more research needs to be carried out on fish waste solubilization with the objective to transform all added nutrients into plant biomass. There are two methods for mineralizing organic material that could be implemented: (1) anoxic digestion in special mineralization or settling units using bioleaching abilities of heterotrophic bacteria (e.g., Lactobacillus plantarum) (Jung and Lovitt, 2011); and/or (2) using earthworm species such as Lumbricus rubellus capable of converting organic wastes to water enriching compounds in wet composting or grow beds (Bajsa et al., 2003). Vermiculture can facilitate a high degree of mineralization as worm casts contain micro- and macronutrients broken down from organic compounds (Qi, 2012; Torri and Puelles, 2010). Addition of external sources (e.g., food waste) of feed for the worms to provide the aquaponic system with additional organic fertilizers has also been suggested (Jorgensen et al., 2009).

Feed composition directly affects the nutrient excretion by fish, consequently affecting the water chemistry (Martins et al., 2011; Rakocy and Hargreaves, 1993). One challenge is to find the right fish feed composition for aquaponics in order to attain a water composition that is as close as possible to hydroculture requirements. There is a need to establish the macro- and micronutrient proportion that fish can release in the water for a given feed in a given system; this depends on fish species, fish density, temperature, and type of plants (i.e., fruity plants or leafy greens). This will allow prediction of the subsequent mineral addition needed to match optimal plant growth requirements. Inorganic mineral input adds extra cost and issues for sustainable resource management (e.g., global P peak production reality) (Gilbert, 2009; Ragnarsdottir et al., 2011; Sverdrup and Ragnarsdottir, 2011). Thus, fish feed composition should be adapted to minimize this mineral addition while ensuring required nutrition properties for fish yield and avoiding phytotoxic mineral accumulation (e.g., $\mathrm{Na}$ ). The fish feed origin regarding its environmental footprint should also be taken into account. Low trophic fish species should be preferred and alternative production solutions should be promoted such as human food waste recycling (Amadori and Daley, 2012), insects, worms, aquatic weed, and algae as a feed base (Mandal et al., 2010; van Huis, 2013). Also, some fishplant couples might be more appropriate than others in terms of overlap between nutrients 
profiles offered by excreta and nutrient profiles demanded by plants. Identifying these couples would assure an optimum use of the available nutrients.

A comparison of mineral concentrations in the published aquaponics literature (Table 2.3), with recommended recirculating hydroponics solutions leads to two main observations: (1) there is a lack of aquaponic data for some macro- and micro-elements, indicating the necessity of more research focus on them; (2) for the available data, the aquaponic concentrations are below the recommended hydroponic level. However, Rakocy and Lennard (pers. comm.) report that hydroponics and aquaponics nutrient solutions are not comparable for many reasons. The nature of the total dissolved solid (TDS) is not the same in these systems. In hydroponics, TDS consists mainly of mineral compounds, while in aquaponics it includes organic molecules wherein nutrients can be locked up and overlooked by measuring procedures such as electrical conductivity (EC) or aqueous sample filtration. Both aqueous sample filtration and the EC measurement methods only take nutrients that are available in ionic form into account. These suspended organic solids are assumed to promote growth because they might simulate natural growing conditions as found in soil, unlike the growing environment of hydroponics (Böhme, 1999). 


\begin{tabular}{|c|c|c|c|c|c|c|c|c|c|}
\hline 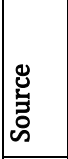 & 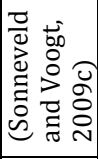 & 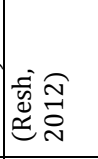 & 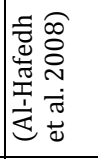 & 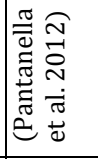 & 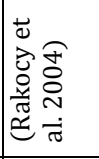 & 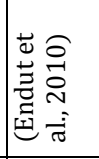 & 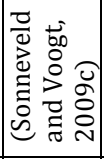 & 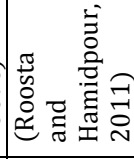 & 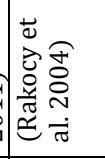 \\
\hline$\stackrel{0}{\Sigma}$ & $\begin{array}{l}2 \\
0 \\
0 \\
0\end{array}$ & $\stackrel{2}{2}$ & & & ¿- & & In & & 苛 \\
\hline$\infty$ & ma & m. & & & $\stackrel{9}{\stackrel{7}{0}}$ & & กั & & 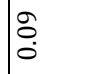 \\
\hline ฟี & ma & $\stackrel{2}{\stackrel{1}{0}}$ & & & $\underset{\ddagger}{\sharp}$ & & $\stackrel{m}{m}$ & $\hat{n}$ & mे \\
\hline$\vec{\jmath}$ & \begin{tabular}{l}
2 \\
\hdashline \\
0 \\
0
\end{tabular} & 늠. & & & $\stackrel{0}{\circ}$ & & 눙 & ¿ & $\stackrel{m}{m}$ \\
\hline 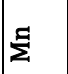 & m. & 눙 & & & $\stackrel{\infty}{0}$ & & : & & : \\
\hline 童 & N & is & & & $\stackrel{\sim}{\text { ก }}$ & & $\stackrel{\infty}{\infty}$ & $\stackrel{\sim}{0}$ & $\stackrel{m}{r}$ \\
\hline $\bar{J}$ & & เ่่ & & & & & & & $\approx$ \\
\hline ¿্ं & m & 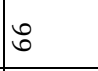 & & & & & $\stackrel{\infty}{+}$ & & 0 \\
\hline 离 & ชู & in & 욱 & $a$ & $\infty$ & 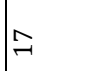 & ळे & $\infty$ & $\stackrel{2}{\sim}$ \\
\hline$\overbrace{z}^{\prime} z$ & : & $\stackrel{\circ}{\circ}$ & กิ & $\hat{m}$ & F & 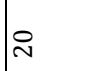 & 돔 & $\stackrel{m}{m}$ & 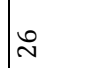 \\
\hline 态 & $\stackrel{\infty}{\sim}$ & & & & $\underset{\text { N }}{\stackrel{\text { N }}{ }}$ & & $\stackrel{\infty}{-}$ & $\stackrel{m}{m}$ & 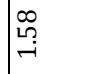 \\
\hline$\triangle$ & $\stackrel{\circ}{\not}$ & $\stackrel{ }{\text { N }}$ & $\stackrel{\infty}{+}$ & $\stackrel{0}{\circ}$ & $\stackrel{2}{7}$ & & 岕 & $\hat{N}$ & t' \\
\hline$\tilde{z}$ & & ம் ஃ & & 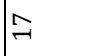 & & & & & $\exists$ \\
\hline$\sum^{\infty}$ & N & iᄋ & & F & $\wedge$ & & $\stackrel{\sim}{N}$ & & 0 \\
\hline త & 文 & ஓे & & $\stackrel{\infty}{\infty}$ & 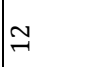 & & $\stackrel{ }{\exists}$ & ウे & ন \\
\hline 垔 & ம & & $\infty$ & & $\stackrel{r}{~}$ & 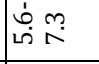 & in & $\grave{r}$ & $\stackrel{r}{r}$ \\
\hline 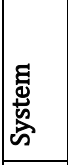 & 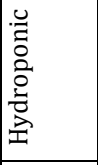 & 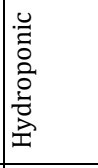 & 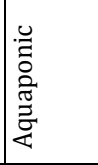 & 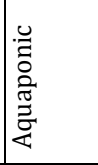 & 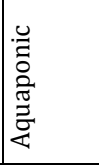 & 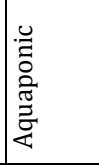 & 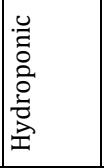 & 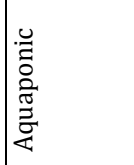 & 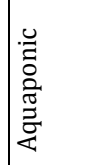 \\
\hline 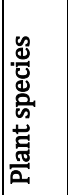 & 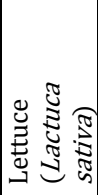 & 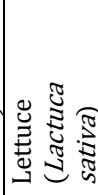 & 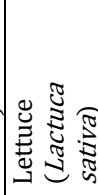 & 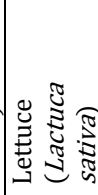 & 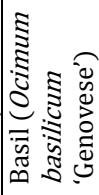 & 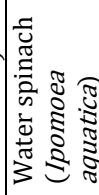 & 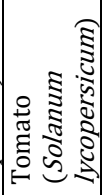 & 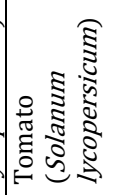 & 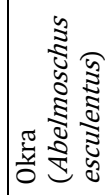 \\
\hline
\end{tabular}


There is a lack of knowledge about the nature of organic molecules and the biochemical processes occurring for their assimilation by plants. Some can be taken up directly or need complex biodegradation to make them available. Another difference is the microflora inherent to aquaponics while sterilization occurs in hydroponics. This microflora can have significant beneficial effects on plant growth and organic molecules assimilation. Hence some aquaponics investigators report similar or even better yield than hydroponics for some crops, despite lower concentrations of mineral nutrients (Lennard and Leonard, 2005; Nichols and Lennard, 2010; Pantanella et al., 2012; Rakocy, 1989; Savidov, 2005; Savidov et al., 2007).

Voogt (2002) identifies three aspects of the hydroponic nutrient solution composition that should be taken into account in aquaponics: (1) elemental uptake ratio compared to nutrient composition; (2) ease of uptake of specific elements; (3) the type of growing system that also require a specific nutrient composition. The composition of a nutrient solution must reflect the uptake ratios of individual elements by the crop, otherwise it will lead to either accumulation or depletion of certain elements. As the demand between crops differ, the basic compositions of nutrients solutions are crop specific (de Kreij et al., 1999). The uptake of certain elements differs widely, the absorption of some of them can be more difficult and necessitates relatively higher ratios than the mere uptake ratio of the crop.

The optimal nutrient levels for leafy and fruity vegetables in aquaponics systems are not yet well established. Additional research should be carried out to assess the optimum value of mineral concentration per single crop or hybrid multi-crop systems regarding growth rate and crop yield. Optimal suspended organic solids level should be identified with respect to its impact on vegetative growth. Also, a special emphasis should be placed on crop quality since productivity should not be the only argument for competitiveness. For output purposes, this should be compared to (1) hydroponic crop grown with mineral nutrient solution, (2) conventionally soil-based agricultural methods, and (3) organic soil-based agricultural methods. Within-system comparative studies address the productivity, as the macro- and micronutrient composition of the products will play a decisive role with respect to future orientation of healthy and efficient quality food production. A deeper understanding of the biochemical processes occurring in solid fish waste solubilization is necessary with the aim to increase mineral levels in aquaponic water by implementing process and specific waste biofiltration units.

\subsubsection{Phosphorus}


Among the different minerals, phosphorus (P) deserves a specific attention. It is a macronutrient, which is assimilated by plants in its ionic orthophosphate form $\left(\mathrm{H}_{2} \mathrm{PO}_{4}\right.$, $\mathrm{HPO}_{4}^{2-}, \mathrm{PO}_{4}{ }^{3-}$ ). It is essential for both vegetative and flowering stages of plant growth (LópezArredondo et al., 2013). In RAS, 30-65\% of the phosphorus added to the system via fish feed is lost in the form of fish solid excretion that is filtered out by either settling tanks or mechanical filters (Schneider et al., 2005; Seawright et al., 1998b). Moreover, organic P solubilized as orthophosphate can precipitate with calcium (e.g. hydroxyapatite $\mathrm{Ca} 5\left(\mathrm{PO}_{4}\right)_{3}(\mathrm{OH})$ ) making these elements less available in solution (Krom et al., 2014; Seawright et al., 1998b). Consequently, aquaponic experiments report a range of 1-17 mg L${ }^{1} \mathrm{PO}_{4}$-P (Al-Hafedh et al., 2008; Endut et al., 2010; Rakocy et al., 2004; Villarroell et al., 2011). However, recommended concentrations in standard hydroponics are generally between 40 and $60 \mathrm{mg} \mathrm{L}^{-1} \mathrm{PO}_{4}-\mathrm{P}$ (Resh, 2012; Sikawa and Yakupitiyage, 2010; Sonneveld and Voogt, 2009c). This discrepancy suggests that phosphate should be added to aquaponic systems, especially for fruity vegetables that do not yet show satisfying yields in aquaponics (Nichols and Savidov, 2012). Phosphorus is a finite and scarce mining resource and subsequently, an expensive component of hydroponic solutions. Sufficient phosphorus production will certainly be a major concern in the near future (Gilbert, 2009; Ragnarsdottir et al., 2011; Sverdrup and Ragnarsdottir, 2011). Therefore solutions to reuse the discharge of P-rich effluents must be explored (Cordell et al., 2011; Shu et al., 2006). As up to 65\% of P can be wasted in form of aquaculture effluent sludge, recovery solutions should be developed to achieve zero-discharge systems. For example, leachate rich in P could be obtained by sludge digestion with selected P-solubilizing microorganisms (Jung and Lovitt, 2011) and then reinserted in the hydroponic part of the system. The ultimate objective is to develop a zerodischarge recirculating system with maximum nutrient recycling transformed into plant biomass and improved yield.

\subsubsection{Pest and Disease Management}

The challenges of disease management is another aspect that needs further improvement (Vermeulen and Kamstra, 2013). Aquaponic systems are characterized by a broader range of microflora than conventional hydroponic systems, especially because the breeding of fish and biofiltration occur in the same water loop. Conventional pesticides that are used in hydroponics cannot be used in aquaponics because of toxicity risk to the fish and to the desired biofilm (e.g. autotrophic nitrifying biofilm) (Nichols and Savidov, 2012). The need to maintain the nitrification biofilm and other nutrient solubilizing microorganisms also prevents the use of antibiotics and fungicides for fish pathogen control and removal in the aquatic environment. Furthermore, antibiotics are not allowed for plant application so their use against fish pathogens must be avoided in aquaponic systems. These constraints demand 
innovative pest management solutions for fish and plants that minimize impacts on fish and desired microorganisms.

Rearing and crop practices that decrease the occurrence of diseases could be applied such as preventive sanitary measures, low density of fish and/or plants, and/or control of environmental conditions, which decrease relative humidity around the plants. In addition to these practices, a few innovative methods of biocontrol already exist for plants cultivated under field or greenhouse conditions. These methods are based on the use of microorganisms with biocontrol activity (Jijakli, 2011; Saraf et al., 2014), or extracts of such microorganisms or extracts of plants (including essential oils) that show high antimicrobial efficiency and short residence time (Kouassi et al., 2012; Lang and Buchbauer, 2012). It will be a challenge to select and adapt these methods to aquaponics systems, considering their compatibility with the other living organisms of the system. Furthermore, microbial diversity can be beneficial for plants. The presence of some mutualistic microorganisms in the plant biosphere can retard the development of pathogens (Bulgarelli et al., 2013; Fujiwara et al., 2013, 2012) while promoting growth (e.g. plant growth-promoting rhizobacteria and plant growth-promoting fungi).

Since the presence of a broad range microflora belongs to aquaponic practices, the occurrence of pathogens and risk for human health should also be established, in order to assess the safety of aquaponics and conduct to appropriate quality control. These challenges can lead to the production of products that are quality and pesticide free certified (e.g. organic) and thereby achieve a higher prize in the market and leads to a healthier population (Crinnion, 2010).

\subsubsection{Other Technical Challenges}

The regulation of the nitrate level in aquaponics is another challenge. Leafy vegetables need 100-200 mg L-1 of $\mathrm{NO}_{3}-\mathrm{N}$ concentration, while fruity vegetables need lower level at species specific growth stages (Resh, 2013). Intermittent intervals of high nitrate can be harmful for fish and nitrate concentration must stay under a certain threshold to avoid adverse physical effects to sensitive species (e.g. 100, 140, $250 \mathrm{mg} \mathrm{L}^{-1} \mathrm{NO}_{3}-\mathrm{N}$ for Oncorhynchus mykiss, Clarias gariepinus, Oreochromis niloticus, respectively (Davidson et al., 2014; Schram et al., 2012; Webster and Lim, 2008)). Therefore it is of particular relevance to determine the best practical means (BPM) fish:plant ratio before setup and/or implement a flow-controlled denitrification unit in the system in order to be able to adjust the desired nitrate level. Some denitrification tanks are already used in RAS (Martins et al., 2010), however, the technology is not yet fully developed. The approach involves creating anoxic conditions in a column by 
using the sludge as an organic carbon source for heterotrophic denitrifying microorganisms and recirculates the nitrate-rich water through it. If anoxic conditions are applied in sludge, heterotrophic microorganisms are able to use nitrate instead of oxygen as electron acceptor and reduce it successively to gaseous nitrogen $\left(\mathrm{N}_{2}\right)$ (Kampschreur et al., 2009). A critical step is to guarantee additional bio filtration before discharging the treated water back into the system to reduce the risk of toxic $\mathrm{NO}_{2}$ - ions from the denitrification process entering the system.

Together with environmental conditions, the population density is the most important parameter for the fish well-being. In outdoor aquaponics facilities such as the UVI system, the common tilapia fish density without use of pure oxygen is around $30-40 \mathrm{~kg} \mathrm{~m}^{-3}$. A higher density up to $60 \mathrm{~kg} \mathrm{~m}^{-3}$ can be achieved in greenhouses (Losordo et al., 1999); this may be due to more algae and cyanobacteria blooms under longer daylight conditions, producing more oxygen from increased photosynthesis. These characteristics, however, cannot be generalized. In fact, different fish species require different optimal water quality; e.g. warm water species tilapia require a dissolved oxygen (DO) level of 4 - $6 \mathrm{mg} \mathrm{L}^{-1}$, whereas the cold water species trout needs at least 6 - $8 \mathrm{mg} \mathrm{L}^{-1}$ DO (Timmons and Ebeling, 2013). Dissolved oxygen is not the only factor that needs to be kept stable. Large fluctuations in temperature and pH might harm fish, plants, and nitrifying microorganisms (Stark, 1996; Zhu and Chen, 2002). Despite this fact, temperatures for warm water species such as tilapia and nitrifying bacteria can be $25^{\circ} \mathrm{C}$ to $30^{\circ} \mathrm{C}$, whereas most plants rather prefer colder water temperatures (approx. $20^{\circ} \mathrm{C}-25^{\circ} \mathrm{C}$ ).

Thus far, aquaponics has been built on a trade-off between the needs of fish and plants, respectively. Development is now needed to achieve optimal conditions for both fish and plants with either: (1) emphasis on interdependent parameters of both system components (e.g. combining fish and plant species that preferably require similar environmental conditions within the same range of temperatures and $\mathrm{pH}$ that ensure bacterial nitrification); or (2) the physical separation in two recirculating loops, i.e. an aquaculture and hydroponic loop, described as decoupled systems, where optimal condition for each system is applied with periodic water exchange between them. These are different types of solutions that may contribute to the breakthrough of commercial aquaponics.

\subsection{Socio-Ecological Challenges}

Aquaponics as such is also responding to diverse ecological and social challenges, which point to the importance to focus on efficient and sustainable forms of agricultural production. Socio-ecological challenges include mineral recycling, water scarcity, energy 
availability, overfishing, as well as urban farming and short supply chains. They are outlined below.

\subsubsection{Mineral Recycling}

In terms of sustainability, both phosphorus and potassium are major components of agricultural fertilizers, and like oil, they are non-renewable resources. Therefore, increasing use and depletion of these minerals without reuse or recapture has a negative impact on and is of significance to their future supply. The current annual human population growth rate of $1.14 \%$ also increases the demand for food production (FAO, 2012b). In this context, an essential aspect to be considered is the maximum in the rate of extraction of global phosphorus and potassium that can be expected within the next decades (Beardsley, 2011; Sonneveld and Voogt, 2009b). Sverdrup and Ragnarsdottír (2011) demonstrate that phosphorus production peak is now whereas Cordell et al. (2011) anticipate a global phosphorus peak for 2030, and the total depletion will occur most likely within this century. This in turn would have dramatic consequences for global food security. Nutrient recycling policies, especially for phosphorus, are crucial in order to avoid global food shortages (Ragnarsdottir et al., 2011; Sverdrup and Ragnarsdottir, 2011).

\subsubsection{Water}

An increasing number of countries are facing economic and physical water scarcity, leading to a growing incapability in feeding their people (WWAP, 2012). On average, global agriculture uses around 70 percent of the available freshwater resources. In arid climate zones such as the Middle East and North Africa the agricultural water consumption can even be up to $90 \%$ (FAO, 2005a). Compared to conventional agriculture, aquaponics uses less than $10 \%$ of water, depending on the climatic conditions (Bernstein, 2011). Aquaponics can reduce fresh water depletion associated with irrigation whilst guaranteeing safe farming and food production practices, which in turn reduce the freshwater consumption in countries facing water stress. System related water losses that occur in evaporation, plant transpiration and the water content of the agricultural products can be compensated by capturing water from air humidity (Fraunhofer-Gesellschaft, 2009) or by reverse osmosis desalination plant in coastal areas (Duriau, 1968; Greenlee et al., 2009).

\subsubsection{Energy}

The energy requirements of aquaponics are likely to be based on system configuration (design, species, scale, technologies) and geographic location (climate, available resources). 
For each location different measures are needed in order to ensure that each system will have a suitable sustainable energy source all year around to provide stable conditions for fish and plants. This is crucial, as fluctuations in temperature might harm fish, plants, and nitrifying microorganisms (Stark, 1996; Zhu and Chen, 2002). This requirement constitutes a mandatory factor in regions with constantly and seasonally changing climatic conditions as well as in hot and arid climatic zones. Ensuring stable conditions may be practicable in equatorial areas without additional technology. Harnessing the sun energy can be beneficial in order to either run climate control systems within greenhouses (e.g. via air conditioning operated by solar photovoltaic modules), or to heat up a low-energy greenhouse with passive solar heating (Chan et al., 2010). The latter option is practicable for small sized noncommercial (passive solar) greenhouses, but may not be suitable for larger greenhouses because of the high thermal resistance and high energy losses, associated with medium and large greenhouses. These larger structures may require alternative solutions. In countries such as Iceland, and Japan near-surface geothermal energy can be used by means of heat pumps and direct geothermal heat for maintaining the indoor temperature at the desired level (Bakos et al., 1999; Ragnarsson, 2003). Countries with comparatively unfavourable geological conditions still might assess possible options in terms of using waste heat of combined heat and power (CHP) units to heat the greenhouse during cold days (Ismail and Ahmed, 2009) or cool them down during hot days. Those CHP units can mostly be found in combination with agricultural biogas plants, which surplus heat is fairly cheap for further disposal.

\subsubsection{Overfishing}

Eighty percent of the world's oceans are fully- or over-exploited, depleted or in a state of collapse (Pulvenis, 2014). One hundred million tons of fish are consumed worldwide each year, providing 2.5 billion people with at least $20 \%$ of their average per capita animal protein intake (FAO, 2012b). Fish is one of the most efficient animal protein producer - with a food conversion ratio (FCR) between 1 and 2 (Belal, 2005). Since fish demand is increasing whilst the fishing grounds are overexploited (Millennium Ecosystem Assessment, 2005), aquaculture is the fastest growing sector of world food production (FAO, 2012b). Adverse effects of this development include the high water consumption in case of conventional fish protein production (EPI, 2008), and release of up to $80 \%$ of $\mathrm{N}$ and $85 \%$ of $\mathrm{P}$ per $\mathrm{kg}$ of fish feed (Schneider et al., 2005; Van Rijn, 2013) into the environment. This causes the loss of valuable nutrients, resulting in eutrophication in rivers, lakes and coastal waters, leading to vast dead zones in the oceans (Dybas, 2005). 


\subsubsection{Urban Farming and Short Supply Chains}

Aquaponic systems can be set up almost everywhere and have the potential to (sub-) urbanize food production. This could bring important socio-environmental benefits. Aquaponic farming plants could be implemented in old industrial neglected buildings with the advantages of re-establishing a sustainable activity without increasing urbanization pressure on land. Roof gardens would be another possibility, allowing the saving of space in urban areas. If greenhouses are used on roofs, they can insulate buildings while producing food (Hui, 2011). Another important aspect is minimizing the distance between the food producer and consumer. The longer the supply chain, the higher transport, packaging, conservation and labour needed, leading to substantial decrease for resources and energy consumption (e.g. up to $79 \%$ of the retail price in US conventional food distribution (Wohlgenant, 2001)). Shortening and simplifying the food supply chains can drastically diminish its environmental impacts, while providing cities with fresher products. This also allows the consumer to clearly apprehend his food origin (Bon et al., 2010; Toumi and Vidal, 2010).

\subsection{Economic Challenges}

The current literature cannot be used to critically assess and predict economic challenges; as presented in Table 2.2, only two economic sub-studies are available in the peer-reviewed literature (Adler et al., 2000; Rakocy et al., 2004). At this early stage of scientific research the main focus has been on technical aspects of aquaponics; financial figures held by private research entities are not shared with the public. Furthermore, it is difficult to compare the two systems to determine which is better as information may not be available for all system parameters and outputs. For example, light intensity ( $\mathrm{lm}$ ) was not reported by Rakocy et al. (2004), yet this is one of the major factors affecting plant growth and thus the harvested biomass. Overall, system costs can be measured in the cost per square meter, which is influenced by the complexity of the system and this is closely related to climatic and geographic conditions such as seasonal daylight availability, temperature extremes, and fluctuation of warmth and cold. Also dynamic costs as maintenance costs (i.e. price per $\mathrm{kWh}$ and labour) and sales revenues in regional markets might differ, complicating conclusions towards economic evaluations. Even comparing the most expensive item within a system is difficult, as they differ per region and country (e.g. electricity prices, heat availability, etc.). Consequently, there is no general optimal system, as the system must be adjusted to their environmental conditions. Another approach could be to calculate the cost saving by comparing the cost of RAS and hydroponics run separately to the same system integrated as aquaponic system, in the same environmental and market conditions. Hence, Rupasinghe and Kennedy (2010) calculated an improvement of the net present value of $4.6 \%$ in an 
integrated aquaponic system of lettuce and barramundi. Unfortunately, there are no other studies available for comparison.

Market prices, one of the major factors for profit, can greatly vary between countries due to several (e.g. cultural, historical availability) reasons. However, the profit margins will definitely be higher if the product manufacturing costs are low and the food distribution supply chain is short. The transport, packaging and conservation of the food are time and energy consuming, which has an effect on the additional costs and freshness of the products. In order to meet these problems, more urban and peri-urban fresh food production plants need to be implemented to guarantee efficient short food supply chains (Toumi and Vidal, 2010).

Rakocy (2012) showed with respect to the crop choice, leafy greens generally achieve a higher profitability than fruity vegetables. In an initial economic analysis, given the University of Virgin Islands (UVI) system design, they had profit margin with basil exceeding almost by a factor 4 the one of lettuce. This finding should be viewed with a degree of caution because of different domestic market dependencies. Nonetheless, when addressing economic optimization, the three most important factors are: (1) sustainability considerations, as in the case of aquaponics, are interrelated with economic profits, since the reuse of resources should cut costs for the producer and for the customer; (2) technical optimization of processes (e.g. nutrient availability in different growth stages, nutrient recycling, etc.), and; (3) system components (e.g. design of the hydrological regime, $\mathrm{P}$ recycling unit, $\mathrm{pH}$ stabilizing reactors, etc.).

Although, Vermeulen and Kamstra (2013) state that the actual perceived environmental benefits of nutrient reuse, energy efficiency and land use seem only marginally cost-effective, the aspects of possible differences in product quality and societal value are not necessarily reflected in business costs. Also the use and cost of fertilizers in hydroponic production systems has an increasing importance, as fertilizers cost lie between $5-10 \%$ of the overall costs, and scarce fossil fuels are required in their manufacture (Hochmuth and Hanlon, 2010). The costing forecasts for fossil fuels could rather exacerbate the situation further and increase the demand of alternative fertilizing solutions such as using waste. Another resource that becomes increasingly scarce is fresh water. Reprocessing instead of discharging contaminated water will be a big challenge that needs to be met in the future. Taxes for wastewater discharge or strong limitations in discharge by local or national policies might become a factor as all point source discharges are regulated by water quality policies. Anticipating this trend will ensure economic and financial advantages with respect to conventional agriculture or hydroponic approaches. 


\subsection{Education as a Necessity}

A broad range of knowledge is required to understand and implement the multidisciplinary concept of aquaponics. From the theoretical perspective, the multidisciplinarity of the field and a lack of training in holistic thinking is a hurdle to fully comprehend the concept of aquaponics covering all interrelating issues. The bundling of field-specific in-depth knowledge is required in order to consolidate available scientific knowledge and evidence. At most universities, the two main disciplines, i.e., hydroponics and aquaculture, are either not taught, or offered in different schools, which could complicate access and exchange of knowledge. In practice, aquaculture and hydroponic technologies are well-known. The problem lies in the fact that those disciplines need to be connected. This lack of informationsharing shows the necessity for developing an education network dealing with the improvement of the interconnection between (scientific) disciplines involved in this field. Aquaponic stakeholders, including researchers, entrepreneurs and technicians, need to have basic knowledge covering all disciplines that are involved in this field. Furthermore, experts within every connected field are required to address specific issues within theoretical, scientific, financial as well as practical frameworks.

\subsection{Discussion}

Challenges underlying sustainable socio-ecological, technical and economic factors pertaining to aquaponics are discussed in this paper to demonstrate the need and the means of extensively investing more research and development and education in the aquaponics sector. Taking these factors into account is necessary because a pure financial perspective faces significant constraints, notably in terms of natural resource scarcity and their longterm economic consequences. The commercial development of sustainable and financially viable aquaponic systems confronts several technical challenges that need to be addressed further: (1) improved nutrient solubilization and recovery for a better use of the nutrient input and reducing extra-mineral addition, e.g. phosphorus recycling; (2) adapted pest management; (3) reduce water consumption to a high degree by limiting the need for water exchange; (4) use of alternative energy sources for hot/cold and arid areas (e.g. CHP waste heat, geothermal heat, etc.); and (5) innovative $\mathrm{pH}$ stabilization methods by implementing fluidized lime-bed reactors that have successfully been used in natural waters (Sverdrup et al., 1981).

All the factors mentioned above require additional attention, because some production parameters still need to be determined and optimized to prepare aquaponics for commercial 
use as some components and their interactions are not technically mature yet. This cannot be sufficiently achieved without a greater focus on combining existing knowledge of the different involved fields within a scientific and international framework. These aspects are important, as the commercially aligned technology should not be restricted by certain external conditions. Instead, the systems to be developed should be universally applicable, which implies resource-economic (i.e. resource-saving) production systems that can be run in arid, hot, cold, and urban areas or any combination thereof.

Vermeulen and Kamstra (2013) report only a marginal cost reduction for environmental benefits of nutrient reuse and energy efficiency when aquaponics is compared to RAS and hydroponics run separately. However, this study did not take socio-ecological factors into account, such as operating in a resource (e.g. phosphorous, water) limited world. Energy cost and fertilizer prices are constantly rising and governmental policies encourage reduction of emitted pollution (e.g. tax incentive schemes), so this cost margin benefit of aquaponics is inevitably expected to rise. Although the highest financial profit margin has been shown with leafy greens, it is still necessary to determine the purpose and the scale of the respective systems before building them; the needs on a microeconomic level in terms of food selfsufficiency or local food supply might differ from profit-oriented approaches. It may be speculated that aquaponics is especially beneficial and profitable for certain niche markets, which will differ from country to country.

\subsection{Conclusions}

Aquaponics seems to be a promising solution for sustainable aquaculture and hydroponic practices. However, further research and developments are needed as demonstrated by the challenges described in this paper. These challenges need to be resolved with the aim to get fully controlled and standardized aquaponic systems that will be easy to handle and economically viable. The competitiveness of the production method depends on technological developments, local markets, and climatic and geographic conditions that need to be assessed and cannot be generalized. Only addressing those factors thoroughly will eventually confirm aquaponics as a sustainable food production alternative. 
- 


\title{
Chapter 3 Lettuce (Lactuca sativa L. var. Sucrine) Growth Performance in Complemented Aquaponic Solution Outperforms Hydroponics
}

This chapter is based on:

Delaide, B., Goddek, S., Gott, J., Soyeurt, H., Jijakli, M. (2016): Lettuce (Lactuca sativa L. var. Sucrine) Growth Performance in Complemented Aquaponic Solution Outperforms

Hydroponics. Water 8, 467.

\begin{abstract}
Plant growth performance is optimized under hydroponic conditions. The comparison between aquaponics and hydroponics has attracted considerable attention recently, particularly regarding plant yield. However, previous research has not focused on the potential of using aquaponic solution complemented with mineral elements to commercial hydroponic levels in order to increase yield. For this purpose, lettuce plants were put into AeroFlo installations and exposed to hydroponic (HP), aquaponic (AP), or complemented aquaponic (CAP) solutions. The principal finding of this research was that AP and HP treatments exhibited similar $(p>0.05)$ plant growth, whereas the shoot weight of the CAP treatment showed a significant $(\mathrm{p}<0.05)$ growth rate increase of $39 \%$ on average compared to the HP and AP treatments. Additionally, the root weight was similar ( $p>0.05)$ in AP and CAP treatments, and both were significantly higher $(\mathrm{p}<0.05)$ than that observed in the HP treatment. The results highlight the beneficial effect of recirculating aquaculture system (RAS) water on plant growth. The findings represent a further step toward developing decoupled aquaponic systems (i.e., two- or multi-loops) that have the potential to establish a more productive alternative to hydroponic systems. Microorganisms and dissolved organic matter are suspected to play an important role in RAS water for promoting plant roots and shoots growth.
\end{abstract}




\subsection{Introduction}

Aquaponics is an integrated closed-loop multi-trophic food production system that combines elements of a recirculating aquaculture system (RAS) and hydroponics (Endut et al., 2010; Goddek et al., 2015; Graber and Junge, 2009a). Aquaponic systems where the nutrient flows and concentrations within the different components (e.g., aquaculture and hydroponic parts) are independent of one another are called decoupled aquaponic systems (DAPS) (Goddek et al., 2016b), or double recirculation aquaponic systems (DRAPS) (Kloas et al., 2015). Aquaponic systems designed with independent loops offer greater control over the hydroponic component, where water can be complemented with mineral salts for increased nutrient concentrations, and $\mathrm{pH}$ adjusted to fall within an optimal range.

A number of studies have attempted to show optimal nutrient solutions for growing lettuce in hydrocultural environments (Resh, 2013; Sonneveld and Voogt, 2009a). Table 3.1 provides the results obtained by Resh. Several factors determine the nutrient uptake performance of plants, including the availability of all essential nutrients, their presence in appropriate ratios, and favourable external conditions, for instance, $\mathrm{pH}$, temperature, $\mathrm{O}_{2}$, and $\mathrm{CO}_{2}$. According to Liebig's 'law of the minimum' nutrient availability constitutes a critical factor; the nutrient least available determines the maximum growth rate. Several researchers (Jones, 2005; Savvas et al., 2006; Sonneveld, 2002) reported an enhanced $\mathrm{NO}_{3}-$ uptake when the nutrient solution's $\mathrm{N}$ source contained between $5 \%$ and $25 \% \mathrm{NH}_{4}{ }^{+}$. At a pH of 6.8, both $\mathrm{NO}_{3}-$ and $\mathrm{NH}_{4}{ }^{+}$are equally absorbed, whereas $\mathrm{NO}_{3}-$ is preferred in acidic and $\mathrm{NH}_{4}{ }^{+}$in alkaline environments (Jones, 2005). The influence of $\mathrm{pH}$ on nutrient uptake is also observed for other macro- and micronutrients. Indeed, a $\mathrm{pH}$ from 6.0 to 8.0 is optimal for the uptake of macronutrients such as phosphorus $\left(\mathrm{H}_{2} \mathrm{PO}_{4}{ }^{-}, \mathrm{HPO}_{4}{ }^{2-}\right.$ or $\left.\mathrm{PO}_{4}{ }^{3-}\right)$, potassium $\left(\mathrm{K}^{+}\right)$, sulphur $\left(\mathrm{SO}_{4}{ }^{2-}\right)$, Calcium $\left(\mathrm{Ca}^{2+}\right)$, and Magnesium $\left(\mathrm{Mg}^{2+}\right)$. Considering that micronutrients such as Iron $\left(\mathrm{Fe}^{3+}, \mathrm{Fe}^{2+}\right)$, manganese $\left(\mathrm{Mn}^{2+}\right)$, boron $\left(\mathrm{BO}_{3}{ }^{2-}, \mathrm{B}_{4} \mathrm{O}_{7}{ }^{2-}\right)$, copper $\left(\mathrm{Cu}^{2+}, \mathrm{Cu}^{+}\right)$, and zinc $\left(\mathrm{Zn}^{2+}\right)$ are preferentially absorbed at pH values below 6.0 (Lucas and Davis, 1961; Polomski, 2007); the trade-off pH in hydroponics is approximately 5.5-6.0 (Resh, 2013).

Table 3.1. Optimal nutrient solutions for lettuce growth using nutrient flow technique (NFT) and in the University of the Virgin Islands (UVI) system.

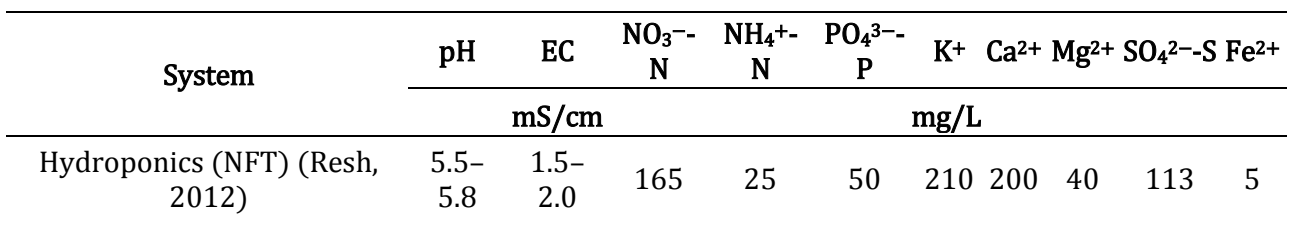




\begin{tabular}{|c|c|c|c|c|c|c|c|c|c|}
\hline \multirow[t]{2}{*}{ System } & $\mathrm{pH}$ & EC & $\begin{array}{c}\mathrm{NO}_{3}^{--} \\
\mathrm{N}\end{array}$ & $\begin{array}{c}\mathrm{NH}_{4}^{+-} \\
\mathrm{N}\end{array}$ & $\begin{array}{l}\mathrm{PO}_{4}^{3--} \\
\mathrm{P}\end{array}$ & $\mathrm{K}^{+} \mathrm{Ca}^{2+}$ & $\mathrm{Mg}^{2+}$ & $\mathrm{SO}_{4}{ }^{2-}-\mathrm{S}$ & $\mathrm{Fe}^{2+}$ \\
\hline & & $\mathrm{mS} / \mathrm{cm}$ & & & & $\mathrm{mg} / \mathrm{L}$ & & & \\
\hline $\begin{array}{c}\text { Aquaponics (UVI) } \\
\text { (Rakocy et al., 2004) }\end{array}$ & $\begin{array}{c}7.0- \\
7.6 \\
\end{array}$ & $\begin{array}{c}0.7- \\
0.8 \\
\end{array}$ & 42.2 & 2.2 & 8.2 & 44.911 .9 & 6.5 & 15 & 2.5 \\
\hline
\end{tabular}

In the domain of efficient agriculture the root: shoot ratio of plants has become an important issue. Root hairs will be limited or almost absent if the plants are exposed to $\mathrm{NO}_{3}{ }^{-}-\mathrm{N}$ concentrations of at least $100 \mathrm{mg} / \mathrm{L}$ or to high $\mathrm{P}$ content. However, a phosphorus deficiency in the plant's tissues can be observed if their $\mathrm{Al}^{3+}$ or $\mathrm{Ca}^{2+}$ concentrations are too high at the root surface. Sonneveld and Voogt (2009c) showed that a Ca:P ratio of approximately 3:1 was the most efficient target value. Jones (2005) also showed that the optimal Ca: Mg ratio was 3:1. Furthermore, uptake imbalance mostly occurs when $\mathrm{K}^{+}$concentrations are too high in the system in proportion to $\mathrm{Ca}^{2+}$ and $\mathrm{Mg}^{2+}$. In such cases, $\mathrm{K}^{+}$is more readily absorbed than $\mathrm{Ca}^{2+}$ and $\mathrm{Mg}^{2+}$.

Although lower nutrient levels are observed in one-loop aquaponic systems compared to hydroponic cultivation methods, a number of researchers have reported a similar lettuce yield (Licamele, 2009; E. Pantanella et al., 2012). In most recent studies the growth of lettuce has been measured only in aquaponic (AP) and hydroponic (HP) systems. However, the growth performance of aquaponic and hydroponic lettuce exposed to similarly high nutrient concentrations has not been comprehensively investigated. It remains unclear to what degree the aquaculture effluent generates an impact (negative, neutral, or positive) on plant growth performance.

The leaf nutrient content can give information on plant health (e.g., nutrient deficiency detection); however, this has not yet been investigated in aquaponics. The strict regulations within the EU concerning the maximum levels of contaminants in food further the need for leaf composition analysis. Consequently, the objective of this study was to compare shoot and root yields and leaf nutrient content of lettuce grown in conventional hydroponic solutions to those grown in complemented and normal aquaponic solutions.

\subsection{Materials and Methods}

Two identical trials (trial 1 and 2) were conducted between May and September 2015 in the climate-controlled experimental greenhouse of the Integrated and Urban Plant Pathology Laboratory of the University of Liège (Gembloux, Belgium, latitude $50^{\circ} 33^{\prime} \mathrm{N}$, longitude $4^{\circ} 41^{\prime}$ E, altitude $157 \mathrm{~m}$ ). Trial 1 started on 21 May 2015 and trial 2 on 20 August 2015. The air 
temperature and relative humidity in the greenhouse were recorded every 30 min with a USB datalogger (MOINEAU Instruments, Chef-Boutonne, France) in order to control the similar climate conditions between trial 1 and 2. Light availability was dependent on the natural fluctuations of solar irradiance. The total accumulated solar radiant exposures measured from a local meteorological station (IRM-KMI Ernage, Gembloux, Belgium) were 316.21 and $180.94 \mathrm{MJ} / \mathrm{m}^{2}$ for trial 1 and 2, respectively. The experimental setup consisted of three identical nutrient film technique (NFT) systems (i.e., AeroFlo 28, GHE, Fleurance, France) that were exposed to the specific nutrient solutions. Each AeroFlo system comprised a sump that was connected to four NFT channels containing seven holes each. The total planting area was $1 \mathrm{~m}^{2}$ per system with a water volume of $100 \mathrm{~L}$ that was constantly recirculated by a submersible pump.

For both trials 15-day-old Latin-type lettuce seedlings (Lactuca Sativa 'Sucrine', Semailles, Faulx-Les-Tombes, Belgium) were placed into the AeroFlo and harvested after 36 days.

The AeroFlo systems were filled with a fresh $100 \mathrm{~L}$ solution on a weekly basis to maintain stable nutrient conditions for better reproducibility and comparison among treatments. In order to validate such stability, during trial 2 the water nutrient content of the one-week-old solution was sampled for analysis before spillage, and another sample of the fresh solution was taken directly after the refill.

\subsubsection{Nutrient Solution Formulation and Control}

To match the nutrient concentration targets high-purity mineral salts were added. The HP solution (i.e., the control) and the CAP solution were formulated to have their nutrient concentrations equal to conventional NFT lettuce nutrient solutions based on Resh (2012). The HP control solution was formulated with 100\% rainwater and the added high-purity mineral salts. The CAP solution consisted of $100 \%$ RAS water complemented with highpurity mineral salts to reach the same nutrient concentrations as in the HP control solution. The RAS water was taken directly from the sump of a running tilapia RAS fed with a $40 \%$ protein, $12 \%$ lipid, and $3.7 \%$ sugar feed (Omegabaars, Lambers-Seghers, Baasrode, Belgium). The water did not receive any treatment prior to being used in the AeroFlo system. The AP solution was designed to reproduce the macro- and micronutrient concentrations found in the single loop aquaponic system of the University of the Virgin Islands (UVI) published in Rakocy et al. (2004c). It was formulated with RAS water. The concentrations of several nutrients in RAS water were higher than the concentration targets. RAS water was, therefore, diluted 1:10 in rainwater, and high-purity mineral salts added to match the nutrient concentration targets. For all treatments, the $\mathrm{pH}$ was adjusted by adding $\mathrm{HCl}$ and 
$\mathrm{Na}_{2} \mathrm{CO}_{3} . \mathrm{PH}$, electrical conductivity (EC) and nutrient concentration targets of the three solutions are presented in Table 3.1.

The RAS water macronutrient content was analyzed with a multiparameter spectrophotometer (HI 83200, HANNA instruments, Woonsocket, RI, USA) with the following reagents: HI 93700 (TAN), HI $93728\left(\mathrm{NO}_{3}{ }^{-}\right)$, HI $93717\left(\mathrm{PO}_{4}^{3-}\right)$, HI $93751\left(\mathrm{SO}_{4}{ }^{2-}\right)$, HI $93750\left(\mathrm{~K}^{+}\right)$, HI $93752\left(\mathrm{Ca}^{2+}\right)$, and HI $93752\left(\mathrm{Mg}^{2+}\right)$. The macronutrient analysis allowed the calculation of salt quantities necessary to add to the AP and CAP solution formulations. Salt additions were calculated with the hydroponic-specific HydroBuddy free software to match the target concentration values. Sulfate was used as a degree of freedom. For the first experimental week only half the quantities of salts were added in order to limit the EC and allow the seedlings to adapt to the nutrient solution and avoid osmotic shocks.

The mineral salts used for the macronutrients were $\mathrm{MgSO}_{4} \cdot 7 \mathrm{H}_{2} \mathrm{O}, \mathrm{NH}_{4} \mathrm{NO}_{3}, \mathrm{~K}_{2} \mathrm{HPO}_{4}$, $\mathrm{Ca}\left(\mathrm{NO}_{3}\right)_{2} \cdot 4 \mathrm{H}_{2} \mathrm{O}, \mathrm{KNO}_{3}, \mathrm{~K}_{2} \mathrm{SO}_{4}$, and $\mathrm{HNO}_{3}(65 \%)$, and for the micronutrients were Fe-EDTA, $\mathrm{MnSO}_{4} \cdot 4 \mathrm{H}_{2} \mathrm{O}, \mathrm{CUSO}_{4} \cdot 5 \mathrm{H}_{2} \mathrm{O}, \mathrm{ZnSO}_{4} \cdot 7 \mathrm{H}_{2} \mathrm{O}$, $\left(\mathrm{NH}_{4}\right)_{6} \mathrm{Mo}_{7} \mathrm{O}_{24} \cdot 4 \mathrm{H}_{2} \mathrm{O}$, and $\mathrm{H}_{3} \mathrm{BO}_{3}$.

The water EC, dissolved oxygen (DO), temperature, and $\mathrm{pH}$ were controlled regularly. EC was recorded with a conductivity tester (AD31 Waterproof, ADWA, Szeged, Hungary). The DO and temperature were measured with a DO meter (HI 98193, HANNA instruments, Woonsocket, RI, USA), and $\mathrm{pH}$ with a $\mathrm{pH}$-meter (Inolab $\mathrm{pH}$ level 1, WTW, Weilheim, Germany).

To assess water quality, the concentrations of $\mathrm{P}, \mathrm{K}, \mathrm{Ca}, \mathrm{Mg}, \mathrm{S}, \mathrm{Fe}, \mathrm{Cu}, \mathrm{Zn}, \mathrm{B}, \mathrm{Mo}, \mathrm{Mn}$, and $\mathrm{Na}$ in AeroFlo solutions were measured during trial 2 with an ICP-OES (5100 VDV, Agilent Technologies, Santa Clara, CA, USA). Total ammonia nitrogen (TAN) was measured with a spectrophotometer (HI 83200, HANNA instruments, Woonsocket, RI, USA) using the reagent $\mathrm{HI} 93700$ based on the Nessler method. $\mathrm{NO}_{3}{ }^{-}-\mathrm{N}$ was measured with a Nanocolor standard test (Ref 918 65, Macherey-Nagel, Düren, Germany) using the 2,6-dimethylphenol method. Samples of $150 \mathrm{~mL}$ of solution were taken directly from the sump of each AeroFlo just before and just after weekly renewal of the solution. Samples were $0.45-\mu \mathrm{m}$-filtered (Acrodisc, Pall corporation, Portsmouth, UK) and frozen immediately after collection. They were analysed for TAN within $24 \mathrm{~h}$ and for nitrate within 30 days. All measurements were performed in triplicate.

To detect potential differences in water composition among the used systems, the measured micro- and macronutrient concentrations and the key physiological macronutrient ratios (i.e., TAN:NO3-N, $\mathrm{Ca}: \mathrm{P}, \mathrm{Ca}: \mathrm{K}, \mathrm{Ca}: \mathrm{Mg}$ ) were analysed using a repeated model because of weekdependent measurements. The model included the treatment as the fixed effect, the week as 
the repeated effect, and their corresponding interaction realized as shoot and root yields. All calculations used PROC GLM in SAS software (SAS 9.4., Cary, NC, USA), and a Duncan multiple-comparison was used to assess the significance of treatment differences. These differences are reported in this paper as least square (LS) means.

\subsubsection{Lettuce Growth and Leaf Nutrient Content}

During the lettuce harvests of trials 1 and 2, the weight of both shoots and roots were recorded and then analysed by a one-way analysis of variance (ANOVA). The fixed variation factor was the treatment (i.e., AP, CAP, and HP). The lettuce leaf nutrient content ( $\mathrm{P}, \mathrm{K}, \mathrm{Ca}$, $\mathrm{Mg}, \mathrm{S}, \mathrm{Fe}, \mathrm{Cu}, \mathrm{Zn}, \mathrm{B}, \mathrm{Mo}, \mathrm{Mn}$, and $\mathrm{Na}$ ) was measured during trial 2 with an ICP-OES (5100 VDV, Agilent Technologies, Santa Clara, CA, USA). Prior to the ICP analysis, six lettuce plants per treatment were randomly chosen and were dried in an oven at $105^{\circ} \mathrm{C}$ for $48 \mathrm{~h}$, pulverized together, and acid-mineralized with 1:1 nitric (65\%) and perchloric acid (70\%). Nutrient content was analysed by a one-way analysis of variance (ANOVA) using the treatment as the fixed effect. A Duncan multiple-comparison was used to assess the significance of treatment differences estimated using least square (LS) means. All calculations used PROC GLM in SAS software (SAS 9.4.).

\subsection{Results}

\subsubsection{Shoot and Root Fresh Weight}

In both trials, the average fresh weight of the harvested shoots from the CAP treatment was significantly higher $(\mathrm{p}<0.05)$ than those observed for the AP and HP treatments, while no difference could be found between the latter two $(\mathrm{p}>0.05)$ (Table 3.2). For both trials, the shoot weight of the CAP treatment showed a $39 \%$ higher growth rate compared to the HP treatment.

Table 3.2. LS means of shoot and root fresh weight and shoot:root ratio of harvested lettuce.

\begin{tabular}{|c|c|c|c|c|}
\hline \multicolumn{2}{|c|}{ Treatment $^{1}(\mathrm{~N})^{2}$} & $\begin{array}{c}\text { Shoot Fresh Weight } \\
\text { (g/Plant) }{ }^{3}\end{array}$ & $\begin{array}{l}\text { Root Fresh Weight } \\
\text { (g/Plant) }\end{array}$ & $\begin{array}{c}\log _{10} \\
\text { (Shoot:Root) } \\
\end{array}$ \\
\hline \multicolumn{5}{|c|}{ Trial 1} \\
\hline CAP & 26 & 136.28 a & $4.86^{\mathrm{a}}$ & $1.47 \mathrm{a}$ \\
\hline HP & 26 & 98.17 b & $3.58 \mathrm{~b}$ & $1.47 \mathrm{a}$ \\
\hline AP & 25 & $80.55^{b}$ & $5.80^{a}$ & $1.14^{b}$ \\
\hline \multicolumn{2}{|c|}{ Significance } & $* * * 4$ & * & $* * *$ \\
\hline
\end{tabular}




\begin{tabular}{|c|c|c|c|c|}
\hline \multicolumn{2}{|c|}{ Treatment $^{1}(\mathrm{~N})^{2}$} & $\begin{array}{c}\text { Shoot Fresh Weight } \\
\text { (g/Plant) }{ }^{3}\end{array}$ & \multirow[t]{2}{*}{$\begin{array}{l}\text { Root Fresh Weight } \\
\text { (g/Plant) }\end{array}$} & \multirow[t]{2}{*}{$\begin{array}{c}\log _{10} \\
\text { (Shoot:Root) }\end{array}$} \\
\hline \multicolumn{3}{|c|}{ Trial 2} & & \\
\hline CAP & 24 & $55.05^{a}$ & $1.71^{a}$ & $1.52 \mathrm{a}$ \\
\hline HP & 20 & $39.64 \mathrm{~b}$ & $1.08^{b}$ & $1.53^{\mathrm{a}}$ \\
\hline $\mathrm{AP}$ & 25 & $35.72 \mathrm{~b}$ & $1.52 \mathrm{a}$ & $1.39 \mathrm{~b}$ \\
\hline Significar & & $* *$ & $* *$ & $* *$ \\
\hline
\end{tabular}

Notes: ${ }^{1}$ CAP: complemented aquaponic solution, HP: hydropoonic solution, AP: aquaponic solution; ${ }^{2}(\mathrm{~N})$ : number of observations; ${ }^{3}$ within columns, LS means followed by different letters (a, b) are significantly different at the 0.05 level; ${ }^{*},{ }^{* *},{ }^{* * *}$ Equal significance level of $\mathrm{p}<0.05, \mathrm{p}<0.01$ and $\mathrm{p}<0.001$, respectively.

In both trials, no difference of root fresh weights could be found between the CAP and AP treatments, while the one observed for the HP treatment was significantly lower. However, the shoot:root ratio observed for CAP and HP were not different, while it was significantly lower for AP. A two-fold difference in the harvested biomass between trial 1 and 2 was observed for all treatments. This finding may be explained mainly by different external environmental conditions that affected lettuce plant growth. The only substantially identified change was the total accumulation of solar radiant exposure, which was 316.21 and $180.94 \mathrm{MJ} / \mathrm{m}^{2}$ for trial 1 and 2, respectively. This uncontrolled parameter was nearly halved for trial 2 because of shorter daily light periods and cloudier days.

\subsubsection{Nutrient Solutions}

Within each trial, the environmental conditions affecting growth, such as water temperature, water DO, light intensity, air temperature, $\mathrm{pH}$, and relative humidity, were similar with the exception of the $\mathrm{pH}$ value that was slightly different in the AP system (Table 3.3).

Table 3.3. Growth environmental conditions for trial 1 and 2.

\begin{tabular}{|c|c|c|c|c|c|c|c|c|c|c|c|c|c|c|c|}
\hline & & \multicolumn{2}{|r|}{1} & $\mathrm{pH}$ & \multicolumn{3}{|c|}{$\mathrm{EC}(\mu \mathrm{S} / \mathrm{cm})$} & \multicolumn{3}{|c|}{ DO (mg/L) } & \multicolumn{3}{|c|}{ Water $\mathrm{T}\left({ }^{\circ} \mathrm{C}\right)$} & \multirow{2}{*}{$\begin{array}{c}\begin{array}{c}\text { Air T } \\
\left({ }^{\circ} \mathrm{C}\right)\end{array} \\
\mathrm{GH}\end{array}$} & \multirow{2}{*}{$\begin{array}{c}\begin{array}{c}\text { Air RH } \\
(\%)\end{array} \\
\text { GH }\end{array}$} \\
\hline & & CAP & HP & AP & CAP & HP & $\mathrm{AP}$ & CAP & HP & $\mathrm{AP}$ & CAP & HP & $\mathrm{AP}$ & & \\
\hline \multirow{5}{*}{$\begin{array}{c}\text { Trial } \\
1\end{array}$} & Mean & 5.59 & 5.73 & 7.32 & 2606 & 2453 & 823 & -4 & 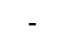 & - & 20.01 & 21.07 & 19.60 & 22.84 & 58.21 \\
\hline & $\mathrm{SD}^{2}$ & 0.69 & 0.45 & 0.50 & 297 & 206 & 163 & - & - & - & 1.46 & 1.28 & 1.43 & 3.78 & 14.69 \\
\hline & $(\mathrm{N})^{3}$ & 21 & 14 & 18 & 7 & 7 & 9 & - & - & - & 10 & 10 & 10 & 4461 & 4461 \\
\hline & Min & 4.30 & 4.76 & 6.50 & 2236 & 2189 & 630 & - & - & - & 17.50 & 18.60 & 17.20 & 15.60 & 27.20 \\
\hline & Max & 7.55 & 6.56 & 8.20 & 2945 & 2710 & 1014 & - & - & - & 22.30 & 22.5 & 21.40 & 35.60 & 86.90 \\
\hline & [ea & 37 & 5.77 & 7.50 & 49 & 2418 & 642 & 75 & 1 & & & & 28 & 22.15 & 71.29 \\
\hline
\end{tabular}




\begin{tabular}{|c|c|c|c|c|c|c|c|c|c|c|c|c|c|c|c|}
\hline & \multicolumn{3}{|r|}{$\mathrm{pH}$} & \multicolumn{3}{|c|}{$\mathrm{EC}(\mu \mathrm{S} / \mathrm{cm})$} & \multicolumn{3}{|c|}{$\mathrm{DO}(\mathrm{mg} / \mathrm{L})$} & \multicolumn{3}{|c|}{ Water $\mathrm{T}\left({ }^{\circ} \mathrm{C}\right)$} & \multirow{2}{*}{$\begin{array}{c}\begin{array}{c}\text { Air T } \\
\left({ }^{\circ} \mathrm{C}\right)\end{array} \\
\text { GH } \\
\end{array}$} & \multirow{2}{*}{$\begin{array}{c}\begin{array}{c}\text { Air RH } \\
(\%)\end{array} \\
\text { GH } \\
\end{array}$} \\
\hline & & CAP & HP & $\mathrm{AP}$ & CAP & $\mathrm{HP}$ & $\mathrm{AP}$ & CAP & HP & $\mathrm{AP}$ & CAP & $\mathrm{HP}$ & $\mathrm{AP}$ & & \\
\hline \multirow{4}{*}{$\begin{array}{c}\text { Trial } \\
2\end{array}$} & SD & 0.43 & 0.34 & 0.25 & 116 & 140 & 48 & 0.34 & 0.53 & 0.32 & 1.39 & 1.26 & 0.96 & 2.58 & 10.26 \\
\hline & $(\mathrm{N})$ & 19 & 20 & 17 & 9 & 9 & 16 & 10 & 10 & 10 & 15 & 16 & 15 & 1162 & 1162 \\
\hline & Min & 5.24 & 5.32 & 7.10 & 23182 & 2237 & 567 & 6.92 & 6.12 & 6.91 & 19.10 & 19.50 & 20.90 & 18.50 & 37.90 \\
\hline & Max & 6.84 & 6.80 & 7.94 & 26562 & 2672 & 749 & 7.91 & 7.82 & 7.92 & 24.70 & 24.80 & 25.00 & 33.20 & 88.30 \\
\hline
\end{tabular}

Notes: ${ }^{1}$ CAP: complemented aquaponic solution, HP: hydroponic solution, AP: aquaponic solution, GH: greenhouse; ${ }^{2}$ SD: standard deviation; ${ }^{3}(\mathrm{~N})$ : number of observations; ${ }^{4}$ Missing data.

Water composition during trial 2 was assessed through the average of weekly LS means for each measured macro- and micronutrient in order to improve the clarity of results (Table 3.4). The averages of weekly LS means for all concentrations measured were close to the desired macronutrient target value for each treatment (Table 3.1). Depending on the nutritive mineral, AP treatment had four-to ten-fold lower macronutrient concentrations compared to the other treatments, whereas the micronutrient concentrations were similar in all treatments. Hence, the average EC was three to four times lower in the AP treatment compared to CAP and HP (Table 3.3).

Table 3.4. Average of the LS mean of macro- and micronutrients concentration in CAP, HP, and AP treatments for trial $2(\mathrm{mg} / \mathrm{L})$.

\begin{tabular}{ccccccc}
\hline Element & Treatment $^{1}$ & $(\mathrm{~N})^{2}$ & Average & SD $^{3}$ & Min & Max \\
\hline $\mathrm{NO}_{3}{ }^{-}-\mathrm{N}$ & $\mathrm{CAP}$ & 6 & 215.54 & 28.13 & 164.00 & 245.80 \\
& $\mathrm{HP}$ & 6 & 193.29 & 12.35 & 181.23 & 211.55 \\
& $\mathrm{AP}$ & 8 & 50.31 & 1.80 & 46.57 & 52.39 \\
\hline \multirow{2}{*}{ TAN } & $\mathrm{CAP}$ & 4 & 25.79 & 3.09 & 22.83 & 29.87 \\
& $\mathrm{HP}$ & 6 & 23.95 & 2.51 & 20.53 & 26.67 \\
& AP & 8 & 1.82 & 1.35 & 0.25 & 3.32 \\
\hline $\mathrm{PO}_{4}{ }^{3-}-\mathrm{P}$ & $\mathrm{CAP}$ & 6 & 52.66 & 2.42 & 50.03 & 56.27 \\
& $\mathrm{HP}$ & 5 & 50.93 & 4.47 & 44.20 & 55.57 \\
& AP & 6 & 7.83 & 0.52 & 7.06 & 8.49 \\
\hline $\mathrm{SO}_{4}{ }^{2-}-\mathrm{S}$ & $\mathrm{CAP}$ & 6 & 66.72 & 6.97 & 57.33 & 77.60 \\
& $\mathrm{HP}$ & 5 & 95.36 & 4.72 & 87.77 & 99.97 \\
& AP & 8 & 10.99 & 1.17 & 9.24 & 12.30 \\
\hline $\mathrm{K}^{+}$ & $\mathrm{CAP}$ & 6 & 219.31 & 39.46 & 169.13 & 260.60 \\
& $\mathrm{HP}$ & 5 & 242.27 & 36.69 & 212.67 & 295.90 \\
& AP & 8 & 59.51 & 7.89 & 48.87 & 73.03 \\
\hline $\mathrm{Ca}^{2+}$ & CAP & 6 & 175.09 & 14.87 & 154.43 & 192.63
\end{tabular}




\begin{tabular}{|c|c|c|c|c|c|c|}
\hline Element & Treatment ${ }^{1}$ & $(\mathrm{~N})^{2}$ & Average & $\mathrm{SD}^{3}$ & Min & Max \\
\hline & HP & 4 & 205.68 & 12.58 & 192.30 & 217.27 \\
\hline & $\mathrm{AP}$ & 8 & 14.72 & 2.03 & 12.73 & 19.07 \\
\hline \multirow[t]{3}{*}{$\mathrm{Mg}^{2+}$} & CAP & 6 & 43.02 & 4.44 & 36.70 & 49.40 \\
\hline & HP & 5 & 43.11 & 3.15 & 39.13 & 45.83 \\
\hline & $\mathrm{AP}$ & 8 & 7.36 & 0.64 & 6.76 & 8.56 \\
\hline \multirow[t]{3}{*}{$\mathrm{Fe}^{3+}$} & CAP & 6 & 4.40 & 0.20 & 4.19 & 4.69 \\
\hline & HP & 5 & 3.83 & 0.29 & 3.39 & 4.11 \\
\hline & $\mathrm{AP}$ & 8 & 3.47 & 1.05 & 1.58 & 4.33 \\
\hline \multirow[t]{3}{*}{$\mathrm{B}^{3+}$} & CAP & 6 & 0.59 & 0.03 & 0.54 & 0.63 \\
\hline & HP & 5 & 0.51 & 0.08 & 0.37 & 0.59 \\
\hline & $\mathrm{AP}$ & 8 & 0.47 & 0.13 & 0.24 & 0.60 \\
\hline \multirow[t]{3}{*}{$\mathrm{Cu}^{+}$} & CAP & 6 & 0.12 & 0.01 & 0.11 & 0.13 \\
\hline & HP & 5 & 0.09 & 0.01 & 0.07 & 0.11 \\
\hline & $\mathrm{AP}$ & 8 & 0.09 & 0.03 & 0.05 & 0.12 \\
\hline \multirow[t]{3}{*}{$\mathrm{Mn}^{2+}$} & CAP & 6 & 0.66 & 0.06 & 0.58 & 0.73 \\
\hline & HP & 5 & 0.64 & 0.10 & 0.48 & 0.75 \\
\hline & $\mathrm{AP}$ & 4 & 0.50 & 0.12 & 0.32 & 0.60 \\
\hline \multirow[t]{3}{*}{$\mathrm{Mo}^{+}$} & CAP & 6 & 0.33 & 0.02 & 0.29 & 0.35 \\
\hline & HP & 5 & 0.32 & 0.04 & 0.25 & 0.36 \\
\hline & $\mathrm{AP}$ & 8 & 0.32 & 0.10 & 0.14 & 0.41 \\
\hline \multirow[t]{3}{*}{$\mathrm{Zn}^{2+}$} & CAP & 6 & 0.16 & 0.03 & 0.11 & 0.19 \\
\hline & HP & 5 & 0.15 & 0.01 & 0.13 & 0.16 \\
\hline & $\mathrm{AP}$ & 8 & 0.14 & 0.03 & 0.11 & 0.19 \\
\hline \multirow[t]{3}{*}{$\mathrm{Na}^{+}$} & CAP & 6 & 71.67 & 18.24 & 40.20 & 93.53 \\
\hline & HP & 5 & 7.95 & 4.52 & 4.22 & 13.77 \\
\hline & $\mathrm{AP}$ & 8 & 49.73 & 20.98 & 5.01 & 74.37 \\
\hline
\end{tabular}

Notes: ${ }^{1}$ CAP: complemented aquaponic solution, HP: hydroponic solution, AP: aquaponic solution; ${ }^{2}(\mathrm{~N})$ : number of observations; ${ }^{3}$ SD: standard deviation.

The solution nutrient concentrations and macronutrient ratios for both CAP and HP treatments were compared for each sampling time (i.e., just before and just after weekly renewal of the solution) and were significantly different (data not shown). However, for trial 2 the differences recorded were on average $22,2,2,29,23,31$, and $0 \mathrm{mg} / \mathrm{L}$ for $\mathrm{NO}_{3}{ }^{-}-\mathrm{N}$, TAN, $\mathrm{PO}_{4}{ }^{3-}-\mathrm{P}, \mathrm{SO}_{4}{ }^{2-}-\mathrm{S}, \mathrm{K}^{+}, \mathrm{Ca}^{2+}$, and $\mathrm{Mg}^{2+}$, respectively. Only $\mathrm{SO}_{4}{ }^{2-}-\mathrm{S}$ concentrations had a consistent difference in CAP compared to HP (i.e., approximately 30\% lower in CAP) because sulphate was used as a degree of freedom for the adjustment of mineral concentrations, which is a common practice in hydroponic solution formulation (Resh, 2012). 
The evolution of physiological ratios between macronutrient concentrations (Figure 3.1) calculated for each sampling time showed considerable smaller differences between CAP and HP than with AP treatment. For each treatment, the ratio tended to slightly increase between the fresh and the old solution. This was due to water evaporation, which was not balanced with the plant nutrient uptake. The exception was the TAN:NO$-\mathrm{N}$ ratio that was systematically lower before solution exchange. Notably, these crucial ratios stayed closed to the targets throughout the experiment.

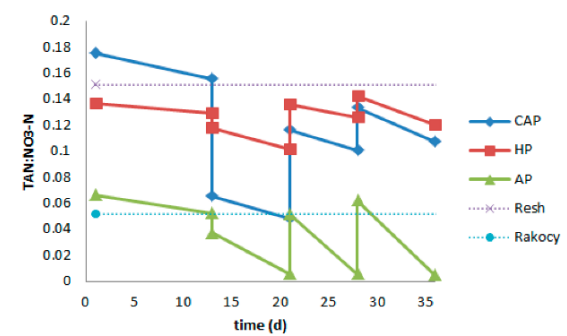

(a)

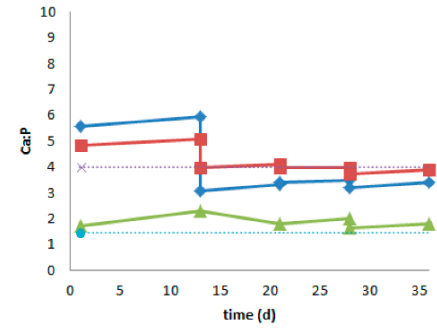

(c)

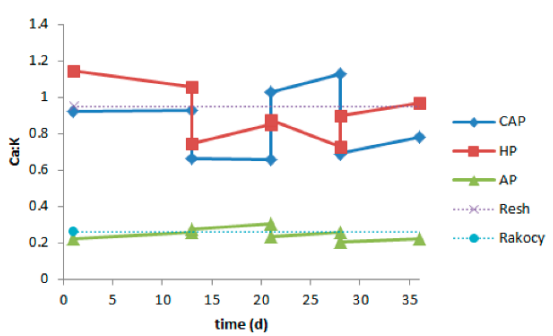

(b)

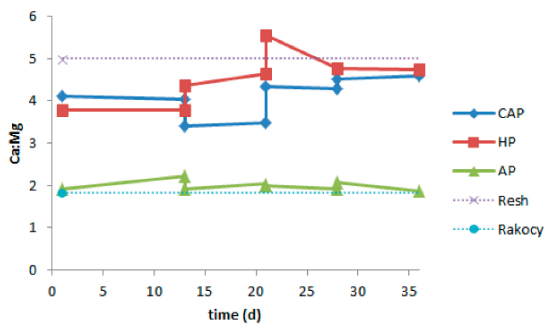

(d)

Figure 3.1. LS mean of macronutrient concentration ratio evolution in complemented aquaponic (CAP), hydroponic (HP), and aquaponic (AP) treatments during trial 2. Resh's and Rakocy's ratios are given for comparison. (a) TAN to $\mathrm{NO}_{3}{ }^{-}-\mathrm{N}$ ratio; (b) $\mathrm{Ca}^{2+}$ to $\mathrm{K}^{+}$ratio; (c) $\mathrm{Ca}^{2+}$ to $\mathrm{P}$ ratio; (d) $\mathrm{Ca}^{2+}$ to $\mathrm{Mg}^{2+}$ ratio.

In this study, the $\mathrm{Na}^{+}$concentrations were 6-9 times higher in both AP and CAP treatments compared to the HP treatment, with a maximum of $93.5 \mathrm{mg} / \mathrm{L}$ in the CAP system in trial 2 . Substantial $\mathrm{Na}^{+}$concentrations were present because some $\mathrm{Na}^{+}$was present in the RAS water but mostly because, in CAP and AP solutions, $\mathrm{Na}_{2} \mathrm{CO}_{3}$ was used to control the $\mathrm{pH}$, which tended to drop during aquaponic solution formulation and throughout the experiment. 


\subsubsection{Lettuce Leaf Nutrient Content}

Leaf nutrient content showed a significant difference $(\mathrm{p}<0.05)$ among each treatment for each nutrient, except for K between AP and HP, and B between CAP and HP (Table 3.5). The CAP lettuce leaves had a significantly $(p<0.05)$ higher macronutrient content for all nutrients. AP had the lowest content for each nutrient. With respect to the micronutrients, the contrasts were greater; Fe and Zn content were significantly higher $(p<0.05)$ in HP, while AP had the highest content of Mn and Mo.

Table 3.5. LS mean of lettuce leaf nutrient content in trial 2.

\begin{tabular}{|c|c|c|c|c|c|c|c|c|c|c|c|c|c|c|}
\hline Treatment 1 & $(\mathrm{~N})^{2}$ & $\mathrm{TKN}^{5}$ & $\mathrm{P}^{3}$ & $\mathrm{~K}$ & $\mathrm{Ca}$ & $\mathrm{Mg}$ & $S$ & $\mathrm{Na}$ & $\mathrm{Fe}$ & B & $\mathrm{Cu}$ & $\mathrm{Zn}$ & Mn & Mo \\
\hline $\mathrm{AP}$ & 3 & - & $\begin{array}{l}5.47^{a} \\
(0.02)\end{array}$ & $\begin{array}{l}24.6^{\mathrm{a}} \\
(0.0)\end{array}$ & $\begin{array}{l}6.36^{a} \\
(0.01)\end{array}$ & $\begin{array}{l}2.28^{a} \\
(0.00)\end{array}$ & $\begin{array}{l}1.97^{\mathrm{a}} \\
(0.01)\end{array}$ & $\begin{array}{l}3.70^{\mathrm{a}} \\
(0.00)\end{array}$ & $\begin{array}{c}739^{a} \\
(5)\end{array}$ & $\begin{array}{l}8.1^{a} \\
(0.1)\end{array}$ & $\begin{array}{l}12.6^{\mathrm{a}} \\
(0.1)\end{array}$ & $\begin{array}{c}37.0 \mathrm{a} \\
(0.3)\end{array}$ & $\begin{array}{c}1343^{a} \\
\text { (3) }\end{array}$ & $\begin{array}{c}26.5^{a} \\
(0.1)\end{array}$ \\
\hline CAP & 3 & 18.2 & $\begin{array}{c}9.25^{b} \\
(0.01)\end{array}$ & $\begin{array}{c}29.8^{b} \\
(0.1)\end{array}$ & $\begin{array}{c}11.3^{b} \\
(0.0)\end{array}$ & $\begin{array}{l}3.36^{b} \\
(0.01)\end{array}$ & $\begin{array}{l}2.75^{b} \\
(0.01)\end{array}$ & $\begin{array}{l}2.80^{\mathrm{b}} \\
(0.01)\end{array}$ & $\begin{array}{c}935^{b} \\
(4)\end{array}$ & $\begin{array}{c}19.4^{\mathrm{b}} \\
(0.1)\end{array}$ & $\begin{array}{c}20.2^{b} \\
(0.2)\end{array}$ & $\begin{array}{c}69.1^{b} \\
(0.8)\end{array}$ & $\begin{array}{c}208^{b} \\
(2)\end{array}$ & $\begin{array}{c}19.8^{\mathrm{b}} \\
(0.3)\end{array}$ \\
\hline HP & 3 & 17.6 & $\begin{array}{l}8.56^{c} \\
(0.02)\end{array}$ & $\begin{array}{c}24.7^{\mathrm{a}} \\
(0.1)\end{array}$ & $\begin{array}{c}10.8^{c} \\
(0.0)\end{array}$ & $\begin{array}{l}3.00^{\mathrm{c}} \\
(0.01)\end{array}$ & $\begin{array}{l}2.56^{\mathrm{c}} \\
(0.01)\end{array}$ & $\begin{array}{l}0.40^{c} \\
(0.00)\end{array}$ & $\begin{array}{c}1511^{c} \\
(4)\end{array}$ & $\begin{array}{c}19.3 \text { b } \\
(0.1)\end{array}$ & $\begin{array}{c}15.3^{c} \\
(0.1)\end{array}$ & $\begin{array}{c}102^{c} \\
(0)\end{array}$ & $\begin{array}{c}202^{c} \\
(1)\end{array}$ & $\begin{array}{l}19.0^{\mathrm{c}} \\
(0.1)\end{array}$ \\
\hline Significance & & - & $* * * 4$ & $* * *$ & $* * *$ & $* * *$ & $* * *$ & $* * *$ & $* * *$ & $* * *$ & $* * *$ & $* * *$ & $* * *$ & $* * *$ \\
\hline
\end{tabular}

Notes: ${ }^{1}$ AP: aquaponic solution, CAP: complemented aquaponic solution, HP: hydroponic solution; ${ }^{2}(\mathrm{~N})$ : number of observations; ${ }^{3}$ Within columns, LS means followed by different letters $(a, b, c)$ are significantly different at the 0.05 level. Na and macroelements are reported in $\mathrm{mg} / \mathrm{gDM}$ and microelements in $\mu \mathrm{g} / \mathrm{gDM}$. Standard deviations are between brackets; ${ }^{4 *}, * *, * * *$ Equal significance level of $\mathrm{p}<0.05, \mathrm{p}<0.01$ and $\mathrm{p}<$ 0.001 , respectively. ${ }^{5}$ data is incomplete; we have failed to measure CAP and HP in duplicates due to insufficient resources.

The Na content showed the highest observed values in the AP treatment, closely followed by CAP. The Na content was almost 10 times higher in the AP than in the HP treatment.

\subsection{Discussion}

While the experiment was conducted to keep the $\mathrm{pH}$, the macro- and micronutrient concentrations, and the macronutrient ratios of HP and CAP treatment in a very close range in order to have the water origin as the only difference (i.e., rain and RAS), a significant difference between most values of macro- and micronutrient concentrations was observed (note: this analysis can be found online on http://www.developonics.com/sysint.xlsx). Due to technical limitations, it is very difficult to obtain concentrations significantly similar in both solutions. However, lettuce growth differences between CAP and HP treatments cannot be attributed to the concentration differences recorded and, especially, the small macronutrient ratio variations. Indeed, previous reports have shown that growth was not affected by the fluctuation of a given concentration of a specific nutrient in conditions where 
lettuce roots are directly exposed to the flowing nutrient solution (e.g., NFT and deep water culture (DWC)). Unlike in soil conditions, where there are both diffusion gradients and nutrient depletion, a given constant concentration can be maintained the root surface. Consequently, nutrients can be absorbed at a constant rate regardless of the nutrient solution's concentrations (Olsen, 1950). However, the concentrations must be maintained above a minimum threshold. Santos et al. (2004) showed that by increasing the $\mathrm{PO}_{4}{ }^{3-}-\mathrm{P}$ concentration, whilst keeping other nutrients constant, lettuce growth and final weight remained constant as long as the $\mathrm{PO}_{4}{ }^{3-}-\mathrm{P}$ concentration exceeded $20 \mathrm{mg} / \mathrm{L}$. Similar observations have been made previously in other plants for $\mathrm{NO}_{3}{ }^{-}-\mathrm{N}$ with a minimum concentration threshold of $1 \mathrm{mg} / \mathrm{L}$ (Clement et al., 1978; Edwards and Barber, 1976; Warncke and Barber, 1974). Letey et al. (1982) reported no significant differences on average shoot and root fresh weight of Romaine lettuce cultivated in DWC for 26 days with different $\mathrm{NO}_{3}{ }^{-}-\mathrm{N}$ concentrations (i.e., from 5 to $105 \mathrm{mg} / \mathrm{L}$ ).

In both trials a similar shoot mass between AP and HP treatment was recorded. In line with previous studies (Licamele, 2009; Pantanella et al., 2012) these results confirm AP systems as an alternative to conventional hydroponic systems, producing similar yields. Importantly, this study shows that considerable lower nutrient concentrations and different macronutrient ratios in AP solution did not alter yields. When the RAS water was complemented (i.e., CAP treatment) to reach nutrient concentrations and macronutrient ratios close to the HP control solution, to our surprise, 39\% higher shoot mass was obtained in both trials. These results indicate that $39 \%$ of shoot increase can be achieved if lettuces are grown in RAS water where mineral salts are added and $\mathrm{pH}$ kept around 5.5. Such production implicates a specific design that could be achieved with DAPS (Goddek et al., 2016b; Kloas et al., 2015).

Trial 2 had lower yields in all treatments. This reduced growth was due to lower light intensity and is a well-known phenomenon. Burns et al. (2010) confirmed these results by reporting that lettuce yield in fresh weight was halved in their 28-day trial when reducing the light intensity by $50 \%$, which was close to the light intensity reduction measured for trial 2. Sucrine is a Latin-type lettuce that is close to the Bibb butterhead type lettuce. The biomass of the sucrine lettuce obtained in HP treatment in trial 1 was $98.2 \mathrm{~g}$ per shoot, which is in the range of Bibb lettuce produced in hydroponics with Resh's solution.

The shoot:root ratio in AP treatment was significantly lower than in CAP, but CAP and AP treatment had similar root mass. Hence, the lettuce produced less shoot mass in the AP solution. This could have been due to a higher $\mathrm{pH}$ and/or to unfavorable nutrient ratios that hindered lettuce nutrient uptake and then limited shoot growth. Interestingly, the shoot:root 
ratio was similar for both HP and CAP treatments. The increase in shoot mass for CAP seems thus to be related to an increase in root mass. It can be suspected that this increase in root mass has been influenced by others factors that were present in solution rather than the observed small differences in the nutrient concentrations.

The lettuce leaf nutrient content supports these assumptions. The low nutrient content in the leaves of the AP treatment indicates less favorable nutrient solution for nutrient uptake. Leaves in the CAP treatment had higher nutrient content. This could be correlated to the water's EC. However, it is not certain that the small difference in average ECs of $75 \mu \mathrm{S} / \mathrm{cm}$ between CAP $(2493 \mu \mathrm{S} / \mathrm{cm})$ and HP $(2418 \mu \mathrm{S} / \mathrm{cm})$ can explain this; other factors present in the RAS water might have boosted the nutrient uptake and the shoot and root mass.

The superiority of shoot weight and nutrient uptake in CAP treatment, and especially the superiority of root weight in both AP and CAP treatments compared to the HP treatment (Table 3.2), indicate that RAS water must contain factors that stimulate root growth. Presumably, these factors also stimulate the nutrient uptake. Two factors having a plant growth-promoting effect can be assumed to be present in RAS water: (1) dissolved organic matter (DOM), and (2) plant growth-promoting rhizobacteria and/or fungi (PGPR and/or PGPF). Several humic-like and protein-like DOM components have been identified that tend to accumulate in RAS water (Hambly et al., 2015). Humic acids, such as fulvic acid, and also certain phenolics can increase shoot and root growth as well as root ATPase activity (Canellas et al., 2009; Mylonas and McCants, 1980; Pingel, 1976). Haghiaghi (2012) showed that humic acid added to a hydroponic solution was also able to improve the nitrogen metabolism and photosynthetic activity of lettuce, which leads to an improved yield. Similar to DOM, PGPR were also identified to be able to promote plant growth and improve root development. PGPR can release phytohormones or induce hormonal changes within plants that stimulate plant cell elongation and division (Ruzzi and Aroca, 2015). Mangmang et al. (2015) inoculated Azospirillum brasilense to lettuce grown on perlite/vermiculite substrate irrigated with fish effluent. The author recorded an increase in endogenous levels of indole3-acetic acid (IAA), peroxidase activity, total leaf chlorophyll, and protein content in lettuce. IAA is known to regulate biochemical signals controlling plant growth and development. A special focus on DOM and PGPR occurring in water is, thus, required to better understand their impact and potential for improving plant production in aquaponics.

Interestingly, while $\mathrm{Na}^{+}$concentrations were considerably higher in the AP and the CAP treatments, this did not seem to have a negative effect on lettuce growth. Moreover, the Na content in the leaves of these treatments highlights the ability of lettuce to absorb some $\mathrm{Na}^{+}$ and subsequently remove it from aquaponic water. These conclusions are important because 
substantial $\mathrm{Na}^{+}$concentrations in aquaponic waters occur and are unavoidable due to $\mathrm{Na}$ release by the fish (Vermeulen, 2012). Na tolerance and assimilation in lettuce should be more specifically studied in aquaponics in order to define the $\mathrm{Na}^{+}$toxic threshold.

\subsection{Conclusions}

The purpose of the current study was to determine differences in growth rates when exposing lettuce plants to normal (i.e., AP), CAP, and HP solutions. The findings of this study indicated that there was a significantly higher growth rate in the CAP treatment. These findings highlight the potential usefulness of aquaponic systems because it was previously considered that the decisive competitive advantage of HP systems was the enhanced growth potential. This research has demonstrated that aquaponic systems could surpass the growth rates found in conventional HP systems. Notably, with respect to the increasing scarcity of phosphorus (Ulrich and Frossard, 2014), it is remarkable that, in AP solution, significantly lower macro- and micro-nutrient concentrations gave equivalent yields to HP solution.

From these results, we can conclude that the application of RAS water stimulates both root and shoot growth. It is difficult to ascertain which mechanism led to the increase in this particular case but microorganisms and DOM are suspected to play an important role. A special emphasis should be placed on the DOM species present, their effect on plant growth, and their optimal concentrations. Additionally, microbiota available in both water and the rhizosphere should be identified; it can be assumed that they host efficient growthpromoting rhizobacteria and/or fungi. 


\section{-}

- 


\title{
Chapter 4 Comparison of Lactuca sativa growth performance in rainwater and RAS-water- based hydroponic nutrient solutions
}

This chapter is based on:

Goddek, $S$, Vermeulen, T. (2016): Comparison of Lactuca sativa growth performance in rainwater and RAS-water-based hydroponic nutrient solutions. Submitted.

\begin{abstract}
A recent study related to aquaponics (Delaide et al., 2016a) has shown that hydroponic lettuce grown in aquaculture-derived water grew significantly better than lettuce grown in a conventional hydroponic system. The principal objective of this study was to verify this finding in a larger setup. Even though the aquaculture water that was added to the aquaculture-based hydroponic system contained relatively high amounts of sodium, we were still able to observe an enhanced growth performance of the lettuce in that system compared to the lettuce grown in the conventional hydroponic nutrient solution. The lettuce final wet weight was $7.9 \%$, and its final dry weight even $33.2 \%$ higher than the one of the hydroponics control. We hypothesise that microorganisms in the aquaculture water promote nutrient uptake by the plant roots, but this needs to be confirmed in isolated and dedicated experiments.
\end{abstract}




\subsection{Introduction}

Aquaponics is an upcoming technology that has received broad attention in both the civil society and the scientific community. Traditionally, aquaponics is an integrated multitrophic food production system that combines the elements of recirculating aquaculture system (RAS) and hydroponics in one-loop recirculating systems (Knaus and Palm, 2017; Schmautz et al., 2016; Yogev et al., 2016). Data from several studies have also showed that aquaponic systems perform well in both water and resource usage (Reyes Lastiri et al., 2016; Suhl et al., 2016). Its lack of the ability to provide optimal conditions for both fish and plants is most likely the main reason, why it is currently mainly being used for educational purposes (Villarroel et al., 2016). The commercial breakthrough is still outstanding (dos Santos, 2016; Goddek et al., 2015). Recent trends in aquaponics have led to a renewed approach that aims at optimizing the conditions in both system components. Kloas et al. (2015) and Goddek et al. (2016a) both showed, that nutrient concentrations in one-loop systems are suboptimal and suggest to focus on so-called decoupled multi-loop systems to allow optimal conditions (i.e. in nutrient concentrations, temperature, $\mathrm{pH}$, etc.) for both fish and plants. This paper will focus on such systems.

Although most of the turnover in aquaponic systems is made with the sale of plants, only two studies have attempted to investigate the plant growth potential in aquaponic systems on commercial hydroponic nutrient levels. Delaide et al. (2016) claimed that aquaponic grown lettuce in significantly similar chemical nutrient solutions show a growth advantage of approximately $40 \%$ over hydroponics. Contrary to that, another recent study (Suhl et al., 2016) that investigated tomato growth under similar conditions failed to show any significant production advantage. Taken together, there is a lack of formal experimental data with respect to growth of plants in RAS based nutrient solutions on hydroponic levels. Consequently, this study was set out to confirm or disaffirm the findings of Delaide et al. (2016) in a larger setup using RAS-water versus a typical hydroponic reference.

\subsection{Materials and Methods}

\subsubsection{Experimental Setup}

Two NFT systems were placed in a plastic tunnel greenhouse in Bleiswijk, The Netherlands during a warm August-October season. The gullies of the NFT-systems, each system servicing 16 gullies of $7.7 \mathrm{~m}$ long, were mounted in two blocks of eight rows and distributed in alternation. The system of cross-over NFT was applied, leading to a drip irrigation nozzle for every plant, while drain water was directly collected and did not affect neighbouring crops. 
These individual water nozzles gave a water flow of 2 litre per hour. No additional $\mathrm{CO}_{2}$ was applied. The recirculation container of each NFT-system contained $250 \mathrm{~L}$ of water.

Gullies were planted with 38 lettuces each, leading to a planting density of 12 heads per $\mathrm{m}^{2}$. Gullies use a crossover-NFT, where a drip irrigation is installed through the length of the gully, with a dripper per plant and vertical water drainage to prevent water flow from one plant to another. Hydrologically, this approach, however, cannot be considered as a repetition. The scheme as well as a picture of the experimental setup can be seen in Figures 4.1 and 4.2 .

The hydroponic treatment tank has been filled up with rain water continuously and the RAS treatment tank with $30 \%$ RAS water and $70 \%$ rain water. To both tanks, hydroponic nutrient solutions (General Hydroponics, FloraMicro, FloraGrow and FloraBloom, 3:2:1 mixing ratio) were added daily. The RAS water was taken from a RAS system cultivating carps. The climate was monitored (temperature, RH, irradiation). Water loss due to transpiration and leakage was replaced continuously in the basin, while the electrical conductivity (EC) and acidity $(\mathrm{pH})$ were measured daily, and kept constant on $1800 \mu \mathrm{Sm}^{-2}$ and $\mathrm{pH}$ 5.0-6.0 respectively. Every two weeks 40 L RAS water was added to the treatment. 


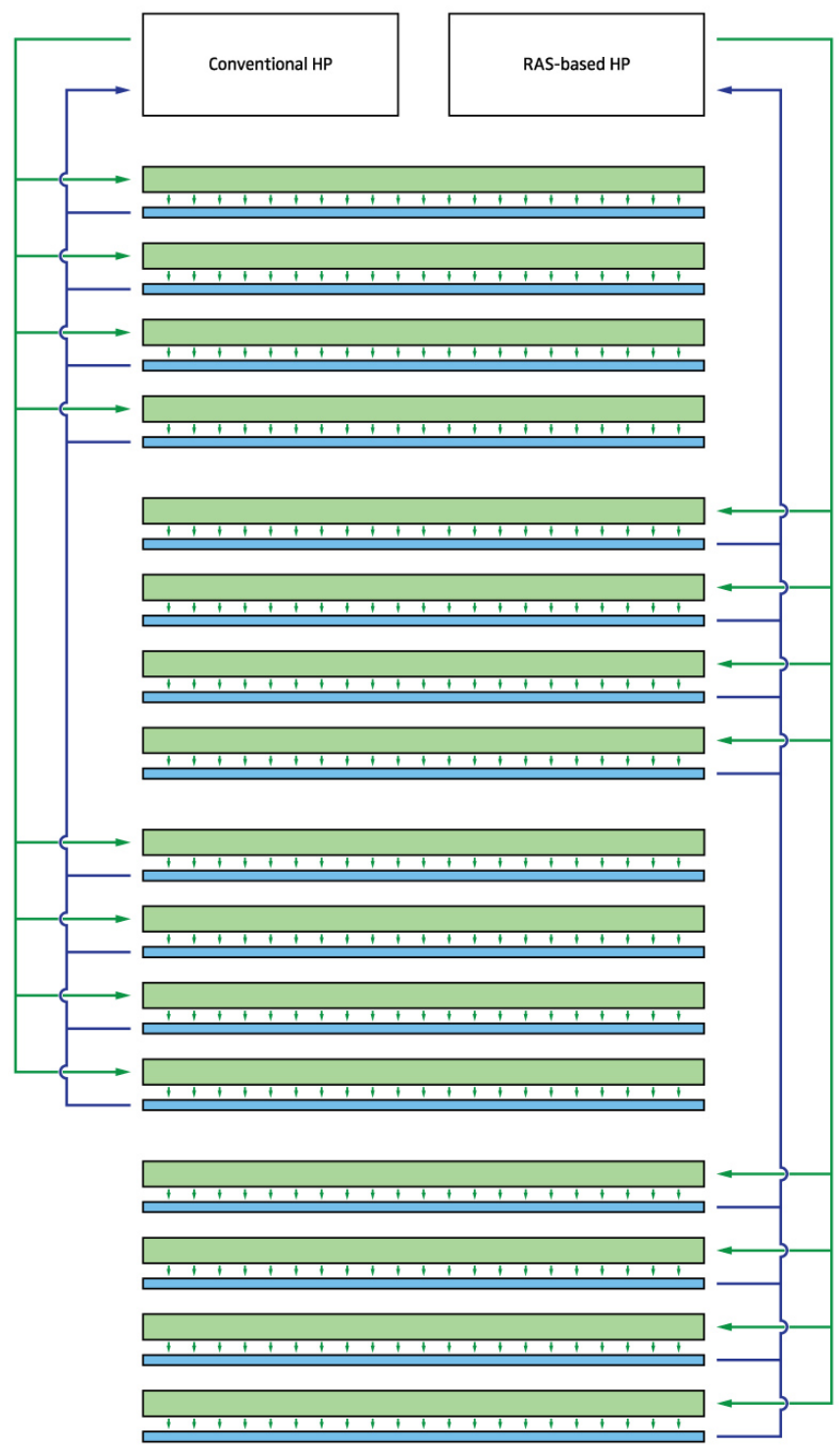

Figure 4.1. Scheme of the experimental setup consisting of a conventional hydroponic system as well as a RAS-based hydroponic system. Every plant was drip-irrigated individually. The drain water was led back to the respective recirculation containers via a shaded gutter. 


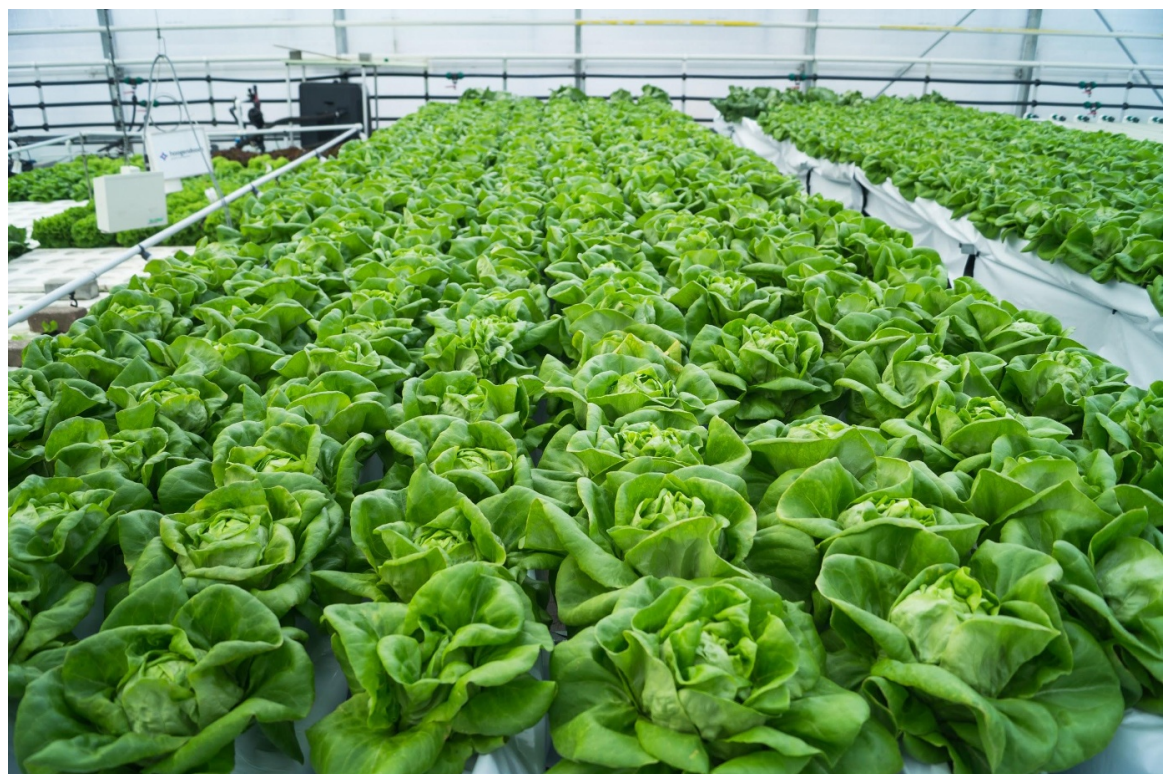

Figure 4.2. Picture of the experimental setup in Bleiswijk, The Netherlands.

\subsubsection{Water Analysis}

Once every 2 weeks, water of both systems, as well as the RAS water, have been sent to analysis for the plant-relevant ion composition. The water samples have been measured by the commercial lab Groen Agro Control, Delft, The Netherlands using HPLC according to the ISO 17025 norm.

\subsubsection{Lettuce}

Butterhead lettuce (variety Cosmopolia, RZ) were sown in $4 \times 4$ peat blocks on $23^{\text {rd }}$ of August 2016. Seven weeks after planting (11 ${ }^{\text {th }}$ of October), 20 lettuce shoots were randomly selected, harvested and weighed individually. Prior to sending in the milled lettuce shoots for leaf analysis, the lettuce heads of each system were cut into small pieces, weighed and merged in brown bags and dried to determine their dry weight. The leaf analysis was performed by Groen Agro Control according to their certified analysis protocol. 


\subsubsection{Statistical Analysis}

Data are presented as mean \pm standard deviation (SD) and ranges respectively of $n$ samples with a confidence interval of $95 \%$ (i.e. $\alpha<.05$ ). Analysis of statistical significance and ANOVA were conducted in R. Furthermore, the nonparametric two-sample Kolmogorov-Smirnov test was used to test whether the two (i.e. in the RAS and HP system) Na concentration probability distributions differ. Genstat software was used to conduct a principal component analysis with respect to the lettuce's nutrient composition.

\subsection{Results and Discussion}

The EC was maintained constant throughout the experiment. Average day-temperatures were $17.7{ }^{\circ} \mathrm{C}$, while average outside irradiation was $1584.66 \mathrm{~J} \mathrm{~cm}^{-2}$ day $^{-1}$ and light transmission index of the foil-greenhouse was $57.7 \%$. The nutrient concentrations of the RAS water and the respective systems can be seen in Table 4.1 and 4.2 . What attracts attention is that the difference in sodium concentrations is significant (Table 4.1, Figure 4.3). This difference can be attributed to the RAS water (Table 4.1). In RAS systems, sodium chloride is often added to counteract stress, restore osmoregulation, and to prevent and control diseases. Adding sodium chloride in aquaponic systems, however, is not common practice, as it is known to inhibit plant growth.

Table 4.1. RAS water composition (mean $\pm S D, \alpha=.05$ )

\begin{tabular}{|c|c|c|c|c|c|c|c|c|c|c|c|}
\hline$p H$ & $E C$ & $K$ & $\mathrm{Na}$ & $\mathrm{Ca}$ & $M g$ & $\mathrm{NO}_{3}$ & $C l$ & $\mathrm{SO}_{4}$ & $\mathrm{HCO}_{3}$ & $P$ & $Z n$ \\
\hline & $\begin{array}{l}\mathrm{mS} \\
\mathrm{cm}^{-1}\end{array}$ & $\begin{array}{l}\mathrm{mmol}_{\mathrm{L}^{-1}} \\
\text { lal }\end{array}$ & $\begin{array}{l}\mathrm{mmol}_{\mathrm{L}^{-1}} \\
\text { lal }\end{array}$ & $\begin{array}{l}\mathrm{mmol}_{\mathrm{L}^{-1}} \\
\mathrm{l}^{2}\end{array}$ & $\begin{array}{l}\mathrm{mmol}_{\mathrm{L}^{-1}} \\
\mathrm{l}^{2}\end{array}$ & $\begin{array}{l}\mathrm{mmol}_{\mathrm{L}^{-1}} \\
\mathrm{l}^{2}\end{array}$ & $\begin{array}{l}\mathrm{mmol}_{\mathrm{L}^{-1}} \\
\mathrm{l}^{2}\end{array}$ & $\begin{array}{l}\mathrm{mmol}_{\mathrm{L}^{-1}} \\
\text { lat }\end{array}$ & $\begin{array}{l}\mathrm{mmol}_{\mathrm{L}^{-1}} \\
\mathrm{l}^{2}\end{array}$ & $\begin{array}{l}\mathrm{mm} \\
\text { ol L L }^{-1}\end{array}$ & $\begin{array}{l}\mu \mathrm{mol} \\
\mathrm{L}^{-1}\end{array}$ \\
\hline $\begin{array}{l}7.66 \\
\pm \\
0.11\end{array}$ & $\begin{array}{l}1.18 \\
\pm \\
0.26\end{array}$ & $\begin{array}{l}0.20 \\
\pm \\
0.28\end{array}$ & $\begin{array}{l}8.62 \\
\pm \\
2.37\end{array}$ & $\begin{array}{l}0.72 \\
\pm \\
0.08\end{array}$ & $\begin{array}{l}0.12 \\
\pm \\
0.04\end{array}$ & $\begin{array}{l}1.58 \\
\pm \\
0.38\end{array}$ & $\begin{array}{l}7.44 \\
\pm \\
0.38\end{array}$ & $\begin{array}{l}0.22 \\
\pm \\
0.08\end{array}$ & $\begin{array}{l}1.06 \\
\pm \\
0.38\end{array}$ & $\begin{array}{l}0.04 \\
\pm \\
0.05\end{array}$ & $\begin{array}{l}0.16 \\
\pm \\
0.05\end{array}$ \\
\hline
\end{tabular}

Table 4.2. Nutrient concentration in each system (mean $\pm S D, \alpha=.05, \mathrm{n}=7$ ).

\begin{tabular}{|l|l|l|l|l|}
\hline Parameter & Unit & $\begin{array}{l}\text { System HP } \\
(\text { mean } \pm \text { SD })\end{array}$ & $\begin{array}{l}\text { System RAS } \\
(\text { mean } \pm \text { SD })\end{array}$ & ANOVA \\
\hline $\mathrm{pH}$ & $5.10 \pm 0.70$ & $5.86 \pm 0.91$ & $\mathrm{p}=.105$ \\
\hline $\mathrm{NH}_{4}{ }^{+}$ & $\mathrm{mmol} \mathrm{L}^{-1}$ & $1.56 \pm 0.92$ & $0.87 \pm 0.74$ & $\mathrm{p}=.151$ \\
\hline $\mathrm{K}^{+}$ & $\mathrm{mmol} \mathrm{L}^{-1}$ & $3.39 \pm 2.10$ & $2.36 \pm 2.00$ & $\mathrm{p}=.367$ \\
\hline $\mathrm{Na}^{+}$ & $\mathrm{mmol} \mathrm{L}^{-1}$ & $\mathbf{0 . 4 9} \pm \mathbf{0 . 5 9}$ & $\mathbf{3 . 0 7} \pm \mathbf{3 . 0 8}$ & $\mathrm{p}=.049$ \\
\hline
\end{tabular}




\begin{tabular}{|c|c|c|c|c|}
\hline $\mathrm{Ca}^{2+}$ & $\mathrm{mmol} \mathrm{L}^{-1}$ & $2.16 \pm 0.46$ & $2.24 \pm 0.53$ & $p=.753$ \\
\hline $\mathrm{Mg}^{2+}$ & $\mathrm{mmol} \mathrm{L}^{-1}$ & $0.15 \pm 0.39$ & $0.14 \pm 0.36$ & $p=.728$ \\
\hline $\mathrm{Fe}^{2+}$ & $\mu \mathrm{mol} \mathrm{L}-1$ & $53.74 \pm 37.81$ & $39.60 \pm 23.19$ & $\mathrm{p}=.415$ \\
\hline $\mathrm{Mn}^{2+}$ & $\mu \mathrm{mol} \mathrm{L}-1$ & $17.31 \pm 9.84$ & $12.99 \pm 9.57$ & $\mathrm{p}=.420$ \\
\hline $\mathrm{Zn}^{2+}$ & $\mu \mathrm{mol} \mathrm{L}-1$ & $73.76 \pm 55.06$ & $29.01 \pm 22.58$ & $\mathrm{p}=.070$ \\
\hline $\mathrm{Cu}^{2+}$ & $\mu \mathrm{mol} \mathrm{L}-1$ & $2.63 \pm 1.03$ & $2.14 \pm 1.09$ & $\mathrm{p}=.409$ \\
\hline $\mathrm{Mo}^{6+}$ & $\mu \mathrm{mol} \mathrm{L}^{-1}$ & $0.66 \pm 0.56$ & $0.47 \pm 0.53$ & $p=.537$ \\
\hline $\mathrm{P}$ & $\mathrm{mmol} \mathrm{L}^{-1}$ & $0.97 \pm 0.49$ & $0.94 \pm 0.47$ & $\mathrm{p}=.913$ \\
\hline B (III) & $\mu \mathrm{mol} \mathrm{L}-1$ & $19.00 \pm 6.00$ & $19.14 \pm 5.52$ & $p=.964$ \\
\hline $\mathrm{HCO}_{3}^{-}$ & $\mathrm{mmol} \mathrm{L}^{-1}$ & $0.06 \pm 0.10$ & $0.37 \pm 0.47$ & $\mathrm{p}=.110$ \\
\hline $\mathrm{NO}_{3}^{-}$ & $\mathrm{mmol} \mathrm{L}^{-1}$ & $8.07 \pm 3.13$ & $6.63 \pm 2.76$ & $p=.378$ \\
\hline $\mathrm{Cl}^{-}$ & $\mathrm{mmol} \mathrm{L}^{-1}$ & $0.79 \pm 0.50$ & $2.84 \pm 2.67$ & $p=.068$ \\
\hline $\mathrm{SO}_{4}^{2-}$ & $\mathrm{mmol} \mathrm{L}^{-1}$ & $1.17 \pm 0.35$ & $1.09 \pm 0.39$ & $p=.650$ \\
\hline
\end{tabular}

K-S Test: HP / RAS

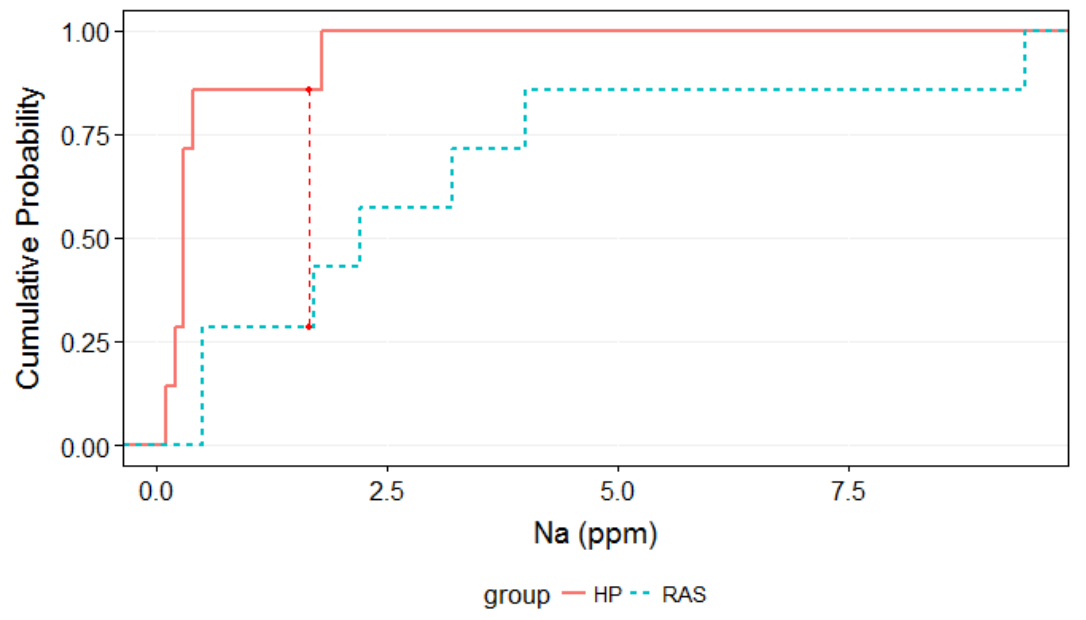

Figure 4.3. Two-sample Kolmogorov-Smirnov test, where $\mathrm{D}=0.857, \mathrm{n}=7$, and $\mathrm{p}=0.01$. Thus it is reasonable to assume that the data comes from different distributions, since $p>0.05$. Similar observations have been made for $\mathrm{Cl}$. 
Throughout the experiment, a visually different growth was observed. At harvest, the lettuce from the RAS water system was further developed than the lettuce that was grown in pure hydroponic water. This was indicated by the fact that the RAS-system lettuce was in the heading stage at harvest, while the hydroponic-system lettuce was still in the previous cupping stage (Figure 4.4). Table 4.3, which shows the wet weight of the plants rejects the possible assumption that the faster development could have been caused by physiological stress due to high sodium chloride values. Although lettuce is known to be a relatively sodium-insensitive plant, it is remarkable to see that the wet weight difference is highly significant to the advantage of the RAS-system lettuce. Its final wet weight was $7.9 \%$, and its final dry weight even $33.2 \%$ higher than the one of the hydroponics control. While in our case the chemical composition of the RAS water was suboptimal for plant production, the findings are still consistent with those of Delaide et al. (2016), even though our observations in final weight differences were lower.

Zinc levels in the hydroponic control were found to be higher than in the RAS-treatment. However no visual nutrient deficiencies (Fe or Mn deficiencies could become evident) were found in the leaves, suggesting no reduced growth due to elevated Zn-levels

Despite repetitive addition of sodium-rich RAS water, the treatment did not show accumulation to the extent expected (Figure 4.5). This could be due to solely increased uptake of sodium by the plants. Based on modelled evaporation by the plants, calculated uptake concentrations were found to be 0.04 and $0.21 \mathrm{mmol} \mathrm{L}^{-1}$ for the control and RAStreatment respectively. Leakage of the system, combined with continuous refill of the water reservoir with rain water would explain the decrease of sodium concentration over time. EC levels remained the same due to daily application of nutrient solution. These concentrations are still lower than uptake concentrations of $0.5-0.8 \mathrm{mmol} \mathrm{L}^{-1}$ found under high sodium levels in the nutrient solution (Sonneveld and Voogt, 2009b). Taking a look at the lettuce leaf composition (Table 4.4) shows that the uptake of the other salts $\mathrm{K}, \mathrm{Ca}, \mathrm{Mg}$, and $\mathrm{P}$ also was stimulated in the RAS-water growth environment (Figure 4.6), while the uptake of the micronutrients $\mathrm{Zn}$ and Mo uptake was rather inhibited compared with the lettuce grown in the hydroponics environment. It could be hypothesised that a possible interaction with micro-organism in the rhizosphere caused a better photosynthesis and nutrient uptake. However, we do not know what the uptake rate of the hydroponic control would be if the same amount of $\mathrm{Na}$ was added there. Consequently, it is yet to find out which plant species are able to take up these high amounts of sodium and to what degree different species would have to be combined in one system to avoid accumulations. 


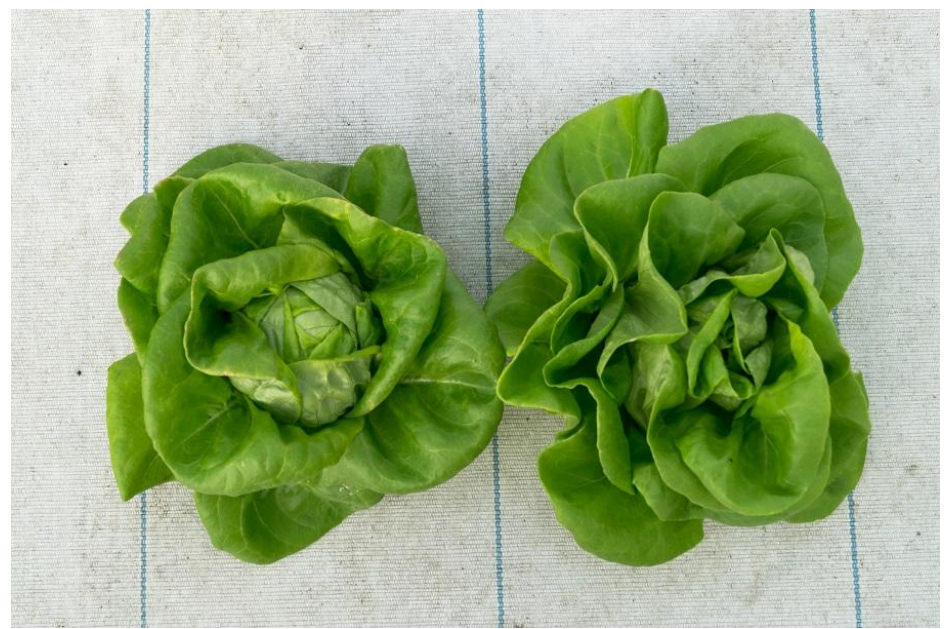

Figure 4.4. Comparison of the leaves of the RAS-system lettuce (left) and hydroponic system lettuce (right). The leaves of the RAS-system lettuce overlap and cover the growing point of the plant, which indicated that the lettuce is being in the heading stage, while the HP-system lettuce is still in the cupping stage. The cupping stage is prior to the heading stage, where the inner leaves begin to curl inwards on the edges.

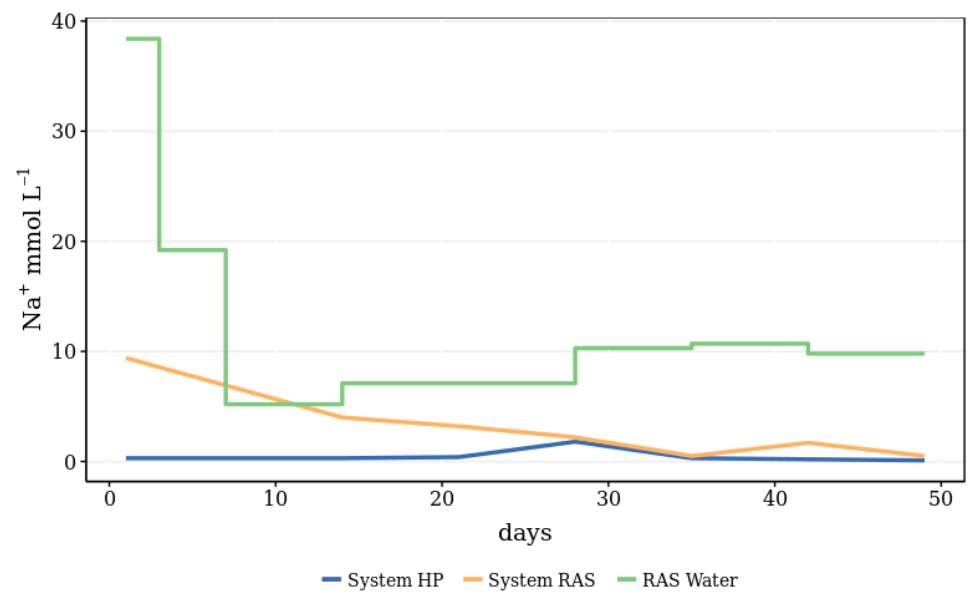

Figure 4.5. Sodium concentration in both RAS and HP systems as well as the sodium concentration of the RAS water that was added to the RAS System on a weekly basis. System RAS was first prepared with RAS water of higher sodium concentration (data not shown). 


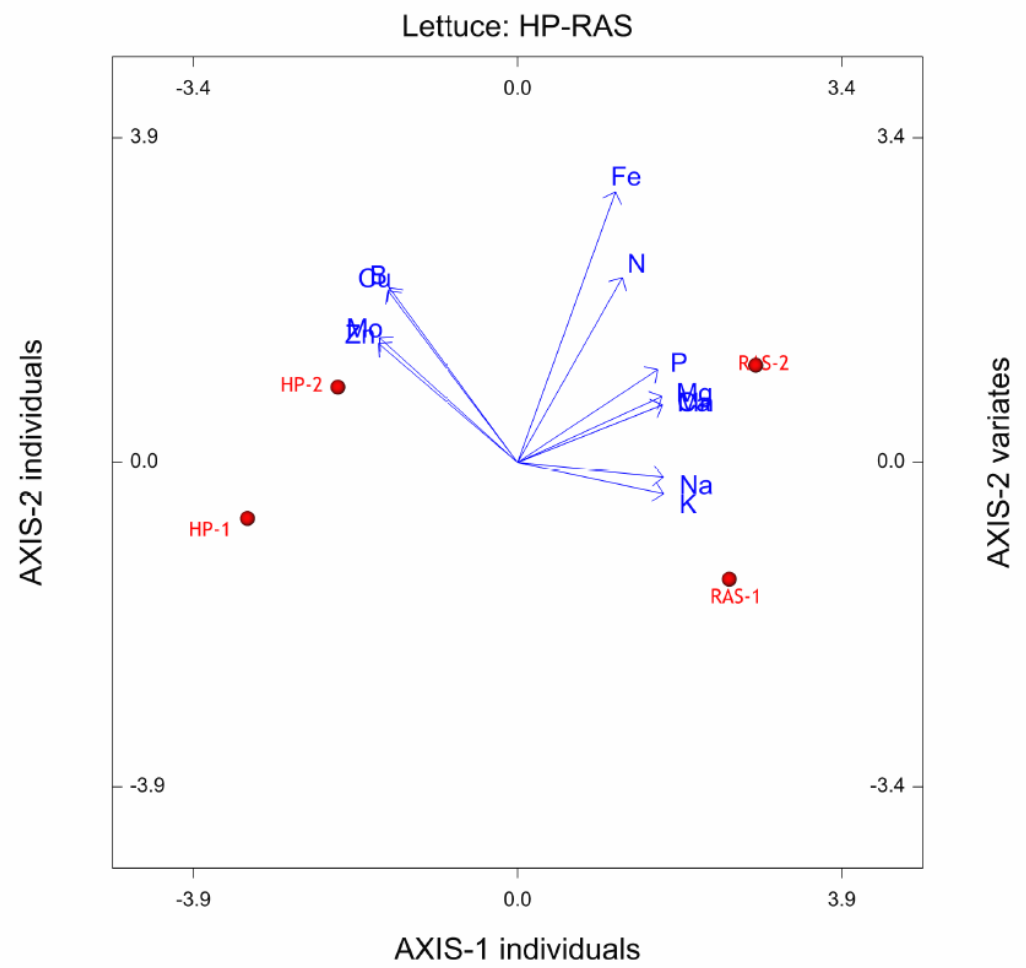

Figure 4.6. Principal component analysis of the lettuce leaf composition (Table 4.4). It can be seen that the uptake of the macronutrients $\mathrm{P}, \mathrm{Mg}, \mathrm{Ca}, \mathrm{Na}$, and $\mathrm{K}$ correlate with the RAS-system grown lettuces, and the micronutrients $\mathrm{Cu}, \mathrm{B}, \mathrm{Mo}$, and $\mathrm{Zn}$ correlate with the HP-system grown lettuces. Fe and $\mathrm{N}$ rather seem to be independent variables.

Table 4.3. Weight of the wet matter (mean $\pm S D, \alpha=.05, \mathrm{n}=20)$ and dry matter $(\mathrm{n}=2)$ of the lettuce.

\begin{tabular}{|l|l|l|l|l|}
\hline Parameter & Unit & System HP $($ mean \pm SD) & System RAS $($ mean \pm SD) & ANOVA \\
\hline Wet matter & $\mathrm{g}$ & $286.83 \pm 47.78$ & $309.48 \pm 32.96$ & $\mathrm{p}=.016$ \\
\hline Dry matter & $\mathrm{g}$ & $9.08[7.92,10.24]$ & $12.09[10.40,13.79]$ & $\mathrm{p}=.280$ \\
\hline
\end{tabular}

Table 4.4. Lettuce leaf composition of the dry matter $(\mathrm{dm})$ samples $(\mathrm{n}=2)$.

\begin{tabular}{|l|l|l|l|l|}
\hline Parameter & Unit & System HP & System RAS & ANOVA \\
\hline
\end{tabular}




\begin{tabular}{|l|l|l|l|l|}
\hline $\mathrm{K}^{+}$ & $\mathrm{mmol} \mathrm{kg} \mathrm{dm}^{-1}$ & $1808.00[1795,1821]$ & $2327.50[2325,2330]$ & $\mathrm{p}=.000$ \\
\hline $\mathrm{Na}^{+}$ & $\mathrm{mmol} \mathrm{kg} \mathrm{dm}^{-1}$ & $25.50[25,26]$ & $91.90[86.1,97.7]$ & $\mathrm{p}=.008$ \\
\hline $\mathrm{Ca}^{2+}$ & $\mathrm{mmol} \mathrm{kg} \mathrm{dm}^{-1}$ & $325.00[314,336]$ & $408.50[396,421]$ & $\mathrm{p}=.038$ \\
\hline $\mathrm{Mg}^{2+}$ & $\mathrm{mmol} \mathrm{kg} \mathrm{dm}^{-1}$ & $167.00[160,174]$ & $\begin{array}{l}206.50 \pm 7.78[201, \\
212]\end{array}$ & $\mathrm{p}=.047$ \\
\hline $\mathrm{N}$ & $\mathrm{mmol} \mathrm{kg} \mathrm{dm}^{-1}$ & $3708.00[3526,3890]$ & $3909.50[3864,3955]$ & $\mathrm{p}=.395$ \\
\hline $\mathrm{P}$ & $\mathrm{mmol} \mathrm{kg} \mathrm{dm}^{-1}$ & $311.00[306,316]$ & $369.00[353,385]$ & $\mathrm{p}=.075$ \\
\hline $\mathrm{Fe}^{2+}$ & $\mathrm{mmol} \mathrm{kg}^{-1} \mathrm{dm}^{-1}$ & $3.25[3.1,3.4]$ & $3.70[3.3,4.1]$ & $\mathrm{p}=.403$ \\
\hline $\mathrm{Mn}^{2+}$ & $\mathrm{mmol} \mathrm{kg}^{-1} \mathrm{dm}^{-1}$ & $3.55[3.4,3.7]$ & $4.80[4.6,5.0]$ & $\mathrm{p}=.038$ \\
\hline $\mathrm{Zn}^{2+}$ & $\mathrm{mmol} \mathrm{kg}^{-1} \mathrm{dm}^{-1}$ & $15.50[15,16]$ & $7.35[6.5,8.2]$ & $\mathrm{p}=.014$ \\
\hline $\mathrm{B}$ & $\mathrm{mmol} \mathrm{kg}^{-1} \mathrm{dm}^{-1}$ & $3.20[3.2,3.2]$ & $3.05[3.0,3.1]$ & $\mathrm{p}=.095$ \\
\hline $\mathrm{Mo}^{6+}$ & $\mu \mathrm{mol} \mathrm{kg} \mathrm{dm}^{-1}$ & $25.20[24.6,25.8]$ & $18.10[17.2,19.0]$ & $\mathrm{p}=.022$ \\
\hline $\mathrm{Cu}^{2+}$ & $\mu \mathrm{mol} \mathrm{kg} \mathrm{dm}^{-1}$ & $170.50[170,171]$ & $148.50[142,155]$ & $\mathrm{p}=.078$ \\
\hline $\mathrm{K}^{+}$ & $\mathrm{mmol} \mathrm{kg} \mathrm{dm}^{-1}$ & $1808.00[1795,1821]$ & $2327.50[2325,2330]$ & $\mathrm{p}=.000$ \\
\hline
\end{tabular}

\subsection{Conclusion}

The purpose of the current study was to perform a practical large-scale verification of a former study where lettuce showed a better growth performance in hydroponic nutrient solutions based on RAS-derived water (Delaide et al., 2016). The results of this study let us presume that lettuce growth might still outperform hydroponic growth rates under chemically suboptimal (i.e. high sodium chloride) conditions. However, this study does not explain this phenomenon. A possible explanation could be the beneficial interaction between microorganisms from the RAS-water and the plant roots. Earlier Mayak et al. (2004) described conferred stress resistance in tomato against sodium due to symbiosis with bacteria. With a larger setup and uniform cultivation conditions, this study does not falsify earlier findings by Delaide et al. (2016) that integration between fish production and plant cultivation - aquaponics - could lead to stronger plant development. Further studies are currently carried out in order to validate this hypothesis. Future studies should also clarify whether similar conclusions could be drawn, if the same amount of sodium chloride as in the RAS-derived water were added to the hydroponic group, or studies where RAS-derived water was sterilised before supplying it to the root zone. 


\title{
Chapter 5 The Effect of Anaerobic and Aerobic Fish Sludge Supernatant on Hydroponic Lettuce
}

This chapter is based on:

Goddek, S., Schmautz, Z., Scott, B., Delaide, B., Keesman, K., Wuertz, S., Junge, R. (2016): The Effect of Anaerobic and Aerobic Fish Sludge Supernatant on Hydroponic Lettuce. Agronomy 6,37 .

\begin{abstract}
The mobilization of nutrients from fish sludge (i.e., feces and uneaten feed) plays a key role in optimizing the resource utilization and thus in improving the sustainability of aquaponic systems. While several studies have documented the aerobic and anaerobic digestion performance of aquaculture sludge, the impact of the digestate on plant growth has yet to be understood. The present study examines the impact of either an aerobic or an anaerobic digestion effluent on lettuce plant growth, by enriching a mixture of aquaculture and tap water with supernatants from both aerobic and anaerobic batch reactors. The lettuce plants grown in the hydroponic system supplied with supernatant from an anaerobic reactor had significantly better performance with respect to weight gain than both, those in the system where supernatant from the aerobic reactor was added, as well as the control system. It can be hypothesized that this effect was caused by the presence of $\mathrm{NH}_{4}{ }^{+}$as well as dissolved organic matter, plant growth promoting rhizobacteria and fungi, and humic acid, which are predominantly present in anaerobic effluents. This study should therefore be of value to researchers and practitioners wishing to further develop sludge remineralization in aquaponic systems.
\end{abstract}




\subsection{Introduction}

A primary concern of aquaponics is the efficient utilization of all nutrients that enter the system. Several studies have documented a high loss of nutrients from the recycling loop via the mechanical water treatment unit as well as unused RAS-derived sludge (Goddek et al., 2016b; Neto and Ostrensky, 2013; Rafiee and Saad, 2005; Shnel et al., 2002; Suzuki et al., 2003; Van Rijn, 2013) that consists of faeces and uneaten feed. Consequently, the reuse of sludge is gaining importance and plays a crucial role in the utilization of the supplied nutrients, and thereby reduction of nutrient emissions (Goddek et al., 2016b; Monsees et al., 2015). With respect to the usage of RAS water in hydroponic systems, Delaide et al. (2016) examined whether complementing the RAS water with mineral elements to levels usually targeted in hydroponics improves crop growth. They observed an increased plant growth of the complemented aquaponic solutions by up to $39 \%$ compared to the hydroponic control nutrient solution, which was composed of an equivalent nutrient composition. Their work shows that plants in a highly concentrated RAS nutrient solution grow better. However, their study has only a limited relevance with regard to the impact of aerobic and anaerobic supernatants from fish sludge digestion on plant growth performance.

Although some research was carried out on the impact of domestic sewage and industrial wastes on plant growth (Krishnasamy et al., 2012; Penetra et al., 1999; Salminen et al., 2001), to date, the impact of aerobically and anaerobically treated RAS-derived sludge on plant growth has not yet been experimentally investigated. Effluents from anaerobic digestion generally have high concentrations of nutrients, as sources of carbon are metabolized preferentially during treatment (Krishnasamy et al., 2012; Salminen et al., 2001). However, most anaerobic effluents are characterized by high chemical oxygen demands (COD), hydrogen sulphides $\left(\mathrm{H}_{2} \mathrm{~S}\right)$ content, and low dissolved oxygen (DO) concentrations, and thus can be considered phytotoxic. In this case a post-treatment (e.g. aerobic detoxification) for the anaerobic effluent is required before being directed to the plants (de Lemos Chernicharo, 2007; Penetra et al., 1999; Salminen et al., 2001).

The primary aim of this study was to comparatively assess the effect of effluents originating from anaerobic and aerobic batch digesters on to plant growth performance. Even though simple digestion techniques were used that did not exploit the entire potential of both treatments, this study offers some important insights into the role remineralization practices may play in aquaponic systems with respect to plant growth performance.

\subsection{Material and Methods}

\subsubsection{Experimental Setup}


The experiment was conducted in a greenhouse in Wädenswil, Switzerland, from 16 October to 20 November 2015. Three one-cycle aquaponics systems were used for this experiment, each built of a sump, a settling tank, and a biofilter, and three nutrient film technique (NFT) channels (Figure 5.1) were run in parallel and were planted with 36 lettuce plants (Lactuca sativa yacht variety Salanova $\left.{ }^{\circledR}\right)$. The total volume of one system was approximately $400 \mathrm{~L}$. Aeration into the sump and the biofilter was provided via compressed air (AL-80, Alita Industries, Arcadia , CA, USA) and air stones to assure sufficient DO levels as well as proper mixing of biochips in the biofilter. A water pump (Aquarius Universal Eco 4000, Oase, Germany) with an approximate flow rate of $62 \mathrm{~L} / \mathrm{h}$ directed water from the biofilter to the NFT channels. A heater (NEWA Therm pro $250 \mathrm{~W}$, NEWA Tecno Industrial Srl, Loreggia, Italy) was installed in the biofilter maintaining constant temperatures in the system (22 \pm $\left.1.5^{\circ} \mathrm{C}\right)$. No additional lighting was used.

For two months (since July 2015), 4 L of RAS sludge of Nile tilapia culture fed with Hokovit Tilapia Vegi feed were added weekly to two reservoirs. One was constantly aerated and the other one was kept under anaerobic conditions. No additional sludge was added to the reservoirs during the experiment (i.e., after 16 October). To gather the supernatant, the sludge was stirred and centrifuged (Eppendorf Centrifuge 5430, Fisher Scientific, Waltham, MA, USA), $2.5 \mathrm{~min}$ at $7000 \mathrm{rcf}$. Supernatant nutrient composition was determined in the second week of the experiment (Table 5.1).

At the start of the experiment, all systems were filled with 85\% tap water and 15\% RAS water (Table 5.1). After that, one litre of supernatant from each aerobic and anaerobic reservoir was added to the aerated system (AER) and unaerated system (ANA) three times a week, respectively. System RAS, acting as a control, was given one litre of RAS water instead. The $\mathrm{pH}$ of the respective systems remained unadjusted as a high $\mathrm{pH}(>7.5)$ is often observed in one-loop aquaponic systems.

Table 5.1. Nutrient composition (mg/L) of the Recirculating Aquaculture System (RAS) and tap water, as well as AER and ANA supernatants, at the beginning of the experiment.

\begin{tabular}{ccccccccccc}
\hline & $\mathrm{Cl}$ & $\mathrm{NO}_{2}$ & $\mathrm{NO}_{3}$ & $\mathrm{PO}_{4}$ & $\mathrm{SO}_{4}$ & $\mathrm{Na}$ & $\mathrm{NH}_{4}$ & $\mathrm{~K}$ & $\mathrm{Ca}$ & $\mathrm{Mg}$ \\
\hline $\mathrm{AER}^{1}$ Supernatant & 7.9 & 18.5 & 51.8 & 2.7 & 19.7 & 4.4 & 0.7 & 17.2 & 14.2 & 5.1 \\
ANA $^{2}$ Supernatant & 6.1 & 0.0 & 0.0 & 2.7 & 0.5 & 3.6 & 56.4 & 16.3 & 11.7 & 2.5 \\
Tap & 0.3 & 0.0 & 0.2 & 0.0 & 0.8 & 4.9 & 0.0 & 1.0 & 59.8 & 16.3 \\
$\mathrm{RAS}^{3}$ & 6.4 & 0.2 & 88.2 & 2.0 & 6.9 & 3.4 & 0.5 & 9.0 & 10.8 & 5.6 \\
\hline
\end{tabular}

${ }^{1}$ supernatant from the aerated reactor; ${ }^{2}$ supernatant from the anaerobic reactor; ${ }^{3}$ water from a recirculating aquaculture system. 


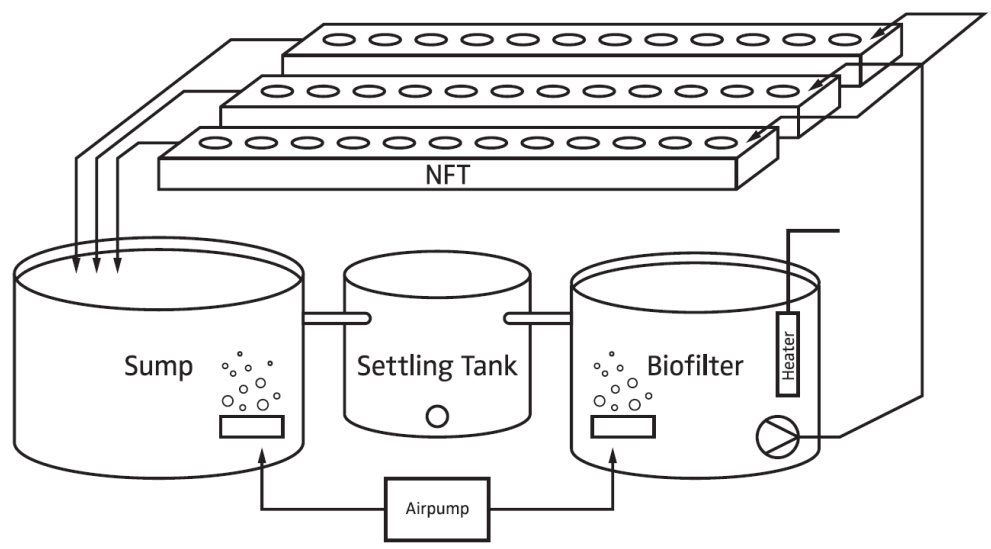

Figure 5.1. Schematic outline of the experimental systems comprising a sump (max. $280 \mathrm{~L}$ ), a settling tank $(70 \mathrm{~L})$, and a biofilter $(110 \mathrm{~L})$. Extensive aeration with an air pump ensured reduction of chemical oxygen demands (CODs) as well as optimal dissolved oxygen (DO) in the process water for plant growth. Undiluted AER and ANA supernatants as well as Recirculating Aquaculture System (RAS) water entered the system via the sumps of the respective systems three times a week. Samples for measurements were taken in the sump at least $24 \mathrm{~h}$ after the supernatants or RAS water were added.

\subsubsection{Supernatant and Water Analysis}

Samples of both aerobic and anaerobic supernatants were taken at the end of the first week of the experiment. Macronutrients $\left(\mathrm{NO}_{2}, \mathrm{NO}_{3}, \mathrm{PO}_{4}, \mathrm{SO}_{4}, \mathrm{NH}_{4}, \mathrm{~K}, \mathrm{Ca}\right.$, and $\left.\mathrm{Mg}\right)$ and micronutrients ( $\mathrm{Cl}$ and $\mathrm{Na}$ ) were analysed with an IC (930 Compact IC Flex, Metrohm, Zofingen, Switzerland) and other micronutrients (B, $\mathrm{Cu}, \mathrm{Fe}, \mathrm{Mn}, \mathrm{Mo}$, and $\mathrm{Zn}$ ) with an ICP-AES (Varian Vista AX CCD Simultaneous ICP-AES, Agilent Technologies, Santa Clara, CA, USA). Prior to these analyses, homogenous anaerobic and aerobic sludge was taken from both reservoirs and centrifuged for $7.5 \mathrm{~min}$ at $7000 \mathrm{rcf}$ and filtrated with $0.22 \mu \mathrm{m}$ syringe filters (Table 5.1).

The initial nutrient concentration within the three aquaponics systems was derived from the initial RAS and tap water values that were analysed with the IC Flex 930 Metrohm (Table 2). The same equipment was used to determine the water nutrient concentration in the sump of each system three times (on Days 19, 27, and 36) throughout the 5-week experiment. These samples were taken from the sump one day after tap water was added to compensate for water losses due to evapotranspiration to make sure the water was well mixed. $\mathrm{DO}, \mathrm{pH}$, EC, and temperature were measured twice a week with a portable multi-parameter meter (HQ40d Portable Multi-Parameter Meter, Hach Lange, Düsseldorf, Germany). 


\subsubsection{Lettuce}

Six weeks before the beginning of the experiment, single pelleted lettuce was seeded into rock wool. The initial weight of the lettuce seedlings when transferred into the aquaponic system was $10.3 \mathrm{~g} \pm 0.2 \mathrm{~g}$, which was determined by pre-weighting the rock wool. After 36 days of cultivation, nine lettuce plants (front, middle, back) laid down in advance were sampled from each system for further analysis. The shoots were separated from the roots by cutting it just above the rockwool block, whereas the roots were cut off at the bottom side of the rockwool block. The shoots were dried at $80{ }^{\circ} \mathrm{C}$ for $48 \mathrm{~h}$ for dry weight determination. The content of $\mathrm{P}, \mathrm{S}, \mathrm{Mg}, \mathrm{Ca}, \mathrm{K}, \mathrm{Fe}, \mathrm{Cu}, \mathrm{Mn}, \mathrm{Zn}, \mathrm{B}, \mathrm{Mo}$, and Na was determined with an ICP-OES (5100 VDV ICP-OES, Agilent Technologies, Santa Clara, CA, USA) after the dried biomass was pulverized and acid mineralized. The $\mathrm{C}, \mathrm{H}$, and $\mathrm{N}$ content was measured on three samples of dry lettuce plants per system using an elemental analyser (TruSpec CHN Macro Analyzer, LECO, Saint Joseph, MI, USA).

\subsubsection{Statistical Analysis}

Data are presented as mean of $\mathrm{n}$ replicates. Analysis of statistical significance was conducted in R software (R Core Team, 2012), using analysis of variance (ANOVA) test and post hoc multiple comparison. Here, the parametric Tukey's HSD test $(p<0.05)$ was performed.

\subsection{Results and Discussion}

During the experiment DO levels in the sump and the recorded water temperatures were stable (Table 5.2). Even though all three systems were started with the same initial mix of tap water with RAS outflow, the EC in the sump of System AER was initially higher than in the other two sumps (Figure 5.2a; Table 5.2). This difference is probably due to the fact that the systems were used for experiments before. Ca and $\mathrm{K}$ residues in both, the pipes, and the biofiltration media might have caused these slightly higher values. An indication for that is the higher $\mathrm{Ca}$ and $\mathrm{K}$ content in System AER (see Figures 5.3d,e), while the Ca and K concentrations of both supernatant solutions did not reveal similar differences (Figure 5.4; Table 5.1). The $\mathrm{pH}$ values during the trial did not show major symmetric differences in the three systems and fluctuated between 8.1 and 8.7 (Figure 5.2b; Table 5.2). 
Table 5.2. Means and standard deviation of main measured water parameters during the 35 days of the experiment $(n=11)$.

\begin{tabular}{cccc}
\hline & System AER $^{1}$ & System ANA $^{2}$ & ${\text { System } \mathrm{RAS}^{3} \text { (Control) }}$ \\
\hline $\mathrm{DO}^{4}(\mathrm{mg} / \mathrm{L})$ & $8.5 \pm 0.3$ & $8.4 \pm 0.3$ & $8.6 \pm 0.3$ \\
Water Temperatures $\left({ }^{\circ} \mathrm{C}\right)$ & $22.9 \pm 1.3$ & $22.6 \pm 1.6$ & $21.2 \pm 1.6$ \\
$\mathrm{EC}^{5}(\mu \mathrm{S} / \mathrm{cm})$ & $895.5 \pm 59.8$ & $766.6 \pm 41.2$ & $725.1 \pm 49.2$ \\
$\mathrm{pH}$ & $8.4 \pm 0.2$ & $8.5 \pm 0.2$ & $8.5 \pm 0.2$ \\
\hline
\end{tabular}

${ }^{1}$ supernatant from the aerated reactor; ${ }^{2}$ supernatant from the anaerobic reactor; ${ }^{3}$ water from a recirculating aquaculture system; ${ }^{4}$ dissolved oxygen; ${ }^{5}$ electrical conductivity.

(a)

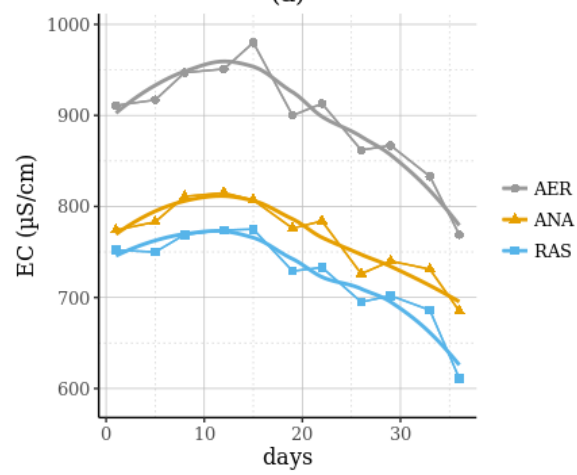

(b)

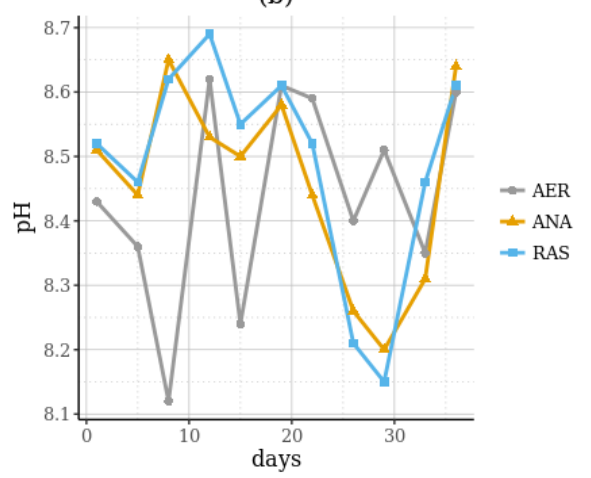

Figure 5.2. Variation of (a) electric conductivity (EC) and (b) $\mathrm{pH}$ (on a scale from 8.1 to 8.7 ) in the sump of the aerobic (AER), anaerobic (ANA), and RAS systems over the 35-day experimental period. 
(a)

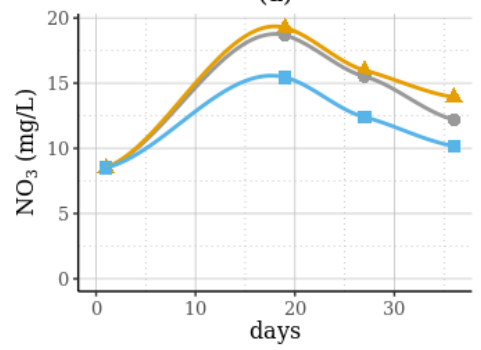

(c)

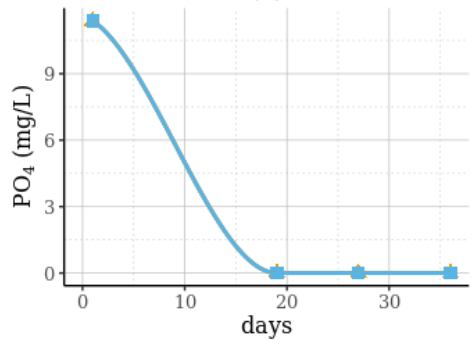

(e)

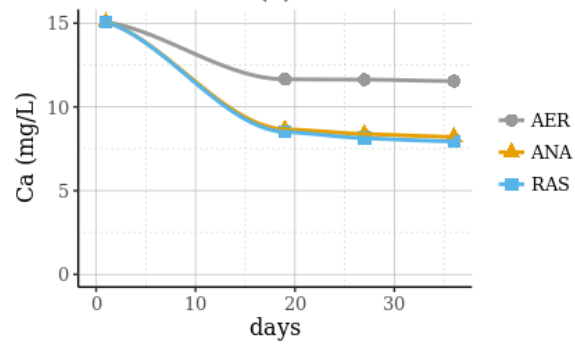

(b)

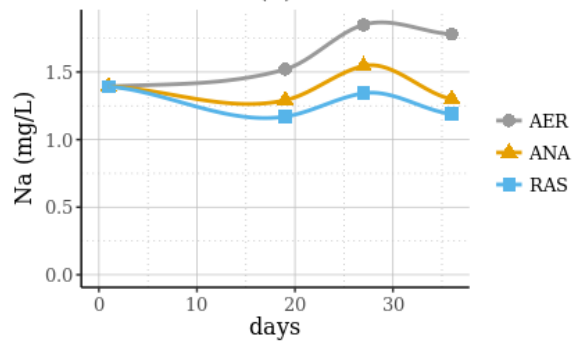

(d)

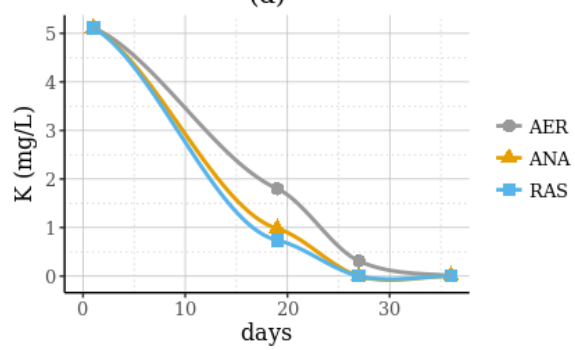

(f)

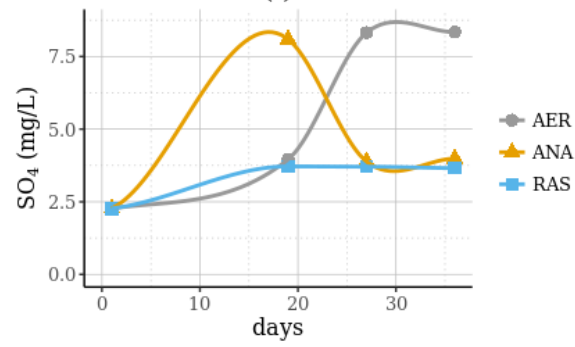

Figure 5.3. Concentrations of (a) nitrate; (b) sodium; (c) phosphate; (d) potassium; (e) calcium; and (f) sulfate in the sump of the aerobic (AER), anaerobic (ANA), and RAS systems over the 35-day experimental period.

Figures 5.4 and 5.5 show the macro- and micronutrient concentrations in the aerobic and the anaerobic supernatant at the beginning of the experiment. It must be mentioned that, due to ICP analysis, we do not have any information about the form of the analysed metals (i.e., to what degree they are chelated). The results in Figure 5.5 show an increased manganese (Mn) concentration in the aerobic supernatant. According to Resh (2013), the optimum $\mathrm{Mn}$ in hydroponic solutions ranges between 0.5 and $0.8 \mathrm{ppm}$, which is in compliance with the concentration in the aerobic supernatant before being diluted in the experimental system. Upon dilution, deficiencies of Mn would be expected in both systems, but to a higher degree in System ANA. Micronutrients in the RAS water were not measured. 


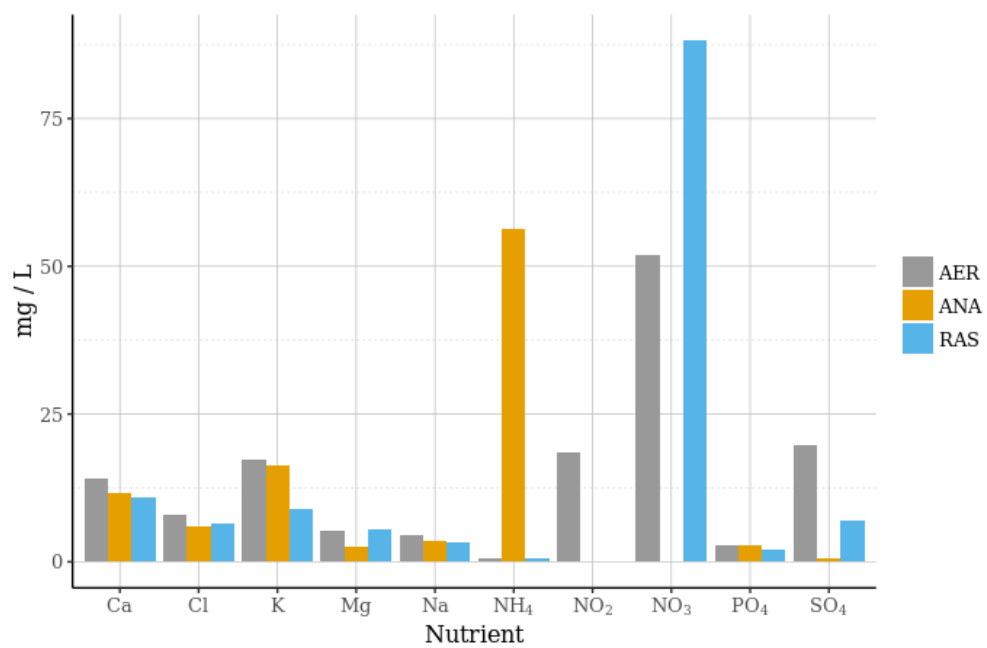

Figure 5.4. Nutrient composition of both undiluted AER and ANA supernatants as well as Recirculating Aquaculture System (RAS) water at the beginning of the experiment.

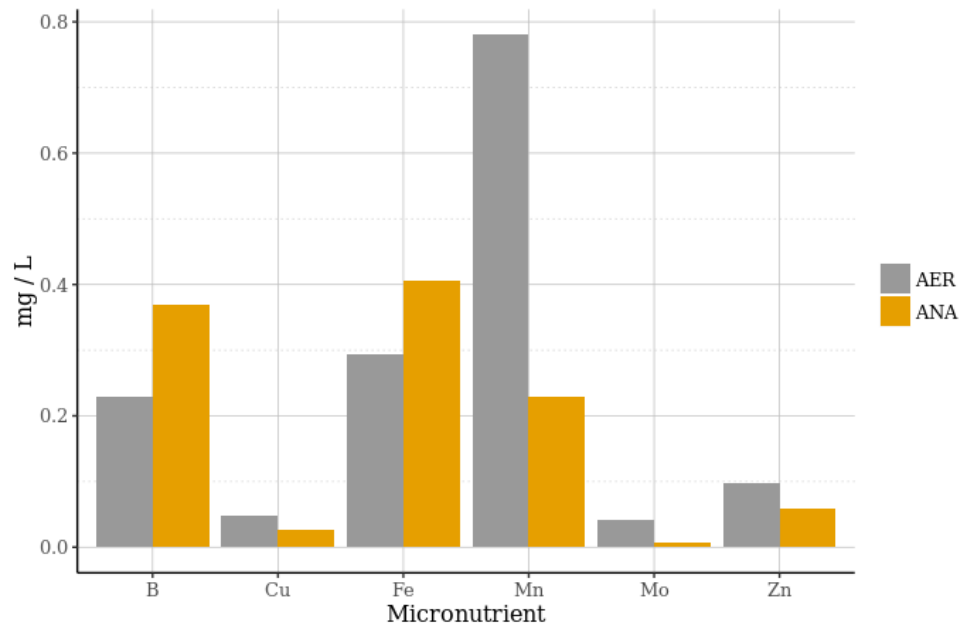

Figure 5.5. Micronutrients of the undiluted AER and ANA supernatant additives at the beginning of the experiment.

The observed AER and ANA supernatant nutrient values (Figures 5.4 and 5.5) were relatively stable throughout the whole experiment. However, four days before the end of the experiment, we observed an unexplainable drop in the redox potential in the aerobic 
reservoir - the sludge blackened within. Additional analysed IC data showed that only $\mathrm{NO}_{3}$ and $\mathrm{NO}_{2}$ levels were affected. The corresponding drop in $\mathrm{NO}_{3}$ concentration can be seen in Figure 5.3a, where the graphs of System AER and ANA are not congruent anymore within the last couple of days. Apart from the different forms of nitrogen, the remineralization performance of both reservoirs was similar. However, we hypothesize that a better remineralization performance can be expected when using other methods of anaerobic digestion such as upflow anaerobic sludge blanket (UASB) treatments with granular sludge (Mirzoyan et al., 2012; Mirzoyan and Gross, 2013; Suhr et al., 2015), including a longer startup time that ensures the presence of sufficient anaerobic bacteria, which tend to grow slower than aerobic bacteria.

Another interesting finding is that $\mathrm{SO}_{4}$ was present in the sump of System ANA (Figure 5.3f) at the beginning of the experiment, but was not found in the anaerobic supernatant (Figure 5.4). These results show that the aerobic remineralization performance was slightly more effective than the anaerobic treatment. It can clearly be seen that the main nitrogen species in RAS water was $\mathrm{NO}_{3}$, compared with the aerobic and especially the anaerobic supernatant additives (Figure 5.4). Here, in the anaerobic supernatant, $\mathrm{NO}_{3}$ was already reduced to $\mathrm{NH}_{4}$. It should also be mentioned that the aerobic effluent contained almost three times as much $\mathrm{SO}_{4}$ than the RAS water, whereas the anaerobic effluent did not contain any $\mathrm{SO}_{4}$ at the time the sample was taken. This, however, can be explained by the fact that sulphate gets converted to $\mathrm{H}_{2} \mathrm{~S}$ - which has not been measured-under anaerobic conditions (Gangagni Rao et al., 2003). This assumption is supported by Krayzelova et al. (2015), who report oxidation of $\mathrm{H}_{2} \mathrm{~S}$ to $\mathrm{SO}_{4}$ under aerobic conditions. Thereby, $\mathrm{H}_{2} \mathrm{~S}$, which is hazardous to plants, is eliminated. Congruently, in our study, $\mathrm{a} \mathrm{SO}_{4}$ peak was observed on Day 18 (Figure 5.3f). The decrease of $\mathrm{SO}_{4}$ in System ANA cannot be directly explained, but we hypothesize that bacteria and fungi might have stimulated its uptake by the plants. Furthermore, $\mathrm{SO}_{4}$ accumulated to a concentration of about $8 \mathrm{mg} / \mathrm{L}$ in System AER due to oxidation of all sulphur components.

Concentrations of six nutrients- $\mathrm{NO}_{3}, \mathrm{Na}, \mathrm{PO}_{4}, \mathrm{~K}, \mathrm{Ca}$, and $\mathrm{SO}_{4}$ - within the Systems AER and ANA over the experimental period of 35 days are shown in Figure 5.4. In contrast to the anaerobic supernatant, $\mathrm{NH}_{4}$ was not found in any of the systems, which is plausible, as aeration assures the oxidation of $\mathrm{NH}_{4}$ to $\mathrm{NO}_{3}$.

Unexpectedly, lettuce had better growth in System ANA (Figure 5.6). The opposite effect was observed with regard to the root growth of the plants (Figure 5.7), leading to a higher shootto-root ratio of System ANA (2.14) compared with Systems AER (1.39) and RAS (1.30). With respect to the general nutrient uptake of plants, Liebig's law of the minimum must be 
considered, which indicates that the nutrient that is least present determines the maximum growth rate. Still, Figures 5.3-5.5 do not indicate that there was any nutrient that was not available in System AER but present in System ANA. However, Lynch et al. (2012) report that an increased shoot-to-root ratio is particularly marked with an increased $\mathrm{N}$ supply, which was not observed in our experiment.

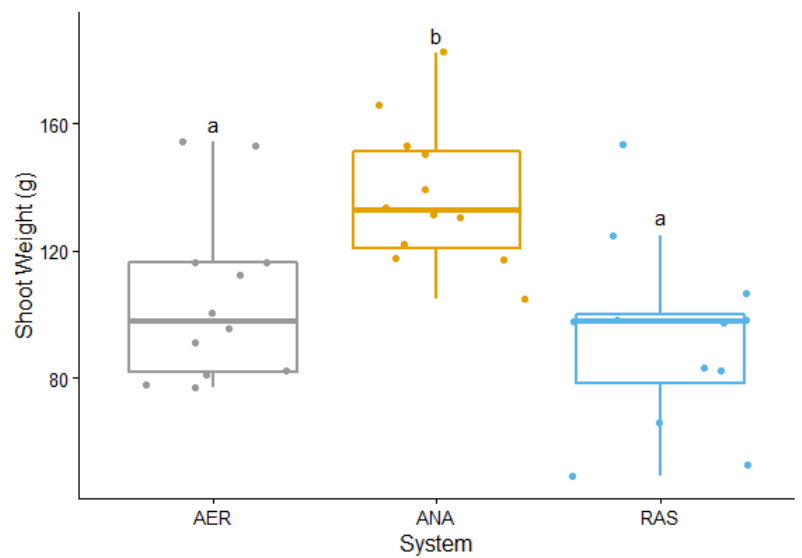

Figure 5.6. Lettuce shoot fresh weight in the aerobic (AER), anaerobic (ANA), and RAS systems after 35 days. Different letters indicate significant differences (Tukey's HSD, $n=12, p<.05$ ). Descriptive statistical data of this box plot can be found in Table 5.3.

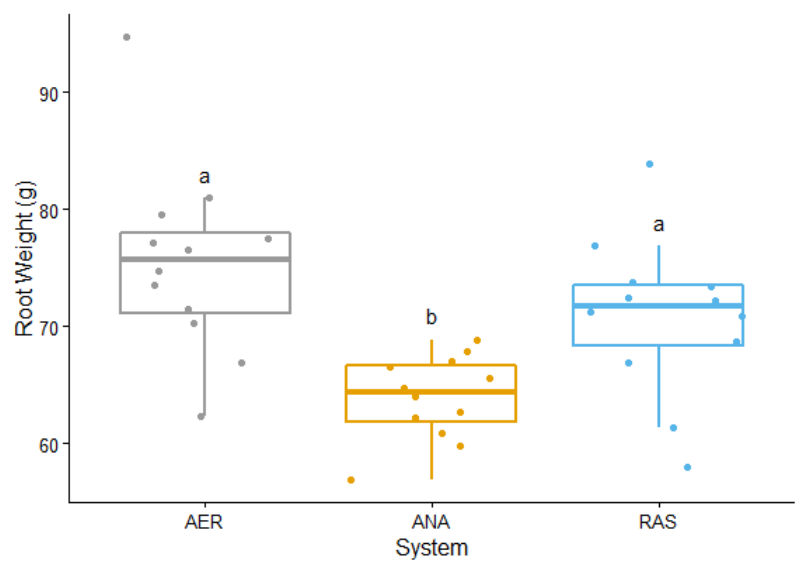

Figure 5.7. Lettuce root fresh weight in the aerobic (AER), anaerobic (ANA), and RAS systems after 35 days. Different letters indicate significant differences (Tukey's HSD, $n=12, p<.05$ ). Descriptive statistical data of this box plot can be found in Table 5.3. 
Table 5.3. Descriptive statistical data for shoot and root fresh weight in g.

\begin{tabular}{ccccccc}
\hline & \multicolumn{3}{c}{ Shoots } & \multicolumn{3}{c}{ Roots } \\
\cline { 2 - 7 } & System AER & System ANA & System RAS & System AER & System ANA & System RAS \\
\hline Min. & 77.1 & 105.0 & 49.0 & 62.3 & 56.9 & 58.0 \\
1st Quantile & 81.8 & 120.9 & 78.2 & 71.1 & 61.9 & 68.3 \\
Median & 97.8 & 132.6 & 97.7 & 75.7 & 64.4 & 71.8 \\
Mean & 104.8 & 137.4 & 92.4 & 75.5 & 63.9 & 70.8 \\
3rd & 116.4 & 151.1 & 100.2 & 78.0 & 66.6 & 73.5 \\
Quantile & 154.4 & 182.5 & 153.5 & 94.7 & 68.8 & 83.9 \\
Max. & & & &
\end{tabular}

There are several plausible explanations for the increased shoot-to-root ratio observed in the system ANA. Firstly, the utilization of $\mathrm{NH}_{4}$ provided by the ANA is energetically more favourable for most plants, since in most cases $\mathrm{NO}_{3}$ has to be converted to $\mathrm{NH}_{4}$ by the plant (Gangagni Rao et al., 2003). Moreover, the uptake of one of these two N-sources also seems to be pH-dependent. Jones (2005) reports that plants prefer $\mathrm{NO}_{3}$ in acidic environments, whereas $\mathrm{NH}_{4}$ is the favoured nitrogen source in alkaline environments. Since the $\mathrm{pH}$ values in the three systems were between 8.1 and $8.7, \mathrm{NH}_{4}$ is the preferred nitrogen source for the plants. In addition, several authors (Jones, 2005; Marschner, 2012; Sonneveld, 2002) have suggested or reported that $\mathrm{NH}_{4}$ boosts plant growth if it represents a small proportion of the nitrogen available. For instance, it has been observed that a proportion of $30 \%$ of $\mathrm{NH}_{4}$ increased the lettuce harvest in a dripping irrigation system (Savvas et al., 2006). This is in accordance with Sonneveld (2002) and Jones (2005), who state that a supply of $10 \%-15 \%$ and $25 \%$ of $\mathrm{NH}_{4}$, respectively, is optimal for most plants grown on substrates. Contrary to standing aerated systems, even $5 \%$ of $\mathrm{NH}_{4}$ could stimulate $\mathrm{NO}_{3}$ uptake in constantly operated systems like the ones used in this experiment. This is attributed to the fact that the specific nitrogen uptake is water-flow-dependent. That is, the lower the $\mathrm{NH}_{4}$ concentration, the higher the flow should be (Jones, 2005). In our case, the $\mathrm{NH}_{4}$ content of the anaerobic supernatant was high (Figure 5.4) and could have contributed to an increased uptake. However, since the system was highly aerated, nitrification must have occurred very fast. Measurements of the water were always taken one day after the supernatants were added. This could be the reason why we had not measured $\mathrm{NH}_{4}$ in the system. Secondly, the $\mathrm{NH}_{4}$ is also likely to lower the $\mathrm{pH}$ (which was considerably high) in the rhizosphere, leading to more favourable conditions to take up nutrients. Last but not least, the sodium level in ANA was slightly lower (Figure 5.3b). The sodium levels most likely did not slow down the growth performance of the lettuce plants, as the concentration was far below the salinity threshold (Hill et al., 1998; Stofberg et al., 2015).

Even though $\mathrm{pH}$ values between 8.2 and 8.7 were measured in the sump of System ANA, the possibility that the $\mathrm{pH}$ in the rhizosphere of System ANA was temporarily lower than in the 
other two systems cannot be excluded. This could have been caused by the addition of the ANA supernatant. To restore the electrochemical balance in root cells and nutrient solution, the uptake of cations (i.e., $\left.\mathrm{NH}_{4}\right)$ is balanced by a release of protons $\left(\mathrm{H}^{+}\right)$that decrease the rhizosphere pH (Dudal and Roy, 1995; Neumann and Römheld, 2012; Silber et al., 2004). A lower $\mathrm{pH}$ than the observed one in the sump, most likely would have caused an increase in nutrient uptake. The uptake of most macronutrients is optimal between pH values 6 and 8 , whereas the uptake of micronutrients is better below pH 6 (Marschner, 1986; Silber et al., 2004). In commercial hydroponic systems, the pH is typically around 5.5 and 6.0 (Resh, 2012), which is much lower than the $\mathrm{pH}$ values reported here.

With respect to the plant growth performance, there are several arguments that could explain an opposite effect. $\mathrm{SO}_{4}$ concentration could have restricted the growth of lettuce in System AER. However, just like the temporary $\mathrm{H}_{2} \mathrm{~S}$ availability in system ANA, the observed $\mathrm{SO}_{4}$ concentration is much lower than recommended for hydroponic practice (Resh, 2012; Sonneveld and Voogt, 2009c). Another factor that decreases plant growth is a high COD level (Krishnasamy et al., 2012), which is much higher in anaerobic effluents than in aerobic effluents. Since our systems were highly aerated and showed a saturated DO level over the entire experimental period, we can reject this assumption. Besides COD, volatile fatty acids (VFAs) are present in high concentrations in anaerobic effluents, inhibiting shoot and root growth (Pang et al., 2007). All these factors are enforced in low $\mathrm{pH}$ environments, which was not the case in our experiment with $\mathrm{pH}$ between 8.1 and 8.7 in the sump.

Another factor that could explain the results is that the anaerobic effluent contained substances that promote the shoot growth and nutrient uptake (Table 5.1). Literature indicates that these substances could be (1) dissolved organic matter (DOM) and (2) plant growth promoting rhizobacteria and/or fungi (PRPR and/or PGPF). Haghighi (2012) showed that the addition of humic acid to a hydroponic solution improved $\mathrm{N}$ metabolism and photosynthesis activity of the lettuce plants, which led to a higher yield. These findings are supported by Ruzzi and Aroca (2015), who state that PGPR can release phytohormones or induce hormonal changes within plants that stimulate plant cell elongation and division. Even though the results show better growth in the ANA treatment, this study did not look into human pathogens that might occur on the roots and leaves. This question could be addressed with metagenomics analyses of the present microbiota.

\subsection{Conclusions}


This study examined the differences in lettuce plant growth performance comparing the addition of anaerobic and aerobic sludge effluents and RAS effluent to the hydroponic system. Our findings provide strong empirical confirmation that anaerobic effluents generally have a positive impact on plant growth. We hypothesize that the enhanced growth of lettuce in System ANA is a result of the added $\mathrm{NH}_{4}$ from the anaerobic fish sludge supernatant (Figure 5.4), which improves the nutrient uptake and at least temporarily lowers the $\mathrm{pH}$ in the rhizosphere that contributes to the same effect. Moreover, DOM, PRPR/PGPF, and humic acid that occur in anaerobic effluents could play an important role in the lettuce's nutrient uptake and utilization. Although the scope in this study was limited in terms of regular measurements of the supernatant composition that might have changed within this period, the study clearly indicates enhanced growth performance when exposing the plants to anaerobic supernatant enriched RAS water. Furthermore, anaerobic digestion generally needs a start-up period of several months to reach full efficiency, which was not fully realized. Further studies should focus on a better understanding of the factors that led to these results, as well as the determination of the optimal dilution of anaerobic supernatant with RAS water. Within the framework of decoupled aquaponic systems, this information is encouraging with regard to the development and implementation of anaerobic nutrient recycling from sludge, improving resource utilization and reducing nutrient emissions in aquaponics. It would also be interesting to see whether a cumulative effect can be observed when exposing plants to a hydroponic solution that contains ANA supernatant as well as RAS water. 


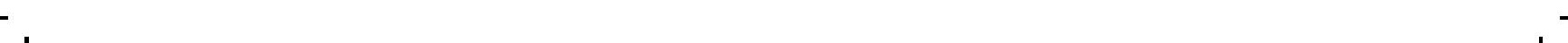




\title{
Chapter 6 Navigating towards Decoupled Aquaponic Systems: A System Dynamics Approach
}

This chapter is based on:

Goddek, S., Espinal, C., Delaide, B., Jijakli, M., Schmautz, Z., Wuertz, S., Keesman, K. (2016): Navigating towards Decoupled Aquaponic Systems: A System Dynamics Design Approach. Water 8, 303.

\begin{abstract}
The classical working principle of aquaponics is to provide nutrient-rich aquacultural water to a hydroponic plant culture unit, which in turn depurates the water that is returned to the aquaculture tanks. A known drawback is that a compromise away from optimal growing conditions for plants and fish must be achieved to produce both crops and fish in the same environmental conditions. The objective of this study was to develop a theoretical concept of a decoupled aquaponic system (DAPS), and predict water, nutrient (N and P), fish, sludge, and plant levels. This has been approached by developing a dynamic aquaponic system model, using inputs from data found in literature covering the fields of aquaculture, hydroponics, and sludge treatment. The outputs from the model showed the dependency of aquacultural water quality on the hydroponic evapotranspiration rate. This result can be explained by the fact that DAPS is based on one-way flows. These one-way flows results in accumulations of remineralized nutrients in the hydroponic component ensuring optimal conditions for the plants. The study also suggests to size the cultivation area based on P availability in the hydroponic component as $\mathrm{P}$ is an exhaustible resource and has been identified one of the main limiting factors for plant growth.
\end{abstract}

\subsection{Introduction}

Aquaponics may be defined as an integrated quasi closed-loop multi-trophic food production system comprising a recirculating aquaculture system (RAS) and a hydroponic unit. In an 
aquaponic system, the nutrient-enriched water derived from the fish is directed to the hydroponic unit providing nutrients for plant growth. The appeal of aquaponics lies on its capacity to produce aquatic animals (e.g., fish, crayfish, etc.) and plants (e.g., vegetables, herbs, medical plants, fruits, etc.) in an environmentally-friendly way, ensuring high levels of water reuse (Rakocy 2012) and nutrient recycling (Graber and Junge, 2009b; Vermeulen and Kamstra, 2013). Despite varying water quality requirements in both RAS and hydroponic production units, the traditional aquaponics practice has been based on compromising the needs of plants and fish within a single water process loop, thereby reducing the efficiency of aquaponic systems compared to the sum of single crop production, fish and plant, respectively (Goddek et al., 2015). Although many aquaponics systems are constructed and operated as a recirculating loop, commercial growers and researchers carry on expanding this initial aquaponics system design towards an independent control over each system unit (i.e., RAS, hydroponics, and nutrient recovery via sludge remineralization). Systems where fish, plants and, if applicable, remineralization are integrated as separate functional units comprising individual water cycles that can be controlled independently, are called decoupled aquaponic systems (DAPS). Still, as a matter of fact, system design aims at a high degree of self-sufficiency of the entire system. Components are consequently designed and sized in the way that the required manipulation to adjust conditions within the cycle can be minimized. Recently, Kloas et al. (2015) presented a DAPS comprising a RAS and a hydroponic unit arranged as two individual water cycles, where water loss due to evapotranspiration of the plants was replaced on demand via a one way valve from the RAS, which in turn was refilled with tap water. Thereby, an improved control of the nutrient flows as well as optimized species-specific water conditions in both units were achieved. The fate of this approach is that the water consumption (i.e., mainly evapotranspiration rate) is the decisive factor of DAPS, as it defines the water replacement and water quality in the RAS as well as the nutrient supply for the plants, if no additional supplementation/fertilization is carried out. Consequently, understanding the impact of water and nutrient flows within such systems is crucial for determining their conceptual framework.

Growth advantages of DAPS have been observed in lab-scale experiments (Delaide et al., 2016a; Goddek, 2016). Delaide et al. (2016a) observed an increased plant growth of 39\% compared to a pure hydroponic control nutrient solution when supplementing the hydroponic component with additional fertilizer. Moreover, Goddek (2016) showed that anaerobic digestates also increased plant growth. To our knowledge, the concept of DAPS has not yet been applied to systems comprising more than two units. In this study, we extended the concept by integrating a third functional unit for the remineralization of RAS derived sludge. Similar to a food web, a number of functional units representing different trophic levels such as autotrophic producers (plant crops), heterotrophic consumers (fish, 
crustaceans, molluscs) and decomposers (remineralization unit) could be arranged in individual, though communicating water cycles, providing a better control of the nutrient flows and increasing the efficiency of the production and reducing emissions further. Most importantly, such concept may allow for better fine tuning of nutrient flows between several units and may add stability with regard to imbalances or disturbances.

Nutrient dynamics in one-loop integrated aquaculture-hydroponic systems have first been investigated by Seawright et al. (1998b). However, nutrient flows and accumulations were not comprehensible due to unreported nutrient supplementations. A nitrogen (N) balance study for one-loop aquaponic systems was conducted by Graber and Junge (2009b) and Licamele (2009), who observed that growth of hydroponic and aquaponic lettuce was similar even though the lettuce in the hydroponic system was exposed to a solution with a higher nutrient concentration. Another mass balance study has been conducted by Neto and Ostrensky (2013) who estimated the nutrient load and waste productions in tilapia cage production systems. Regarding the nutrient flow from RAS to the plants in one-loop systems, several authors have made examinations of this issue and observed low levels of $\mathrm{P}$, potassium, magnesium, manganese, iron, and sulphur (Adler et al., 1996; Graber and Junge, 2009; Licamele, 2009; Rakocy, 2012; Roosta and Hamidpour, 2011; Savidov et al., 2007). Consequently, the plant growth performance could probably even be improved by providing a sufficient amount of nutrients, which can either be achieved by supplementation (Goddek et al., 2015; Rakocy et al., 1997), or remineralization of fish sludge as observed in several studies comprising mass balance approaches (Mirzoyan et al., 2012, 2010; Mirzoyan and Gross, 2013).

\subsection{Objectives and Scope}

Typically, models are created to understand, predict, and control complex dynamic systems (Sterman, 2000). The scope of this study is to develop a system dynamics model for N, phosphorus (P), water, fish, plants, and sludge (aquacultural biosolids), based on a decoupled system approach. The reason why the macronutrient $\mathrm{P}$ is used in this paper is due to the fact that it is an exhaustible resource (Sverdrup and Ragnarsdottir, 2011). Even though it is mostly sufficiently available in the fish feed, other more available nutrients can be supplemented to the hydroponic component. The system dynamics model of this study can be used to design and further optimize systems. The main objective of this paper is to present a theoretical design approach for DAPS by addressing the scope's conceptual criteria, and coping with design drawbacks based on the model's outcome. The model elaborated in this paper assesses the system's organic loading rates to achieve optimal conditions for both hydroponic and RAS components of the system under given conditions. 
This will lead to a perspective that covers the evaluation regarding the need for further studies that have to be pursued to develop and improve a plant-wide model for decoupled aquaponic systems.

\subsection{Methodology and Data Sources}

\subsubsection{Dynamic Systems Analysis}

Dynamic systems analysis was used to evaluate the N, P, fish (i.e., tilapia), plant (i.e., lettuce plant), and water balance within DAPS. This method also enabled us to assess the impact of a remineralization component on the overall system's performance, as well as sizing the hydroponic part depending on different evapotranspiration rates. However, as a basis for physically-based dynamic modelling, as opposed to data-driven modelling, well-grounded flow charts and causal loop diagrams (CLD) are required (Sterman, 2000). Whereas flowcharts provide an overview of all procedures considered necessary in the context of a comprehensive diagnostic process, CLDs represent a fundamental tool to understand and illustrate complex systems. Both served as foundation plans and constituted the basis for the software computer model.

Although CLDs are a good tool to identify causal relationships between activities or events and their latent effects, they need to be combined with the factor time to simulate and reveal short to long term impact factors and changes due to e.g., accumulations, fluctuations in temperature and fish biomass, etc. The resulting system dynamics models allow analysing the interplay of key factors in order to reveal key leverage points and optimal conditions and system settings. Here, the specific system modelling software AnyLogic was used (Borshchev, 2013). For the CLDs the following choices were made: (1) RAS, hydroponics, and sludge remineralization are displayed independently to constitute the need for different conditions in each sub-system; and (2) in the RAS component, a nitrifying biofilter is included in the model. Laying the basis for the models, assumptions for the flow charts are: (1) there is no need to exchange water in addition to the water replacement as consequence of evapotranspiration; (2) it is provided that the RAS components contain biofilters of adequate size to fully transform total ammonia nitrogen (TAN) into nitrate; and (3) nutrient supplementations for the hydroponic units are not taken into account.

The system dynamics model simulations were based on a decoupled system with four fish tanks. The modeling procedure was divided into four steps: (1) Before N, P, water, tilapia, lettuce, and sludge flows were simulated, a parameter variation experiment was run in order to estimate the amount of fish that needed to be incorporated to the system to have a 
maximum stocking density of $50 \mathrm{~kg} \cdot \mathrm{m}^{-3}$. For higher densities the use of pure oxygen could be required; (2) Given this data, the plant cultivation area for maximum nitrogen-nitrate (N$\mathrm{NO}_{3}$ ) water concentration for sensitive and resistant fish species (i.e., trout and tilapia) was simulated using a parameter variation experiment depending on crop evapotranspiration rates $\left(\mathrm{ET}_{\mathrm{c}}\right)$ under natural and artificial light conditions. For trout the limit was set to 40 $\mathrm{mg} \cdot \mathrm{L}^{-1} \mathrm{~N}-\mathrm{NO}_{3}$ (Davidson et al., 2014, 2011; Schrader et al., 2013), for tilapia to $200 \mathrm{mg} \cdot \mathrm{L}^{-1}$ $\mathrm{N}-\mathrm{NO}_{3}$; (3) P was used as an alternative design parameter to size the hydroponic component since it is often limiting plant growth and global mineral resources are finite. However, if the obtained size suggestion does not correspond with the needed water exchange rates, active denitrification in the RAS is required. For this study, an optimization step was conducted, which determined the amount of lettuce that can be produced with RAS-derived nutrients and remineralized $P$ inflow from an anaerobic nutrient remineralization component (ANRC). In this study, the ANRC was composed by an upflow anaerobic sludge blanket (UASB) reactor. UASB reactor performance parameters were used to determine the remineralization rates; (4) Given the P parameter the flow of the UASB was determined.

\subsubsection{FAO Penman-Monteith Equation}

The evapotranspiration rate is dependent on net radiation, temperature, wind velocity, relative humidity, and crop species (Bonachela et al., 2006; FAO, 1998). Net solar radiation can be determined using the FAO Penman-Monteith equation (FAO, 1998). This equation is initially developed for outdoor environments, but can be adjusted for greenhouse crop production (Bonachela et al., 2006; Zolnier et al., 2004). Instead of a total dependency on nature, both greenhouse characteristics and climate control equipment have a high impact on the evapotranspiration (Boulard, 2003; Jolliet and Bailey, 1992). Fernández et al. (2010) report a reduced reference evapotranspiration $\left(\mathrm{ET}_{\mathrm{o}}\right)$ by $21.4 \%$, when using plastic greenhouses in Spain. Greenhouses also reduce the wind speed considerably, which has a reducing impact on the reference evapotranspiration (Fernández et al., 2010; Möller and Assouline, 2006). Surface covers as they are used, for instance in nutrient flow techniques (NFT) or deep water culture (DWC) methods are reported to reduce the single crop coefficient $\left(\mathrm{K}_{c}\right)(\mathrm{FAO}, 1998)$ that is multiplied with the reference evapotranspiration to receive the crop evapotranspiration. Licamele (2009) reported that plant density of 32 lettuce plants $\mathrm{m}^{-2}$ required $1 \mathrm{~L}$ of water each. These findings were consistent with the estimated covered single crop coefficient (Figure 6.1). Therefore a comparative analysis was conducted with AnyLogic to estimate the range of expected evapotranspiration rates under constant lighting conditions of $200 \mathrm{~W} \cdot \mathrm{m}^{-2}$ for $16 \mathrm{~h} \cdot \mathrm{day}^{-1}$ and the sole use of natural light. 


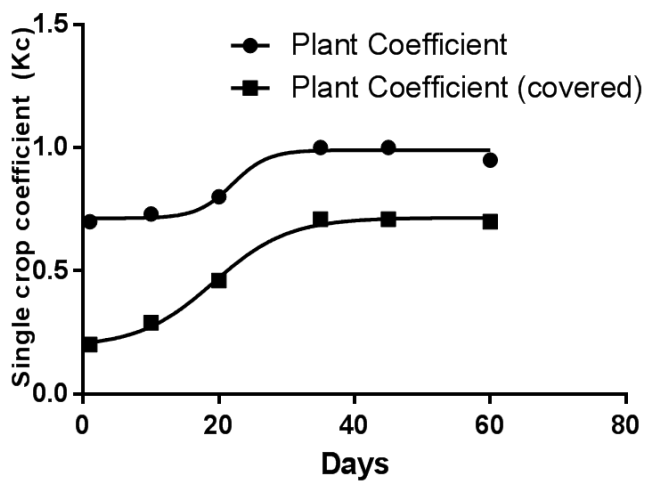

Figure 6.1. Lettuce crop coefficient for non-covered and surface covered cultivation assuming planting of seedlings after 15 days (in the graph shown as day 0 ).

Knowing both $\mathrm{ET}_{\mathrm{o}}$ and $K_{\mathrm{c}}$, the crop evapotranspiration in $\mathrm{m}^{3}$ per $\mathrm{m}^{2}$.day ${ }^{-1}$, and typically expressed in $\mathrm{mm} \cdot \mathrm{day}^{-1}$, was estimated as follows:

$$
\mathrm{ET}_{\mathrm{c}}=\mathrm{ET}_{\mathrm{o}} \times K_{\mathrm{c}}
$$

where $\mathrm{ET}_{\mathrm{c}}$ is the crop evapotranspiration $\left(\mathrm{mm} \cdot \mathrm{day}^{-1}\right), \mathrm{Et}_{\mathrm{o}}$ the reference evapotranspiration $\left(\mathrm{mm} \cdot \mathrm{day}^{-1}\right)$, and $K_{\mathrm{c}}$ the plant coefficient for lettuce (dimensionless).

The reference evapotranspiration for the natural light option has been estimated based on measured hourly solar radiation data for Köln-Bonn (Table 6.1), Germany (50 $47^{\prime} \mathrm{N} ; 7^{\circ} 5^{\prime} \mathrm{E}$ ) of 2014 (Deutscher Wetterdienst, 2015) representative for the Central European region. The temperature range within the greenhouse was determined at $20-24{ }^{\circ} \mathrm{C}$, the relative humidity set between $60 \%$ and $80 \%$. It was assumed that the greenhouse glazing transmittance reduces incident radiation by $10 \%$. The shading factor due to construction and surrounding reduced it by another $15 \%$, which made us assume that the net radiation of natural light under greenhouse conditions decreased by $25 \%$. Figure 6.2 shows the estimated ETo $_{0}$ difference under natural and artificial lighting. The natural lighting reference evapotranspiration can be expressed in to the following formula, which refers to the natural lighting curve in Figure $6.2\left(r^{2}=0.994\right.$; statistical measure of how close the data are to the fitted regression line):

$$
\mathrm{ET}_{\mathrm{o}}=2.758 \times \exp \left(-0.5 \times((X-6.14) / 2.36)^{2}\right)
$$

where $X$ is the time in months. 
Table 6.1. Observed sunshine hours (per month) and the respective estimated reference evaporation (ETo in mm/day) for Köln-Bonn.

\begin{tabular}{|c|c|c|c|c|c|c|c|c|c|c|c|c|}
\hline $\begin{array}{c}\text { Paramet } \\
\text { ers }\end{array}$ & $\begin{array}{c}\text { Janua } \\
\text { ry }\end{array}$ & $\begin{array}{c}\text { Februa } \\
\text { ry }\end{array}$ & $\begin{array}{c}\text { Marc } \\
\mathrm{h}\end{array}$ & $\begin{array}{c}\text { Apri } \\
1\end{array}$ & lay & June & ly & $\begin{array}{l}\text { Augu } \\
\text { st }\end{array}$ & $\begin{array}{c}\text { Septemb } \\
\text { er }\end{array}$ & $\begin{array}{l}\text { Octob } \\
\text { er }\end{array}$ & $\begin{array}{c}\text { Novemb } \\
\text { er }\end{array}$ & $\begin{array}{c}\text { Decemb } \\
\text { er }\end{array}$ \\
\hline$S_{1}$ & 73 & 7 & $\begin{array}{c}187 . \\
5\end{array}$ & $\begin{array}{c}143 . \\
9\end{array}$ & 8 & $\begin{array}{c}212 . \\
1\end{array}$ & $\begin{array}{c}209 . \\
8\end{array}$ & 150.7 & 13 & 996 & 68 & U \\
\hline $\mathrm{ET}_{0}$ & 0.18 & 0.53 & 1.30 & 1.82 & 2.36 & 2.76 & 2.64 & 1.99 & 1.36 & 0.70 & 0.26 & 0.17 \\
\hline
\end{tabular}

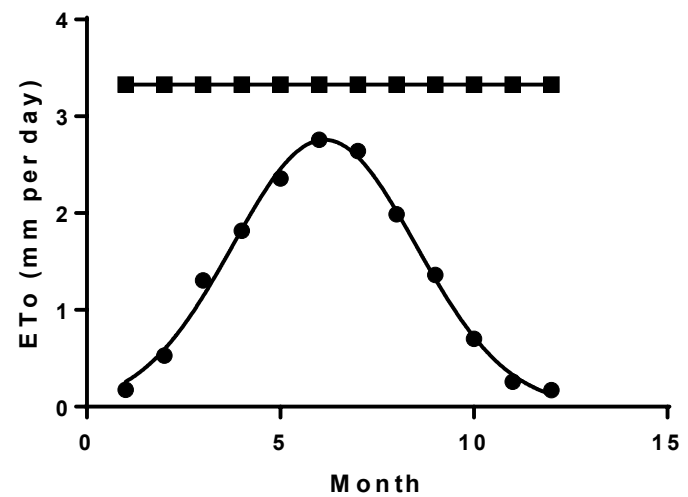

Figure 6.2. Reference evapotranspiration ( $\mathrm{ET}_{\mathrm{o}}$ in $\mathrm{mm} /$ day) upon plain natural lighting (Köln-Bonn) or at constant radiation using (additional) artificial light.

\subsubsection{Input Data and Parametrization for RAS}

The modelled RAS comprised four fish tanks with a volume of $1 \mathrm{~m}^{3}$ each. Additional RAS components (i.e., biofilter, drum filter, sump, etc.) add another $3 \mathrm{~m}^{3}$ of volume. The RAS water temperature is held stable at about $28^{\circ} \mathrm{C}$. Temperature is an important factor for fish growth and its influence on tilapia growth $\left(\mathrm{cm} \cdot \mathrm{month}^{-1}\right)$ can be predicted given the following formula for a maximum temperature of $29.5^{\circ} \mathrm{C}$ (Timmons and Ebeling, 2013):

$$
\text { Growth }\left(\mathrm{cm} \cdot \text { month }^{-1}\right)=\frac{T-18.3}{3.28}
$$

where $T$ is the average temperature $\left(\right.$ in $\left.^{\circ} \mathrm{C}\right)$ of the RAS.

Knowing the fish length allows to calculate the fish weight (Timmons and Ebeling, 2013):

$$
W T=\frac{2.08 \times L^{3}}{3.28}
$$

where $W T$ is the weight of the tilapia (in g), and $L$ the length of tilapia (in $\mathrm{cm}$ ). 
In the model, fingerlings $10 \mathrm{~cm}$ in size were sequentially added to the fish tanks. The total fish growth cycle was set at 200 days. Thus, every 50 days fish were harvested and re-added to one of the fish tanks. The fish were fed with species specific feed with a protein content of $35 \%$, of which $9.2 \%$ of proteins become TAN (Timmons and Ebeling, 2013, p. 289). The feeding rate was calculated based on a percentage of body weight that, in turn, was depending on the feed conversion ratio (FCR) (Timmons and Ebeling, 2013). It was assumed that the optimal FCR is 1.1-1.3 for tilapia depending on their growth stage (Timmons and Ebeling, 2013, p. 82), even though in aquaponics FCRs of 1.7-1.8 have been observed (Rakocy et al., 2006). It was also assumed that water quality parameters of the RAS lie within acceptable limits (Table 6.2) and did not have any impact on the mortality rate. The main factor for the fish's survival rate was thus the density (Gullian-Klanian and ArámburuAdame, n.d.). The passive denitrification rate was 10\% (Timmons and Ebeling, 2013). The fish feed uptake rate (i.e., the percentage of feed the fish actually consume) was assumed being 95\% (Timmons and Ebeling, 2013).

Table 6.2. Optimal growth parameters for tilapia.

\begin{tabular}{lll}
\hline Parameter & Threshold for Optimal Growth & References \\
\hline TAN $(\mathrm{mg} / \mathrm{L})$ & $<2.9$ & (El-Shafai et al., 2004) \\
$\mathrm{NO}_{2}-\mathrm{N}(\mathrm{mg} / \mathrm{L})$ & $<0.5-1$ & (Al-Hafedh et al., 2003) \\
$\mathrm{NO}_{3}{ }^{-}-\mathrm{N}(\mathrm{mg} / \mathrm{L})$ & $<100-200$ & (Dalsgaard et al., 2013) \\
$T\left({ }^{\circ} \mathrm{C}\right)$ & $27-29$ & (DeLong et al., 2009) \\
$\mathrm{O}_{2}(\mathrm{mg} / \mathrm{L})$ & $4-6$ & (Eding et al., 2009) \\
$\mathrm{pH}$ & $6-9$ & (DeLong et al., 2009) \\
Photoperiod & $18 \mathrm{~L}: 6 \mathrm{D}$ & (Veras et al., 2013) \\
\hline
\end{tabular}

Given these parameters, the optimization experiment that has been conducted with AnyLogic with the decision variable "amount of fish" suggested to start with 60 fingerlings to gain a fish biomass of approximately $50 \mathrm{~kg} \cdot \mathrm{m}^{-3}$ fishes per tank after 200 days.

\subsubsection{Input Data and Parametrization for Hydroponics}

The growth cycle for lettuce was set at 35 days. They were grown in DWC systems with a depth of $30 \mathrm{~cm}$. The inflow from the RAS to the DWC was determined by the evapotranspiration rate, that is $\mathrm{ET}_{\mathrm{c}}$ times area of the hydroponic system, and is given by:

$$
\text { Hydroponic inflow from RAS = Evapotranspiration }- \text { inflow from ANRC }
$$

where ANRC represents the anaerobic nutrient remineralization component. 
Under optimal conditions, lettuce head weights of $150 \mathrm{~g}$ can be achieved 4 weeks after transplanting the seedlings into the hydroponic system (Rakocy et al., 2006; Resh, 2012). 16 lettuce plants were cultivated per $\mathrm{m}^{2}$, each of which takes up $6 \mathrm{~g}$ of $\mathrm{N}$ and $50 \mathrm{mg}$ of $\mathrm{P}$ within the growth cycle (Licamele, 2009).

\subsubsection{Input Data and Parametrization for Remineralization}

Nitrate and nitrite are degraded to ammonia and dinitrogen gas under anaerobic conditions (Appels et al., 2008). Both Zhao et al. (2015) and Cuervo-López et al. (1999) observed nitrate and nitrite degradation efficiencies of approx. 99\% in UASB reactors operating with an hydraulic retention time (HRT) of 9-12 days and 2 days, respectively. Mirzoyan and Gross (2013) show similar nitrate and nitrite removal rates. However, in their work, the effluent consisted of $17.7 \mathrm{mg} \cdot \mathrm{L}^{-1}$ TAN (for every $102 \mathrm{~g} \cdot \mathrm{kg}^{-1}$ entering the UASB reactor) at an HRT of 8 days and a total suspended solids sludge concentration of 3.8\%. The $\mathrm{N}$ composition of the inflowing sludge is a sum of $\mathrm{N}$ water content and $\mathrm{N}$ in dry matter sludge. The composition of the latter has been shown by Neto and Ostrensky (2013), who report an N content of approximate $15 \%$ of dry sludge for a feed $\mathrm{N}$ content of $5.3 \%$, and a P feed content of $1.5 \%$ (Neto and Ostrensky, 2013; Roosta and Hamidpour, 2011).

The volume of the UASB reactor has been determined by the following HRT formula:

$$
\operatorname{HRT}(\mathrm{h})=\frac{\text { Reactor Volume }\left(\mathrm{m}^{3}\right)}{\text { Flow Rate }\left(\mathrm{m}^{3} \mathrm{~h}^{-1}\right)}
$$

where HRT is the hydraulic retention time in hours.

The desired HRT was 10 days, because it showed best digestion performance recently (Mirzoyan and Gross, 2013). Since an HRT of 10 days cannot practically fulfill this requirement, an additional circulation pump was required for each UASB reactor. The flow rate going into the reactor has been determined by the amount of daily sludge produced by the fish, which has been recovered from the settling basin (see Figure 6.3) with a specific TSS. In our case the sludge retention time (SRT) was 80 days considering that the sludge blanket occupied $60 \%$ of the volume of the reactor with a TSS of $3 \%$. The amount of sludge withdrawn on a daily basis has been assumed to be $10 \%$ of the organic loading rate (ORL); i.e., of the added fresh sludge. Mirzoyan and Gross (2013) showed a fresh sludge TSS removal of $90 \%$. The same TSS removal has been assumed in this study.

$$
\text { SRT }(\mathrm{d})=\frac{\text { Total sludge present in reactor }(\mathrm{kg})}{\text { sludge withdraw }\left(\mathrm{kg} \mathrm{d}^{-1}\right)}
$$


An upflow velocity of $0.5 \mathrm{~m} \cdot \mathrm{h}^{-1}$ must be maintained to keep the sludge blanket in suspension (Lettinga and Pol, 2011). The upflow velocity formula is as follows.

$$
\mathrm{V}_{\mathrm{up}}=\frac{\mathrm{H}}{\mathrm{HRT}}
$$

where $V_{u p}$ is the upflow velocity $\left(\mathrm{m} \cdot \mathrm{h}^{-1}\right), \mathrm{H}$ is the reactor height $(\mathrm{m})$, and HRT is the hydraulic retention time $(\mathrm{h})$.

\subsection{Theory}

\subsubsection{Decoupled System Design}

\subsubsection{Justification for Decoupled Systems}

Nitrate concentrations in aquaponic systems can be controlled either by water exchange, plant uptake, and/or denitrification through anoxic bacterial reduction. Water exchange rates can be determined via mass balance, whilst $\mathrm{N}$ removal by denitrification or plant uptake must be calculated using available information on $\mathrm{N}$ removal rates by different plants and denitrification reactor configurations. Unlike $\mathrm{N}$, which is present in aquaponics mostly in dissolved forms that tend to accumulate, several important plant nutrients are found almost exclusively in biosolids originating from uneaten food and faeces.

Until recently, the principal focus of publications in the field of aquaponics was mostly on the availability, concentration, and accumulation of nitrate, which has been considered the most important macronutrient for vegetative growth. Even though it increases the complexity of the overall process and is not a focus of this paper, it is inevitable to address the accumulation of all micro- and macronutrients that are necessary for optimal growth conditions. This becomes more relevant given the fact that in DAPS the nutrient accumulation in the hydroponic component results from several sources (i.e., inflow from RAS, inflow from remineralization component, and nutrient supplementation) and reduces dilution due to the fact that the ANRC outflows only dilutes in the hydroponic component instead of systemwide. As the specific nutrient needs of fish and plants depend on a large number of dependencies and interactions, design trade-offs towards best practicable means need to be made, to achieve best possible conditions for both the fish and the plant and thus the optimization of the sub-systems with regard to the use/recycling of nutrients. These heterogeneous conditions of the respective sub-systems and their impact on nutrient accumulation have a significant effect on the overall system performance.

The advantages of independently controllable components are underlined in the Tables 6.3 and 6.4. The in Table 6.3 given examples of optimal conditions for different plant and fish 
species, as well as the bio filtration and ANRC components are cases in point. The more the conditions of RAS and hydroponics deviate from their optimal conditions, the lower the production efficiency that can be expected. Instead of accounting for trade-offs between those component parts, the objective should be to provide the best practicable conditions for each component and combination of species. Even though similar growth performances between aquaponics and hydroponics have been observed, optimizing the respective conditions could lead to an enhanced fish and plant growth (Delaide et al., 2016). This is only achievable in independently controlled and running sub-systems. This concurs with Table 6.4. Here too, one can see major differences in environmental and nutritional factors. The significant difference in terms of nutrient concentration can be explained by the fact that trade-offs have to be made with respect to plants' and fish' specific needs, which is the reason for these gaps. 


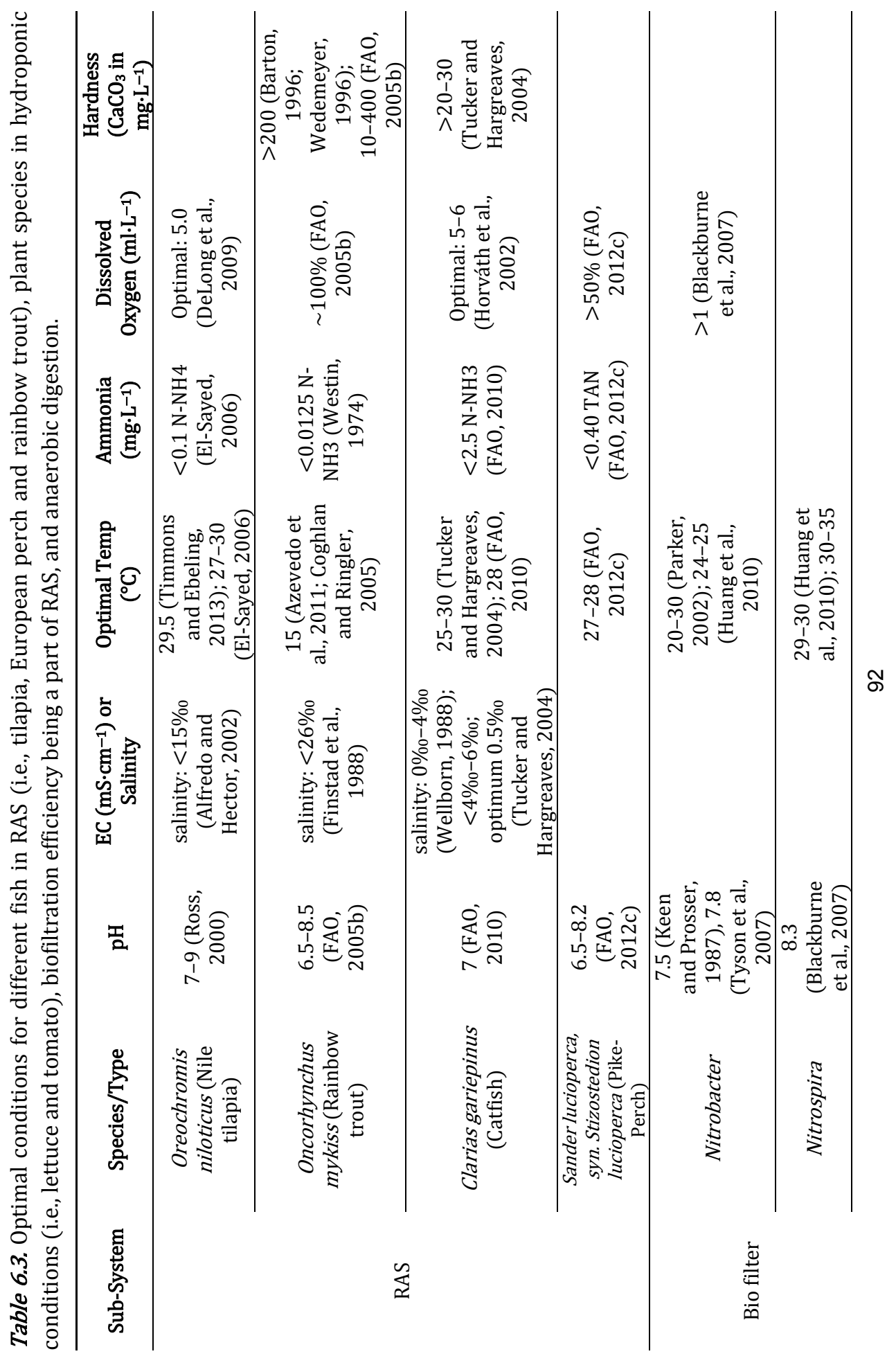




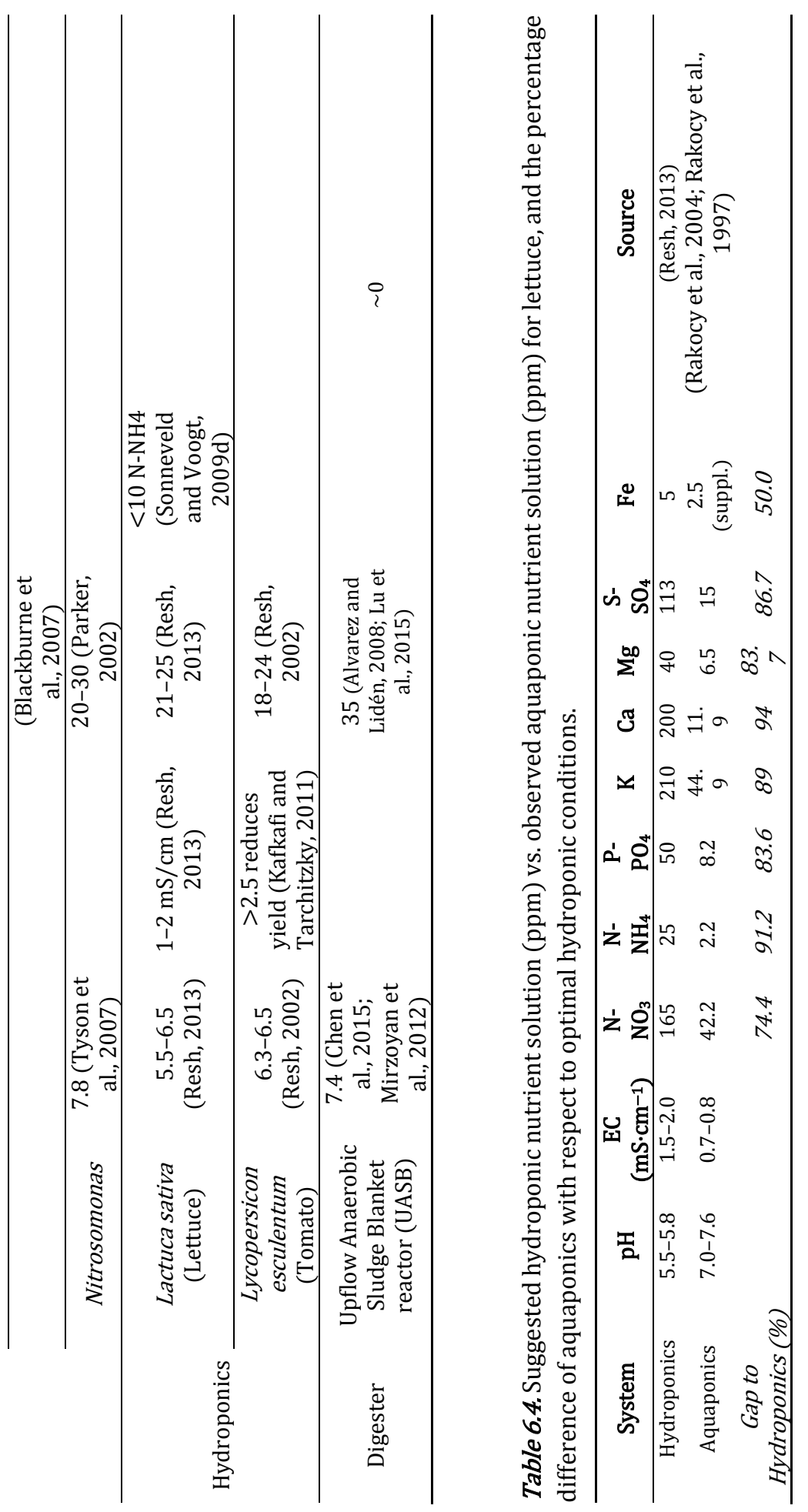


With respect to nutrient dynamics, the flow of each nutrient depends upon many factors including species, system design, biofilter performance, remineralization method, feed composition, etc. Around 25\% of feed (dry matter) becomes sludge (Davidson and Summerfelt, 2005; Timmons and Ebeling, 2013). Neto and Ostrensky (2013) analyzed the nutrient compositions of sludge (Table 6.5). They report that $55 \%$ of the $\mathrm{P}$ that entered the system via the fish feed accumulates in sludge. The sludge is composed of $37 \%$ feces and $18 \%$ non-consumed feed. The percentage of non-consumed feed, however, must be treated with caution as the data is collected from RAS cage breeding systems. Even though the values of Neto and Ostrensky (2013) base on cage breeding systems, our observed values (Table 6.5) are closer to these values, than to observations made by Rafiee and Saad (2005) in RAS. We observed similar concentrations, using fish feed consisting of $9.7 \% \mathrm{~N}$ and $1.7 \% \mathrm{P}$. However, more $\mathrm{P}$ accumulated in the fish than in the sludge. Yet, the implementation of remineralization technology has great potential to recycling a high proportion of macronutrients such as $\mathrm{P}, \mathrm{K}$, and N (i.e., if carried out under anaerobic conditions) etc. (Mirzoyan et al., 2012, 2010; Suhr et al., 2015).

Table 6.5. Nitrogen (N) and phosphorous (P) flow from Nile tilapia feeding in RAS cage production.

\begin{tabular}{ccccc}
\hline \multirow{2}{*}{ Parameters } & $\mathbf{N}(\%)$ & $\mathbf{P}(\%)$ & $\mathbf{N}(\%)$ & $\mathbf{P ~ ( \% )}$ \\
\cline { 2 - 5 } & \multicolumn{1}{c}{ Neto and Ostrensky (2013) } & Personal Observations (RAS) \\
\hline Feed & 100 & 100 & 100 & 100 \\
Fish retention & 35 & 28 & $35-50$ & $60-70$ \\
Water (Soluble Excretion) & 33 & 17 & $20-30$ & $5-10$ \\
Total Sludge & 31 & 55 & $15-25$ & $35-45$ \\
Thereof non-consumed feed & 18 & 18 & $5-10$ & $5-10$ \\
Thereof feces & 13 & 37 & $10-15$ & $30-35$ \\
\hline
\end{tabular}

As compared to one-loop aquaponics, the nutrient flow in DAPS is slightly different. Figure 6.8 illustrates the extent to which the sludge remineralization process can add to the development of an integrated system approach. Apart from nutrient supplementation, nutrient remineralization can be used to accumulate nutrients in the hydroponic component. This may have a commercial advantage, as the root:shoot ratio (i.e., the ratio between the edible parts and the residuals) of plants is dependent on nutrient concentration in the plant. According to Lambers et al. (2008) the root:shoot ratio of plants is decreased under sufficient presence of $\mathrm{N}, \mathrm{P}$, and very likely sulphate deficiency, which is the case in one-loop aquaponics systems.

The most important principle in aquaponics design states that the nutrient load of the system can be balanced between both the nutrient load, as a function of fish biomass and feeding rate, metabolic conversion and subsequent excretion as well as uneaten feed and feces, and 
the nutrient requirement of the plants (Licamele, 2009). Consequently, the determination of fish:plant ratios has become the most commonly used design approach for balancing the systems. However, as every plant and fish species have different nutritional needs that are also dependent on the growth stage/life-cycle and external factors (including system design), the exact determination of this ratio is complex, system-dependent and commonly carried out with empirical data. The more system designs are studied, the more accurately fish:plant ratios can be estimated and, as a consequence, the more efficient nutrient flows and yields can be managed. Although specific estimations might apply to a particular system setup, adopting this practice to size or balance entirely new designs without experimental evaluation can be problematic.

Irrespective of the system's input and the specific optimized nutrient solution, the nutrient uptake of plants is highly dependent on nutrient availability, illumination, temperature, $\mathrm{pH}$, etc. These deviating optimal conditions are reflected by plant specific coefficients. Being able to select the best combination of plants and fish as well as feed that achieves the best possible water quality and thus growth performance provides a good argument for DAPS. Achieving the best possible water quality still remains a minor criterion in system design engineering. However, when both fish and plant species and their specific nutritional needs are known, it will be possible to predict the plant component size based on the estimation of the RAS nutrient loading as well as the remineralization capacity of the used digestion method. Several mathematical N-uptake models have been developed (Letey et al., 1982; Mathieu et al., 2006; Steingrobe and Schenk, 1994) and can provide a good estimation for the plants' Nconsumption. However, the nutrient removal performance for different plant species and life stages under aquaponic conditions remains to be studied in order to be able to model the flows for all important nutrients within DAPS.

\subsubsection{Hardware Layout}

The schematic design of a DAPS layout is illustrated in Figure 6.3. It consists of three parts: (1) conventional RAS; (2) hydroponic component; and (3) ANRC. Implementing such an ANRC into an aquaponic system and following a one-way flow approach require several design considerations, which are outlined below:

1. The RAS is intended to manage the fish sludge and to provide control over the most important water quality parameters (dissolved oxygen, TAN, suspended solids, and carbon dioxide).

2. Since UASBs have a high denitrification potential that is dependent on both HRT and SRT, a direct one way flow from RAS to the hydroponic component is required to control the 
nitrate dosing (i.e., provide the plants with $\mathrm{N}$ ). This also includes a return overflow option; e.g., in case a sub-system needs to be re-coupled.

3. Sludge thickening is a necessary prerequisite for the anaerobic digestion process (Mirzoyan et al., 2010). An offline settling tank prior to the UASB is used for this process. In practice, activated sludge denitrification reactors can be installed upstream of the UASB to use some of the carbon source to get rid of nitrate and reduce sludge volume (Klas et al., 2006). In our case, $\mathrm{N}$ is preferred to be kept in the system. However, $\mathrm{N}$ recovery in anaerobic sludge treatment is very much HRT dependent and only marginal, when exceeding an HRT over several hours (Mirzoyan et al., 2012).

4. Hypothetically, digester effluents to RAS, even though they contain a high amount of sulfide, are not expected to affect water quality and therefore fish welfare due to dilution (Mirzoyan and Gross, 2013). This also applies for the hydroponics-RAS return overflow.

5. Two mechanical filtration steps are used to minimize the TSS in the UASB effluent.

6. The hydroponic system is a hybrid system that utilizes dosing systems to manage nutrients, $\mathrm{pH}$, electrical conductivity (EC), dissolved oxygen, and redox potential to maintain acceptable nutrient levels with precision.

7. The outflow from both the ANRC and RAS, and the utilized water in the hydroponic component are congruent. Consequently, the utilized water in the hydroponic component, and thus the replenishment of water to the fish tanks must be high enough to avoid accumulation of nutrients in the RAS.

8. The ANRC can be complemented with an aerobic pre- or post-treatment, as better remineralization performance can be assumed, and chemical oxygen demand (COD) reduction has been observed (González-González and Cuadros, 2015). Yet, it must be noted that the drawback of an additional aerobic step is additional production of biomass (i.e., bacteria growth) that consumes part of the available nutrients. Whether the aerobic treatment proceeds or follows the anaerobic treatment depends on whether one prefers to increase the carbon dioxide concentration in the greenhouse (pre) or use the anaerobic digester as a biogas producing device (post). Even though the aerobic treatment most likely provides additional advantages (e.g., $\mathrm{H}_{2} \mathrm{~S}$ reduction), it is no part of our software calculations. For the sake of completeness, we nonetheless added it to this scheme.

9. The produced energy in form of electricity and heat, gained through $\mathrm{CH}_{4}$ combustion, can be returned to the system. This combustion also reduces greenhouse gas emissions. The combustion's products (i.e., $\mathrm{CO}_{2}$ and $\mathrm{H}_{2} \mathrm{O}$ ) can be lead back to the system as clean water and $\mathrm{CO}_{2}$ (greenhouse required) in order to enhance plant growth. 


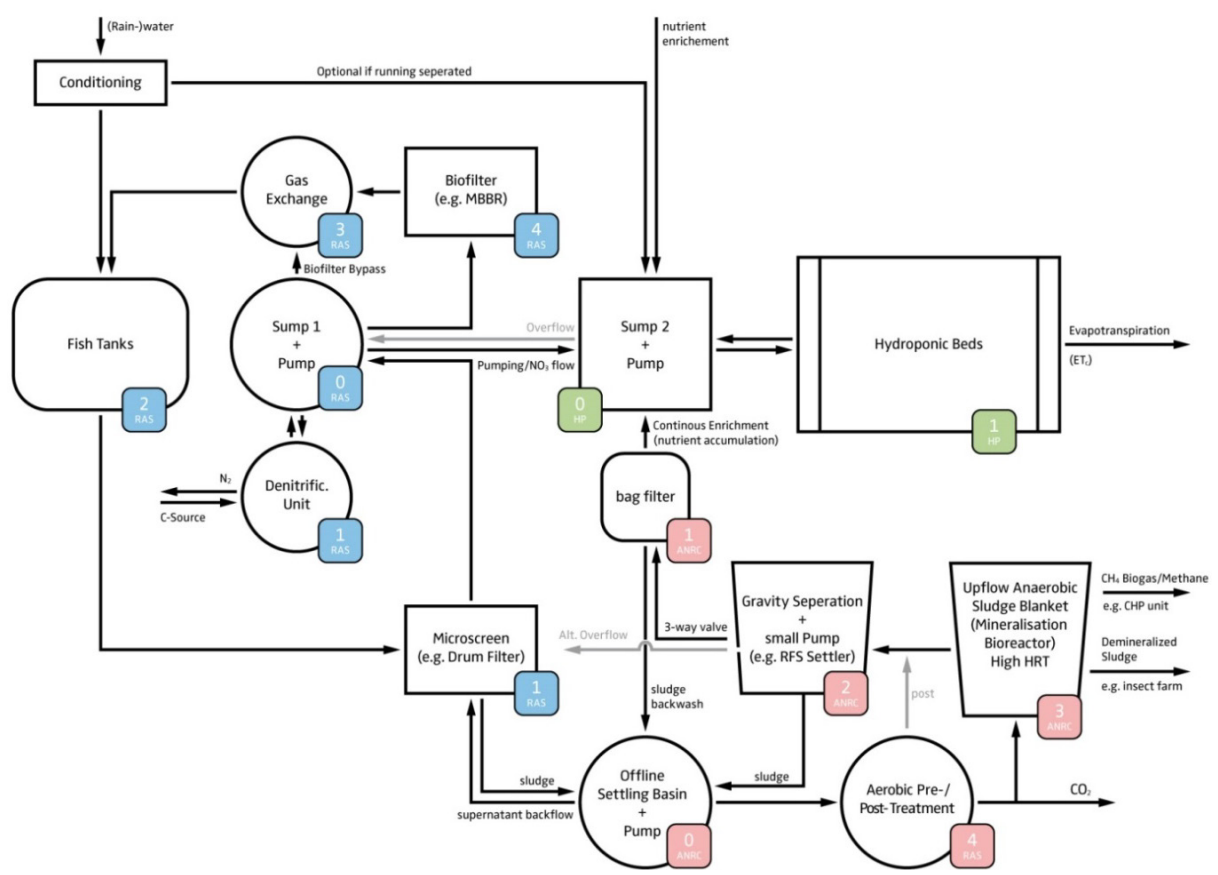

Figure 6.3. Process flow drawing of a basic DAPS layout. The blue tags comprise the RAS component, the green tags the hydroponic component, and the red tags the ANRC components. The level of each component is illustrated numerically in the small box and refers to the vertical direction the flow needs to travel to; whereas high numbers refer to high positioning and low numbers to low positioning. Gravity flow occurs, when water flows from high levels to low levels, and pressurized flow is required when the flow goes from low to high numbers.

\subsubsection{Model Description}

Figures 6.4 and 6.5 show the water flow of traditional RAS and one-loop aquaponic systems. Whereas the outflow in RAS is mainly defined by water discharge rates and sludge removal, the main outflow in one-loop aquaponic systems occurs via evapotranspiration and sludge removal. Figure 6.6 illustrates in what DAPS differ from the other approaches. Although its main water outflow is also defined through evapotranspiration, it reduces water loss by recycling the sludge, whose production can kept stable by maintaining a constant fish biomass (Figure 6.7). It must be noted that, as aquacultural sludges contain $95 \%-97 \%$ of water (Timmons and Ebeling, 2013), the sludge remineralization process also recycles the water back into the hydroponic component (Figure 6.8). Depending on the sizing parameter and/or cultivation area, additional denitrification might be needed in the RAS in case the 
evaporation-dependent water flow to the hydroponic component is not sufficient in order to maintain required nitrate levels in the RAS.

Following the sludge treatment approach (illustrated in Figures 6.8 and 6.9), the nutrient loss drawbacks can be limited. Sludge produced by commercial RAS must undergo treatment before disposal unless centralized waste treatment utilities are available (Van Rijn, 2013). Consequently, the implementation of future-oriented recycling solutions should be considered when designing DAPSs (Figure 6.6).

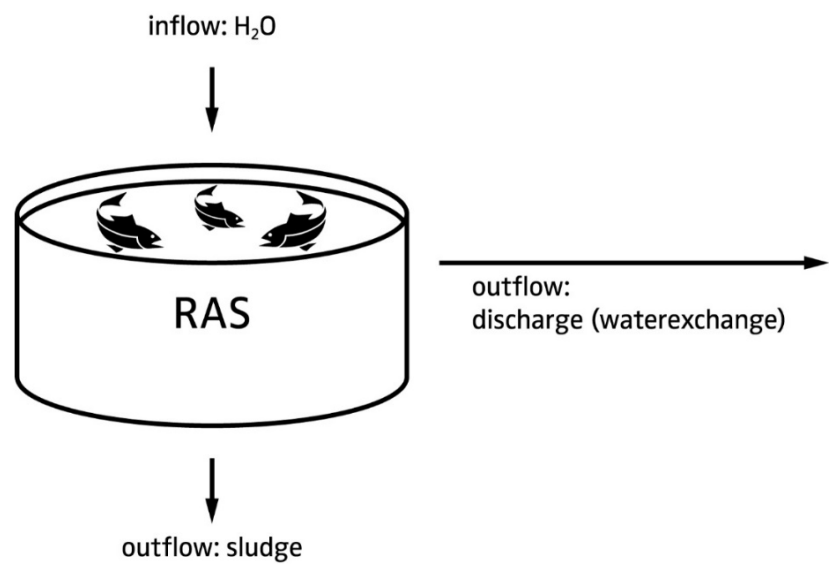

Figure 6.4. Water flow in a RAS system, whereas the tank represents the whole RAS system comprising all parts of a RAS (this is also applicable to the following figures). In terms of sustainability, the water use efficiency presents a drawback of this approach, as water is discharged to maintain an acceptable water quality for the fish. This constitutes a waste of water and nutrient resources as well as nutrient emissions. In addition, the nutrient-rich sludge often is not reused for fertilizing purposes, but instead is discharged to the sewage system. 


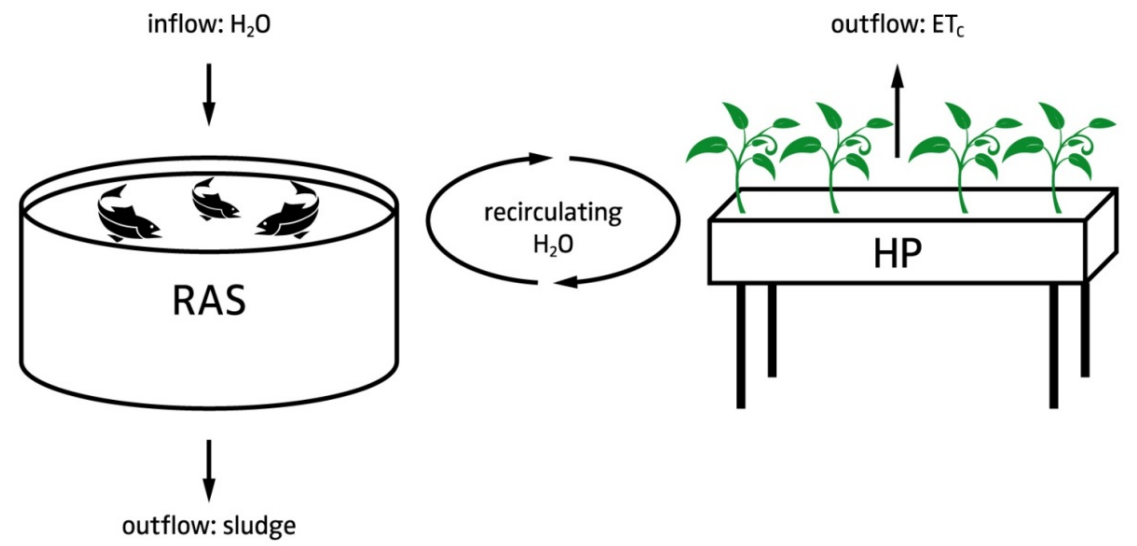

Figure 6.5. Water flow in a one-loop aquaponic system. This system approach provides the basis for aquaponics. Unlike RAS, the nutrient-rich water is not discharged, but instead used for the fertilization of a plant crop. Both components are exposed to similar water conditions. In one-loop systems the water primarily leaves the system via the crop evapotranspiration $\left(\mathrm{ET}_{\mathrm{c}}\right)$ and the sludge. Minor water loss can be seen in the integrated water flow chart in Figure 6.9.

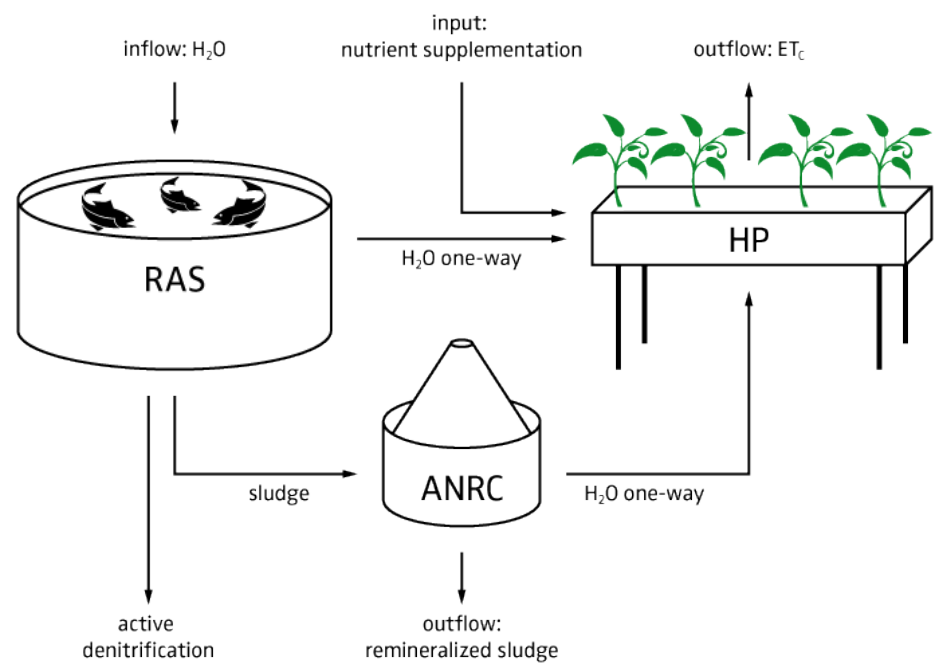

Figure 6.6. Water flow in a DAPS. As the ANRC is expected to remove most of the N, active denitrification might be needed in the RAS to reduce the nitrate concentration. This is especially the case if the water flow to the hydroponic component is not sufficient to keep the RAS water quality at a desired level. The flow chart also shows other amendments to the one-loop aquaponic system approach: (1) an ANRC that remineralizes the sludge and reduces water and fertilizer requirements; 
and (2) manual nutrient supplementation and nutritious ANRC nutrient outflows provide the hydroponic component with optimal nutrient concentrations that do not dilute in the whole system.

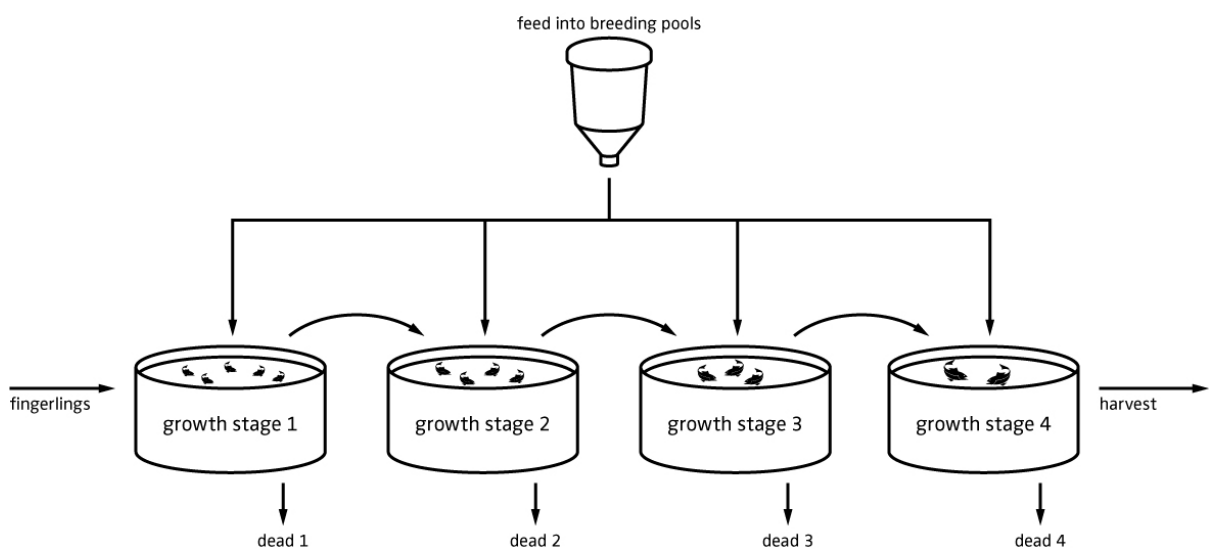

Figure 6.7. Fluctuation of the water composition is closely linked with the system's nutrient input. As the main input in aquaponic systems is fish feed, aquaponic systems should be running with fish of several growth stages to ensure a close to constant uniform feed input to the system. The amount of fish does not change drastically; different fish sizes were used for illustration purposes only.

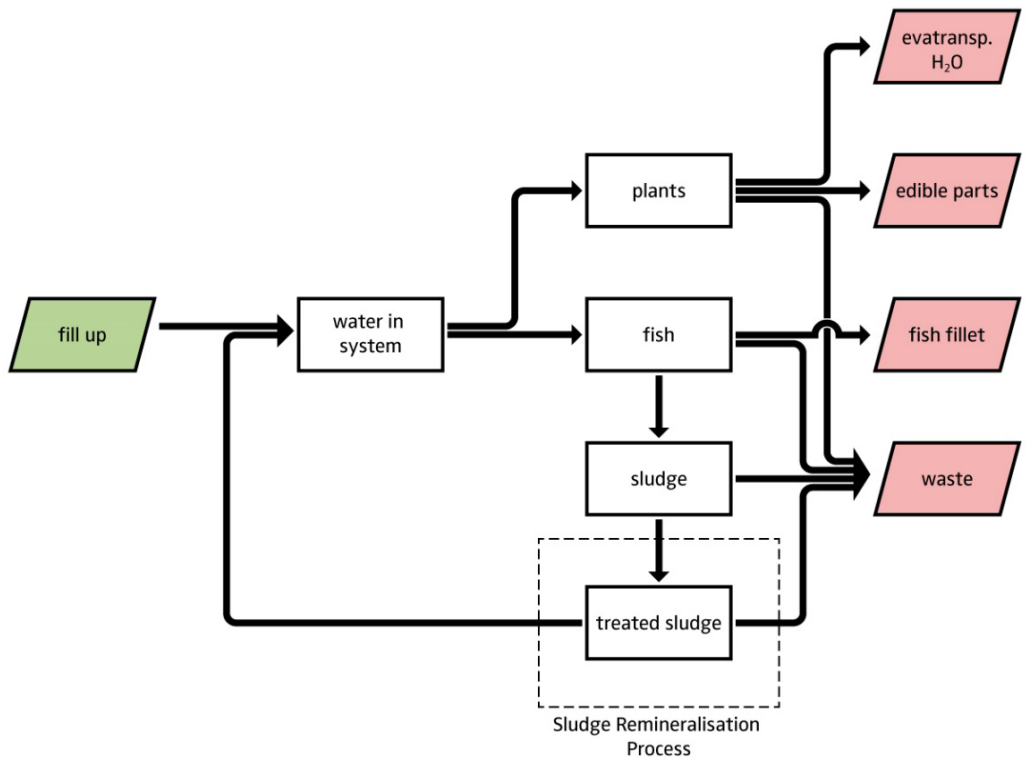

Figure 6.8. The water flow chart shows the water flows within a DAPS system. It can be seen, that the implementation of an ANRC has an impact on the water availability in the system. Even though, the water loss through evapotranspiration outweighs the loss through sludge removal, it is still an important step towards closing the cycle. 


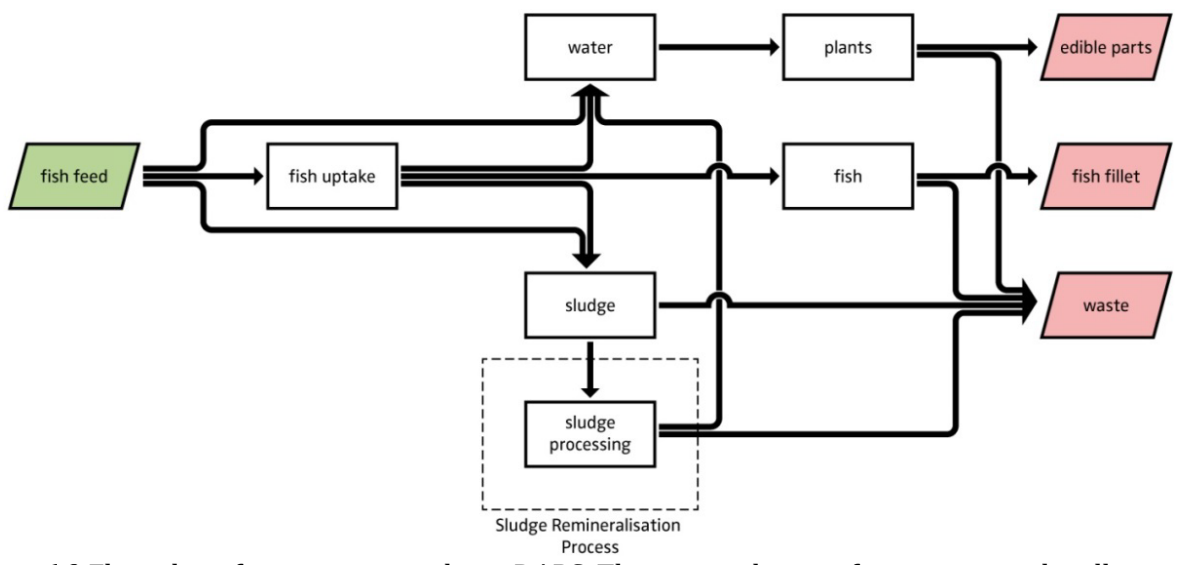

Figure 6.9. Flow chart for nutrients within a DAPS. The accumulation of nutrients can be allocated to edible parts of the plants, edible parts of the fish (i.e., fish fillet) and waste. The dashed line shows the impact of an ANRC on the nutrient flows. Recycled nutrients are added to the hydroponic water and can accumulate in the plant tissues, while fish are not exposed to deleterious nutrient concentrations in the water.

\subsection{Results}

\subsubsection{Fish Biomass Estimates}

The DAPS model outputs are shown in Figures 6.10-6.19. Figure 6.10 presents the output of a parameter variation experiment that was conducted to determine the amount of fish needed to have a maximum fish stocking density of $50 \mathrm{~kg} \cdot \mathrm{m}-3$ per tank. Based on this parameterization the average fish density could be determined (Figure 6.11). Figure 6.11 outlines the advantage of using several fish tanks to avoid sharp fluctuations in fish biomass and thus feed input by use of a standing stock of different size classes. 


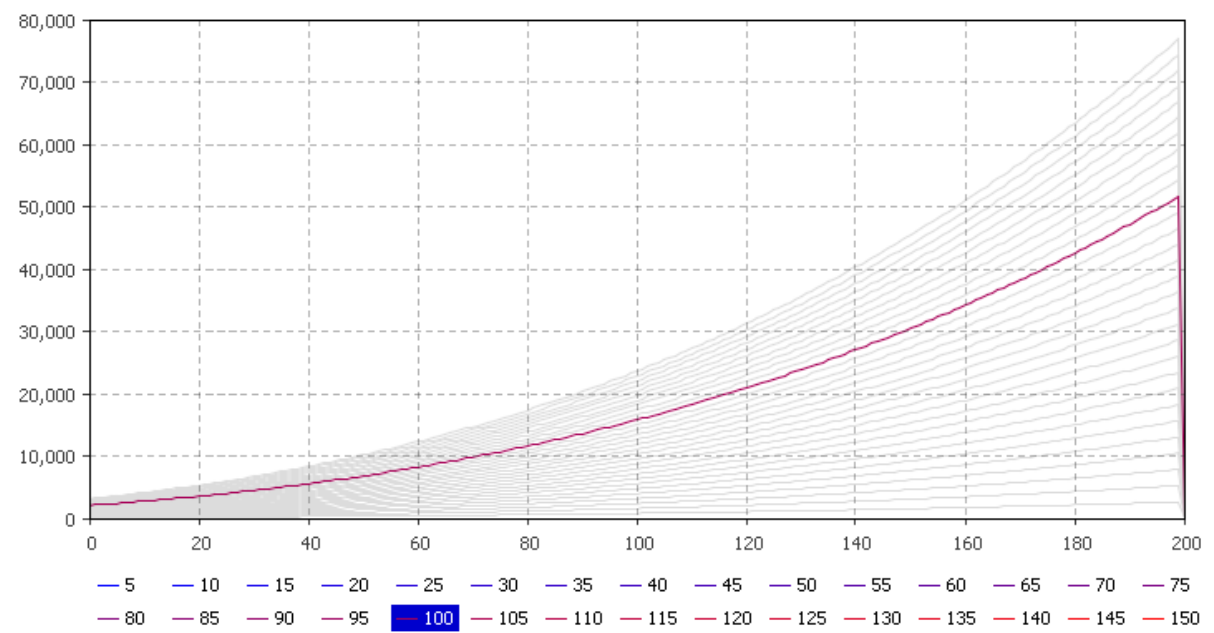

Figure 6.10. Outcome of a parameter variation experiment assessing the amount of required fish to achieve a maximum stocking density ( $y$-axis) of $50 \mathrm{~kg} \cdot \mathrm{m}^{-3}$ per tank. The days are displayed on the $x$ axis. For this simulation, approximately 100 fish were needed to meet that objective.

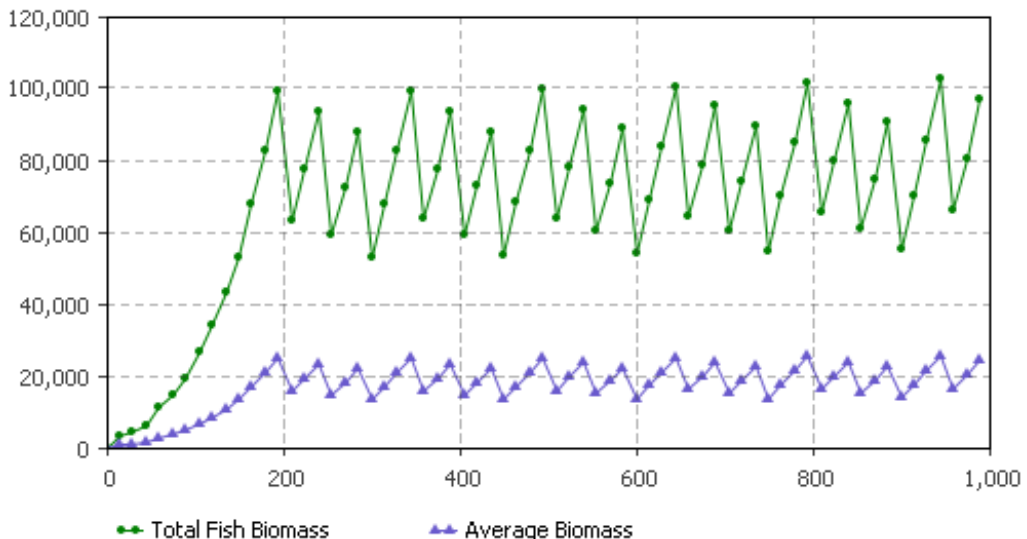

Figure 6.11. Average biomass per fish tank and total fish biomass of all fish tanks (in g; $y$-axis) in the RAS for the first 1000 days ( $x$-axis). Fish biomass peaks every 50 days corresponding to the proposed harvest schedule. 


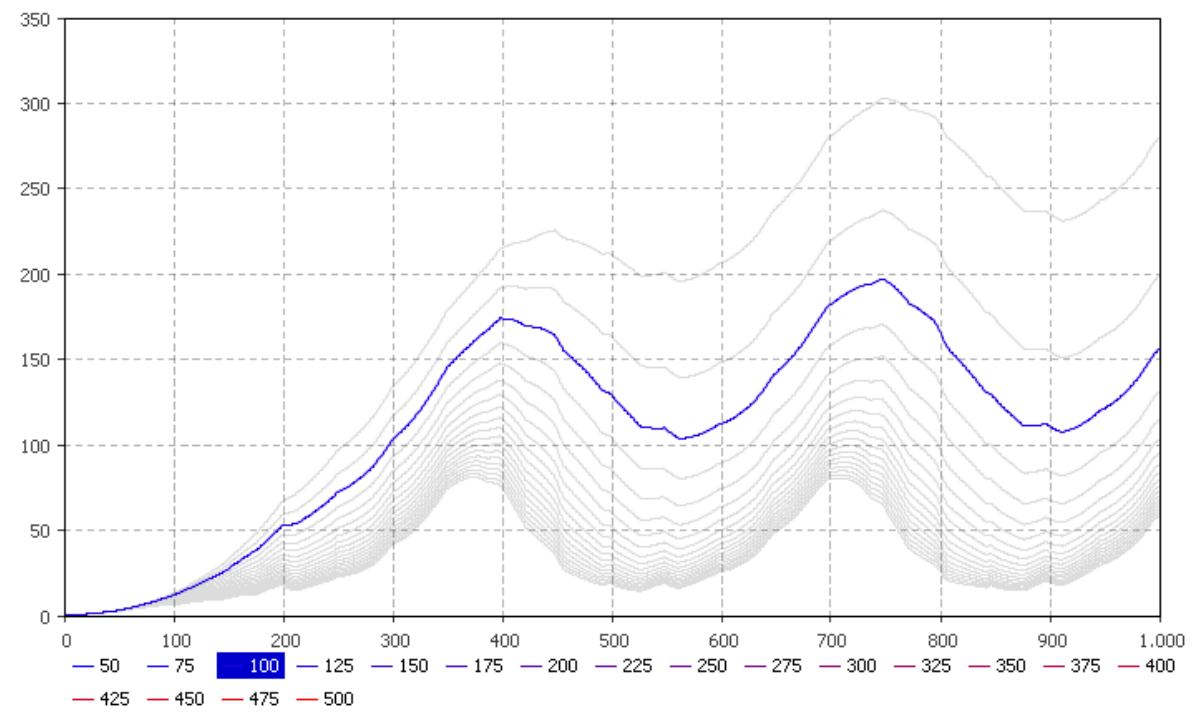

Figure 6.12. Parameter variation experiment estimating the RAS-derived $\mathrm{N}-\mathrm{NO}_{3}$ concentration in $\mathrm{mg} / \mathrm{L}$ ( $y$-axis) based on different cultivation area $\left(\mathrm{m}^{2}\right)$ options under natural light conditions. The days are displayed on the $x$-axis. It can be seen that $200 \mathrm{mg} / \mathrm{L} \mathrm{N}-\mathrm{NO}_{3}$ are not exceeded, when having $100 \mathrm{~m}^{2}$ cultivation area.

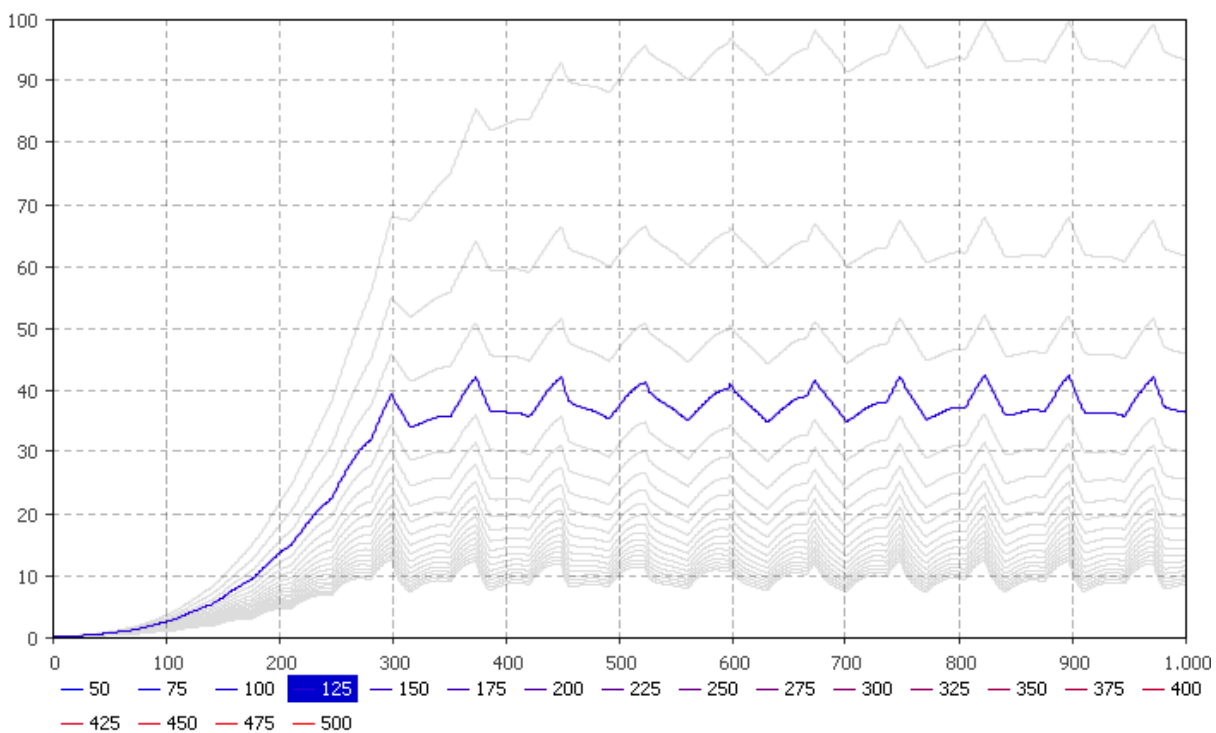

Figure 6.13. Parameter variation experiment for estimated $\mathrm{N}^{-\mathrm{NO}_{3}}$ concentration (in $\mathrm{mg} / \mathrm{L}$ ) when using different cultivation areas (in $\mathrm{m}^{2}$ ) Compared to the exclusive use of natural light, the application of artificial light for industrial production shows a different picture. The $y$-axis shows the RAS N-NO${ }_{3}$ concentration, whereas the $x$-axis displays the days. 


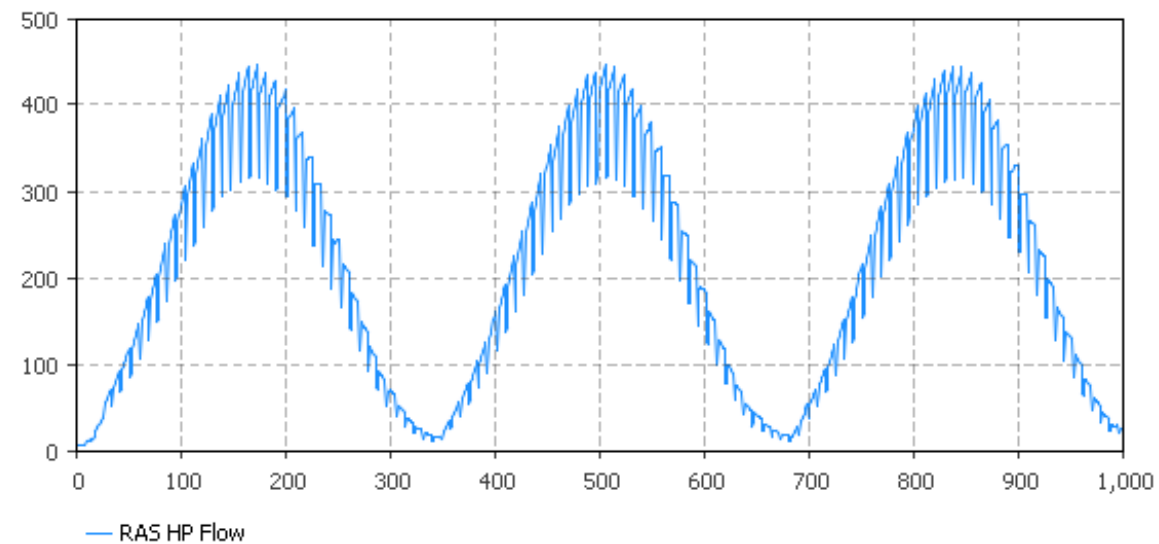

Figure 6.14. The evapotranspiration dependency for the water flow (in L; $y$-axis) from RAS to the hydroponic component can be seen clearly in this figure showing the flow from the RAS to the hydroponic component under natural light conditions. The days are displayed on the $x$-axis.

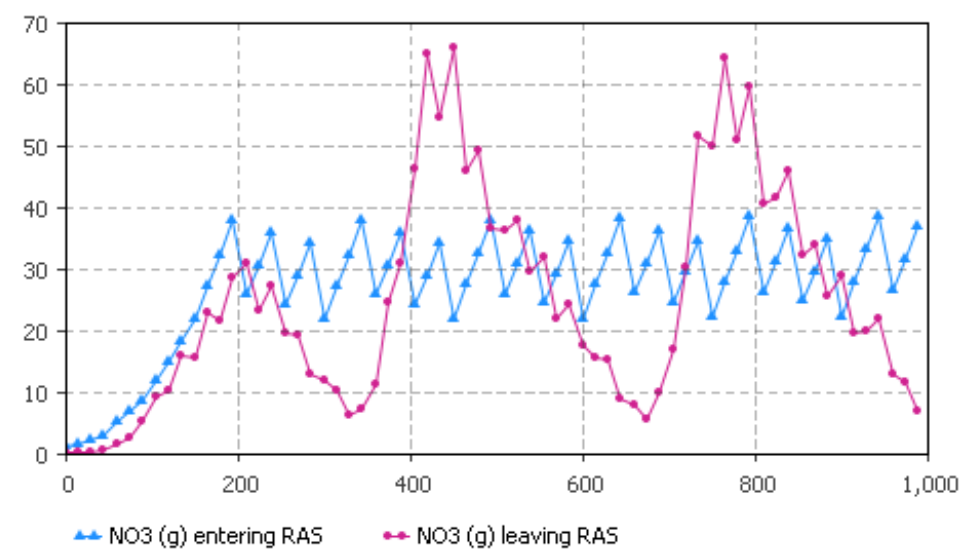

Figure 6.15. Dependent on the evapotranspiration rate (Figure 6.14), different nitrate flows from RAS to the hydroponic component can be observed. The RAS nitrate balance in $\mathrm{mg} \cdot \mathrm{L}^{-1}$ ( $y$-axis) for the first 1000 days ( $x$-axis) can be seen using exclusively natural illumination and a cultivation area of $600 \mathrm{~m}^{2}$. 


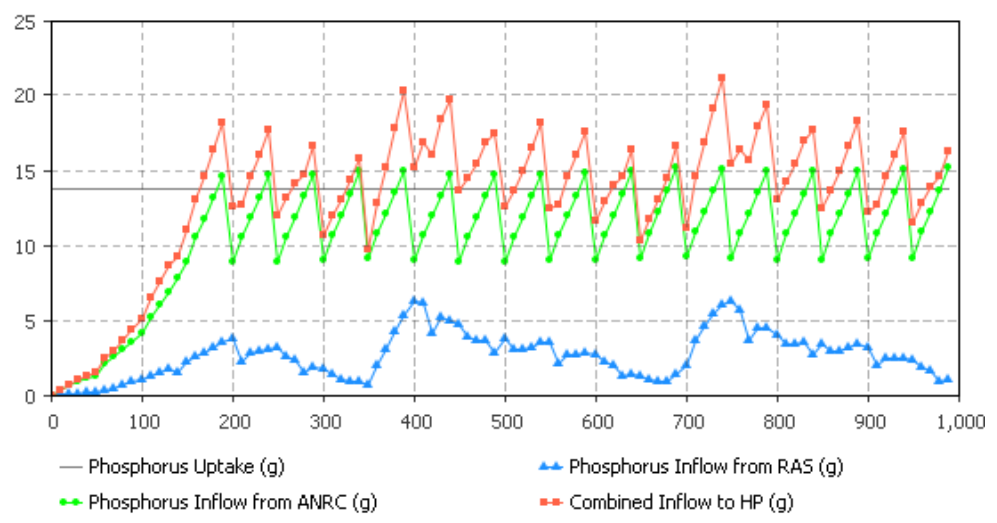

Figure 6.16. $\mathrm{P}$ dynamics in the hydroponic component with a cultivation area of $600 \mathrm{~m}^{2}$. The $\mathrm{P}$ lettuce consumption ( $y$-axis) is assumed being constant, although this is not the case. However, this does not diminish the lettuces $\mathrm{N}$ total uptake. The days are displayed on the $x$-axis.

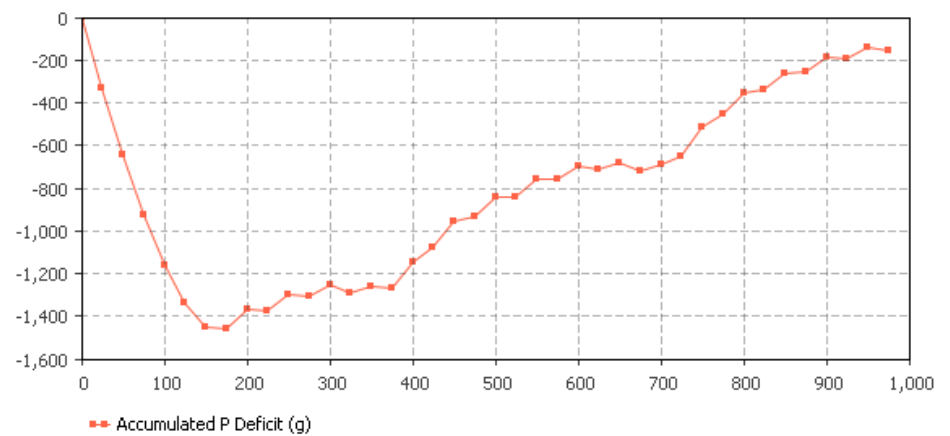

Figure 6.17. Accumulated P ( $y$-axis) deficit in the system's hydroponic component with a cultivation area of $600 \mathrm{~m}^{2}$. After 1000 days ( $x$-axis), the deficit is almost corrected.

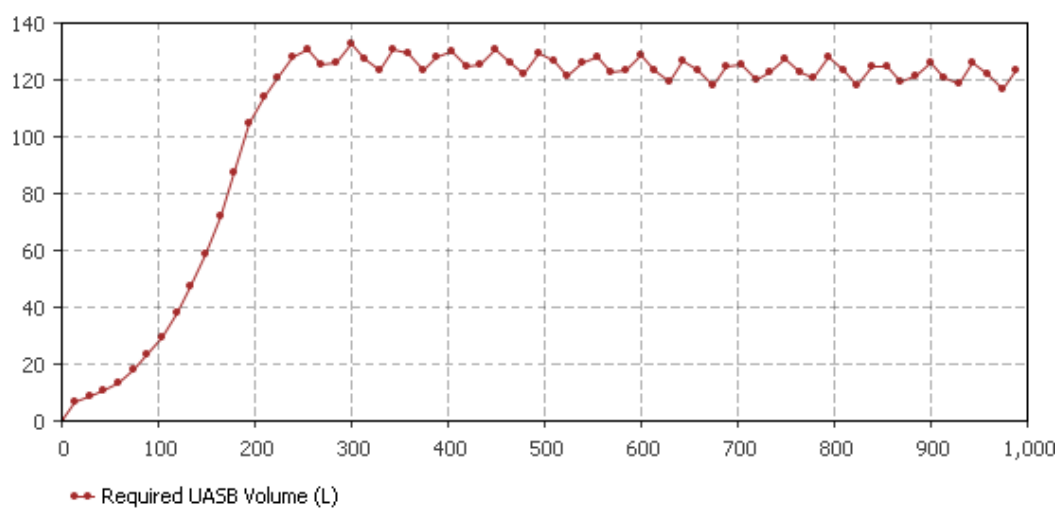


Figure 6.18. The required volume (L) of the UASB is dependent on the inflowing sludge, its SRT, and the HRT. Here, we assume that the sludge blanket covers $60 \%$ of the UASB reactor's volume. Thus, the total filling capacity is around $140 \mathrm{~L}$ and serves as a good indication for sizing the reactor. The days are displayed on the $x$-axis.

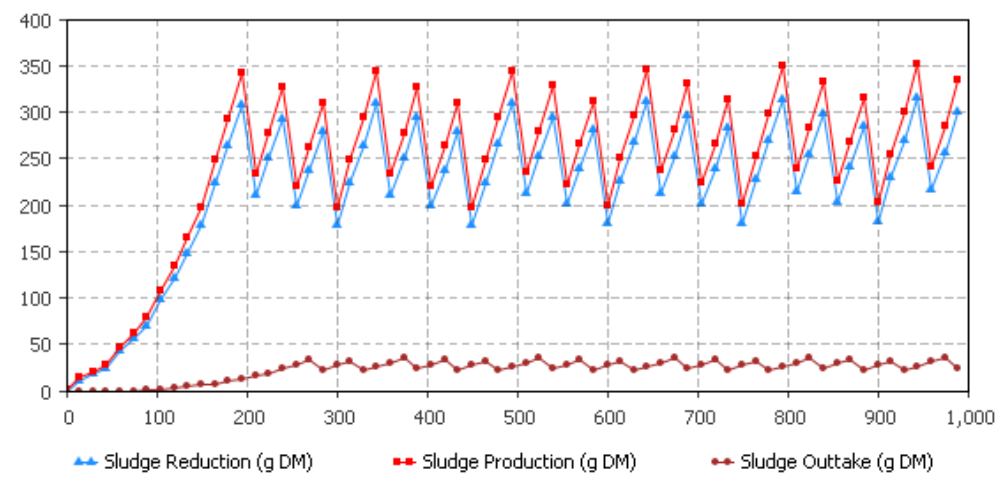

Figure 6.19. Graphical comparison between sludge production, sludge reduction, and sludge outtake assuming a TSS reduction of $90 \%$, a HRT of 10 days, and an SRT of 80 days ( $y$-axis). The days are displayed on the $x$-axis.

\subsubsection{Nitrate Flow Estimates}

As can be seen schematically in Figure 6.6, the flow rate from RAS to the plants is determined by the plant evapotranspiration rate derived from the FAO Penman-Monteith Equation. Unlike in the case of other macronutrients, the remineralization potential for $\mathrm{N}$ is marginal, as almost all of it is denitrified to atmospheric dinitrogen gas due to anaerobic activity in the system. The graphs in Figures 6.12-6.14 show the hydrological flow under natural light conditions, and the associated RAS nitrate balance and the N-NO3 concentration in the RAS depending on different cultivation area sizes in non-illuminated greenhouse environments in Central Europe. For robust fish at rearing densities of approx. $50 \mathrm{~kg} \cdot \mathrm{m}-3,100 \mathrm{~m} 2$ of growth area would be sufficient to maintain acceptable water quality for the fish in a DAPS. The situation is different for more sensitive fish species, for whom these densities are suboptimal such as sturgeon or if bio labels are targeted that usually require lower densities $(10-25 \mathrm{~kg} / \mathrm{m} 3)$. However, using artificial light in industrial DAPS production systems result in a different scenario (Figure 6.13). In this case, a much smaller cultivation area is needed to achieve a sufficient evapotranspiration rate to maintain low and stable N-NO3 values in the RAS system for both robust and sensitive fish species.

\subsubsection{Hydroponics Sizing Based on P Availability}


Figure 6.16 shows the $\mathrm{P}$ dynamics in the hydroponic component with a cultivation area of $600 \mathrm{~m} 2$, when running the model for 1000 days under natural light conditions (growing lettuce as it requires low light intensities allowing for an extended production period). This optimization step determines a sufficient cultivation area based on the P inflow from both RAS and ANRC to the hydroponic component. The nutrient remineralization results in the fact that a much higher amount of plants can be supplied with P; i.e., in this case $600 \mathrm{~m} 2$. At fish biomass saturation (Figure 6.17) the $\mathrm{P}$ availability is expected to correct its deficit. Consequently, when starting the system, $\mathrm{P}$ would have to be added until day 150 . Alternatively, one could cultivate an area that is proportional to the amount of fish tanks that are in use, and adapt it accordingly.

\subsubsection{UASB Sizing Determination}

Figure 6.18 shows the maximum load of the UASB in liters of sludge, whereas Figure 6.19 displays the sludge flow within the UASB. To achieve an upflow of $0.5 \mathrm{~m} \cdot \mathrm{h}-1$ a circulation pump with a sufficient capacity is needed. Sizing a UASB should be treated with caution, as the sludge concentration has a high impact on the volume requirement. For this analysis, a TSS proportion of $3 \%$ was considered. Sludge that is not pre-treated (i.e., pre-concentrated) most likely has a lower TSS proportion and thus requires a higher UASB reactor volume.

\subsection{Discussion}

The main purpose of this study was to elaborate an integrated design approach for DAPS and to spot possible drawbacks based on a system dynamics model that has been developed here. The findings of this theoretical study indicate that the evapotranspiration rate will have a high impact on the RAS water quality in DAPS. This is because the water use in the hydroponic component is the main factor for RAS water replacement (and thus refill with clean water) that regulates water quality (Figures 6.14-6.16). As a consequence of this dependency, determining the evapotranspiration rate of a specific plant species appears to be a crucial step when designing a DAPS. A comparison between natural lighting (Figure 6.12) and artificial greenhouse lighting (that has an impact on the ETc; Figure 6.13) underpins these findings and additionally shows a considerably greater potential for cultivating sensitive fish species (Table 6.3). To what degree artificial lighting pays out needs to be explored in a crop and fish dependent economic assessment. Another option-mainly for RAS focused systems-to regulate the nitrate levels in the RAS is the implementation of a denitrification tank. This conflicts with the general objective of aquaponics that aims at using all available nutrients and, dependent on the carbon source used (e.g., formalin, methanol), raises concerns about the consumer safety. DAPS that follow an even more goal- 
oriented approach by recycling generated sludge, however, should not waste resources unnecessarily. On that score, a hybrid system as illustrated in Figure 6.20 could be a viable alternative for regulating nitrate levels in the RAS. To size the N-regulating hybrid part, Licamele (2009) provides the sizing parameter of $2.5 \mathrm{~kg}$ fish feed for the production of 16 lettuce plants.

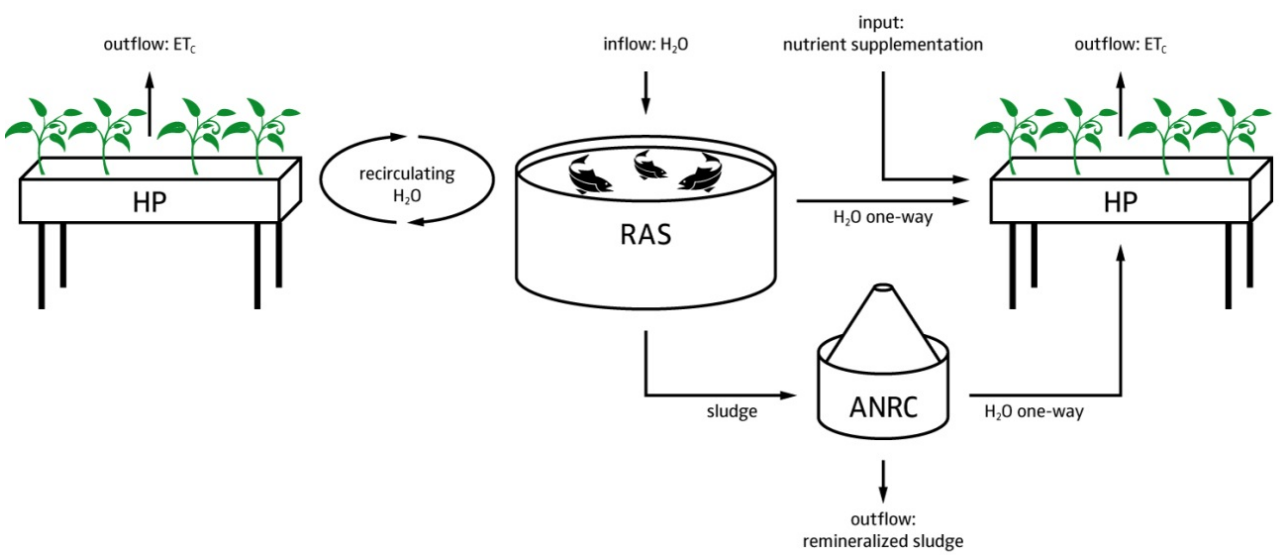

Figure 6.20. The hybrid decoupled system is a combination of the one-loop and the decoupled approach. Whereas the one-loop aquaponic system is regulating the nitrate of the RAS system, the decoupled hydroponic part utilizes the recycled nutrients from the ANRC. Especially for systems that focus on fish production, their advantage is that no denitrification, and thus no waste of nitrate is required.

Sizing the hydroponics cultivation area of a DAPS requires another approach than in a balanced one-loop system. Whereas it is custom to take feed as a sizing factor (i.e. grams of feed per square meter hydroponic cultivation area), in DAPS, it might be more reasonable to size the hydroponic component based on the evapotranspiration potential and other macronutrient availabilities. There are two main reasons: (1) the remineralization capacity of $\mathrm{N}$ is low, whereas it is expected to be high for other macro nutrients; (2) Since nutrient supplementation in DAPS is managed anyway to achieve highly concentrated nutrient solutions, it is more favourable to add $\mathrm{N}$ as it is largely available and cheap. In contrast, $\mathrm{P}$ being a declining and limited resource on earth (Dawson and Hilton, 2011), should be recycled to a high degree and not added from an external source. The result showed that enough $\mathrm{P}$ for lettuce was available to cultivate at least $600 \mathrm{~m}^{2}$ of lettuce with a density of 16 lettuce plants per $\mathrm{m}^{2}$. Taking this as a reference parameter, the graphs of the variation experiments (Figures 6.12 and 6.13) display good water qualities for this cultivation area. With respect to the hybrid 
approach, only the ANRC effluents can be used in order to size the decoupled hydroponic component.

In DAPS, the nutrient and water use efficiency is quite remarkable, as an agricultural irrigation efficiency of $10 \%$ would free up more water than is evaporated off by all other users (Rogers, 2008). The results showed that also in terms of P-recycling this approach is progressive as $P$ for agricultural purposes is a limited fossil resource (Goddek et al., 2015) (i.e., this refers to soil-based agriculture as well as fertilization in hydroponic systems) and P-recycling is crucial to avoid world hunger (Ragnarsdottir et al., 2011; Sverdrup and Ragnarsdottir, 2011). Nevertheless, the sludge remineralization has to be applied with caution. Zekki et al. (1996) reported that nutrient solution recycling could lead to declining harvests in NFT systems. It is suspected that this is most likely due to sulfate ion accumulation in the nutrient solution. However, since it dilutes in the DAPS hydroponic component, it can be expected to be high enough to avoid negative impact on plant growth.

For commercial aquaponic systems, DAPS might provide the best solution on the long run, as running the sub-systems semi-autonomously allows the supplementation of nutrients that are only required by the plant crop separately, in a smaller volume, and without any consequences for the water quality in the RAS. In addition, compared to intensive aquaculture, coupled as well as decoupled approaches can improve the water quality in the fish rearing tanks as accumulation of nitrate is reduced. As reported from commercial scale aquaponic production systems, sublethal effects on growth performance, feed conversion, health, but also reproductive functions may substantially impede harvest yield and profitability when nitrate levels in water exceed species-specific thresholds (Davidson et al., 2014, 2011; van Bussel et al., 2012).

We must, however, remark that this study is of a theoretical kind and needs to be verified. Even though there is sufficient knowledge about the impact of several parameters on RAS, the effect of (long term) accumulation of nutrients on plant growth (and nutrient uptake rates) still remains to be determined. The same applies to the impact of different HRTs on the nutrient remineralization performance. More information about it is needed under different environmental conditions in order to determine the optimal settings for DAPS. Moreover, upscaling effects need to be integrated in the future to add robustness to the model. It is also not clear yet, whether the use of DAPS is economically feasible. Still, we believe that restrictions on nutrient emissions and associated cost of wastewater disposal in the future will most probably be a major driver for aquaponic development. To figure this out, further investigations integrating the economic side are required. 


\subsection{Conclusions}

AnyLogic software and system dynamics analysis constituted a valuable tool to understand the dynamics and design boundaries of DAPS. During the last decades, scientific aquaponics literature was mainly based on one-loop aquaponic systems. However, this approach results from a trade-off between RAS and hydroponics instead of meeting the optimal conditions for the respective sub-systems. Even though there is no empirical data on the productivity of the system's hydroponic component, we conclude that in terms of nutrient and water recycling the system contributes to closing the cycle. The results showed that sizing the system is contingent on the evapotranspiration rate. The higher the evapotranspiration rate, the smaller the required hydroponic cultivation area. The AnyLogic outcome showed that this is particularly relevant when focusing on sensitive fish species. In the long term, this is of great relevance as fertilizer costs are rising with the increasing world population as well as the demand for no-emission systems minimizing environmental impact. Regarding the ANRC, further research is needed with respect to its remineralization performance depending on different HRT and SRT. This and the specific nutrient uptake of plants in a DAPS hydroponic environment are required to substantiate the current DAPS model. In conclusion, it can be said that while technical research in this area is important, additional geographically dependent follow-up studies are needed, dealing with the economically viable size of DAPS as well as the comparison with equivalent hydroponic systems. 
- 


$$
\text { - }
$$

- 


\title{
Chapter 7 The Necessity of Desalination Technology for Designing and Sizing Multi-Loop Aquaponic Systems
}

This chapter is based on:

Goddek, S., Keesman, K. (2017): The Necessity of Desalination Technology for Designing and Sizing Multi-Loop Aquaponic Systems. Submitted.

\begin{abstract}
Providing both fish and plants with optimal environmental conditions is a classical problem in the field of aquaponics. Several studies have tackled this problem by decoupling the two loops. However, in order to achieve both high nutrient levels for the plants and water for the fish that is low in nutrients, aquaculture water needed to be discharged and fertilizer added to the plant units continuously. The present study aimed to explore to what degree desalination technology could be used to provide the necessary balance between the two different requirements. This study followed a theoretical modelling approach using contemporary source material. The principal finding of this research is that desalination processes have the potential to contribute to the nutrient balances in multi-loop aquaponic systems to attain optimal growth conditions for both fish and plants.
\end{abstract}




\subsection{Introduction}

Climate change requires innovative agricultural approaches to food security, particularly in countries facing water scarcity and chronic drought. In this context, aquaponics has been identified as a possible partial solution to tackle sustainable development goals-for eradicating poverty and hunger.

Traditional designs for one-loop aquaponic systems comprise of both aquaculture and hydroponics units between which water recirculates. In such traditional systems, it is necessary to make trade-offs conditions of both subsystems in terms of $\mathrm{pH}$, temperature, nutrient concentrations, etc. (Goddek et al., 2015). Decoupled double-loop aquaponic systems separate the aquaculture and aquaponics units from one another, with inherent advantages for both plants and fish (Karimanzira et al., 2016; Kloas et al., 2015). A decoupled three-loop system as described by Goddek et al. (2016) consists of a recirculating aquaculture system (RAS) loop, a hydroponic (HP) loop, and a remineralization loop. The benefits of a decoupled approach is that environmental conditions of each loop can be adapted to the species-dependent requirements, and by reducing trade-offs, can lead to enhanced growth performance (Delaide et al., 2016b; Goddek and Vermeulen, 2017; Saha et al., 2016).

Several studies have previously suggested a rule of thumb for general nutrient demands of plants within one-loop aquaponic systems, such that leafy plants (e.g. lettuce, spinach, basil) require between 20-50g fish feed per $\mathrm{m}^{2}$ cultivation area, and fruity plants (e.g. tomatoes, bell pepper, eggplants) require between $50-80 \mathrm{~g}$ fish feed per $\mathrm{m}^{2}$ (Y S Al-Hafedh et al., 2008; Endut et al., 2010; FAO, 2014; Licamele, 2009a). However, none of these studies have examined scale with respect to the total nutrient demands of the plants. The system dynamics model presented by Goddek et al. (2016a) showed that decoupled three-loop aquaponic systems are evapotranspiration-dependent and that a remineralization-loop can improve sustainability performance. In a unidirectional flow approach, the macro- and micro-nutrient concentration in the RAS loop is automatically consistently higher than in the hydroponic component (i.e. without additional fertilizer inputs). As shown in Table 7.1, the converse should be true. Moreover, this cannot be altered by the fact that the remineralization loop supplies the hydroponic component with additional nutrients. In short, decoupled approaches require a significant amount of additional fertilizer or nutrient manipulation in order to meet the optimal growth parameters.

Table 7.1. Optimal environmental factors for cold and warm water fish species, as well as leafy (lettuce) and fruity (tomato) vegetables. It should be noted that ammonium $\left(\mathrm{NH}_{4}\right)$ 
levels are not taken into account here, even though there is evidence that the presence of $\mathrm{NH}_{4}$ stimulates $\mathrm{NO}_{3}$ uptake (Jones, 2005). Note that preferred hydroponic $\mathrm{NH}_{4}$ levels are lethal for all fish species.

\begin{tabular}{|c|c|c|c|c|}
\hline Sub-System & Species/Type & $p H$ & Temperature $\left({ }^{\circ} \mathrm{C}\right)$ & Nitrate $\left(\mathrm{NO}_{3}\right)(\mathrm{mg} / \mathrm{L})$ \\
\hline \multirow[t]{2}{*}{ RAS } & $\begin{array}{l}\text { Oreochromis } \\
\text { niloticus (Nile tilapia) }\end{array}$ & $\begin{array}{l}7-9 \text { (Ross, } \\
2000)\end{array}$ & $\begin{array}{l}\text { 27-30 (El-Sayed, } \\
\text { 2006) }\end{array}$ & $\begin{array}{l}<100-200 \text { (Dalsgaard } \\
\text { et al., 2013) }\end{array}$ \\
\hline & $\begin{array}{l}\text { Oncorhynchus mykiss } \\
\text { (Rainbow trout) }\end{array}$ & $\begin{array}{l}6.5-8.5 \\
\text { (FAO, } \\
2005 b)\end{array}$ & $\begin{array}{l}15 \text { (Coghlan and } \\
\text { Ringler, 2005) }\end{array}$ & $\begin{array}{l}<40 \text { (Davidson et al., } \\
\text { 2011; Schrader et al., } \\
\text { 2013) }\end{array}$ \\
\hline \multirow[t]{2}{*}{ Hydroponics } & $\begin{array}{l}\text { Lactuca sativa } \\
\text { (Lettuce) }\end{array}$ & $\begin{array}{l}5.5-6.5 \\
\text { (Resh, } \\
2012)\end{array}$ & $\begin{array}{l}\text { 21-25 (Resh, } \\
2012)\end{array}$ & $730($ Resh, 2012) \\
\hline & $\begin{array}{l}\text { Lycopersicon } \\
\text { esculentum (Tomato) }\end{array}$ & $\begin{array}{l}6.3-6.5 \\
\text { (Resh, } \\
2002)\end{array}$ & $\begin{array}{l}\text { 18-24 (Resh, } \\
2002)\end{array}$ & $\begin{array}{l}666 \text { (Sonneveld and } \\
\text { Voogt, 2009c) }\end{array}$ \\
\hline
\end{tabular}

One possible solution to this conundrum would be to increase nutrient concentration in the hydroponic loop, while ensuring RAS water conditions meet specific species requirements. Desalination technologies have the potential to separate dissolved salts and other minerals from water (Shahzad et al., 2017; Subramani and Jacangelo, 2015). In the context of aquaponics, and as an alternative to additional fertilization with corresponding extra costs, desalination technology could not only provide fresh water to the system, but also ensure desired nutrient concentrations for the food producing sub-systems.

The objective of this study is to demonstrate how implementation of desalination processes could solve specific technical problems within current decoupled aquaponics systems by increasing the nutrient concentration within the hydroponic loop, while ensuring preferable nutrient-poor conditions for the fish. As such, we model the potential implementation of desalination technologies (i.e. as a fourth loop added to the three-loop aquaponic system; Goddek et al. (2016b)), following a numerical approach. In this computer-aided design study, we use experimental parameter values and historical weather data from Namibia.

\subsection{Methodology}

\subsubsection{Dynamic Systems Analysis}

The AnyLogic model used in this study for system design analysis is based on the model elaborated by Goddek et al. (2016a). The dynamic systems analysis focused on the 
evaluation of $\mathrm{N}$-balances within multi-loop aquaponic systems following the feed per square meter rule of thumb. $\mathrm{N}$-balances were evaluated in the presence and absence of desalination technology. Figure 7.1 shows a flow chart of a multi-loop system incorporating a decoupled four-loop aquaponic system consisting of: (1) a RAS loop; (2) a hydroponic loop; (3) a remineralization loop; and (4) a desalination (i.e. nutrient concentration) loop.

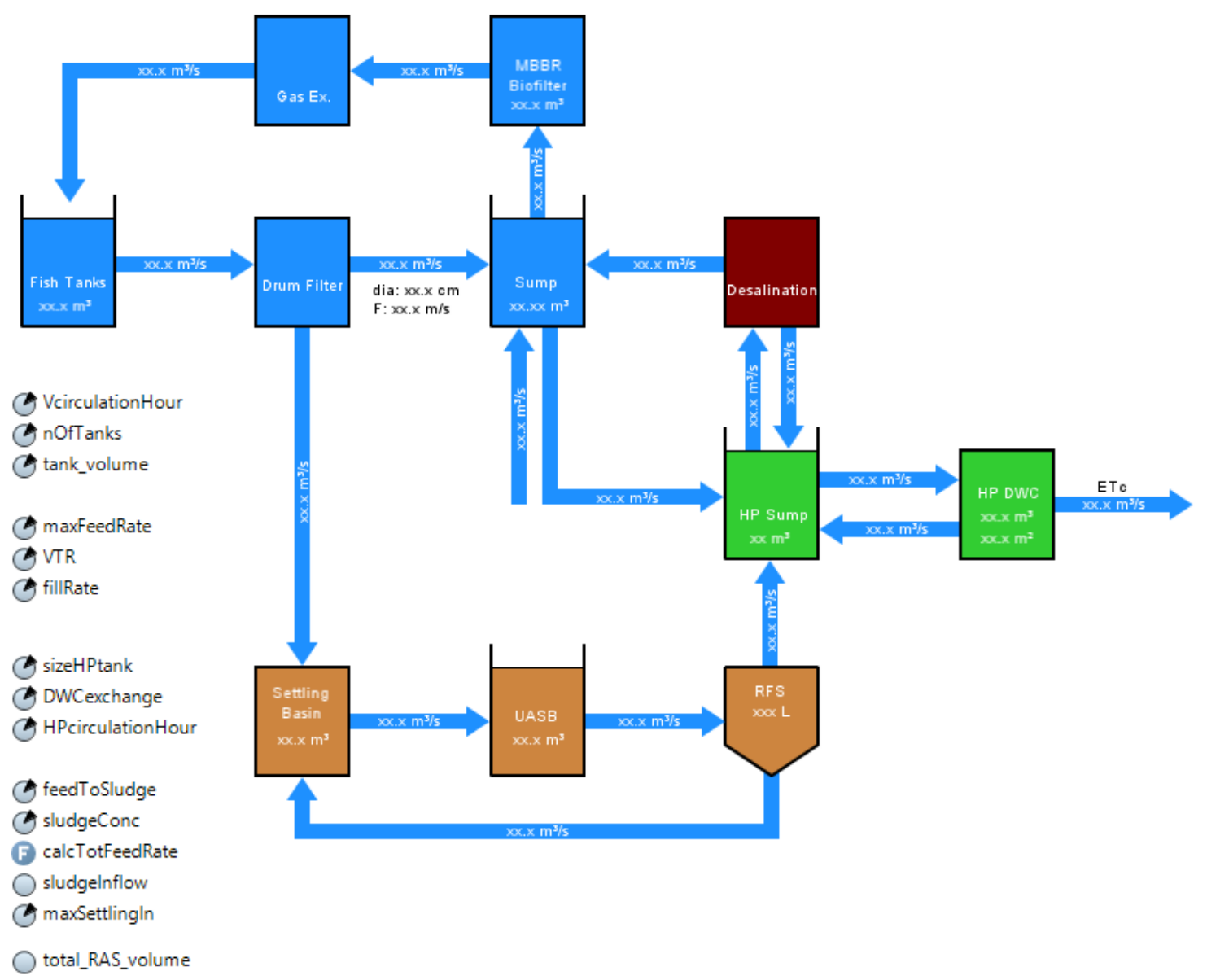

Figure 7.1. Water flow scheme of the multi-loop aquaponic system as proposed in this study using AnyLogic system modeling software; where the blue boxes represent the RAS system, green boxes the hydroponic system, hazel boxes the remineralization loop, and the dark brown box the desalination plant. Water from the hydroponics sump is being concentrated in the desalination plant resulting in two separated flows: (1) demineralized water to the RAS, and (2) concentrated nutrient solution (i.e. brine) flowing back to the hydroponic loop. 
The model was initially developed to estimate the desired scale of the hydroponic component for lettuce crops following a one-loop approach. Based on the output, the impact on the nitrate $\left(\mathrm{NO}_{3}\right)$ mass balance can be shown for a decoupling of the RAS and hydroponic subsystems. An optimization experiment was subsequently performed in order to determine the required flow capacity of the desalination unit.

\subsubsection{Input Data and Parametrization}

\subsubsection{Recirculating Aquaculture System}

The modelled RAS with corresponding parameter values remained the same as in the publication of Goddek et al. (2016a). The parameters that were used for the fish species (Tilapia) can be seen in Table 7.2. Fish feed is time varying and depends on the total fish biomass and fish growth stages. Thus we only consider the protein content as a parameter.

Table 7.2. RAS system parameters for cultivating Tilapia (per the model).

\begin{tabular}{|l|l|l|}
\hline Parameter & Unit & Value \\
\hline Water temperature & ${ }^{\circ} \mathrm{C}$ & 29.5 \\
\hline Amount of fish per fish tank & - & 83 \\
\hline Amount of fish tanks & - & 4 \\
\hline Volume per fish tank & $\mathrm{m}^{3}$ & 1 \\
\hline Total RAS system volume & $\mathrm{m}^{3}$ & 5.1 \\
\hline Fingerling size & $\mathrm{m}$ & 0.1 \\
\hline Harvest weight & $\mathrm{kg}$ & 0.6 \\
\hline Feed protein content & $\%$ & 35 \\
\hline
\end{tabular}

\subsubsection{Hydroponic System}

The data for the $\mathrm{N}$-uptake of lettuce was adjusted for this model. Data from a recent experiment on plant growth rates in a multi-loop aquaponic system (Goddek \& Vermeulen 2017) was used to derive the nitrate uptake of the lettuce (Table 7.3). The uptake observations were consistent with the ones reported by Castro et al. (2009) and Mathieu et al. (2006).

Table 7.3. Hydroponic system parameters for growing lettuce as used in the model.

\begin{tabular}{|l|l|l|}
\hline Parameter & Unit & Value \\
\hline $\begin{array}{l}\text { Required amount of feed for per lettuce cultivation } \\
\text { area (rule of thumb) }\end{array}$ & $\mathrm{g} / \mathrm{m}^{2}$ & 40 \\
\hline Amount of lettuce per $\mathrm{m}^{2}$ & - & 36 \\
\hline Cultivation area (based on model outcome) & $\mathrm{m}^{2}$ & 28 \\
\hline Total deep water culture (DWC) volume & $\mathrm{m}^{3}$ & 9.4 \\
\hline Starting nitrate value & $\mathrm{ppm}$ & 730 \\
\hline
\end{tabular}


Observed nitrogen leaf concentration at the end of the experiment

$\mathrm{mmol} \mathrm{kg}{ }^{-1} \mathrm{dm}^{-1}$

3910

The formula for sizing one-loop aquaponic systems according to given rule of thumb is:

$$
A=\frac{F_{i n}}{x}
$$

where $A$ is the required cultivation area for the amount of fish feed added to the system; $F_{\text {in }}$ is the amount of fish feed added to the RAS, and $x$ is the overall amount of fish feed (in $\mathrm{g}$ ) required per square meter of cultivation area.

The transmittance of polyester film greenhouses is estimated at approximately $80 \%$. The reference evapotranspiration rate has been calculated for Walvis Bay (Namibia), by applying the FAO Penman-Monteith Equation (Table 7.4). This location was selected based on our current efforts to implement multi-loop aquaponic systems in that region (Goddek and Keesman, 2017).

Table 7.4. Weather data from Walvis Bay and the corresponding greenhouse radiation as well as the reference evapotranspiration rate per month.

\begin{tabular}{|c|c|c|c|c|c|c|}
\hline Month & $R_{s}{ }^{1}$ & Max Temp ${ }^{2}$ & Min Temp ${ }^{2}$ & Dew Point ${ }^{2}$ & Humidity $^{2}$ & $E T o$ (inside) \\
\hline & $M J / m^{2} / d$ & ${ }^{\circ} \mathrm{C}$ & ${ }^{\circ} \mathrm{C}$ & ${ }^{\circ} \mathrm{C}$ & $\%$ & $\mathrm{~mm} / \mathrm{d}$ \\
\hline January & 25.58 & 26 & 17 & 15 & 72 & 6.25 \\
\hline February & 23.43 & 27 & 17 & 15 & 71 & 5.73 \\
\hline March & 21.50 & 29 & 16 & 15 & 69 & 5.26 \\
\hline April & 19.30 & 30 & 14 & 12 & 65 & 4.73 \\
\hline May & 17.40 & 28 & 12 & 9 & 60 & 4.27 \\
\hline June & 16.35 & 26 & 10 & 5 & 55 & 4.02 \\
\hline July & 16.42 & 26 & 10 & 5 & 54 & 4.03 \\
\hline August & 18.95 & 23 & 8 & 7 & 67 & 4.65 \\
\hline September & 21.70 & 23 & 10 & 10 & 72 & 5.32 \\
\hline October & 24.96 & 24 & 11 & 11 & 71 & 6.11 \\
\hline
\end{tabular}




\begin{tabular}{|l|l|l|l|l|l|l|}
\hline November & 25.78 & 25 & 13 & 12 & 70 & 6.31 \\
\hline December & 26.03 & 26 & 15 & 13 & 70 & 6.37 \\
\hline
\end{tabular}

${ }^{1}$ solar radiation data (Nott and Savage, 1984); ${ }^{2}$ data derived from timeanddate.com.

The size of the hydroponic part of the system is determined by the amount of nutrients put into the system (i.e. in form of fish feed to the RAS). For instance, when remineralizing (i.e. making nutrients available for the plants) aquaculture sludge more nutrients would be available for the plants, which again has an impact on the corresponding hydroponic system size. In this publication, the remineralization loop plays a subordinate role. However, this type of model can demonstrate to what degree the implementation of a third loop, in addition to the RAS and hydroponic loops, can impact the required scale of hydroponic cultivation area. For these calculations, it was assumed that 55\% of the nutrient input (via fish feed) ends up in sludge (Neto and Ostrensky, 2013; Yavuzcan Yildiz et al., 2017), and that the remineralization potential of an upflow anaerobic sludge blanket (UASB) reactor is approximately 90\% (Mirzoyan and Gross, 2013).

Thus the proportion of fish sludge that is discharged from the RAS to the remineralization unit can be stated as follows:

$$
Q_{s}=1-\alpha-\beta
$$

where $\alpha$ is the proportion of the nutrients that are directly available for the plants, and $\beta$ is the amount of feed remaining in the RAS. Hence, for a one-loop aquaponic system with $\alpha=$ 1 - $\beta$, while explicitly taking into account losses,

$$
A_{0}=\frac{\alpha F_{\text {in }}}{x}=\alpha A
$$

The formula for sizing three-loop aquaponic systems is consequently:

$$
A_{1}=\alpha A+\eta \cdot Q_{s} \cdot A
$$

where $A_{1}$ is the required cultivation area for the amount of fish feed added to the RAS in a three-loop system that include a nutrient recycling unit; $Q_{s}$ is the proportion of the feed input ending up as aquaculture waste sludge, $\eta$ is the sludge remineralization efficiency, and $x$, as shown in (1) is the overall amount of fish feed (in $\mathrm{g}$ ) required per square meter of cultivation area. 


\subsubsection{Desalination Unit}

The purpose of the small-scale desalination plant is to concentrate the hydroponic nutrient solution and to direct demineralized water to the RAS part of the system. We can assume that $40 \%$ of the flow to the desalination unit is remineralized and can be reused within the RAS. A parameter optimization experiment allowed for determination of the optimal feed flow to keep the RAS nitrate levels just below 50ppm.

\subsection{Results}

The outcome of the sizing simulation with this model, and with $\alpha=0.45, \beta=0, \eta=0$, suggests a cultivation area of $28 \mathrm{~m}^{2}$ (if $\frac{F_{\text {in }}}{x}=A$ ) for leafy greens (i.e. the average of the leafy plants cultivation area requirement after the startup of the system). When remineralizing the fish sludge, Figure 7.2 shows that the system provides enough nutrients for twice the cultivation area.

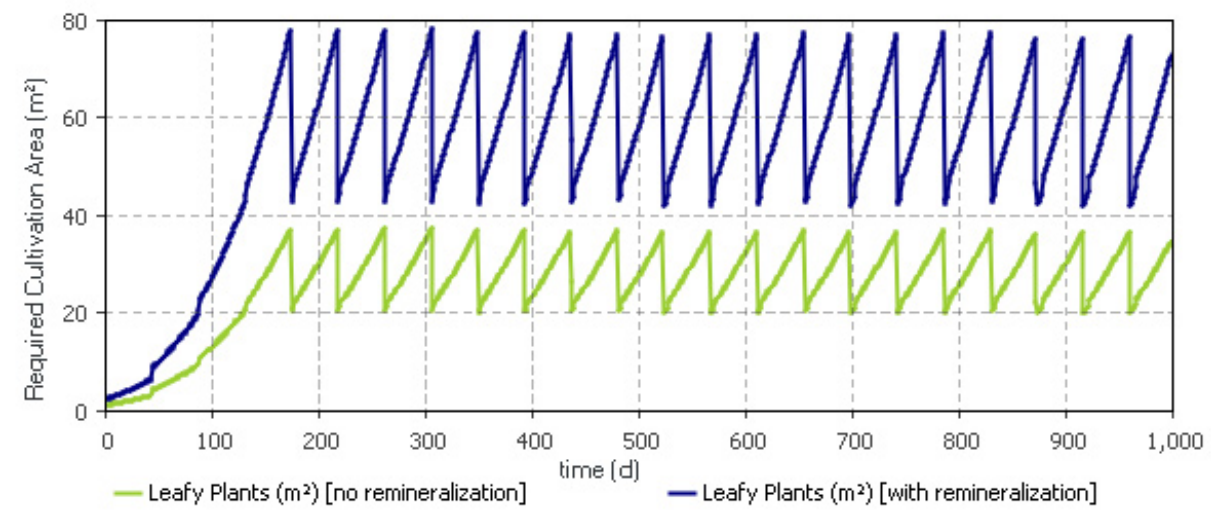

Figure 7.2. Formula 1 is linked to the average feed input in a RAS system. Based on the sizing rule of thumb, approximately $28 \mathrm{~m}^{2}$ can be cultivated in one-loop systems without remineralization, and 60 $\mathrm{m}^{2}$ in one- or multi-loop aquaponic systems with remineralization units (for $\alpha=0.45, \beta=0, \eta=$ $0.90)$.

Based on these findings, the cultivation area has been set to $28 \mathrm{~m}^{2}$; thus the remineralization loop was not needed to proof the necessity of an additional desalination loops for decoupled multi-loop aquaponic systems. This is because the remineralization loop as shown in Figure 7.1 provides the nutrients made available to the hydroponics loop unidirectionally, and correspondingly they do not increase the nutrient concentration in the RAS part of the system. Figure 7.3 and 7.4 show the nitrate concentrations of decoupled systems without and with an additional desalination unit, respectively. 


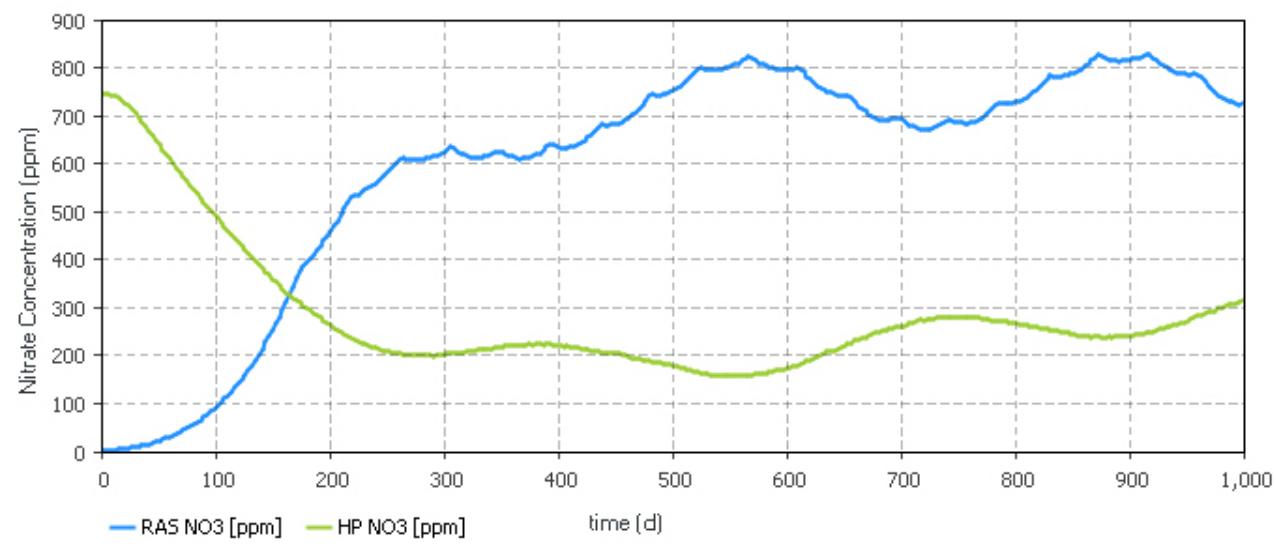

Figure 7.3. This graph shows what happens when the RAS and hydroponic systems are decoupled. The flow from RAS to hydroponics is now totally dependent on the crop specific evapotranspiration rate (Table 4). The starting position an optimal nitrate concentration for the lettuce. Even though Namibia has one of the highest average solar radiation levels in the world, the nitrate levels in the RAS are still suboptimal levels for the reared tilapia.

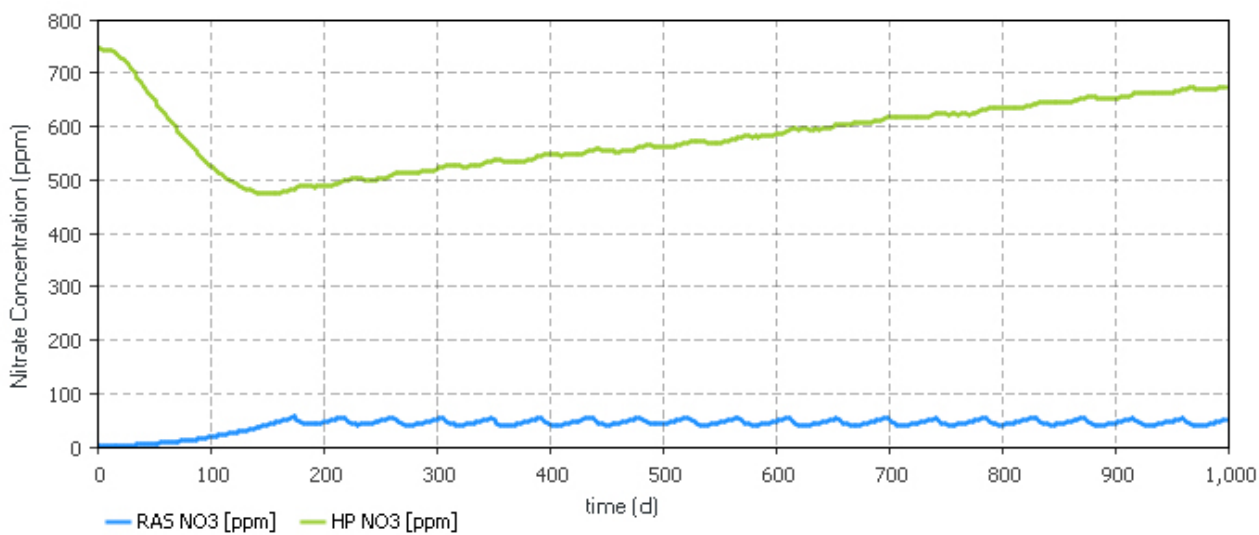

Figure 7.4. The parameter optimization experiment suggested a feed flow of $70 \mathrm{~L} \mathrm{~h}^{-1}$ to the desalination unit. This figure shows that the RAS nitrate concentration is just below $60 \mathrm{ppm}$, while the hydroponic nitrate concentration is at least higher than approx. $500 \mathrm{ppm}$.

\subsection{Discussion}

The design development of multi-loop aquaponics systems has been advanced rapidly, primarily because of the potential of such systems to achieve higher yields while also reducing nutrient and water inputs. Unfortunately, optimal nutrient concentration levels cannot be achieved directly because of oversizing the hydroponic cultivation area to 
guarantee a sufficient water flow from the RAS to the hydroponics system in order to keep the RAS nutrient concentration at an optimal level. Consequently, nutrients for the hydroponic sub-system have to be added in form of artificial fertilizers. From an economical point of view, this means higher operational costs due to additional fertilization requirements.

Table 7.5 provides an overview of existing decoupled aquaponic systems in Europe. The schematic layouts of the respective systems and our proposed design can be found in Appendix A. In this appendix, it can be seen that only the commercial system of NerBreen contains an additional loop in order to both remineralize sludge as well as regulate the nutrient concentrations of the aquaculture and hydroponic subsystems. Their approach (A.2) is different to ours (A.1; Figure 7.1), since in their case the hydroponic and RAS nutrient concentrations are not directly regulated. Instead, the treated sludge is further concentrated to increase the nutrient concentration in the hydroponics, and increase water quality in the RAS. The research systems shown in Table 7.5 as well as A.3-A.5 decoupled their loops while discharging nutrient-rich sludge. It can be seen that without the implementation of on-site sludge treatment as well as the integration of nutrient concentrating technologies, high amounts of additional fertilization for the hydroponics and discharge of RAS-water are required.

Table 7.5. An overview of existing decoupled aquaponic systems in Europe.

\begin{tabular}{|c|c|c|c|c|c|}
\hline Parameter & Unit & NerBreen & Tilamur & IGB Berlin & Inagro \\
\hline Country & 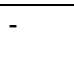 & $\begin{array}{l}\text { Basque } \\
\text { Country, Spain }\end{array}$ & Spain & Germany & Belgium \\
\hline Purpose & - & Commercial & Research & Research & Research \\
\hline Fish Species & - & Nile Tilapia & Nile Tilapia & Nile Tilapia & Pike perch \\
\hline Plant Species & - & $\begin{array}{l}\text { Season } \\
\text { dependent: } \\
\text { Tomato, } \\
\text { pepper, fresh } \\
\text { garlic, } \\
\text { strawberry, } \\
\text { herbs, lettuce }\end{array}$ & Tomato & Tomato & Tomato \\
\hline Total RAS size & $\mathrm{m}^{3}$ & 300 & 45 & 16.5 & 160 \\
\hline Total HP size & $\mathrm{m}^{2}$ & 3500 & 400 & 6.5 & 340 \\
\hline Total HP size & $\mathrm{m}^{3}$ & 100 & 3 & 0.6 & $\mathrm{n} / \mathrm{a}$ \\
\hline HP type & - & $\begin{array}{l}\text { 1/3 RAFT; } \\
\text { 2/3 drip } \\
\text { irrigation }\end{array}$ & $\begin{array}{l}\text { NFT/Rockwoo } \\
\text { l (drip } \\
\text { irrigation) }\end{array}$ & NFT & drip irrigation \\
\hline Amount of Loops & - & $\begin{array}{l}4 \text { (RAS, HP, } \\
\text { vermiculture, }\end{array}$ & 2 (RAS, HP) & 2 (RAS, HP) & $\begin{array}{l}3 \text { (RAS, HP, } \\
\text { sludge }\end{array}$ \\
\hline
\end{tabular}




\begin{tabular}{|l|l|l|l|l|l|}
\hline & & $\begin{array}{l}\text { nutrient } \\
\text { concentrator) }\end{array}$ & 7 & & $\begin{array}{l}\text { removal to } \\
\text { biogas) }\end{array}$ \\
\hline $\begin{array}{l}\text { RAS water } \\
\text { discharge (incl. } \\
\text { sludge) }\end{array}$ & $\%$ day $^{-1}$ & 1 & 7.8 & 16 \\
\hline HP water discharge & $\%$ day-1 $^{-1}$ & Zero & Zero & Zero & Zero ${ }^{1}$ \\
\hline $\begin{array}{l}\text { Remineralization } \\
\text { Technology }\end{array}$ & - & $\begin{array}{l}\text { Vermiculture } \\
\text { (Californian } \\
\text { Red Worm) }\end{array}$ & $\begin{array}{l}\text { Secondary } \\
\text { Clarifier }\end{array}$ & - & Biogas \\
\hline HP fertilization & $\%$ & $40-60$ & 60 & $\begin{array}{l}38.1 \text { (for } \\
\text { lettuce) }\end{array}$ & n/a \\
\hline
\end{tabular}

${ }^{1}$ discharge; water consumption depends on life stage of the tomato plants and on weather conditions as RAS and greenhouse were not specifically dimensioned to be coupled, but have been linked posteriorly, the RAS produces discharge water in excess to what the greenhouse may consume;

The outcome of our model (Figure 7.3) clearly shows that nutrient concentrations of the RAS and hydroponic systems would be far from optimal based on a simple decoupling of the systems. In particular, Figure 7.3 shows that the nitrate levels in the RAS are very high, and since the primary nutrient input (in form of fish feed) takes place in the RAS, it is impossible to achieve higher hydroponic nutrient concentrations while lowering the RAS water nutrient levels in proportion to the hydroponic counterpart. As multi-loop systems aim to reduce the discharge of water and nutrients, periodical bleed-off of aquaculture process water is not a desirable option. Additional nutrient supply via a possible remineralization loop as well as the addition of artificial fertilizer could raise the hydroponic nutrient content, however, it does not solve the problem of the high nitrate values in the RAS.

Apart from the suggested solution of implementing desalination technologies, a denitrification side loop has the potential to lower the RAS nitrate levels. Another option is to integrate the anaerobic sludge remineralization loop into the RAS sub-system, as it also promotes denitrification. Both options would reduce the total nitrogen availability in the system, which again leads to a higher fertilizer requirement. Also, having an independent remineralization loop brings the advantage of providing the plants with $\mathrm{NH}_{4}$ (preferred form of nitrogen) as well as ensuring optimal conditions for anaerobic bacteria.

Additional to proportioning the nutrient concentrations of each subsystem, such desalination units can also be used for their intended purpose: to desalinate sea or brackish water, thus increasing capacity of dry regions to produce food within a sustainable system (Shatat et al., 2013). However, it must be stated that the energy and cost required to install solar desalination technology currently cannot compete with fuel-based desalination methods yet (Ayoub and Malaeb, 2014). 


\subsection{Conclusion}

The present research quantitatively demonstrates that the implementation of desalination processes can contribute to the nitrate balances in multi-loop aquaponic systems to attain optimal growth conditions for both fish and plants, by concentrating the hydroponic nutrient solution while diluting the RAS process water. It builds on prior work by Goddek et al. (2016b) and Kloas et al. (2015), and shows how the integration of desalination technologies can improve the design and practical applications of multi-loop aquaponic systems. 
$-$ 


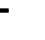




\section{Chapter 8 General Discussion}

The objectives of the thesis were to (1) determine the status quo of aquaponic systems and to identify current bottlenecks that need to be addressed in order to improve commercial feasibility; (2) to determine statistically to what degree RAS-derived water as well as effluents from aerobic and anaerobic remineralization reactors have an impact on plant growth and provide hypotheses that could explain these differences; and (3) to investigate a multi-loop aquaponic system layout by dynamic systems modelling, considering previous findings and ultimately offer important insights into sizing and designing such systems.

Based on these objectives, two research questions were formulated:

1. To what degree does the implementation of technically more complex multi-loop aquaponic systems improve the economic (i.e. production efficiency) and ecological (i.e. nutrient recycling, waste prevention, water consumption, etc.) impact compared with one-loop aquaponic systems?

2. What are the determining parameters for both sizing and designing multi-loop aquaponic systems?

Throughout the following sections, I will critically reflect on these objectives, before answering the research questions empirically and conceptually in the general conclusions section.

\subsection{Commercial Aquaponics}

Aquaponics as a closed loop system has the potential to contribute to addressing problems regarding climate change, land degradation, water scarcity, and food security. In Chapter 2 that tackled the $1^{\text {st }}$ objective, we have identified a lack of focus on commercial implementation of aquaponics as well as the requirement of different water qualities for fish and plants (i.e. RAS and HP). Based on this outcome, physical separation of the aquaponic sub-system in two recirculating loops have been suggested, where optimal conditions for 
each system are achieved by a one-way (i.e. one directional) water exchange between the fish and plant units. We hypothesized that this approach of separation of production loops could offer an opportunity for commercial aquaponics production based on the fact that fish as well as plants are exposed to different favourable conditions in terms of nutrient concentrations, temperature, $\mathrm{pH}$, etc. In this thesis, we conducted a series of empirical studies (Chapter 3-5) to test the hypothesis that decoupling of the hydroponic subsystem has a positive impact on the plant growth performance.

After my initial review paper (Chapter 2) was published in 2015, several new papers looking at the potential for large-scale commercial aquaponics have been published. Miličić et al. (2017) for instance, examined consumer behaviour and reported that consumers' perception/views are generally positive towards aquaponic products. In a quantitative study of European consumers, they showed that most respondents had a positive perception of aquaponic products based on the fact they would be free of antibiotics, pesticides and herbicides. Another recent quantitative study by Villarroel et al. (2016) attempted to get better insight into aquaponics as a developing field, both commercially and scientifically within Europe. In their survey, only $11.8 \%$ of the 68 respondents sold aquaponic products in the past 12 months, indicating that commercial activities are still limited in this field.

Love et al. (2015) have attempted to discern why aquaponic production has not emerged as a commercially important production area, given its presumed significant potential. Their survey shows that only one-third of the respondents made profit in the previous year, even though similar growth rates to hydroponics can be expected in one-loop aquaponic systems (Delaide et al., 2016; Knaus and Palm, 2017). This could be explained by the fact that approximately three-quarters of the production systems are self-built and do not meet the scale of most industrial hydroponic systems (Villarroel et al. 2016).

\subsection{Multi-Loop Systems}

After identifying the most relevant measures for future improvement such as nutrient recycling, adaptation towards environmental conditions, and water-saving strategies (Objective 1), Objective 2 was to determine to what degree RAS-derived water as well as effluents from aerobic and anaerobic remineralization reactors have an impact on lettuce growth. We chose lettuce as a crop because its growing period is short and contrary to fruity plants, such as tomatoes and peppers, the required nutrient composition does not change as a function of the growth stage. In hydroponics, plant growth performance is optimized by nutrient supplementation (Chapter 3), thus lettuce was supplied with conventional 
hydroponic, aquaponic and complemented aquaponic (CAP) solutions originating from RASbased tilapia (Chapter 3 ) as well as RAS-based perch (Chapter 4) production.

The principal findings of Chapter 3 were that we observed an increased yield (wet matter) of $39 \%$ in the CAP-grown lettuce compared to conventional hydroponics. Even though the nutrient concentrations in the aquaponic water of the aquaponic group was much lower than the nutrient concentrations in the hydroponic treatment (Table 3.1), growth performance between the aquaponic and hydroponic control groups was not statistically different. A follow up large-scale experiment (Chapter 4) did not invalidate these findings. The CAP nutrient solution contained significantly more sodium, which usually leads to plant growth retardation, however, the opposite was observed. The final wet weight of the CAP-lettuce was at least $7.9 \%$, and its final dry weight even $33.2 \%$ higher than those from the hydroponics. Still, the growth improvements ranged from $7.9 \%$ to $39 \%$. We hypothesise that the lower growth improvement of $7.9 \%$ is a consequence of the higher sodium levels in the respective nutrient solutions, but we neither can rule out that different microbial communities (e.g. due to RAS water from different fish species) had an additional influence on the final yield.

Despite these results, questions remain, as Suhl et al. (2016) did not reach similar conclusions when conducting experiments similar to ours (i.e. CAP vs. hydroponics) with tilapia and tomatoes. Our observations must therefore be interpreted with caution. The observed phenomenon of increased plant growth may be species-specific, or related primarily to bacterial communities in specific systems. Additional research is required to determine the reasons for our observed growth differences. Further work under controlled environmental conditions is required to know whether plant growth promoting rhizobacteria (PGPR), dissolved organic matter (DOM) or acids (such as humic acids) are plausible explanations for the observed differences.

Therefore, at this stage we should not claim that aquaponics increases lettuce growth rates relative to hydroponics, as there is a discrepancy in the literature and growth improvements cannot be guaranteed for all plant species. In this dissertation, we were unable to test the wide range of variables required to determine conclusively why plant growth rates might be superior in aquaponics systems as opposed to conventional hydroponics. However, we disproved the often-reported problem of growth retardation (Chapter $3 \& 4$ ). With respect to the economic value of multi-loop systems, we showed that multi-loop aquaponic systems have the potential to be competitive compared to current commercial hydroponic systems. At least, a similar plant yield can be expected for such aquaponic systems, while the external fertilizer input to the hydroponic system and aquaculture waste generation (i.e. fertilizer 
production instead of wastewater discharge fees) is drastically reduced (Graber and Junge, 2009; Suhl et al., 2016). Additionally, valuable fish is obtained as a "by-product", and provides added value to the food chain. However, the need for more complex measurement and control technology, as well as lack of solid theoretical and practical knowledge is a major drawback for decoupled multi-loop aquaponic systems. On the other hand, such systems have the potential to be used on large-scale, which is a considerable advantage for future application.

As stated in Chapter 1, soil erosion, water scarcity, phosphate availability and the corresponding price of fertilization (as well as water discharge fees for nutrient emissions) will become a major issue for the future generations. Aquaponic systems contribute to future solutions to these problems, which undoubtedly will arise. These problems can mainly be categorized in two domains: (1) nutrient recycling, and (2) water use efficiency. One-loop systems that are currently in operation already perform well in following these principles. However, fish sludge that is usually discharged from the system still contains valuable nutrients and a high proportion of water (Chapter 2). Multi-loop aquaponic systems can increase both nutrient recycling and water use efficiency, by implementing a third remineralization cycle (Figure 8.1).

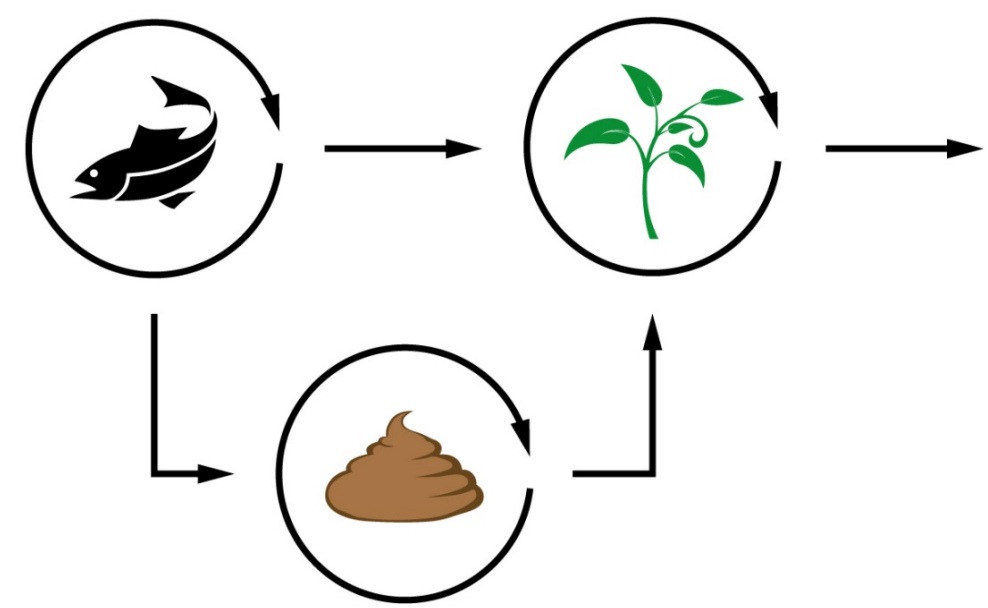

Figure 8.1. Illustration of the major water and nutrient flows from the RAS to the other subsystems of a multi-loop aquaponic systems. Water recirculates within the RAS, hydroponic, and remineralization subsystems. The evapotranspiration within the HP system determines the flow from the RAS to the HP. Additionally to that, there are (here not drawn) minor water and nutrient losses in all three sub-systems. 
Chapter 5 specifically addresses the impact of the implementation of such a third remineralization cycle on plant growth. Contrary to the classical working principle of aquaponics (i.e. continuously providing nutrient-rich RAS water to the hydroponic plant culture unit and redirecting it to the aquaculture tanks), the multi-loop approach is quite different (Figure 8.1). Here, the flows from RAS and the remineralization/mobilization unit are directed one-way and are mainly determined by the evapotranspiration rate of the plants. The mobilization of nutrients from fish sludge plays a key role in closing the nutrient cycle to the highest degree possible. For that reason, the impact of both aerobic and anaerobic digestion effluents have been examined on plant growth to determine which option is more beneficial. The lettuce plants grown in the hydroponic system that were supplied with supernatant from an anaerobic reactor, while keeping the EC at a constant level, had significantly better performance with respect to weight gain than those supplied from an aerobic reactor (Objective 2). Unfortunately, it was beyond the scope of this study to optimize the remineralization unit. Different studies indicate that several parameters (i.e. temperature, $\mathrm{pH}$, feeding rate, sludge density, etc.) have an impact on the mobilization of nutrients (de Lemos Chernicharo, 2007; Mirzoyan and Gross, 2013; Salminen et al., 2001; van Lier et al., 2008). Consequently, our hypothesis that anaerobic remineralization effluents are the optimal solution to plant growth still needs to be verified in a pilot scale setup.

\subsection{Nutrient and Water Mass Balance}

Unlike one-loop aquaponics, multi-loop systems can provide optimal conditions for fish, plants, and remineralization bacteria (Kloas et al., 2015; Suhl et al., 2016; Suhr et al., 2015). Regardless of our work presented in Chapter 6, models simulating the ASTAF-PRO system (Kloas et al., 2015) were created based on Excel (Reyes Lastiri et al., 2016) and VBA Excel (Karimanzira et al., 2016). Both models focus on system analysis as well as optimization of the existing system.

Our model follows a different approach (Chapter 6) and was programmed with AnyLogic. Unlike the models of Reyes Lastiri et al. (2016) and Karimanzira et al. (2016) that can be described as an empirical model, our model is not based on an already working system, and has therefore more the character of a theoretical exploration and optimisation. Objective 3 aimed to develop a feasible multi-loop aquaponic system layout based both on dynamic systems modelling and the former findings, as well as on characterizing parameters that offer important insights into sizing and design of such systems. Model outputs show that the radiation-dependent evapotranspiration is the determining factor for water quality (i.e. nitrate concentration) in the aquaculture component (Chapter 6). In concrete terms, this means that the higher the radiation, the more evapotranspiration will occur in the RAS and 
HP system. This will consequently lead to higher water renewal rates in the RAS system. Under steady-state conditions, i.e. constant volumes in RAS and HP systems, the direct flow from the RAS to the HP can be determined using the following equation

$$
Q_{R A S}=E T+V_{w}+Q_{H P}-Q_{R E M}
$$

whereas $Q_{R A S}$ is the Water flow RAS to HP; ET is the Total Evapotranspiration; $V_{w}$ is the water content in harvested plants; $Q_{H P}$ is the optional discharge (e.g. at the end of growth cycles, if applicable); and $Q_{R E M}$ is the water flow from the remineralization component to HP.

With respect to the identification of phosphorus as a bottleneck resource in the near future (Chapter 2), the model outcome of Chapter 6 shows that in principle sufficient phosphorus could be available for plants within decoupled multi-loop aquaponics systems. However, this statement should be approached with caution as it depends on several other factors. These factors are (1) the remineralization/mobilization performance of the anaerobic reactors that must still be determined and optimized; (2) the feed formulation; (3) the cultivated plant species and its particular nutrient demand. Consequently, our assumption has still to be verified in a number of large-scale comparative studies. Taking one-loop systems as a reference, our approach appears quite promising though, as this system could reduce dependency on phosphate fertilizers, the shortage of which is a concern in global agriculture production (Kloas et al., 2015; Mirzoyan and Gross, 2013; Monsees et al., 2017; Suhl et al., 2016). As parameters of the model can be adjusted and optimized with empirical data, the model can provide good design criteria depending on specific fish loading rates and stocking densities.

The advantage of using AnyLogic is that its models are java applications and can easily be extended. Moreover, AnyLogic supports GUI-based dynamic systems modelling and combines this with agent based and discrete event models. The system dynamics approach enables the user to understand both structures and dynamics of complex systems based on causal loop relationships. A general drawback is that existing models are not compatible with each other due to different interfaces. However, there are already solutions for model integration and co-simulation, e.g. following the Functional Mock-up Interface standard that could allow for combining existing models.

Although this study has tended to focus on optimizing the conditions of each sub-system, less attention has been paid to the actual nutrient concentrations within the RAS and the HP. The main controversy concerns the fact that the nutrient concentration must be higher in the HP 
than in the RAS. Chapter 7 demonstrates that the constituted nutrient dynamics in Chapter 6 within a multi-loop aquaponic systems are accurate in terms of mass balances, but cannot achieve the favourable nutrient concentration especially in the HP. To avoid nutrient supplementation, the research paper presented in Chapter 7 suggests an implementation of a desalination/distillation device to achieve intended nutrient concentrations in both sub systems. The model outcome shows that in theory this could address the issue. However, the proposed solution needs a practical evaluation as the impact of concentrated RAS water on plant growth remains unclear. Additional empirical evidence is required to assess to what degree such a solution makes sense economically as distillation processes are energy intensive (Chandrashekara and Yadav, 2017).

\subsection{Environmental and Social Impact}

There are several arguments for aquaponics addressing the optimised utilization of resources and reduction of emissions, increasing the sustainability of fish and plant production (Chapter 2). Compared to hydroponic food production, the use of antibiotics and pesticides is highly restricted (dos Santos, 2016; Rakocy et al., 2006) and the integrated nature of aquaponics forcibly requires more dependence on biocontrol methods in the RAS subsystem (Goddek et al., 2015). As a result, aquaponics should in theory be eligible for organic certification; however, aquaponic plant products, similar to hydroponic plant products (grown in water) are still excluded from organic labelling in the European Union.

Another important factor in aquaponics is animal welfare. Decoupled multi-loop aquaponic systems offer the best comparative advantage compared with one-loop systems (Chapter 6). This advantage can be attributed to the fact that the water quality can be separately regulated for all system components. A trade-off is no longer necessary (Chapter 2) as fish will no longer have to swim in highly nutrient-concentrated water, while the nutrient concentration of the hydroponic component can be raised to hydroponic levels. Consequently, the following discussion will reflect the trade-offs between one-loop vs. multiloop systems.

From a social point of view, aquaponics enables people/farmers/communities/companies to grow food (dos Santos, 2016) in an efficient and decentralized manner, while decreasing waste generation. Reduced phosphorus dependencies of multi-loop aquaponic systems (Chapter $2 \& 6$ ) as well as yields that can compete with hydroponic standards (Chapter 3 \& 4) show the potential to compensate for the economic disadvantage that current one-loop systems have. The already mentioned reduced P-dependencies of upcoming multi-loop aquaponic systems can compete with hydroponic standards and will only be strengthened 
by the potentially higher industrial productivity that might be achievable in multi-loop aquaponic systems.

\subsection{Recommendations for future research}

This thesis provides a basis for optimizing each sub-cycle in a multi-loop aquaponic system. Further aims and challenges lay in optimizing the system's circularity. The greatest potential in optimizing the resource usage lies in the remineralization technology which constitutes a high potential for future innovation (de Lemos Chernicharo, 2007; Monsees et al., 2015; van Lier et al., 2008). Recent findings indicate that anaerobic sludge treatment has a strong potential to remineralize N, P, and other macro and micro-nutrients (Mirzoyan and Gross, 2013; Suhr et al., 2015). This remineralization is all the more significant because our experimental findings (Chapter 5) have indicated that lettuce has the potential to achieve a higher performance and a more favourable root:shoot ratio when the nutrient solution was enriched with anaerobic supernatant. It must be stated that the experiment (Chapter 5) was conducted under high $\mathrm{pH}$ conditions that are not uncommon in aquaponics. Yet, the question arises whether the increased growth might have occurred as the available ammonia in the anaerobic supernatant might have lowered the $\mathrm{pH}$ in the lettuces' rhizosphere; which again could have caused the enhanced nutrient uptake (Jones, 2005). Future research in this field must examine this phenomenon, including the bacterial role given that a strong biological reason for increased plant growth is likely. However, preliminary data of current ongoing research suggests that RAS-derived anaerobic supernatant has a significant impact on plant growth (Mendoza, pers. communication). With respect to remineralization technologies, further studies still need to address the impact of hydraulic retention time (HRT), sludge retention time (SRT), $\mathrm{pH}$, and possible pre- and post-treatments in order to optimize this process further. In the long term perspective, nearly zero-discharge systems should be achieved.

Additionally, two essential follow-up research recommendations must be emphasized: (1) additional research is necessary to determine the reasons for better lettuce growth in CAP systems with respect to the observed phenomenon (i.e. bacterial role; humic acid; DOM; VFAs) that increased plant growth might be plant species dependent (Chapter $3 \& 4$ ); and (2) a mass balance study is required to examine the effects of optimized aerobic and anaerobic remineralization methods in a pilot multi-loop aquaponic system (Chapter 5).

Challenges on the short term will be (1) the sizing of the components for decoupled aquaponic systems and (2) the implementation and operation of pilot plants that are needed to reach an overall technology readiness level of 8 or 9 (i.e. proof of technology and actual application in its final form, respectively). Medium to large-scale pilot projects are 
particularly suitable for this purpose, and ideally provide comparative experimental data. Bottom-up system models that are largely based on data from RAS, hydroponics, and remineralization reactors derived data could support sizing of systems in a highly flexible manner.

Figure 8.2 shows a conceptual planning of a multi-loop aquaponic system based on our current knowledge. This illustration differentiates from Figure 6.3 in some aspects:

1. Desalination/Distillation technologies are suggested to increase the nutrient concentration in the hydroponic component if necessary, while leading demineralized water to the RAS and thus improving its water quality.

2. Energy and heat generation are taken into account; i.e. the usage of methane as a byproduct of anaerobic digestion, as well as using the waste heat of the lighting equipment. 


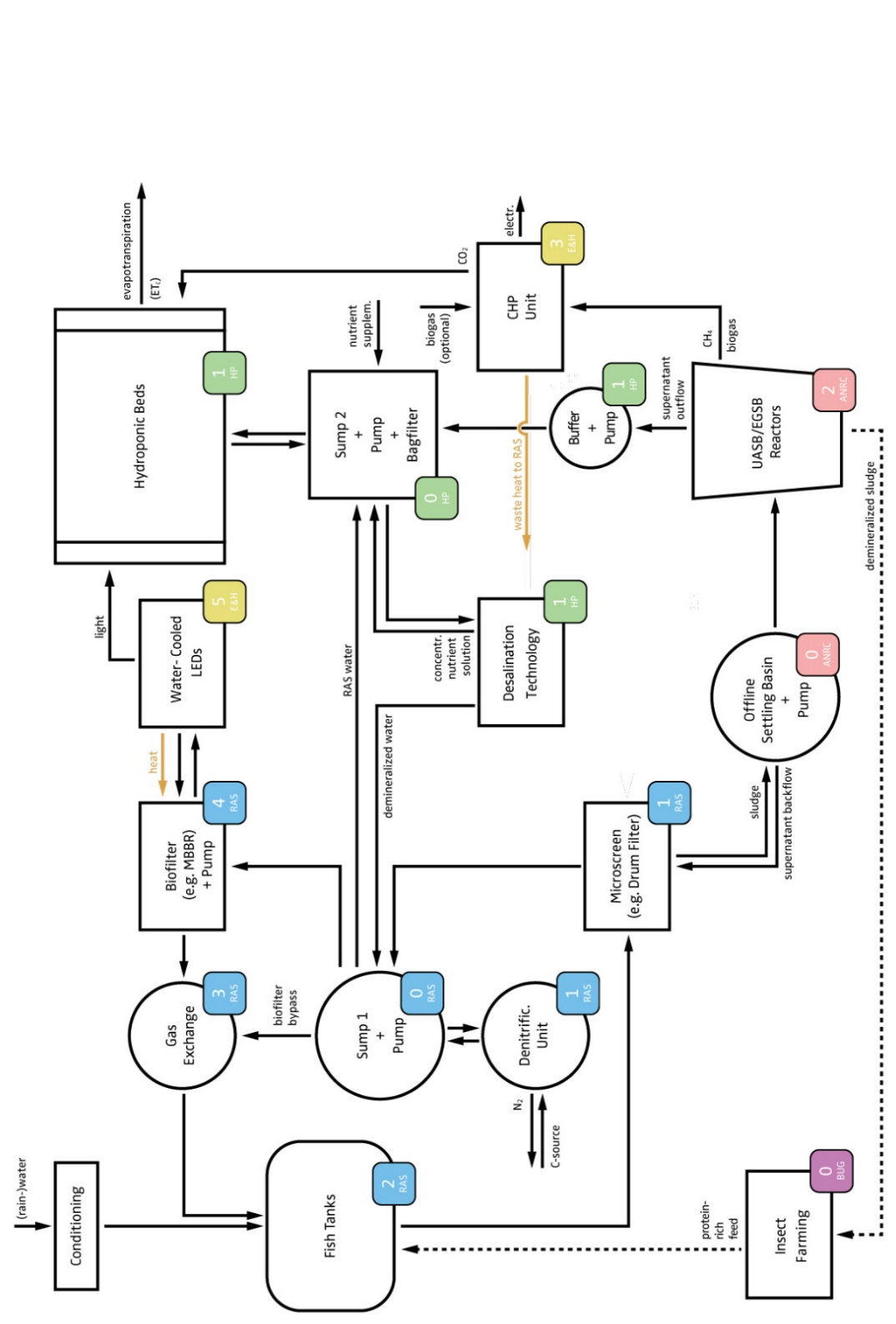

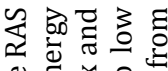

형ㅎㅇ 웡 记

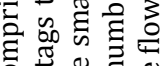

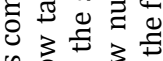
कू⿻ $\stackrel{2}{\Rightarrow} \overline{3}$ 킁 율

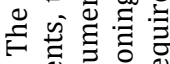
ข่ $\Xi$ 过

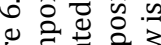
పี 玨

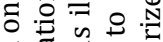

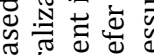

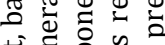

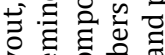
बढ ठ ठ ह ह 동 फ ${ }^{\pi} 5$ के च $\overline{0} \approx$ $\stackrel{m}{\sim}$ क्ष 0 랕ㅎㅇ

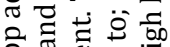
을 気 完 है ठํ

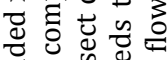

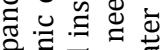
중 $3 \frac{\pi}{3}$

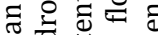

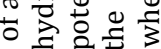
bo $\approx$ क उ ț

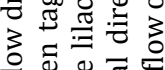
융 ᅰ

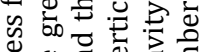

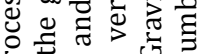

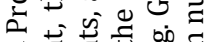

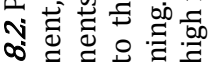
웅 क웅 불을 
Altogether, this thesis provides a deeper insight into both the need and potentials of decoupled multi-loop aquaponic systems.

\subsection{Conclusions}

The preceding sections have critically discussed the main findings of this thesis. To conclude, the two main research questions were:

(1) To what degree does the implementation of technically more complex multi-loop aquaponic systems improve the economic (i.e. production efficiency) and ecological (i.e. nutrient recycling, waste prevention, water consumption, etc.) impact compared with oneloop aquaponic systems?

- In the conducted experiments (Chapter $3 \& 4$ ), lettuce grew significantly better in RAS based hydroponic nutrient solutions than in "sterile" (i.e. without bacteria) hydroponic environments.

- Our developed dynamic systems model enhances the understanding of nutrient and water flows within multi-loop aquaponic systems and can serve as a tool for determining dimension criteria.

- Remineralizing RAS-derived fish sludge decreases waste discharge and at the same time increase water and nutrient recycling within the system.

- Desalination/Distillation technology can control the nutrient concentrations in the respective multi-loop aquaponic subsystems, reducing the external fertilization demand.

(2) What are the determining parameters for both sizing and designing multi-loop aquaponic systems?

- The evapotranspiration rate (which is dependent on the global radiation) was identified as the major parameter to control the RAS water quality in decoupled multi-loop aquaponic systems.

- Fish loading rates as well as the size of the hydroponic culture unit are parameters that need to be sized correctly to maintain RAS water on a desirable level.

- $\mathrm{pH}$, HRT, SRT, and temperature are important parameters for the anaerobic remineralization unit to determine the remineralization efficiency of the reactor and therefore the hydroponic subsystem.

- The radiation level as well as the relative humidity are the main parameters for determining the evapotranspiration rate of the plants and the associated RAS water quality (i.e. the higher the evapotranspiration, the higher the water exchange in the RAS system). 


\section{References}

Adler, P.R., Harper, J.K., Wade, E.M., 2000. Economic analysis of an aquaponic system for the integrated production of rainbow trout and plants. Int. J. Recirc. Aquac. 1, 15-34.

Adler, P.R., Summerfelt, S.T., Glenn, D.M., Takeda, F., 1996. Evaluation of the Effect of a Conveyor Production Strategy on Lettuce and Basil Productivity and Phosphorus Removal from Aquaculture Wastewater, in: Trans Tech Publications, S.E.R.F. (Ed.), Recycling the Resource Ecological Engineering for Wastewater Treatment. Proceedings of the Second International Conference. Waedenswil -Zurich, Switzerland, pp. 131-136.

Al-Hafedh, Y.S., Alam, A., Alam, M.A., 2003. Performance of plastic biofilter media with different configuration in a water recirculation system for the culture of Nile tilapia (Oreochromis niloticus). Aquac. Eng. 29, 139-154. doi:Doi 10.1016/S0144-8609(03)00065-7

Al-Hafedh, Y.S., Alam, A., Beltagi, M.S., 2008. Food Production and Water Conservation in a Recirculating Aquaponic System in Saudi Arabia at Different Ratios of Fish Feed to Plants. J. World Aquac. Soc. 39, 510-520. doi:10.1111/j.1749-7345.2008.00181.x

Al-Hafedh, Y.S., Alam, A., Beltagi, M.S., 2008. Food production and water conservation in a recirculating aquaponic system in Saudi Arabia at different ratios of fish feed to plants. J. World Aquac. Soc. 39, 510-520. doi:DOI 10.1111/j.1749-7345.2008.00181.x

Alexandratos, N., Bruinsma, J., 2012. World Agriculture Towards 2030 / 2050 The 2012 Revision. FAO.

Alfredo, M.H., Hector, S.L., 2002. Blood gasometric trends in hybrid red tilapia Oreochromis niloticus (Linnaeus) $\times 0$. mossambicus (Peters) while adapting to increasing salinity. J. Aquac. Trop. 17, 101-112.

Alvarez, R., Lidén, G., 2008. The effect of temperature variation on biomethanation at high altitude. Bioresour. Technol. 99, 7278-84. doi:10.1016/j.biortech.2007.12.055

Amadori, M., Daley, D., 2012. An Engineered Ecosystem for Waste Management and Food Production. State University of New York College.

Antoniou, P., Hamilton, J., Koopman, B., Jain, R., Holloway, B., Lyberatos, G., Svoronos, S.A., 1990. Effect of temperature and ph on the effective maximum specific growth rate of nitrifying bacteria. Water Res. 24, 97-101. doi:10.1016/0043-1354(90)90070-M

Appels, L., Baeyens, J., Degrève, J., Dewil, R., 2008. Principles and potential of the anaerobic digestion of waste-activated sludge. Prog. Energy Combust. Sci. 34, 755-781. doi:10.1016/j.pecs.2008.06.002

Arsenault, C., n.d. Only 60 Years of Farming Left If Soil Degradation Continues [WWW Document]. Sci. Am. URL https://www.scientificamerican.com/article/only-60-years-of-farming-left-ifsoil-degradation-continues/ (accessed 2.20.17).

Ayoub, G.M., Malaeb, L., 2014. Economic feasibility of a solar still desalination system with enhanced productivity. Desalination 335, 27-32. doi:10.1016/j.desal.2013.12.010

Azevedo, P.A., Podemski, C.L., Hesslein, R.H., Kasian, S.E.M., Findlay, D.L., Bureau, D.P., 2011. Estimation of waste outputs by a rainbow trout cage farm using a nutritional approach and monitoring of lake water quality. Aquaculture 311, 175-186. doi:10.1016/j.aquaculture.2010.12.001

Bajsa, O., Nair, J., Mathew, K., Ho, G.E., 2003. Vermiculture as a tool for domestic wastewater management. Water Sci. Technol. 48, 125-132.

Bakos, G.C., Fidanidis, D., Tsagas, N.F., 1999. Greenhouse heating using geothermal energy. Geothermics 28, 759-765. 
Barton, B.A., 1996. Principles of Salmonid Culture, Developments in Aquaculture and Fisheries Science, Developments in Aquaculture and Fisheries Science. Elsevier. doi:10.1016/S01679309(96)80005-6

Beardsley, T.M., 2011. Peak Phosphorus. Bioscience. doi:10.1525/bio.2011.61.2.1

Belal, I.E.H., 2005. A review of some fish nutrition methodologies. Bioresour. Technol.

Bernstein, S., 2011. Aquaponic gardening : A step-by-step guide to raising vegetables and fish together. New Society Publishers, Gabriola Island, BC.

Bindraban, P.S., van der Velde, M., Ye, L., van den Berg, M., Materechera, S., Kiba, D.I., Tamene, L., Ragnarsdóttir, K.V., Jongschaap, R., Hoogmoed, M., Hoogmoed, W., van Beek, C., van Lynden, G., 2012. Assessing the impact of soil degradation on food production. Curr. Opin. Environ. Sustain.

Blackburne, R., Vadivelu, V.M., Yuan, Z., Keller, J., 2007. Kinetic characterisation of an enriched Nitrospira culture with comparison to Nitrobacter. Water Res. 41, 3033-42. doi:10.1016/j.watres.2007.01.043

Böhme, M., 1999. Effects of lactate, humate and bacillus subtilis on the growth of tomato plants in hydroponic systems. Acta Hortic. 481, 231-239.

Bon, H., Parrot, L., Moustier, P., 2010. Sustainable urban agriculture in developing countries. A review. Agron. Sustain. Dev. 30, 21-32. doi:10.1051/agro:2008062

Bonachela, S., González, A.M., Fernández, M.D., 2006. Irrigation scheduling of plastic greenhouse vegetable crops based on historical weather data. Irrig. Sci. 25, 53-62. doi:10.1007/s00271006-0034-z

Borshchev, A., 2013. The Big Book of Simulation Modeling. AnyLogic North America.

Boulard, T., 2003. Evapotranspiration in Greenhouses. Encycl. Water Sci. doi:10.1081/E-EWS 120010311

Brown, L.R., 2009. Could Food Shortages Bring Down Civilization? Sci. Am. 300, 50-57. doi:10.1038/scientificamerican0509-50

Bulgarelli, D., Schlaeppi, K., Spaepen, S., van Themaat, E.V.L., Schulze-Lefert, P., 2013. Structure and Functions of the Bacterial Microbiota of Plants. Annu. Rev. Plant Biol. 64, 807-838. doi:doi:10.1146/annurev-arplant-050312-120106

Burns, I.G., Zhang, K., Turner, M.K., Edmondson, R., 2010. ISO-Osmotic Regulation of Nitrate Accumulation in Lettuce. J. Plant Nutr. 34, 283-313. doi:10.1080/01904167.2011.533328

Buzby, K.M., Lin, L.S., 2014. Scaling aquaponic systems: Balancing plant uptake with fish output. Aquac. Eng. 63, 39-44. doi:10.1016/j.aquaeng.2014.09.002

Buzby, K.M., Waterland, N.L., Semmens, K.J., Lin, L.-S., 2016. Evaluating aquaponic crops in a freshwater flow-through fish culture system. Aquaculture 460, 15-24. doi:10.1016/j.aquaculture.2016.03.046

Canellas, L.P., Spaccini, R., Piccolo, A., Dobbss, L.B., Okorokova-Façanha, A.L., Santos, G. de A., Olivares, F.L., Façanha, A.R., 2009. Relationships Between Chemical Characteristics and Root Growth Promotion of Humic Acids Isolated From Brazilian Oxisols. Soil Sci. 174, 611-620. doi:10.1097/SS.0b013e3181bf1e03

Castro, E., Mañas, M.P., De Las Heras, J., 2009. Nitrate content of lettuce ( Lactuca sativa L.) after fertilization with sewage sludge and irrigation with treated wastewater. Food Addit. Contam. Part A 26, 172-179. doi:10.1080/02652030802425334

Chan, H.-Y., Riffat, S.B., Zhu, J., 2010. Review of passive solar heating and cooling technologies. Renew. Sustain. Energy Rev. doi:10.1016/j.rser.2009.10.030

Chandrashekara, M., Yadav, A., 2017. Water desalination system using solar heat: A review. Renew. Sustain. Energy Rev. 67, 1308-1330. doi:10.1016/j.rser.2016.08.058

Chen, S., Ling, J., Blancheton, J.P., 2006. Nitrification kinetics of biofilm as affected by water quality factors. Aquac. Eng. 34, 179-197. doi:10.1016/j.aquaeng.2005.09.004

Chen, Y., He, J., Mu, Y., Huo, Y.-C., Zhang, Z., Kotsopoulos, T.A., Zeng, R.J., 2015. Mathematical 
modeling of upflow anaerobic sludge blanket (UASB) reactors: Simultaneous accounting for hydrodynamics and bio-dynamics. Chem. Eng. Sci. 137, 677-684.

doi:10.1016/j.ces.2015.07.016

Clement, C.R., Hopper, M.J., Jones, L.H.P., 1978. The Uptake of Nitrate by Lolium perenne from Flowing Nutrient Solution. J. Exp. Bot. 29, 453-464. doi:10.1093/jxb/29.2.453

Coche, A.G., 1967. Fish culture in rice fields a world-wide synthesis. Hydrobiologia 30, 1-44.

Coghlan, S.M., Ringler, N.H., 2005. Temperature-dependent Effects of Rainbow Trout on Growth of Atlantic Salmon Parr. J. Great Lakes Res. 31, 386-396. doi:10.1016/S0380-1330(05)70270-7

Cordell, D., Drangert, J.O., White, S., 2009. The story of phosphorus: Global food security and food for thought. Glob. Environ. Chang. Policy Dimens. 19, 292-305. doi:DOI 10.1016/j.gloenvcha.2008.10.009

Cordell, D., Rosemarin, A., Schröder, J.J., Smit, A.L., 2011. Towards global phosphorus security: a systems framework for phosphorus recovery and reuse options. Chemosphere 84, 747-58.

Cordell, S., Ostertag, R., Rowe, B., Sweinhart, L., Vasquez-Radonic, L., Michaud, J., Cole, T.C., Schulten, J.R., 2009. Evaluating barriers to native seedling establishment in an invaded Hawaiian lowland wet forest. Biol. Conserv. 142, 2997-3004. doi:DOI 10.1016/j.biocon.2009.07.033

Crinnion, W.J., 2010. Organic foods contain higher levels of certain nutrients, lower levels of pesticides, and may provide health benefits for the consumer. Altern. Med. Rev.

Cripps, S.J., Bergheim, A., 2000. Solids management and removal for intensive land-based aquaculture production systems, in: Aquacultural Engineering. pp. 33-56. doi:10.1016/S01448609(00)00031-5

Criscuolo, C., Menon, C., 2015. Environmental policies and risk finance in the green sector: Crosscountry evidence. Energy Policy 83, 38-56. doi:10.1016/j.enpol.2015.03.023

Cuervolopez, F., Martinez, F., Gutierrezrojas, M., Noyola, R., Gomez, J., 1999. Effect of nitrogen loading rate and carbon source on denitrification and sludge settleability in upflow anaerobic sludge blanket (UASB) reactors. Water Sci. Technol. 40, 123-130. doi:10.1016/S02731223(99)00617-4

Dalsgaard, J., Lund, I., Thorarinsdottir, R., Drengstig, A., Arvonen, K., Pedersen, P.B., 2013. Farming different species in RAS in Nordic countries: Current status and future perspectives. Aquac. Eng. 53, 2-13.

Davidson, J., Good, C., Welsh, C., Summerfelt, S.T., 2014. Comparing the effects of high vs. low nitrate on the health, performance, and welfare of juvenile rainbow trout Oncorhynchus mykiss within water recirculating aquaculture systems. Aquac. Eng. 59, 30-40. doi:10.1016/j.aquaeng.2014.01.003

Davidson, J., Good, C., Welsh, C., Summerfelt, S.T., 2011. Abnormal swimming behavior and increased deformities in rainbow trout Oncorhynchus mykiss cultured in low exchange water recirculating aquaculture systems. Aquac. Eng. 45, 109-117.

Davidson, J., Summerfelt, S.T., 2005. Solids removal from a coldwater recirculating systemcomparison of a swirl separator and a radial-flow settler. Aquac. Eng. 33, 47-61. doi:10.1016/j.aquaeng.2004.11.002

Dawson, C.J., Hilton, J., 2011. Fertiliser availability in a resource-limited world: Production and recycling of nitrogen and phosphorus. Food Policy 36, S14-S22. doi:10.1016/j.foodpol.2010.11.012

de Kreij, C., Voogt, W., Baas, R., 1999. Nutrient solutions and water quality for soilless cultures. Broch. Res. Stn. Floric. Glas. Veg. Naaldwijk, Netherlands Brochure 1.

de Lemos Chernicharo, C.A., 2007. Anaerobic Reactors, 4th ed. IWA Publishing, New Delhi, India.

Delaide, B., Goddek, S., Gott, J., Soyeurt, H., Jijakli, M., 2016a. Lettuce (Lactuca sativa L. var. Sucrine) Growth Performance in Complemented Aquaponic Solution Outperforms Hydroponics. Water 8, 467. doi:10.3390/w8100467

Delaide, B., Goddek, S., Gott, J., Soyeurt, H., Jijakli, M., 2016b. Lettuce (Lactuca sativa L. var. Sucrine) 
Growth Performance in Complemented Aquaponic Solution Outperforms Hydroponics. Water 8, 467. doi:10.3390/w8100467

DeLong, D.P., Losordo, T.M., Rakocy, J.E., 2009. Tank Culture of Tilapia. South. Reg. Aquac. Cent. 282. Deutscher Wetterdienst, 2015. WESTE-XL [WWW Document]. URL https://kunden.dwd.de/weste (accessed 9.13.15).

Diver, S., Rinehart, L., 2010. Aquaponics - Integration of Hydroponics with Aquaculture. Water. dos Santos, M.J.P.L., 2016. Smart cities and urban areas-Aquaponics as innovative urban agriculture, Urban Forestry \& Urban Greening. doi:10.1016/j.ufug.2016.10.004

Dudal, R., Roy, R.N., 1995. Integrated Plant Nutrition Systems: Report of an Expert Consultation, Rome, Italy, 13-15 December 1993. Food \& Agriculture Org.

Duriau, Y., 1968. Desalination by reverse osmosis. Desalination. doi:10.1016/S00119164(00)80199-X

Dybas, C.L., 2005. Dead Zones Spreading in World Oceans. Bioscience. doi:10.1641/00063568(2005)055[0552:DZSIWO]2.0.C0;2

Eding, E.H., Verdegem, M., Martins, C., Schlaman, G., Heinsbroek, L., Laarhoven, B., Ende, S., Verreth, J., Aartsen, F., Bierbooms, V., 2009. Tilapia farming using Recirculating Aquaculture Systems (RAS) - Case study in the Netherlands., in: Oberdieck, A., Verreth, J.A.J. (Eds.), Handbook for Sustainable Aquaculture. pp. 70-94.

Edwards, J.H., Barber, S.A., 1976. Nitrogen Uptake Characteristics of Corn Roots at Low N Concentration as Influenced by Plant Age1. Agron. J. 68, 17. doi:10.2134/agronj1976.00021962006800010005x

Ekardt, F., Holzapfel, N., Ulrich, A.E., 2010. Sustainability in Soil Protection - Land Use and Conservation of Natural Resources: Phosphorus Fertilization and Soil Biodiversity as a Legal Problem.

El-Sayed, A.-F.M., 2006. Tilapia Culture. CABI Publishing, Oxfordshire, UK.

El-Shafai, S.A., El-Gohary, F.A., Nasr, F.A., van der Steen, N.P., Gijzen, H.J., 2004. Chronic ammonia toxicity to duckweed-fed tilapia (Oreochromis niloticus). Aquaculture 232, 117-127. doi:10.1016/S0044-8486(03)00516-7

Endut, A., Jusoh, A., Ali, N., Nik, W.B.W., 2011. Nutrient removal from aquaculture wastewater by vegetable production in aquaponics recirculation system. Desalin. Water Treat. 32, 422-430. doi:DOI 10.5004/dwt.2011.2761

Endut, A., Jusoh, A., Ali, N., Wan Nik, W.B., Hassan, A., 2010. A study on the optimal hydraulic loading rate and plant ratios in recirculation aquaponic system. Bioresour. Technol. 101, 1511-1517. doi:http://dx.doi.org/10.1016/j.biortech.2009.09.040

EPI, 2008. Global Assessment of Closed System Aquaculture.

Fao, 2009. World Fisheries and Aquaculture, Aquaculture. doi:issn 10

FAO, 2014. Small-scale aquaponic food production: Integrated fish and plant farming. FAO.

FAO, 2012a. Coping with water scarcity - An action framework for agriculture and food security. Rome.

FAO, 2012b. Statistical Yearbook. Rome.

FAO, 2012c. Cultured Aquatic Species Information Programme. Sander lucioperca [WWW Document]. FAO Fish. Aquac. Dep. [online]. URL http://www.fao.org/fishery/culturedspecies/Sander_lucioperca/en (accessed 8.21.15).

FAO, 2010. Cultured Aquatic Species Information Programme. Clarias gariepinus. [WWW Document]. FAO Fish. Aquac. Dep. [online]. URL http://www.fao.org/fishery/culturedspecies/Clarias_gariepinus/en (accessed 8.21.15).

FAO, 2005a. AQUASTAT Survey, Irrigation in Africa in figures. Rome. doi:ISBN 92-5-105414-2

FAO, 2005b. Cultured Aquatic Species Information Programme. Oncorhynchus mykiss. [WWW Document]. FAO Fish. Aquac. Dep. [online]. URL

http://www.fao.org/fishery/culturedspecies/Oncorhynchus_mykiss/en (accessed 8.21.15). 
FAO, 1998. FAO Irrigation and Drainage Paper: Crop Evapotranspiration. Rome.

FAO, n.d. Databases | FAO | Food and Agriculture Organization of the United Nations [WWW Document]. URL http://www.fao.org/statistics/databases/en/ (accessed 2.20.17).

Fernández, M.D., Bonachela, S., Orgaz, F., Thompson, R., López, J.C., Granados, M.R., Gallardo, M., Fereres, E., 2010. Measurement and estimation of plastic greenhouse reference evapotranspiration in a Mediterranean climate. Irrig. Sci. 28, 497-509. doi:10.1007/s00271010-0210-z

Finstad, B., Staurnes, M., Reite, O.B., 1988. Effect of low temperature on sea-water tolerance in rainbow trout, Salmo gairdneri. Aquaculture 72, 319-328. doi:10.1016/0044-8486(88)902207

Francis, C., Lieblein, G., Gliessman, S., Breland, T.A., Creamer, N., Harwood, R., Salomonsson, L., Helenius, J., Rickerl, D., Salvador, R., Wiedenhoeft, M., Simmons, S., Allen, P., Altieri, M., Flora, C., Poincelot, R., 2003. Agroecology: The Ecology of Food Systems. J. Sustain. Agric.

Fraunhofer-Gesellschaft, 2009. Fraunhofer Research News [WWW Document]. URL https://www.fraunhofer.de/en/press/research-news.html (accessed 3.16.14).

Fujiwara, K., Aoyama, C., Takano, M., Shinohara, M., 2012. Suppression of Ralstonia solanacearum bacterial wilt disease by an organic hydroponic system. J. Gen. Plant Pathol. 78, 217-220. doi:10.1007/s10327-012-0371-0

Fujiwara, K., Iida, Y., Iwai, T., Aoyama, C., Inukai, R., Ando, A., Ogawa, J., Ohnishi, J., Terami, F., Takano, M., Shinohara, M., 2013. The rhizosphere microbial community in a multiple parallel mineralization system suppresses the pathogenic fungus Fusarium oxysporum. Microbiologyopen 2, 997-1009. doi:10.1002/mbo3.140

Gagnon, V., Maltais-Landry, G., Puigagut, J., Chazarenc, F., Brisson, J., 2010. Treatment of hydroponics wastewater using constructed wetlands in winter conditions. Water. Air. Soil Pollut. 212, 483-490.

Gangagni Rao, A., Krishna Prasad, K., Venkata Naidu, G., Chandrashekar Rao, N., Sarma, P.N., 2003. Removal of sulfide in integrated anaerobic?aerobic wastewater treatment system. Clean Technol. Environ. Policy 6, 66-72. doi:10.1007/s10098-003-0194-y

Gelfand, I., Barak, Y., Even-Chen, Z., Cytryn, E., van Rijn, J., Krom, M.D., Neori, A., 2003. A novel zero discharge intensive Seawater recirculating system for the culture of marine fish. J. World Aquac. Soc. 34, 344-358. doi:DOI 10.1111/j.1749-7345.2003.tb00072.x

Gilbert, N., 2009. Environment: The disappearing nutrient. Nature 461, 716-718. doi:10.1038/461716a

Goddek, S., 2016. Three-loop Aquaponics Systems: Chances and challenges. Ljubljana. doi:13140/RG.2.1.3930.0246

Goddek, S., Delaide, B., Mankasingh, U., Ragnarsdottir, K., Jijakli, H., Thorarinsdottir, R., 2015. Challenges of Sustainable and Commercial Aquaponics. Sustainability 7, 4199-4224. doi:10.3390/su7044199

Goddek, S., Espinal, C., Delaide, B., Jijakli, M., Schmautz, Z., Wuertz, S., Keesman, K., 2016 a. Navigating towards Decoupled Aquaponic Systems: A System Dynamics Design Approach. Water 8, 303. doi:10.3390/w8070303

Goddek, S., Espinal, C., Delaide, B., Schmautz, Z., Jijakli, H., 2016b. Navigating towards Decoupled Aquaponic Systems (DAPS): A System Dynamics Design Approach. Water.

Goddek, S., Keesman, K.J., 2017. Aquaponics - climate smart solutions to enhance food security in Namibia: Leaflet Biobases Chemistry \& Technology. Wageningen University \& Research.

Goddek, S., Vermeulen, T., 2017. Comparison of Lactuca sativa growth performance in rainwater and RAS-water-based hydroponic nutrient solutions. Water Submitted.

González-González, A., Cuadros, F., 2015. Effect of aerobic pretreatment on anaerobic digestion of olive mill wastewater (OMWW): An ecoefficient treatment. Food Bioprod. Process. 95, 339345. doi:10.1016/j.fbp.2014.10.005 
Graber, A., Junge, R., 2009a. Aquaponic Systems: Nutrient recycling from fish wastewater by vegetable production. Desalination 246, 147-156.

Graber, A., Junge, R., 2009b. Aquaponic Systems: Nutrient recycling from fish wastewater by vegetable production. Desalination 246, 147-156.

Greenlee, L.F., Lawler, D.F., Freeman, B.D., Marrot, B., Moulin, P., 2009. Reverse osmosis desalination: Water sources, technology, and today's challenges. Water Res.

Gullian-Klanian, M., Arámburu-Adame, C., n.d. Rendimiento de juveniles de tilapia del Nilo Oreochromis niloticus en un sistema híperintensivo de recirculación acuícola con mínimo recambio de agua. Lat. Am. J. Aquat. Res. 41, 150-162. doi:103856/vol41-issue1-fulltext-12

Haghighi, M., 2012. The effect of humic and glutamic acids in nutrient solution on the $\mathrm{N}$ metabolism in lettuce. J. Sci. Food Agric. 92, 3023-8. doi:10.1002/jsfa.5718

Håkanson, L., Carlsson, L., Johansson, T., 1998. A new approach to calculate the phosphorus load to lakes from fish farm emissions. Aquac. Eng. 17, 149-166. doi:10.1016/S0144-8609(97)000186

Hambly, A.C., Arvin, E., Pedersen, L.-F., Pedersen, P.B., Seredyńska-Sobecka, B., Stedmon, C.A., 2015. Characterising organic matter in recirculating aquaculture systems with fluorescence EEM spectroscopy. Water Res. 83, 112-120. doi:10.1016/j.watres.2015.06.037

Hatayama, R., Takahashi, R., Ohshima, M., Shibasaki, R., Tokuyama, T., 2000. Ribulose-1,5bisphosphate carboxylase/oxygenase from an ammonia-oxidizing bacterium, Nitrosomonas sp. K1: Purification and properties. J. Biosci. Bioeng. 90, 426-430. doi:10.1016/S13891723(01)80013-X

Hill, S., Abaidoo, R., Miyasaka, S., 1998. Sodium Chloride Concentration Affects Early Growth and Nutrient Accumulation in Taro. HortScience 33, 1153-1156.

Hochmuth, G.J., Hanlon, E.A., 2010. Commercial Vegetable Fertilization Principles. Univ. Florida, Soil Water Sci. Dept., Florida Coop. Ext. Serv. SL319. 1-17.

Horváth, L., Tamás, G., Seagrave, C., 2002. Carp and Pond Fish Culture, 2nd ed. Blackwell Science Ltd, London, UK.

Huang, Z., Gedalanga, P.B., Asvapathanagul, P., Olson, B.H., 2010. Influence of physicochemical and operational parameters on Nitrobacter and Nitrospira communities in an aerobic activated sludge bioreactor. Water Res. 44, 4351-8. doi:10.1016/j.watres.2010.05.037

Hui, S.C.M., 2011. Green roof urban farming for buildings in high-density urban cities, in: World Green Roof Conference. pp. 1-9.

IME, 2013. Global Food: Waste Not, Want Not. London.

Ismail, B., Ahmed, W., 2009. Thermoelectric Power Generation Using Waste-Heat Energy as an Alternative Green Technology. Recent Patents Electr. Eng. doi:10.2174/1874476110902010027

Jijakli, H.M., 2011. Pichia anomala in biocontrol for apples: 20 years of fundamental research and practical applications. Antonie Van Leeuwenhoek 99, 93-105. doi:10.1007/s10482-010-95412

Jijakli, M.H., Delaide, B., Gott, J., 2016. Plant production capacity and nutrient mass balance in the PAFF Box, an urban aquaponics module: Preliminary findings.

Jolliet, O., Bailey, B.., 1992. The effect of climate on tomato transpiration in greenhouses: measurements and models comparison. Agric. For. Meteorol. 58, 43-62. doi:10.1016/01681923(92)90110-P

Jones, B.J., 2005. Hydroponics - A practical guide for the soilless grower, 2nd ed. CRC Press, Boca Raton, FL.

Jorgensen, B., Meisel, E., Schilling, C., Swenson, D., Thomas, B., 2009. Developing food production systems in population centers. Biocycle.

Jung, I.S., Lovitt, R.W., 2011. Leaching techniques to remove metals and potentially hazardous nutrients from trout farm sludge. Water Res. 45, 5977-5986. 
doi:10.1016/j.watres.2011.08.062

Kafkafi, U., Tarchitzky, J., 2011. Fertigation. A Tool for Efficient Water and Nutrient Management. IFA and IPI, Paris, France.

Kaiser, D.E., Lamb, J.A., Bloom, P.R., 2011. Managing Iron Deficiency Chlorosis in Soybean [WWW Document]. Univ. Minnesota. URL http://www.extension.umn.edu/agriculture/nutrientmanagement/micronutrients/managing-iron-deficiency-chlorosis-in-soybean/ (accessed 8.1.14).

Kampschreur, M.J., Temmink, H., Kleerebezem, R., Jetten, M.S.M., van Loosdrecht, M.C.M., 2009. Nitrous oxide emission during wastewater treatment. Water Res. doi:10.1016/j.watres.2009.03.001

Karimanzira, D., Keesman, K.J., Kloas, W., Baganz, D., Rauschenbach, T., 2016. Dynamic modeling of the INAPRO aquaponic system. Aquac. Eng. 75, 29-45. doi:10.1016/j.aquaeng.2016.10.004

Keen, G.A., Prosser, J.I., 1987. Interrelationship between pH and surface growth of Nitrobacter. Soil Biol. Biochem. 19, 665-672. doi:10.1016/0038-0717(87)90045-9

Klas, S., Mozes, N., Lahav, O., 2006. Development of a single-sludge denitrification method for nitrate removal from RAS effluents: Lab-scale results vs. model prediction. Aquaculture 259, 342-353. doi:10.1016/j.aquaculture.2006.05.049

Klinger, D., Naylor, R., 2012. Searching for Solutions in Aquaculture: Charting a Sustainable Course. Annu. Rev. Environ. Resour. Vol 37 37, 247. doi:10.1146/annurev-environ-021111-161531

Kloas, W., Groß, R., Baganz, D., Graupner, J., Monsees, H., Schmidt, U., Staaks, G., Suhl, J., Tschirner, M., Wittstock, B., Wuertz, S., Zikova, A., Rennert, B., 2015. A new concept for aquaponic systems to improve sustainability, increase productivity, and reduce environmental impacts. Aquac. Environ. Interact. 7, 179-192. doi:doi: 10.3354/aei00146

Knaus, U., Palm, H.W., 2017. Effects of fish biology on ebb and flow aquaponical cultured herbs in northern Germany (Mecklenburg Western Pomerania). Aquaculture 466, 51-63. doi:10.1016/j.aquaculture.2016.09.025

Kouassi, K.H.S., Bajji, M., Jijakli, H., 2012. The control of postharvest blue and green molds of citrus in relation with essential oil-wax formulations, adherence and viscosity. Postharvest Biol. Technol. 73, 122-128.

Krayzelova, L., Bartacek, J., Díaz, I., Jeison, D., Volcke, E.I.P., Jenicek, P., 2015. Microaeration for hydrogen sulfide removal during anaerobic treatment: a review. Rev. Environ. Sci. Bio/Technology 14, 703-725. doi:10.1007/s11157-015-9386-2

Krishnasamy, K., Nair, J., Bäuml, B., 2012. Hydroponic system for the treatment of anaerobic liquid. Water Sci. Technol. 65, 1164-71. doi:10.2166/wst.2012.031

Krom, M.D., Ben David, A., Ingall, E.D., Benning, L.G., Clerici, S., Bottrell, S., Davies, C., Potts, N.J., Mortimer, R.J.G., Van Rijn, J., 2014. Bacterially mediated removal of phosphorus and cycling of nitrate and sulfate in the waste stream of a "zero-discharge" recirculating mariculture system. Water Res. 56, 109-121. doi:10.1016/j.watres.2014.02.049

Lambers, H., Chapin, F.S., Pons, T.L., 2008. Plant Physiological Ecology, 2nd ed. Springer, New York. doi:10.1007/978-0-387-78341-3

Lang, G., Buchbauer, G., 2012. A review on recent research results (2008-2010) on essential oils as antimicrobials and antifungals. A review. Flavour Fragr. J. 27, 13-39. doi:10.1002/ffj.2082

Lehman, H., Clark, E.A., Weise, S.F., 1993. Clarifying the definition of Sustainable agriculture. J. Agric. Environ. Ethics 6, 127-143.

Lekang, O.-I., 2007. Aquaculture Engineering. Blackwell Publishing Ltd.

Lekang, O.-I., Kleppe, H., 2000. Efficiency of nitrification in trickling filters using different filter media. Aquac. Eng. 21, 181-199. doi:http://dx.doi.org/10.1016/S0144-8609(99)00032-1

Lennard, W.A., Leonard, B. V, 2006. A Comparison of Three Different Hydroponic Sub-systems (gravel bed, floating and nutrient film technique) in an Aquaponic Test System. Aquac. Int. 14, 539-550. doi:10.1007/s10499-006-9053-2 
Lennard, W., Leonard, B., 2005. A comparison of reciprocating flow versus constant flow in an integrated, gravel bed, aquaponic test system. Aquac. Int. 12, 539-553. doi:10.1007/s10499005-8528-x

Letey, J., Jarrell, W.M., Valoras, N., 1982. Nitrogen and water uptake patterns and growth of plants at various minimum solution nitrate concentrations. J. Plant Nutr. 5, 73-89. doi:10.1080/01904168209362939

Lettinga, G., Pol, L.W.H., 2011. UASB-Process Design for Various Types of Wastewaters.

Liang, J.Y., Chien, Y.H., 2013. Effects of feeding frequency and photoperiod on water quality and crop production in a tilapia-water spinach raft aquaponics system. Int. Biodeterior. Biodegradation 85, 693-700. doi:DOI 10.1016/j.ibiod.2013.03.029

Licamele, J.D., 2009a. Biomass Production and Nutrient Dynamics in an Aquaponics System.

Licamele, J.D., 2009b. Biomass Production and Nutrient Dynamics in an Aquaponics System.

López-Arredondo, D.L., Leyva-González, M.A., Alatorre-Cobos, F., Herrera-Estrella, L., 2013.

Biotechnology of nutrient uptake and assimilation in plants. Int. J. Dev. Biol. 57, 595-610. doi:10.1387/ijdb.130268lh

Losordo, T.M., Masser, M.P., Rakocy, J.E., 1999. Recirculating Aquaculture Tank Production Systems - A Review of Component Options. Souther Reg. Aquac. Cent.

Love, D.C., Fry, J.P., Genello, L., Hill, E.S., Frederick, J.A., Li, X., Semmens, K., 2014. An international survey of aquaponics practitioners. PLoS One 9, 1-10.

Love, D.C., Fry, J.P., Li, X., Hill, E.S., Genello, L., Semmens, K., Thompson, R.E., 2015. Commercial aquaponics production and profitability: Findings from an international survey. Aquaculture $435,67-74$.

Lu, X., Zhen, G., Estrada, A.L., Chen, M., Ni, J., Hojo, T., Kubota, K., Li, Y.-Y., 2015. Operation performance and granule characterization of upflow anaerobic sludge blanket (UASB) reactor treating wastewater with starch as the sole carbon source. Bioresour. Technol. 180C, 264-273. doi:10.1016/j.biortech.2015.01.010

Lucas, R.E., Davis, J.F., 1961. Relationships between pH values of organic soils and availabilities of 12 plant nutrients. Soil Sci. 92, 177-182.

Lynch, J., Marschner, P., Rengel, Z., 2012. Effect of Internal and External Factors on Root Growth and Development, in: Marschner, P. (Ed.), Marschner's Mineral Nutrition of Higher Plants. Elsevier Ltd, pp. 331-346.

Mandal, R.N., Datta, A.K., Sarangi, N., Mukhopadhyay, P.K., 2010. Diversity of aquatic macrophytes as food and feed components to herbivorous fish - A review. Indian J. Fish.

Mangmang, J.S., Deaker, R., Rogers, G., 2015. Response of lettuce seedlings fertilized with fish effluent to Azospirillum brasilense inoculation. Biol. Agric. Hortic. 31, 61-71. doi:10.1080/01448765.2014.972982

Marschner, H., 2012. Marschner's Mineral Nutrition of Higher Plants, Marschner's Mineral Nutrition of Higher Plants. Elsevier. doi:10.1016/B978-0-12-384905-2.00026-1

Marschner, H., 1986. Mineral Nutrition of Higher Plants. Academic Press, London.

Martins, C.I.M., Eding, E.H., Verdegem, M.C.J., Heinsbroek, L.T.N., Schneider, O., Blancheton, J.P., D'Orbcastel, E.R., Verreth, J.A.J., 2010. New developments in recirculating aquaculture systems in Europe: A perspective on environmental sustainability. Aquac. Eng. 43, 83-93. doi:10.1016/j.aquaeng.2010.09.002

Martins, C.I.M., Eding, E.H., Verreth, J.A.J., 2011. The effect of recirculating aquaculture systems on the concentrations of heavy metals in culture water and tissues of Nile tilapia Oreochromis niloticus. Food Chem. 126, 1001-1005. doi:10.1016/j.foodchem.2010.11.108

Mathieu, J., Linker, R., Levine, L., Albright, L., Both, A.J., Spanswick, R., Wheeler, R., Wheeler, E., deVilliers, D., Langhans, R., 2006. Evaluation of the Nicolet Model for Simulation of Short-term Hydroponic Lettuce Growth and Nitrate Uptake. Biosyst. Eng. 95, 323-337. doi:10.1016/j.biosystemseng.2006.07.006 
Mayak, S., Tirosh, T., Glick, B.R., 2004. Plant growth-promoting bacteria confer resistance in tomato plants to salt stress. Plant Physiol. Biochem. 42, 565-572. doi:10.1016/j.plaphy.2004.05.009

McMurtry, M.R., Sanders, D.C., Cure, J.D., Hodson, R.G., Haning, B.C., Amand, E.C.S., 1997. Efficiency of Water Use of an Integrated Fish/Vegetable Co-Culture System. J. World Aquac. Soc. 28, 420428. doi:10.1111/j.1749-7345.1997.tb00290.x

Miličić, V., Thorarinsdottir, R., Santos, M., Hančič, M., 2017. Commercial Aquaponics Approaching the European Market: To Consumers' Perceptions of Aquaponics Products in Europe. Water 9, 80. doi:10.3390/w9020080

Millennium Ecosystem Assessment, 2005. Ecosystems and Human Well-being: Synthesi. Washington.

Mirzoyan, N., Gross, A., 2013. Use of UASB reactors for brackish aquaculture sludge digestion under different conditions. Water Res. 47, 2843-50. doi:10.1016/j.watres.2013.02.050

Mirzoyan, N., McDonald, R.C., Gross, A., 2012. Anaerobic Treatment of Brackishwater Aquaculture Sludge: An Alternative to Waste Stabilization Ponds. J. World Aquac. Soc. 43, 238-248. doi:10.1111/j.1749-7345.2012.00554.x

Mirzoyan, N., Tal, Y., Gross, A., 2010. Anaerobic digestion of sludge from intensive recirculating aquaculture systems: Review. Aquaculture 306,1-6. doi:10.1016/j.aquaculture.2010.05.028

Möller, M., Assouline, S., 2006. Effects of a shading screen on microclimate and crop water requirements. Irrig. Sci. 25, 171-181. doi:10.1007/s00271-006-0045-9

Monsees, H., Keitel, J., Kloas, W., Wuertz, S., 2015. Potential reuse of aquacultural waste for nutrient solutions in aquaponics., in: Proc of Aquaculture Europe. Rotterdam, The Netherlands.

Monsees, H., Keitel, J., Paul, M., Kloas, W., Wuertz, S., 2017. Potential of aquacultural sludge treatment for aquaponics: evaluation of nutrient mobilization under aerobic and anaerobic conditions. Aquac. Environ. Interact. 9, 9-18. doi:10.3354/aei00205

Mórrígan, T., 2010. Peak Phosphorus - A Potential Food Security Crisis. Santa Barbara, CA, USA.

Mylonas, V.A., McCants, C.B., 1980. Effects of humic and fulvic acids on growth of tobacco. Plant Soil 54, 485-490. doi:10.1007/BF02181841

Neori, A., Krom, M.D., Rijn, J. van, 2007. Biogeochemical processes in intensive zero-effluent marine fish culture with recirculating aerobic and anaerobic biofilters. J. Exp. Mar. Bio. Ecol. 349, 235247.

Neto, R.M., Ostrensky, A., 2013. Nutrient load estimation in the waste of Nile tilapia Oreochromis niloticus (L.) reared in cages in tropical climate conditions. Aquac. Res. n/a-n/a. doi:10.1111/are.12280

Neumann, G., Römheld, V., 2012. Rhizosphere Chemistry in Relation to Plant Nutrition, in: Marschner, P. (Ed.), Marschner's Mineral Nutrition of Higher Plants2. Elsevier Ltd, pp. 347368.

Nichols, M.A., Savidov, N.A., 2012. Aquaponics: A nutrient and water efficient production system. Acta Hort. 129-132.

Nichols, M., Lennard, W., 2010. Aquaponics in New Zealand. Pract. Hydroponics Greenhouses 4651.

Nott, K., Savage, M.J., 1984. Radiation Measurements from the Namib Desert. MADOQUA 14, 165172.

Olsen, C., 1950. The Significance of Concentration for the Rate of Ion Absorption by Higher Plants in Water Culture. Physiol. Plant. 3, 152-164. doi:10.1111/j.1399-3054.1950.tb07498.x

Palm, H.W., Nievel, M., Knaus, U., 2015. Significant factors affecting the economic sustainability of closed aquaponic systems. Part III: Plant units. AACL Bioflux 8, 89-106.

Palm, H.W., Seidemann, R., Wehofsky, S., Knaus, U., 2014. Significant factors affecting the economic sustainability of closed aquaponic systems. Part I: System design, chemo-physical parameters and general aspects. AACL Bioflux 7, 20-32.

Pang, J., Cuin, T., Shabala, L., Zhou, M., Mendham, N., Shabala, S., 2007. Effect of secondary 
metabolites associated with anaerobic soil conditions on ion fluxes and electrophysiology in barley roots. Plant Physiol. 145, 266-76. doi:10.1104/pp.107.102624

Pantanella, E., Cardarelli, M., Colla, G., Rea, E., Marcucci, A., 2012. Aquaponics vs. Hydroponics: Production and Quality of Lettuce Crop. Acta Hort. 927, 887-893.

Pantanella, E., Cardarelli, M., Colla, G., Rea, E., Marcucci, A., 2012. Aquaponics vs. Hydroponics: Production and Quality of Lettuce Crop. Acta Hort. 887-893.

Parker, R., 2002. Aquaculture Science, 2nd ed. Cengage.

Penetra, R., Reali, M., Fortesi, E., Campos, J., 1999. Post-treatment of effluents from anaerobic reactor treating domestic sewage by dissolved-air flotation. Water Sci. Technol. 40, 137-143. doi:10.1016/S0273-1223(99)00619-8

Pingel, U., 1976. Der Einfluß phenolischer Aktivatoren und Inhibitoren der IES-Oxydase-Aktivität auf die Adventivbewurzelung bei Tradescantia albiflora. Zeitschrift für Pflanzenphysiologie 79, 109-120. doi:10.1016/S0044-328X(76)80121-3

Polomski, R.F., 2007. South Carolina Master Gardener Training Manual. Clemson University.

Pulvenis, J.-F., 2014. Fisheries and Aquaculture topics. The State of World Fisheries and Aquaculture (SOFIA). Topics Fact Sheets. Rome.

Qi, Y., 2012. Vermiculture Technology: Earthworms, Organic Wastes, and Environmental Management. Int. J. Environ. Stud. doi:10.1080/00207233.2012.624327

R Core Team, 2012. R: A language and environment for statistical computing. R Foundation for Statistical Computing. Vienna, Austria.

Rafiee, G., Saad, C.R., 2005. Nutrient cycle and sludge production during different stages of red tilapia (Oreochromis sp.) growth in a recirculating aquaculture system. Aquaculture 244, 109118.

Ragnarsdottir, K. V, Sverdrup, H.U., Koca, D., 2011. Challenging the planetary boundaries I: Basic principles of an integrated model for phosphorous supply dynamics and global population size. Appl. Geochemistry 26, S303-S306. doi:DOI 10.1016/j.apgeochem.2011.03.088

Ragnarsson, Á., 2003. Utilization of geothermal energy in Iceland, in: International Geothermal Conference.

Rakocy, J.A., Hargreaves, J.E., 1993. Integration of vegetable hydroponics with fish culture: a review.

Rakocy, J.E., 2012. Aquaponics-Integrating Fish and Plant Culture. Wiley-Blackwell, pp. 344-386. doi:10.1002/9781118250105.ch14

Rakocy, J.E., 2007. Ten Guidelines for Aquaponic Systems. Aquaponics J. 1, 14-17.

Rakocy, J.E., 1989. Hydroponic lettuce production in a recirculating fish culture system. Isl. Perspect. 5-10.

Rakocy, J.E., Bailey, D.S., 2012. Initial Economic Analyses of Aquaponic Systems.

Rakocy, J.E., Bailey, D.S., Shultz, K.A., Cole, W.M., 1997. Evaluation of a commercial-scale aquaponic unit for the production of tilapia and lettuce, in: 4th International Symposium on Tilapia in Aquaculture. p. 1:357--372.

Rakocy, J.E., Bailey, D.S., Shultz, R.C., Thoman, E.S., 2004a. Update on tilapia and vegetable production in the UVI aquaponic system. New dimensions on farmed tilapia., in: Proceedings from the 6th International Symposium on Tilapia in Aquaculture. Manila, Philippines, pp. 1-15.

Rakocy, J.E., Masser, M.P., Losordo, T.M., 2006. Recirculating aquaculture tank production systems: Aquaponics- integrating fish and plant culture. Srac Publ. - South. Reg. Aquac. Cent. 1-16.

Rakocy, J.E., Shultz, R.C., Bailey, D.S., Thoman, E.S., 2004b. Aquaponic production of tilapia and basil: Comparing a batch and staggered cropping system, in: Nichols, M.A. (Ed.), . pp. 63-69.

Rakocy, J.E., Shultz, R.C., Bailey, D.S., Thoman, E.S., 2004. Aquaponic production of tilapia and basil: Comparing a batch and staggered cropping system, in: Acta Horticulturae. pp. 63-69.

Rakocy, J.E., Shultz, R.C., Bailey, D.S., Thoman, E.S., 2004c. Aquaponic production of tilapia and basil: Comparing a batch and staggered cropping system.

Resh, H.M., 2013. Hydroponic Food Production: A Definite Guidebook for the Advanced Home 
Gardener and the Commercial Hydroponic Grower, 7th ed. CRC Press.

Resh, H.M., 2012. Hydroponic food production : a definitive guidebook for the advanced home gardener and the commercial hydroponic grower. Boca Raton, FL : CRC Press, Boca Raton, FL.

Resh, H.M., 2002. Hydroponic Tomatoes. CRC Press, Boca Raton, FL, USA.

Reyes Lastiri, D., Slinkert, T., Cappon, H.J., Baganz, D., Staaks, G., Keesman, K.J., 2016. Model of an aquaponic system for minimised water, energy and nitrogen requirements. Water Sci. Technol. wst2016127. doi:10.2166/wst.2016.127

Rogers, P., 2008. Facing the Freshwater Crisis. Sci. Am. 299, 46-53. doi:10.1038/scientificamerican0808-46

Roosta, H.R., Hamidpour, M., 2011. Effects of foliar application of some macro- and micro-nutrients on tomato plants in aquaponic and hydroponic systems. Sci. Hortic. (Amsterdam). 129, 396402. doi:DOI 10.1016/j.scienta.2011.04.006

Ross, L.G., 2000. Environmental physiology and energetics, in: McAndrew, B.J. (Ed.), Tilapias: Biology and Exploitation. Springer Netherlands, pp. 89-128.

Rupasinghe, J.W., Kennedy, J.O.S., 2010. Economic benefits of integrating a hydroponic-lettuce system into a barramundi fish production system. Aquac. Econ. Manag. 14, 81-96. doi:10.1080/13657301003776631

Ruzzi, M., Aroca, R., 2015. Plant growth-promoting rhizobacteria act as biostimulants in horticulture. Sci. Hortic. (Amsterdam). 196, 124-134. doi:10.1016/j.scienta.2015.08.042

Saha, S., Monroe, A., Day, M.R., 2016. Growth, yield, plant quality and nutrition of basil (Ocimum basilicum L.) under soilless agricultural systems. Ann. Agric. Sci. 61, 181-186. doi:10.1016/j.aoas.2016.10.001

Salminen, E., Rintala, J., Härkönen, J., Kuitunen, M., Högmander, H., Oikari, A., 2001. Anaerobically digested poultry slaughterhouse wastes as fertiliser in agriculture. Bioresour. Technol. 78, 8188. doi:10.1016/S0960-8524(00)00160-7

Santos, B.M., Dusky, J.A., Stall, W.M., Bewick, T.A., Shilling, D.G., Gilreath, J.P., 2004. Phosphorus absorption in lettuce, smooth pigweed (Amaranthus hybridus), and common purslane (Portulaca oleracea) mixtures. Weed Sci. 52, 389-394. doi:10.1614/WS-03-053R

Saraf, M., Pandya, U., Thakkar, A., 2014. Role of allelochemicals in plant growth promoting rhizobacteria for biocontrol of phytopathogens. Microbiol. Res. 169, 18-29. doi:10.1016/j.micres.2013.08.009

Savidov, N., 2005. Evaluation and Development or Aquaponics Production and Product Market Capabilities in Alberta. Alberta Agric. Food Rural Dev.

Savidov, N.A., Hutchings, E., Rakocy, J.E., 2007. Fish and plant production in a recirculating aquaponic system: A new approach to sustainable agriculture in Canada.

Savvas, D., Passam, H.C., Olympios, C., Nasi, E., Moustaka, E., Mantzos, N., Barouchas, P., 2006. Effects of Ammonium Nitrogen on Lettuce Grown on Pumice in a Closed Hydroponic System. HortScience 41, 1667-1673.

Schmautz, Z., Loeu, F., Liebisch, F., Graber, A., Mathis, A., Griessler Bulc, T., Junge, R., 2016. Tomato Productivity and Quality in Aquaponics: Comparison of Three Hydroponic Methods. Water 8, 533. doi:10.3390/w8110533

Schneider, O., Sereti, V., Eding, E.H., Verreth, J.A.J., 2005. Analysis of nutrient flows in integrated intensive aquaculture systems. Aquac. Eng. 32, 379-401. doi:http://dx.doi.org/10.1016/j.aquaeng.2004.09.001

Schrader, K.K., Davidson, J.W., Summerfelt, S.T., 2013. Evaluation of the impact of nitrate-nitrogen levels in recirculating aquaculture systems on concentrations of the off-flavor compounds geosmin and 2-methylisoborneol in water and rainbow trout (Oncorhynchus mykiss). Aquac. Eng. 57, 126-130. doi:10.1016/j.aquaeng.2013.07.002

Schram, E., Roques, J.A.C., Abbink, W., Yokohama, Y., Spanings, T., de Vries, P., Bierman, S., van de Vis, H., Flik, G., 2012. The impact of elevated water nitrate concentration on physiology, 
growth and feed intake of African catfish Clarias gariepinus (Burchell 1822). Aquac. Res. n/an/a. doi:10.1111/are.12098

Seawright, D.E., Stickney, R.R., Walker, R.B., 1998a. Nutrient dynamics in integrated aquaculturehydroponics systems. Aquaculture 215-237.

Seawright, D.E., Stickney, R.R., Walker, R.B., 1998b. Nutrient dynamics in integrated aquaculturehydroponics systems. Aquaculture 160, 215-237.

Shahzad, M.W., Burhan, M., Ang, L., Ng, K.C., 2017. Energy-water-environment nexus underpinning future desalination sustainability. Desalination 413, 52-64. doi:10.1016/j.desal.2017.03.009

Shatat, M., Worall, M., Riffat, S., 2013. Opportunities for solar water desalination worldwide: Review. Sustain. Cities Soc. 9, 67-80. doi:10.1016/j.scs.2013.03.004

Shnel, N., Barak, Y., Ezer, T., Dafni, Z., van Rijn, J., 2002. Design and performance of a zero-discharge tilapia recirculating system. Aquac. Eng. 26, 191-203. doi:10.1016/S0144-8609(02)00013-4

Shu, L., Schneider, P., Jegatheesan, V., Johnson, J., 2006. An economic evaluation of phosphorus recovery as struvite from digester supernatant. Bioresour. Technol. doi:10.1016/j.biortech.2005.11.005

Sikawa, D.C., Yakupitiyage, A., 2010. The hydroponic production of lettuce (Lactuca sativa L) by using hybrid catfish (Clarias macrocephalus\&\#xa0;×\&\#xa0;C. gariepinus) pond water: Potentials and constraints. Agric. Water Manag. 97, 1317-1325. doi:http://dx.doi.org/10.1016/j.agwat.2010.03.013

Silber, A., Yones, L. Ben, Dori, I., 2004. Rhizosphere pH as a result of nitrogen levels and NH 4 /NO 3 ratio and its effect on zinc availability and on growth of rice flower (Ozothamnus diosmifolius). Plant Soil 262, 205-213. doi:10.1023/B:PLSO.0000037042.32687.95

Sonneveld, C., 2002. Composition of nutrient solutions., in: Hydroponic Production of Vegetables and Ornamentals. Embryo Publisher, Athens, pp. 179-2010.

Sonneveld, C., Straver, N., 1994. Nutrient Solutions for Soilless Cultures, in: Nutrient solutions for vegetables and flowers grown in water or substrates. Centrale Landbouwcatalogus, pp. 1-45.

Sonneveld, C., Voogt, W., 2009a. Nutrient Solutions for Soilless Cultures, in: Plant Nutrition of Greenhouse Crops. Springer Netherlands, pp. 257-275. doi:10.1007/978-90-481-2532-6_12

Sonneveld, C., Voogt, W., 2009b. Plant Nutrition in Future Greenhouse Production, in: Plant Nutrition of Greenhouse Crops. Springer Netherlands, pp. 393-403. doi:10.1007/978-90-4812532-6_17

Sonneveld, C., Voogt, W., 2009c. Nutrient Management in Substrate Systems, in: Plant Nutrition of Greenhouse Crops. Springer Netherlands, pp. 277-312. doi:10.1007/978-90-481-2532-6_13

Sonneveld, C., Voogt, W., 2009d. Plant Nutrition in Future Greenhouse Production, in: Plant Nutrition of Greenhouse Crops. Springer Netherlands, pp. 393-403. doi:10.1007/978-90-4812532-6_17

Stark, J.M., 1996. Modeling the temperature response of nitrification. Biogeochemistry. doi:10.1007/BF02183035

Steen, I., 1998. Phosphorus availability in the 21st century- Management of a non-renewable resource. Phosphorus and Potassium 217, 25-31.

Steingrobe, B., Schenk, M.K., 1994. A model relating the maximum nitrate inflow of lettuce (Lactuca satvia L.) to the growth of roots and shoots. Plant Soil 162, 249-257. doi:10.1007/BF01347712

Sterman, J., 2000. Business Dynamics: Systems Thinking and Modeling for a Complex World. McGraw Hill.

Stofberg, S.F., Klimkowska, A., Paulissen, M.P.C.P., Witte, J.-P.M., van der Zee, S.E.A.T.M., 2015. Effects of salinity on growth of plant species from terrestrializing fens. Aquat. Bot. 121, 83-90. doi:10.1016/j.aquabot.2014.12.004

Subramani, A., Jacangelo, J.G., 2015. Emerging desalination technologies for water treatment: A critical review. Water Res. 75, 164-187. doi:10.1016/j.watres.2015.02.032 
Suhl, J., Dannehl, D., Kloas, W., Baganz, D., Jobs, S., Scheibe, G., Schmidt, U., 2016. Advanced aquaponics: Evaluation of intensive tomato production in aquaponics vs. conventional hydroponics. Agric. Water Manag. 178, 335-344. doi:10.1016/j.agwat.2016.10.013

Suhr, K.I., Letelier-Gordo, C.O., Lund, I., 2015. Anaerobic digestion of solid waste in RAS: effect of reactor type on the biochemical acidogenic potential (BAP) and assessment of the biochemical methane potential (BMP) by a batch assay. Aquac. Eng. 65, 65-71. doi:10.1016/j.aquaeng.2014.12.005

Suzuki, Y., Maruyama, T., Numata, H., Sato, H., Asakawa, M., 2003. Performance of a closed recirculating system with foam separation, nitrification and denitrification units for intensive culture of eel: towards zero emission. Aquac. Eng. 29, 165-182. doi:10.1016/j.aquaeng.2003.08.001

Sverdrup, H., Eklund, H., Bjerle, I., 1981. Kalkning av rinnande vatten - Erfarenheter från en fluidiserad kalkbrunn. Mover. Vatten 37, 388-394.

Sverdrup, H.U., Ragnarsdottir, K. V, 2011. Challenging the planetary boundaries II: Assessing the sustainable global population and phosphate supply, using a systems dynamics assessment model. Appl. Geochemistry 26, S307-S310. doi:DOI 10.1016/j.apgeochem.2011.03.089

Timmons, M.B., Ebeling, J.M., 2013. Recirculating Aquaculture, 3rd ed. Ithaca Publishing Company LLC, Ithaca, NY.

Torri, S.I., Puelles, M.M., 2010. Use of vermiculture technology for waste management and environmental remediation in Argentina. Int. J. Glob. Environ. Issues. doi:10.1504/IJGENVI.2010.037269

Toumi, S., Vidal, R., 2010. A Comparison of Urban Agriculture and Short Food Chains in Paris and Tunis. Urban Agric. Mag. 31-34.

Tucker, C.S., Hargreaves, J.A., 2004. Biology and Culture of Channel Catfish. Elsevier Science Ltd.

Turcios, A.E., Papenbrock, J., 2014. Sustainable Treatment of Aquaculture Effluents-What Can We Learn from the Past for the Future? Sustain. 6, 836-856. doi:Doi 10.3390/Su6020836

Tyson, R. V, Simonne, E.H., Davis, M., Lamb, E.M., White, J.M., Treadwell, D.D., 2007. Effect of nutrient solution, nitrate-nitrogen concentration, and $\mathrm{pH}$ on nitrification rate in Perlite medium. J. Plant Nutr. 30, 901-913. doi:Doi 10.1080/15226510701375101

Tyson, R. V, Simonne, E.H., Treadwell, D.D., White, J.M., Simonne, A., 2008. Reconciling pH for ammonia biofiltration and cucumber yield in a recirculating aquaponic system with perlite biofilters. HortScience 43, 719-724.

Ulrich, A.E., Frossard, E., 2014. On the history of a reoccurring concept: phosphorus scarcity. Sci. Total Environ. 490, 694-707. doi:10.1016/j.scitotenv.2014.04.050

UN, 2013. Human development report 2013 [WWW Document]. UN Dev. Program. doi:ISBN: 97892-1-126340-4

van Bussel, C.G.J., Schroeder, J.P., Wuertz, S., Schulz, C., 2012. The chronic effect of nitrate on production performance and health status of juvenile turbot (Psetta maxima). Aquaculture 326-329, 163-167. doi:10.1016/j.aquaculture.2011.11.019

van Huis, A., 2013. Potential of insects as food and feed in assuring food security. Annu. Rev. Entomol. 58, 563-83.

van Lier, J.B., Mahmoud, N., Zeeman, G., 2008. Anaerobic Wastewater Treatment, in: Henze, M., van Loosdrecht, M.C.M., Ekama, G.A., Brdjanovic, D. (Eds.), Biological Wastewater Treatment: Principles, Modelling and Design. IWA Publishing, London, England, pp. 415-456.

Van Rijn, J., 2013. Waste treatment in recirculating aquaculture systems. Aquac. Eng. 53, 49-56. doi:10.1016/j.aquaeng.2012.11.010

Veras, G.C., Murgas, L.D.S., Rosa, P.V., Zangeronimo, M.G., Ferreira, M.S. da S., Leon, J.A.S.-D., 2013. Effect of photoperiod on locomotor activity, growth, feed efficiency and gonadal development of Nile tilapia. Rev. Bras. Zootec. 42, 844-849. doi:10.1590/S1516-35982013001200002

Vermeulen, N.V.J., 2012. Recirculation Aquaculture System (RAS) with Tilapia in a Hydroponic 
System with Tomatoes. Acta Hort. 927.

Vermeulen, T., Kamstra, A., 2013. The need for systems design for robust aquaponic systems in the urban environment.

Villarroel, M., Alvariño, J., Duran, J., 2011. Aquaponics: integrating fish feeding rates and ion waste production for strawberry hydroponics. Spanish J. Agric. Res. 9, 537-545. doi:10.5424/sjar/20110902-181-10

Villarroel, M., Junge, R., Komives, T., König, B., Plaza, I., Bittsánszky, A., Joly, A., 2016. Survey of Aquaponics in Europe. Water 8, 468. doi:10.3390/w8100468

Villarroell, M., Alvarino, J.M.R., Duran, J.M., 2011. Aquaponics: integrating fish feeding rates and ion waste production for strawberry hydroponics. Spanish J. Agric. Res. 9, 537-545.

Villaverde, S., 1997. Influence of $\mathrm{pH}$ over nitrifying biofilm activity in submerged biofilters. Water Res. 31, 1180-1186. doi:10.1016/S0043-1354(96)00376-4

Voogt, W., 2002. Potassium Management of Vegetables Under. N.S. Pasricha S.K. Bansal SK (eds.), Int. potash institute, Bern, Switz. 347-362.

Walan, P., Davidsson, S., Johansson, S., Höök, M., 2014. Phosphate rock production and depletion: Regional disaggregated modeling and global implications. Resour. Conserv. Recycl. 93, 178187. doi:10.1016/j.resconrec.2014.10.011

Warncke, D.D., Barber, S.A., 1974. Nitrate Uptake Effectiveness of Four Plant Species1. J. Environ. Qual. 3, 28. doi:10.2134/jeq1974.00472425000300010009x

Webster, C.D., Lim, C., 2008. Tilapia. CRC-Press.

Wedemeyer, G., 1996. Physiology of Fish in Intensive Culture Systems. Springer. doi:10.1007/9781-4615-6011-1

Wellborn, T.L., 1988. Channel Catfish: Life History and Biology. South. Reg. Aquac. Cent.

Westin, D.T., 1974. Nitrate and nitrite toxicity to salmonid fishes. Progress. Fish-Culturist 36, 86-89.

Wohlgenant, M.K., 2001. Marketing margins: Empirical analysis, Handbook of Agricultural Economics.

World Bank, 2013. Fish to 2030 : prospects for fisheries and aquaculture.

WWAP (World Water Assessment Programme), 2012. The United Nations World Water Development Report 4: Managing Water under Uncertainty and Risk. Paris.

Yavuzcan Yildiz, H., Robaina, L., Pirhonen, J., Mente, E., Domínguez, D., Parisi, G., 2017. Fish Welfare in Aquaponic Systems: Its Relation to Water Quality with an Emphasis on Feed and Faeces-A Review. Water 9, 13. doi:10.3390/w9010013

Yogev, U., Barnes, A., Gross, A., 2016. Nutrients and Energy Balance Analysis for a Conceptual Model of a Three Loops off Grid, Aquaponics. Water 2016, Vol. 8, Page 589 8, 589. doi:10.3390/W8120589

Zekki, H., Gauthier, L., Gosselin, A., 1996. Growth, Productivity, and Mineral Composition of Hydroponically Cultivated Greenhouse Tomatoes, with or without Nutrient Solution Recycling. J. Amer. Soc. Hort. Sci. 121, 1082-1088.

Zhao, L., Guo, J., Lian, J., Guo, Y., Yue, L., Gou, C., Zhang, C., Liu, X., 2015. Study of the dynamics and material transformation characteristics of nitrite denitrification in UASB. Biotechnol. Biotechnol. Equip. 29, 907-914. doi:10.1080/13102818.2015.1050789

Zhu, S., Chen, S., 2002. The impact of temperature on nitrification rate in fixed film biofilters. Aquac. Eng. 26, 221-237.

Zolnier, S., Lyra, G.B., Gates, R.S., 2004. Evapotranspiration estimates for greenhouse lettuce using an intermittent nutrient film technique. Am. Soc. Agric. Biol. Eng. 47, 271-282.

doi:10.13031/2013.15868 


\section{Appendix A}

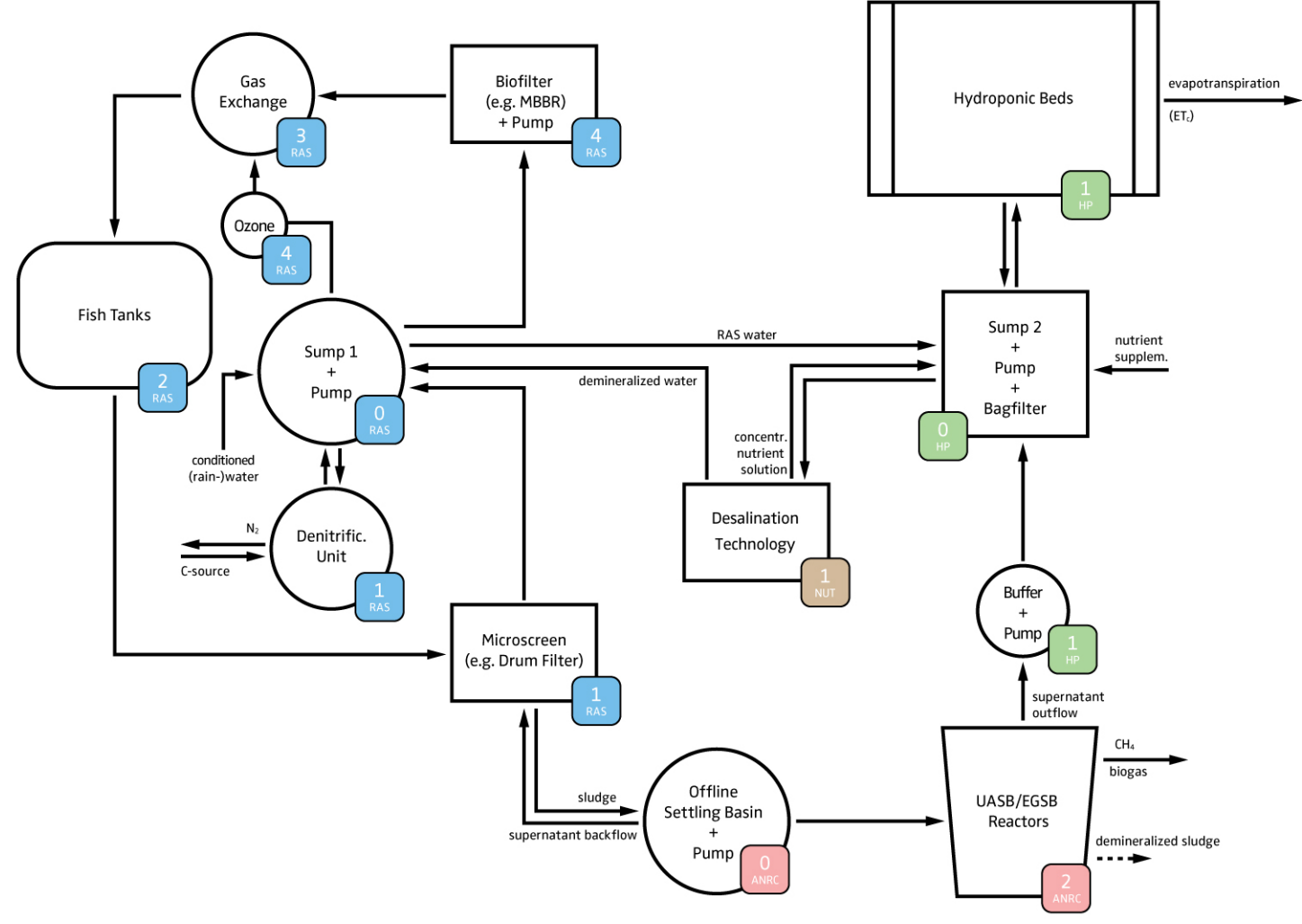

A.1. More detailed scheme of our theoretical design as presented in Figure 8.1. The blue color represents the RAS loop, the green one the hydroponic loop, the pink one the remineralization loop, and the brown one the desalination loop. The level of each component is illustrated numerically in the small box and refers to the vertical direction the flow needs to travel to; whereas high numbers refer to high positioning and low numbers to low positioning. Gravity flow occurs, when water flows from high levels to low levels, and pressurized flow is required when the flow goes from low to high numbers. 


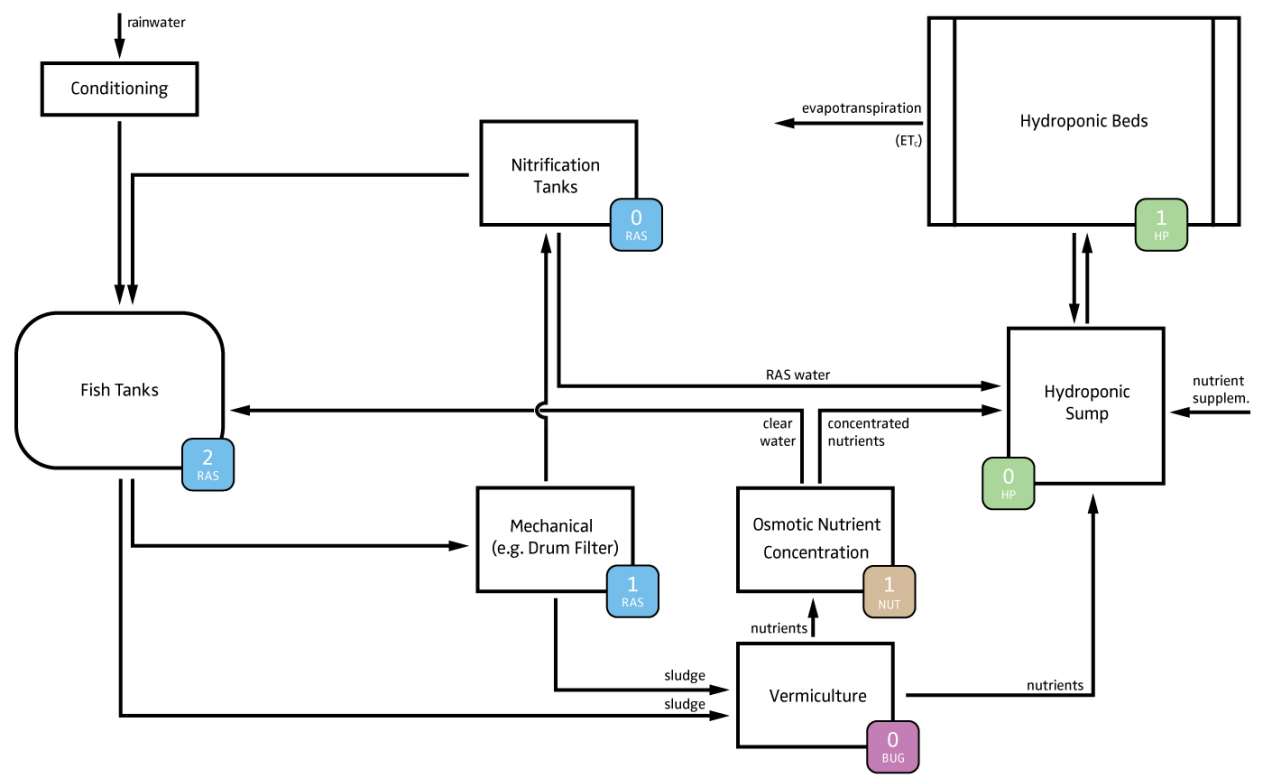

A.2. Scheme of the commerical NerBreen System, located in Hondarribia, Spain. The blue color represents the RAS loop, the green one the hydroponic loop, the purple one the vermiculture remineralization loop, and the brown one the desalination loop. The level of each component is illustrated numerically in the small box and refers to the vertical direction the flow needs to travel to; whereas high numbers refer to high positioning and low numbers to low positioning. Gravity flow occurs, when water flows from high levels to low levels, and pressurized flow is required when the flow goes from low to high numbers. 


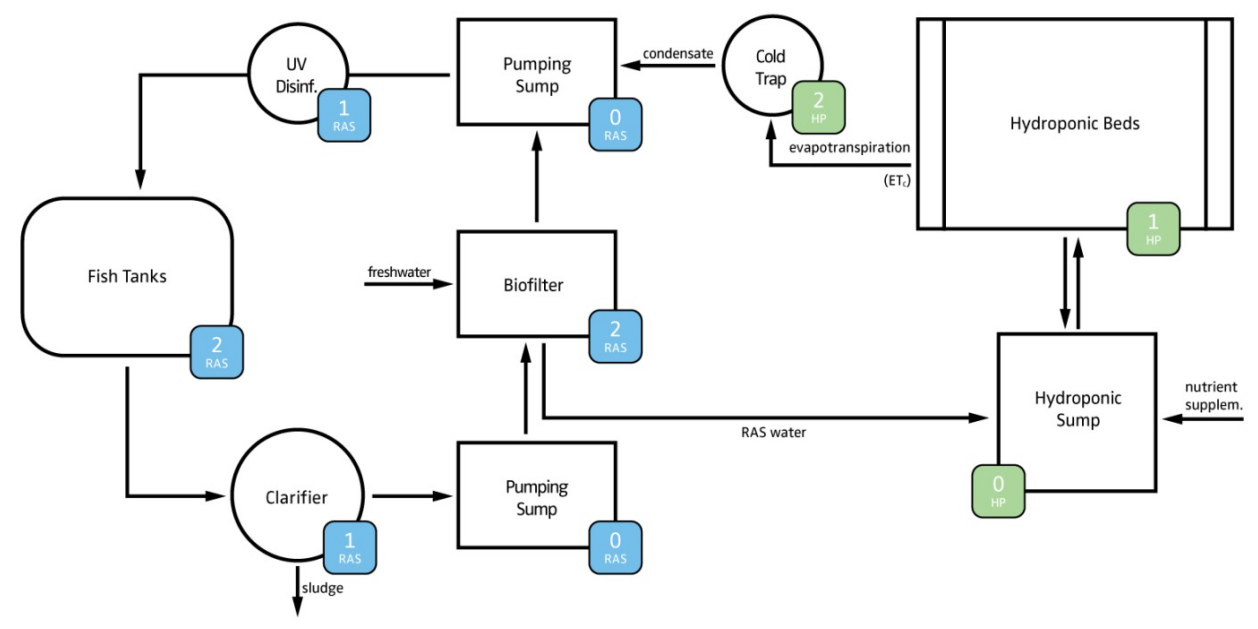

A.3. Scheme of the IGB Berlin aquaponic system for (nearly) emission free tomato and fish production in greenhouses (ASTAF-PRO) located in Berlin, Germany. The blue color represents the RAS loop and the green one the hydroponic loop. The level of each component is illustrated numerically in the small box and refers to the vertical direction the flow needs to travel to; whereas high numbers refer to high positioning and low numbers to low positioning. Gravity flow occurs, when water flows from high levels to low levels, and pressurized flow is required when the flow goes from low to high numbers. 


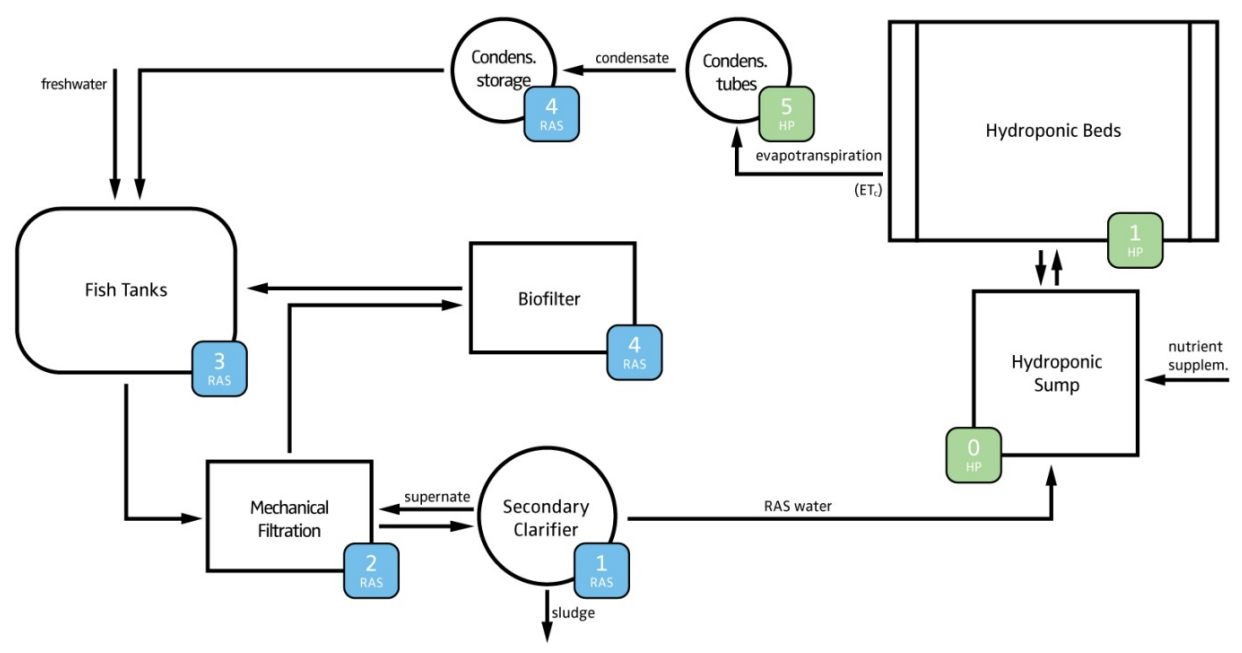

A.4. Scheme of the Tilamur (INAPRO) research system located in Lorquí, Murcia, Spain. The blue color represents the RAS loop and the green one the hydroponic loop. The level of each component is illustrated numerically in the small box and refers to the vertical direction the flow needs to travel to; whereas high numbers refer to high positioning and low numbers to low positioning. Gravity flow occurs, when water flows from high levels to low levels, and pressurized flow is required when the flow goes from low to high numbers.

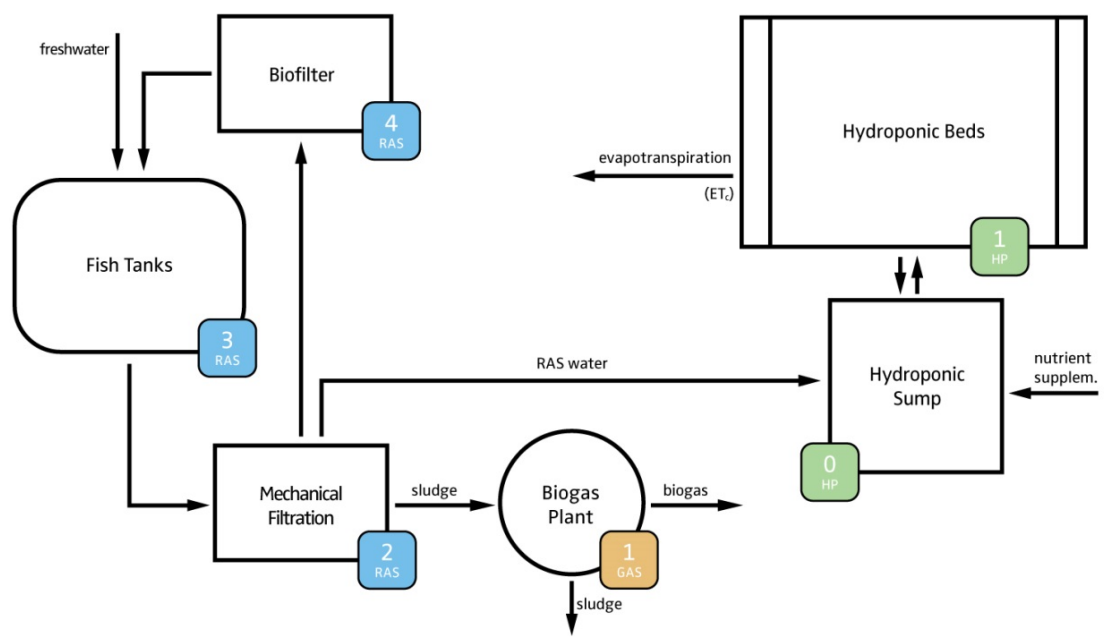


A.5. Scheme of the Inagro vzw research system located in Rumbeke-Beitem, Belgium. The blue color represents the RAS loop, the green one the hydroponic loop, and the brown one the biogas loop. The level of each component is illustrated numerically in the small box and refers to the vertical direction the flow needs to travel to; whereas high numbers refer to high positioning and low numbers to low positioning. Gravity flow occurs, when water flows from high levels to low levels, and pressurized flow is required when the flow goes from low to high numbers. 


\section{Summary}

Coupling the production of aquatic animals and plants in greenhouses forms the basis for all conventional aquaponic systems. In these systems, nutrient-rich wastewater from the aquaculture section, for for instance fish production, is used for fertilization of the plants. Hence, aquaponic systems save water compared to either single fish production or greenhouse systems. State-of-the-art commercial aquaponic systems are typically being built as one-loop systems. Here, the wastewater from the fish tanks is directly fed to the hydroponic section and subsequently directly fed back to the fish tanks. However, these systems often lack stability, technical and technological standardisation, as well as sustainability and economic profitability.

The general approach of this thesis was to assess and improve the physical feasibility of oneloop aquaponic systems by conceiving and developing multi-loop aquaponic systems, where the water from the hydroponic section with its own recirculation is not fed back to the fish tanks in the recirculating aquaculture system (RAS). In this context, the general objectives of the thesis were to (1) determine the status quo of aquaponic systems and identify current bottlenecks that need to be addressed in order to improve commercial feasibility; (2) to determine statistically to what degree RAS-derived water as well as effluents from aerobic and anaerobic remineralization reactors have an impact on lettuce growth and provide hypotheses that could explain these differences; and (3) to develop a multi-loop aquaponic system layout by system dynamic modelling considering previous findings and ultimately offer important insights into sizing and designing such systems.

The review paper presented in Chapter 2 serves as a theoretical basis for this thesis. The analysis performed in this chapter shows that aquaponics as such can become an important driver for the development of integrated food production systems. However, requirements to increase its production efficiency to be able to compete with both intensive aquaculture and hydroponic food production systems were identified. These requirements especially include optimal conditions for both fish and plants in aquaculture and hydroponic systems, respectively, as well as the utilization of the nutrient-rich aquaculture-derived sludge.

Enhanced growth rates of plants cultivated in decoupled multi-loop aquaponic systems compared to conventional hydroponic installations have been observed in experimental research (Chapters 3-5). More specifically, lettuce that was grown in a RAS-water-based hydroponic nutrient solution showed 39\% better growth performances than the rainwater- 
based hydroponic control that had the same chemical nutrient composition (Chapter 3 ). The same study showed that plants grown in a conventional one-loop aquaponic control system showed a lower growth than the hydroponic system. In Chapter 4, we repeated the experiment for validation purposes. The differences to the previous experiment (Chapter 3 ) were that the new experiment was conducted on a larger scale, and that aquaculture water was used that consisted of significantly higher amount of sodium. The latter is known for being a growth-retarding factor. Results showed that sodium rich water might have inhibited lettuce growth in RAS-based nutrient solutions, but also that lettuce grown in this solution still showed a growth advantage of $7.9 \%$ (wet matter) and $33.2 \%$ (dry matter), respectively (i.e. compared to the previous 39\%). Lettuce was even able to take up the sodium. Sodium accumulation within the system was not observed.

A third experiment was carried out to examine the impact of effluent from either aerobic or anaerobic digestion of the fish sludge on lettuce plant growth. In this experiment a mixture of aquaculture and tap water was enriched with supernatants from both aerobic and anaerobic batch reactors (Chapter 5). This experiment played an important role in the decision making process with respect to the preferred remineralization technology (i.e. aerobic or anaerobic) implemented in the multi-loop aquaponic system model (Chapter 6). The research presented in Chapter 5 provides strong empirical confirmation that anaerobic effluents generally have a positive impact on plant growth. Generally, we hypothesize that the application of RAS water as well as anaerobic remineralization digestates stimulate both root and shoot growth. However, it is difficult to ascertain which mechanism led to the increase in this particular case but microorganisms and dissolved organic matter are suspected to play an important role.

In the first technical chapter (Chapter 6), a multi-loop aquaponic system was designed and modelled with AnyLogic. The objective of the model was to evaluate water and nutrient flows. The outcome of the model shows that the higher the evapotranspiration rate (that is dependent on light intensities), the smaller the required hydroponic cultivation area. The model study also suggests that it is possible to size the cultivation area based on P availability in the hydroponic component, as $\mathrm{P}$ is an exhaustible resource and has been identified one of the main limiting factors for plant growth.

Taking Chapter 6 as a basis, the aim of Chapter 7 was to look into optimizing the nutrient concentrations in the aquaculture and hydroponic subsystems and coming up with technical solutions. We found out that the implementation of desalination processes could contribute to concentrating the hydroponic nutrient solution, while purifying the aquaculture water. 
The integration of such a technology would also reduce the water footprint as well as the fertilization demand of multi-loop aquaponic systems.

Overall (Chapter 8), and from a global point of view, we can say that the claim of aquaponics being superior to hydroponics would be a too bold statement. Growth improvements cannot be guaranteed for all plant species. However, we disproved the often-mentioned disadvantage of growth retardation (Chapter $3 \& 4$ ). With respect to the economic value of multi-loop systems, we showed that multi-loop aquaponic systems can be competitive with current commercial hydroponic systems. From a social point of view, aquaponics constitutes a "healthy" alternative to hydroponics, as the use of antibiotics and pesticides is highly restricted in aquaponic systems. Also multi-loop aquaponic systems contribute to animal welfare, since fish will no longer have to swim in high nutrient concentrated water, while the nutrient concentration of the hydroponic component can be raised to hydroponic levels. 


\section{Samenvatting}

De basis voor alle gebruikelijke aquaponics systemen is het koppelen van de productie van aquatische dieren en planten in broeikassen. In deze systemen wordt nutriënten-rijk afvalwater van de aquacultuur, bijvoorbeeld voor de productie van vis, gebruikt voor de bemesting van planten. Door middel van dit concept besparen aquaponics systemen water in vergelijking met losstaande vis- of plantproductiesystemen. Hedendaagse commerciële aquaponics systemen bestaan meestal uit een "one-loop" systeem. Hierin wordt afvalwater uit de vistanks direct gevoed aan het hydroponics gedeelte en vervolgens direct teruggesluisd naar de vistanks. Dit soort systemen missen vaak stabiliteit, technische en technologische standaardisatie, duurzaamheid en economische rendabiliteit.

Het doel van dit proefschrift was het vaststellen en verbeteren van de fysische haalbaarheid van "one-loop" aquaponics systemen door het bedenken en ontwikkelen van "multi-loop" aquaponics systemen. Hier wordt het water van de hydrocultuur met eigen recirculatie niet teruggevoerd naar de vistanks in het "recirculating aquaculture system" (RAS). In deze context is het algemene doel om (1) het bepalen van de status quo van aquaponics systemen en het identificeren van de huidige knelpunten voor het verbeteren van de commerciële haalbaarheid; (2) het statistisch vaststellen in hoeverre RAS- en afvoerwater van aerobe en anaerobe remineralisatie reactoren een impact hebben op de groei van sla, en het geven van hypothesen die deze verschillen kunnen verklaren; en (3) het ontwikkelen van een "multiloop" aquaponics systeemconfiguratie met behulp van dynamische systeemmodellering, gebaseerd op eerder gevonden resultaten, en het verkrijgen van uiteindelijk belangrijke inzichten in het ontwerp van zulke systemen.

Hoofdstuk 2 dient als een theoretische basis voor dit proefschrift. De uitgevoerde analyse in dit hoofdstuk laat zien dat een aquaponics systeem zoals deze een belangrijke drijfveer voor de ontwikkeling van geïntegreerde voedselproductiesystemen kan zijn. De vereisten voor het verhogen van de efficiëntie van de productie om het op te nemen tegen zowel intensieve aquaculture en hydroponic voedselproductiesystemen zijn echter geïdentificeerd. Deze vereisten bevatten vooral optimale condities voor zowel vissen en planten in respectievelijk aquacultuur en hydroponic systemen, evenals het gebruikmaken van het nutriënten-rijke visslib afkomstig van de aquacultuur.

Verbeterde groeisnelheden van planten die gecultiveerd zijn in ontkoppelde "multi-loop" aquaponics systemen ten opzichte van gebruikelijke hydroponic systemen zijn opgemerkt in 
experimenteel onderzoek (Hoofdstuk 3-5). Sla gegroeid in een hydroponic nutriënten oplossing gebaseerd op RAS-water heeft een 39\% betere groeiprestatie geleverd dan de op regenwater gebaseerde hydroponic controlegroep met dezelfde scheikundige nutriënten samenstelling (Hoofdstuk 3). Dezelfde studie heeft laten zien dat planten uit een gebruikelijk "one-loop" aquaponics controlesysteem een lagere groeisnelheid laten zien dan het hydroponic systeem. In hoofdstuk 4 hebben we het experiment gevalideerd door het te herhalen. De verschillen met het vorige experiment (Hoofdstuk 3) zijn de grotere schaal van het nieuwe experiment, en het gebruik van water afkomstig uit aquacultuur dat een significant hogere hoeveelheid natrium bevatte. Het laatste genoemde staat bekend als groeivertragende factor. Resultaten hebben laten zien dat natrium rijk water de groei van sla in RAS gebaseerde nutriënten oplossing onderdrukt zou kunnen hebben, maar ook dat sla die in deze oplossing geroeid heeft alsnog een groeivoordeel had van $7.9 \%$ (natte stof) en $33.2 \%$ (droge stof), respectievelijk (vergeleken met de eerdergenoemde 39\%). Sla was zelfs in staat het natrium op te nemen. Natrium accumulatie in het systeem was niet waargenomen.

Een derde experiment was gedaan om de impact van afvoerwater afkomstig van aerobe of anaerobe visslip op de groei van sla te onderzoeken. In dit experiment is een mengsel van aquacultuur en kraanwater verrijkt met supernatanten van zowel aerobe als anaerobe batch reactoren (Hoofdstuk 5). Dit experiment heeft een belangrijke rol gespeeld in de beslissingen die gemaakt zijn over de voorkeur in remineralisatie technologie (aeroob of anaeroob) die is geïmplementeerd in het multi-loop aquaponic systeem model (Hoofdstuk 6). Het onderzoek dat is gepresenteerd in hoofdstuk 5 levert sterke empirische bevestiging dat anaerobisch afvoerwater in het algemeen een positieve impact hebben op de groei van planten. In het algemeen nemen we aan dat de applicatie van RAS-water en ook anaerobe remineralisatie digestaten zowel wortel als scheut groei stimuleren. Het is echter moeilijk om vast te stellen welk mechanisme leidt tot de toename in dit geval, maar microorganismen en opgeloste organische stof spelen vermoedelijk een belangrijke rol.

In het eerste technische hoofdstuk (Hoofdstuk 6) is een multi-loop aquaponics systeem ontworpen en gemodelleerd met AnyLogic. Het doel van het model was het in kaart brengen van water en nutriënten stromen. De uitkomst van het model laat zien dat een hogere evapotranspiratie snelheid (die afhankelijk is van licht intensiteit) leidt tot een lager vereiste hydroponic teelt oppervlak. Studie naar het model suggereert ook dat het mogelijk is het teelt oppervlak op te stellen, gebaseerd op de P-beschikbaarheid, omdat P een uitputbare grondstof is en is vastgesteld als één van de belangrijkste limiterende factoren in de groei van planten. 
Met hoofdstuk 6 als basis, was het doel van hoofdstuk 7 het onderzoeken van de optimale nutriënten concentraties in de aquaculture en de hydroponic subsystemen en van technische oplossingen. We hebben ontdekt dat het inbrengen van ontzilting processen bij kan dragen aan het concentreren van de hydroponic nutriënten oplossing, terwijl het water van de aquacultuur wordt gezuiverd. De integratie van dergelijke technologie zou het water verbruik verminderen net zoals de vraag naar bemesting van multi-loop aquaponics systemen.

In het algemeen (Hoofdstuk 8), en vanuit een wereldwijd standpunt, kunnen we stellen dat de bewering dat aquaponics superieur is aan hydroponics een te moedige uitspraak is. De verbeteringen in groei kunnen niet worden gegarandeerd voor alle soorten planten. We hebben echter wel het vaak genoemde nadeel groeivertraging weerlegd (Hoofdstuk 3 \& 4). Rekening houdend met de economische waarde van multi-loop systemen, hebben we aangetoond dat multi-loop aquaponics systemen kunnen concurreren met commerciële hydroponic systemen van tegenwoordig. Vanuit een sociaal standpunt geeft aquaponics een "gezond" alternatief op hydroponics, omdat het gebruik van antibiotica en pesticides in aquaponics zeer beperkt is. Ook dragen multi-loop aquaponics systemen bij aan het welzijn van dieren, omdat de vissen niet in water met hoge concentraties nutriënten hoeven te zwemmen, terwijl de nutriënten concentratie van het hydroponic gedeelte verhoogd kan worden. 


\section{Resumo}

O acúmulo de produção de animais aquáticos e plantas em estufas constitui a base para todos os sistemas aquapônicos convencionais. Nestes sistemas, as águas residuais ricas em nutrientes da seção de aquicultura, por exemplo a produção de peixe, são utilizadas para fertilização das plantas. Assim, os sistemas aquapônicos economizam água em comparação com produções de uma única espécie de peixe ou sistemas de estufa. Os sistemas aquapônicos comerciais de última geração são tipicamente construídos como sistemas oneloop. Aqui, as águas residuais dos tanques de peixe são alimentadas diretamente à seção hidropônica e depois alimentadas de volta aos tanques de peixes. No entanto, esses sistemas muitas vezes não possuem estabilidade, padronização tecnológica e tecnológica, bem como sustentabilidade e rentabilidade econômica.

A abordagem geral desta tese foi avaliar e melhorar a viabilidade física dos sistemas aquapônicos one-loop concebendo e desenvolvendo sistemas aquapônicos multi-loop, onde a água da seção hidropônica com sua própria recirculação não é alimentada de volta aos tanques de peixes no sistema de aquicultura de recirculação (RAS). Neste contexto, os objectivos gerais da tese eram (1) determinar o status quo de sistemas aquapônicos e identificar problemas atuais que precisam ser abordados, a fim de melhorar a aumento de viabilidade comercial; (2) determinar estatisticamente até que ponto a água derivada do RAS, bem como os efluentes dos reatores de remineralização aeróbica e anaeróbica, têm um impacto no crescimento da alface e fornecem hipóteses que poderiam explicar essas diferenças; e (3) desenvolver um layout do sistema aquapônico multi-loop por meio de modelagem dinâmica do sistema, considerando as descobertas anteriores e, finalmente, oferecer informações importantes sobre o dimensionamento e a concepção de tais sistemas.

0 artigo de revisão apresentado no Capítulo 2 serve como base teórica para esta tese. A análise realizada neste capítulo mostra que a aquapônica como tal pode se tornar um importante motor para o desenvolvimento de sistemas integrados de produção de alimentos. No entanto, os requisitos para aumentar a eficiência da produção para poder competir com os sistemas de produção intensiva de aquicultura e alimentos hidropônicos foram identificados. Estes requisitos incluem condições óptimas para ambos os peixes e plantas em sistemas de aquacultura e hidropônicas, respectivamente, bem como a utilização das lama derivada da aquicultura rica em nutrientes. 
As taxas de crescimento avançadas de plantas cultivadas em sistemas aquapônicos multiloop desacoplados em comparação com instalações hidropônicas convencionais foram observadas na pesquisa experimental (Capítulos 3-5). Mais especificamente, a alface que foi cultivada em uma solução de nutrientes hidropônicos à base de água RAS mostrou 39\% melhor desempenho de crescimento do que no controle hidropônico à base de água da chuva que tinha a mesma composição de nutrientes químicos (Capítulo 3). 0 mesmo estudo mostrou que as plantas cultivadas em um sistema convencional de controle aquapônico oneloop apresentaram menor crescimento do que o sistema hidropônico. No Capítulo 4, repetimos o experimento para fins de validação. As diferenças para o experimento anterior (Capítulo 3) foram que o novo experimento foi conduzido em uma escala maior, e aquela água de aquicultura que foi usada consistiu em uma quantidade significativamente maior de sódio. Este último é conhecido por ser um fator retardador do crescimento. Os resultados mostraram que a água rica em sódio poderia ter inibido o crescimento da alface em soluções de nutrientes baseadas em RAS, mas também que a alface cultivada nesta solução ainda apresentava uma vantagem de crescimento de 7,9\% (matéria úmida) e 33,2\% (matéria seca), respectivamente (isto é, comparado com os 39\% anteriores). A alface foi até capaz de absorver o sódio. A acumulação de sódio dentro do sistema não foi observada.

Um terceiro experimento foi realizado para examinar o impacto do efluente da digestão aeróbica ou anaeróbia das lamas de peixes no crescimento da planta de alface. Neste experimento, uma mistura de aquicultura e água de torneira foi enriquecida com sobrenadantes de reatores de lote aeróbicos e anaeróbios (Capítulo 5). Este experimento desempenhou um papel importante no processo de tomada de decisão em relação à tecnologia de remineralização preferida (ou seja, aeróbica ou anaeróbica) implementada no modelo de sistema aquapônico multi-loop (Capítulo 6). A pesquisa apresentada no Capítulo 5 fornece uma forte confirmação empírica de que os efluentes anaeróbicos geralmente têm um impacto positivo no crescimento da planta. Geralmente, nós levantamos a hipótese de que a aplicação de água RAS, bem como a digestão de remanescências anaeróbicas, estimulam tanto o crescimento da raiz quanto o crescimento de tiro. No entanto, é difícil determinar qual mecanismo levou ao aumento neste caso, mas os microrganismos e a matéria orgânica dissolvida são suspeitas de desempenhar um papel importante.

No primeiro capítulo técnico (Capítulo 6), um sistema aquapônico multi-loop foi projetado e modelado com o AnyLogic. 0 objetivo do modelo foi avaliar os fluxos de água e nutrientes. 0 resultado do modelo mostra que quanto maior a taxa de evapotranspiração (dependendo das intensidades de luz), menor a área de cultivo hidropônico requerida. 0 estudo modelo também sugere que é possível dimensionar a área de cultivo com base na disponibilidade de 
P no componente hidropônico, pois P é um recurso esgotável e foi identificado como um dos principais fatores limitantes para o crescimento da planta.

Tomando o Capítulo 6 como base, o objetivo do Capítulo 7 era buscar otimizar as concentrações de nutrientes nos subsistemas de aquicultura e hidropônicos e encontrar soluções técnicas. Descobrimos que a implementação de processos de dessalinização poderia contribuir para concentrar a solução de nutrientes hidropônicos, enquanto purifica a água da aquicultura. A integração de tal tecnologia também reduziria o consumo de água, bem como a demanda de fertilização de sistemas aquapônicos multi-loop.

No geral (Capítulo 8), e de um ponto de vista global, podemos dizer que a afirmação de que a aquapônica que é superior à hidropônica seria uma afirmação muito ousada. As melhorias do crescimento não podem ser garantidas para todas as espécies de plantas. No entanto, refutamos a desvantagem geralmente mencionada do retardo do crescimento (Capítulo 3 e 4). Com relação ao valor econômico dos sistemas multi-loop, mostramos que os sistemas aquapônicos multi-loop podem ser competitivos com os atuais sistemas hidropônicos comerciais. Do ponto de vista social, a aquapônica constitui uma alternativa "saudável" à hidroponia, já que o uso de antibióticos e pesticidas é altamente restringido nos sistemas aquapônicos. Além disso, os sistemas aquapônicos multi-loop contribuem para o bem-estar dos animais, uma vez que os peixes não terão que nadar em água concentrada com alto teor de nutrientes, enquanto a concentração de nutrientes do componente hidropônico pode ser aumentada para níveis hidropônicos. 


\section{Acknowledgements}

I want to use these acknowledgements to thank people who really helped me to cope with the long and rocky road towards finalizing this thesis. Traditionally, I would first like to thank my family and close friends who supported me whenever I needed support; starting at my first day at primary school until the present day. Furthermore, I want to thank everybody who was involved in my scientific career, from the University of Twente, University of Iceland, Université de Liège, ZHAW Zürich, COST FA1305, the University of Wageningen, and many more. I could write down pages of names now but for the sake of saving trees, I refrain from doing that; or to quote Nietzsche "It is my ambition to say in ten sentences what others say in a whole book". The wonderful persons I refer to hopefully feel addressed.

Very special thanks is to Karel Keesman, Boris Delaide, Ingo Bläser, and Johan Verreth. Karel, thank you for adopting me as a PhD student and being such a great and positive thinking supervisor. Boris, thank you for being such a great friend and scientific partner - the future belongs to us. Ingo, thank you for making me familiar with the domain of aquaponics and cofinancing my $\mathrm{PhD}$. Johan, you have been a good and straightforward promoter with a critical voice. Thank you for all your support from various time zones.

Also a big applause to my paranymphs Rik Schakenbos \& Peter Bijl. :)

tl;dr - thanks to everybody I know! 


\section{About the Author}

In een notendop: Simon Goddek was born on March $16^{\text {th }}$, 1985 in the wonderful metropolis of Cologne (Germany), spending his childhood in both Germany and the Netherlands (Zeeland FTW). He studied at Saxion University of Applied Science and the University of Twente (both Enschede). During his Masters (MEEM), he got into contact with aquaponics and got passionate about that topic. He consequently decided to contact several universities for starting a $\mathrm{PhD}$ in that field. In January 2014, Simon started a PhD in aquaponics at the University of Iceland. After the first two years, he returned back home and continued his $\mathrm{PhD}$ at Wageningen University. Simon is currently involved in aquaponic projects in Kenya and Namibia with the objective to enhance food security in these countries.

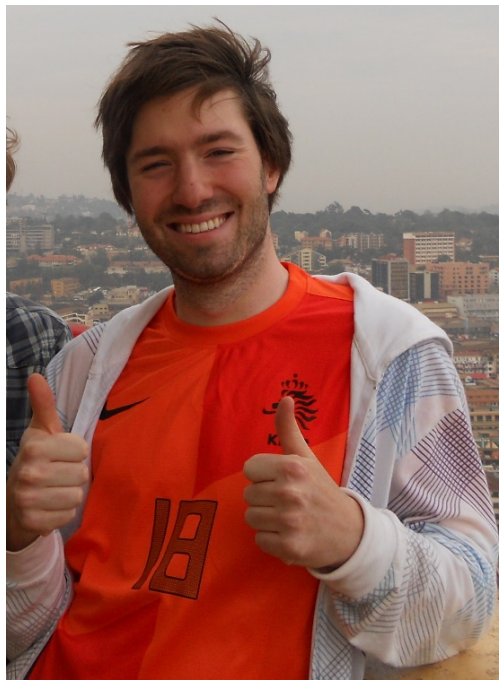




\section{List of Publications}

Goddek, S., Delaide, B., Mankasingh, U., Ragnarsdottir, K., Jijakli, H., Thorarinsdottir, R., 2015. Challenges of Sustainable and Commercial Aquaponics. Sustainability 7, 4199-4224. doi:10.3390/su7044199

Delaide, B., Goddek, S., Gott, J., Soyeurt, H., Jijakli, M., 2016. Lettuce (Lactuca sativa L. var. Sucrine) Growth Performance in Complemented Aquaponic Solution Outperforms Hydroponics. Water 8, 467. doi:10.3390/w8100467

Goddek, S., Schmautz, Z., Scott, B., Delaide, B., Keesman, K., Wuertz, S., Junge, R., 2016. The Effect of Anaerobic and Aerobic Fish Sludge Supernatant on Hydroponic Lettuce. Agronomy 6, 37. doi:10.3390/agronomy6020037

Goddek, S., Espinal, C., Delaide, B., Jijakli, M., Schmautz, Z., Wuertz, S., Keesman, K., 2016. Navigating towards Decoupled Aquaponic Systems: A System Dynamics Design Approach. Water 8, 303. doi:10.3390/w8070303 


\section{SENSE}

Netherlands Research School for the

Socio-Economic and Natural Sciences of the Environment

\section{I P L O M A}

For specialised PhD training

The Netherlands Research School for the Socio-Economic and Natural Sciences of the Environment (SENSE) declares that

\section{Simon Goddek}

born on 16 March 1985 in Cologne, Germany

has successfully fulfilled all requirements of the Educational Programme of SENSE.

Wageningen, 24 October 2017

the Chairman of the SENSE board

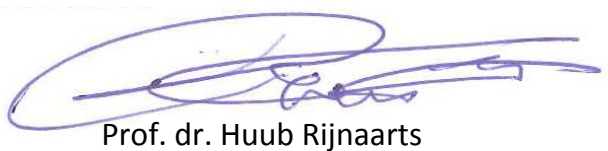

the SENSE Director of Education

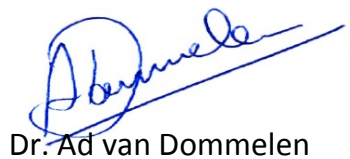

The SENSE Research School has been accredited by the Royal Netherlands Academy of Arts and Sciences (KNAW)

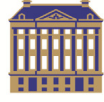

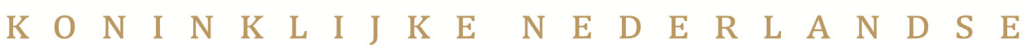
$\begin{array}{llllllllllllllllllllllll}\text { A } & \text { K } & \text { A } & \text { D } & \text { E } & \text { M } & \text { I } & \text { E } & \text { V } & \text { A } & \text { N } & \text { W } & \text { E } & \text { T } & \text { E } & \text { N } & \text { S } & \text { C } & \text { H } & \text { A } & \text { P } & \text { P } & \text { E } & \text { N }\end{array}$ 
The SENSE Research School declares that Mr Simon Goddek has successfully fulfilled all requirements of the Educational PhD Programme of SENSE with a work load of $45.5 \mathrm{EC}$, including the following activities:

\section{SENSE PhD Courses}

- Research in context activity: 'Taking initiative to found start-up Developonics.com, actively writing proposals for research funding and writing press release to clarify the impact of the PhD research' (2017)

\section{Other PhD and Advanced MSc Courses}

- Anaerobic wastewater treatment, UNESCO-IHE (2016)

- Root ecology, University of Copenhagen (Denmark) and Wageningen University (2016)

- Research design and applications, University of Iceland (2014)

- System dynamics modelling, University of Iceland (2014)

\section{External training at a foreign research institute}

- Design and construction of upflow anaerobic sludge blanket reactors, Aquaponik Manufaktur GmbH, Germany (2016)

- Short term scientific mission (STSM) - field research on an Aquaponic system, Zürich University of Applied Sciences, Switzerland (2015)

\section{Oral Presentations}

- Three-loop aquaponics systems: chances and challenges. COST FA1305 conference Aquaponics Research Matters, 22 March 2016, Ljubljana, Slovenia

- System dynamics in AP systems. Workshop COST action FA1305, EU Aquaponics HUB, 22-24 April 2015, Las Palmas, Spain

- Sustainable challenges of commercial aquaponics. RIXC Open Fields conference, 14-18 May 2014, Liepaja, Latvia

SENSE Coordinator PhD Education

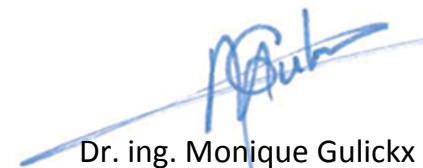




\section{Colophon}

The research described in this thesis was financially supported by Aquaponik Manufaktur $\mathrm{GmbH}$, COST Action FA1305, and myself.

Cover design: Simon Goddek, Michael Reuter \& Ксения Крюкова

Printed by: Digiforce/Proefschriftmaken.nl, Vianen

Financial support from Wageningen University for printing this thesis is gratefully acknowledged. 